\title{
Zweiter Beratungsgegenstand: \\ Verwaltungsverantwortung und Verwaltungsgerichtsbarkeit
}

\author{
1. Bericht von Professor Dr. Rupert Scholz, Berlin
}

Inhalt

Seite

A. Fragestellung . . . . . . . . . . . . 146

B. Strukturen und Grundfunktionen von Verwaltungsverantwortung und Verwaltungsrechtsschutz . . . . . . . 149

I. Die Verwaltungsverantwortung . . . . . . . . . . 149

1. Gestalt und Legitimation . . . . . . . . . . . 149

2. Verwaltungsverantwortung als gegliederter Entscheidungsproze $B \ldots \ldots . . . . . . . .149$

3. Verwaltungsverantwortung, Rechtsverwirklichung und Multidisziplinarität der Verwaltungszweek $\epsilon$. . 151

II. Der Verwaltungsrechtsschutz . . . . . . . . . . . . 154

1. Verwaltungsrechtsschutz als juristische und punktuell-individuale Verwaltungskontrolle . . . 154

2. Tendenzen defizitären Verwaltungsrechtsschutzes. 156

3. Verwaltungsverantwortung und effizienter Verwaltungsrechtsschutz . . . . . . . . 159

C. Verwaltungsverantwortung und Verwaltungsrechtsschutz im System des gewaltenteiligen Rechtsstaates . . . . 160

I. Allgemeines . . . . . . . . . . . . . . . . 160

1. Gewaltengliederung und Gewaltenkontrolle als funktionell offenes und bewegliches System . . . . 160

2. Effizienter Verwaltungsrechtsschutz als flexibler und funktions-akzessorischer Rechtsschutz , . . 160

II. Verwaltungsverantwortung, Verwaltungsrechtsschutz und Gesetz ...... . . . . . . . . . . . 161

1. Gerichts- und Verwaltungsentscheidung als normergänzende Setzung aktual-konkreten Rechts . . 161

2. Konkrete Rechtsetzung als legitime Rechtsprechungs- und Verwaltungskompetenz . . . . 162

III. Verwaltungsverantwortung und Verwaltungsrechtsschutz als kompetenzielle Konkretisierungsverfahren. 163

1. Verwaltungsverantwortung als Konkretisierung gesetzlicher Verwaltungszwecke und Verwaltungsrechtsschutz als Konkretisierung gesetzlicher Rechtszwecke . . . . . . . . . . . 163 
2. Konkretisierungsverfahren, konkrete Rechtsetzung und Ermessen der Verwaltung . . . . . . . . . 164

3. Das Konkretisierungsverfahren als kompetenzleller Auftrag der Verwaltung ........... 170

IV. Verwaltungsrechtliches Konkretisierungsverfahren und gerichtliche Verwaltungskontrolle . . . . . . . 174

1. Gerichtliche Kontrolle als Kompetenz- und Maßstabsproblem .. . . . . . . . . . . . 174

2. Gerichtliche Kontrolle von Planungs-, Ermessensund Prognoseentscheidungen . . . . . . . . . . . 183

D. Sicherung des effizienten Rechtsschutzes im Verwaltungsprozeß . . . . . . . . . . . . . . . . 185

I. Verwaltungsrechtsschutz, Verwaltungseingriff und Handlungsform der Verwaltung . . . . . . . . . . . 185

1. Verwaltungsgerichtliche Eingriffswehr und flexibles Rechtsschutzsystem . . . . . . . . . 185

2. Verwaltungsrechtsschutz und verwaltungsgerichtliche Einzelaktkontrolle . . . . . . . . 187

3. Verwaltungsrechtsschutz und verwaltungsgerichtliche Normenkontrolle . . . . . . . . . 191

4. Präventiver und vorläufiger Verwaltungsrechtsschutz ............... 194

II. Verwaltungsrechtsschutz und rechtlicher Bürgerstatus . 198

1. Systemfunktion und Krise des subjektivöffentlichen Rechts . . . . . . . . . . . 198

2. Funktionale Offnung von subjektiv-öffentlichem Recht und individualem Rechtsschutz . . . . . . . 203

3. Individualer und kollektiver Verwaltungsrechtsschutz . . . . . . . . . . . . . 208

III. Kompensatorischer Rechtsschutz in der Verwaltung . 211

\section{A. Fragestellung}

Das Verhältnis von Verwaltung und Verwaltungsgerichtsbarkeit gehört zu den dauernden Problemstellungen im gewaltenteiligen Rechts- und Sozialstaat moderner, verwaltungsstaatlicher Prägung. Die bisherige Diskussion dieser Thematik ist entsprechend breit und intensivi ${ }^{1}$ ). Inhaltlich hat sie sich vor allem um die institutionelle Abgrenzung von exekutivischer und

1) Vgl. allein die Tagungen der Vereinigung der Deutschen Staatsrechtslehrer 1925, 1928, 1949, 1955 und 1971 mit den Referaten von W. Jellinek (VVDStRL 2, $8 \mathrm{ff}$.) und Lassar (VVDStRL 2, 81 ff.), Layer (VVDStRL 5, 124 ff.) und E. v. Hippel (VVDStRL 5, $178 \mathrm{ff}$.), F. Klein (VVDStRL 8, 67 ff.) und Herrfahrdt (VVDStRL 8, 126 ff.), E. Becker (VVDStRL 14, 96 ff.) und Rumpf (VVDStRL 14, $136 \mathrm{ff}$.) sowie Bachof (VVDStRL 30, $193 \mathrm{ff}$.) und Brohm (VVDStRI 30,245 ff.). 
rechtsprechender Gewalt ${ }^{2}$ ) sowie um die Sicherung eines möglichst effizienten Verwaltungsrechtsschutzes im Sinne der verfassungsrechtlichen Rechtsschutzgarantie des Art. 19 IV GG bemüht ${ }^{3}$ ). So evident beide Fragestellungen sind, haben sie doch nicht verhindern können, daß die Diskussion manchmal auf einbahnige oder weniger realistische Geleise abglitt. Verwaltung und Verwaltungsrechtsschutz wurden allzu oft in scheinbar statisch vorgegebener Gegensätzlichkeit gesehen; und dies führte zur Kontroverse "eigenständige Verwaltung" contra „Entfesselung der Dritten Gewalt“") bzw. „Schutz der eigenständigen Verwaltung " vor dem „überbordenden ,Justiz-' oder ,Rechtswegestaat'“s).

Die tatsächliche Entwicklung ist indessen an Thesen und Befürchtungen dieser Art vorbeigegangen. Die „Eigenständigkeit

2) Vgl. dazu u. a. und mit weiteren Nachweisen Bettermann, Jellinek-Gedächtnisschrift, 1955, S. 361 ff.; Becker, VVDStRL 14, 99 ff.; Achterberg, Probleme der Funktionenlehre, 1970, S. $48 \mathrm{ft}$.; Wolff-Bachof, Verwaltungsrecht I, 9. Aufl. 1974, S. 82 ff.; Menger, System des verwaltungsgerichtlichen Rechtsschutzes, 1954, S. 21 ff., 28 ff., 36 ff.; Ule, Verwaltungsprozeßrecht, 6. Aufl. 1975, S. 5 ff.; Forsthoff, Lehrbuch des Verwaltungsrechts, I, 10. Aufl. 1973, S. $5 \mathrm{ff}$.; König, in: Studien über Recht und Verwaltung, 1967, S. $59 \mathrm{ff}$.

3) Vgl. hierzu und mit weiteren Nachweisen zuletzt besonders Lorenz, Der Rechtsschutz des Bürgers und die Rechtsweggarantie, 1973.

4) van Husen, AöR 78, $49 \mathrm{ff}$.

5) Vgl. in dieser Richtung besonders Forsthoff, Rechtsstaat im Wandel, 1964, S. 213 ff.; ders., VVDStRL 14, 187 f.; ders., Lehrbuch, S. 5 ff., 59 ff., 79 ff.; ders., Gehlen-Festschrift, 1974, S. 41 ff.; Becker, VVDStRL 14, 117 ff.; Peters, Die Verwaltung als eigenständige Staatsgewalt, 1965, S. $19 \mathrm{ff}$; $F$. Klein, VVDStRL 8, $117 \mathrm{ff}$; Nebinger, DOV 53, $626 \mathrm{ff}$; Jahrreiß, in: Recht - Staat - Wirtschaft, II, 1950, S. 203 (213); W. Weber, Spannungen und Kräfte im westdeutschen Verfassungssystem, 1970, S. 29 f.; $K$. Zeidler, Staat 62, 321 (326 ff.).

Zusammenfassend zuletzt Forsthoff, der in der letzten Auflage seines Lehrbuchs des Verwaltungsrechts (10. Aufl. 1973) resignativ resumiert, die Verwaltung sei „innerhalb der Trias der Gewalten“, bei entsprechender Aufwertung der rechtsprechenden Gewalt, „zum schwächsten Glied" geworden (S. 81).

Vgl. in entgegengesetzter Richtung und richtunggebender Differenzierung allerdings und grundlegend $F$. Werner, Recht und Gericht in unserer Zeit, 1971, bes. S. 139 ff., 156 ff., $176 \mathrm{ff}$., $196 \mathrm{ff}$., 259 ff., 304 ff., 367 ff.; vgl. weiterhin K. Meyer, DOV 69, 162 (164 f.); Menger, DOV 69, 153 (157 ff.); Hoppe, DVB1. 75, $684 \mathrm{ff}$.

Im Sinne einer Bedrohung der Verwaltungsgerichtsbarkeit dagegen und deren Kompetenzschwund vgl. nachdrücklich bes. Rupp, NJW 73, 1769 ff. 
der Verwaltung " $\theta$ ) besteht; und die Verwaltungsgerichte haben ihren Rechtsschutzauftrag großenteils erfüllt - ohne die Eigenverantwortung der Verwaltung zu gefährden. Diese Bilanz ist nach mehr als 25jährigem Bestehen der Rechtsschutzgarantie des Art. 19 IV GG zu ziehen; und ein maßgebendes Verdienst dafür gebührt den Richtern an den Verwaltungsgerichten. Sie haben der Verwaltung gegenüber - zumeist - nicht nur das nötige $\mathrm{Maß}$ an rechtlicher Entschiedenheit, sondern auch ein beträchtliches $\mathrm{Maß}$ an politischer Sensibilität bewiesen - eine Sensibilität, die nur den blinden Protagonisten jenes Bildes vom sog. „politisch aktiven“ oder „sozial engagierten (Verwaltungs-)Richter ${ }^{\text {"7) }}$ ) verborgen geblieben ist ${ }^{8}$ ).

Die heutigen Probleme zwischen Verwaltung und Verwaltungsgerichtsbarkeit liegen weniger in der grundsätzlichen $\mathrm{Ab}$ grenzung als in den konkreten Beziehungen beider Gewalten, namentlich bei der Frage nach der konkreten Verteilung verfassungs- und funktionsadäquater Verantwortung im sozialen Rechtsstaat. In dieser grundsätzlichen Beurteilung des Themas sind sich beide Referenten einig. Sie haben demgemäß einige der thematischen Schwerpunkte untereinander geteilt.

-) Zur immanenten Kritik des Begriffs der „Eigenständigkeit“ vgl. $H$. Wagner, Die Vorstellung der Eigenständigkeit in der Rechtswissenschaft, 1967, bes. S. $33 \mathrm{ff}$., $60 \mathrm{ff}$., $95 \mathrm{ff}$., zur „Eigenständigkeit der Verwaltung" vgl. S. 84 f. - Richtiger ist der Begriff der „Eigenverantwortung“ (der Verwaltung), der im folgenden zugrunde gelegt wird.

7) Vgl. in dieser Richtung, wenngleich mit unterschiedlicher Ausrichtung u. a. Rasehorn, in: Wassermann, Justizreform, 1970, S. 32 ff.; Kaupen-Rasehorn, Die Justiz zwischen Obrigkeitsstaat und Demokratie, 1971; Hagen, ZRP 74, 286 ff.; Kaupen, Die Hüter von Recht und Ordnung, 1969; Lautmann, Justiz. Die stille Gewalt, 1972; Wassermann, Zur politischen Funktion der Rechtsprechung, in: Aus Politik und Zeitgeschichte, B 47/74 ff.; ders., Der politische Richter, 1972; Wiethölter, ZRP 70, 155 ff.; Görlitz, Verwaltungsgerichtsbarkeit in Deutschland, 1970, S. 9 f., 287 ff.; Düx, DuR 73, 223 ff.

8) In richtiger Standortbestimmung von Richtertum und rechtsprechender Gewalt sowie zutreffender Abwehr einer solchen „Politisierung" von Richtertum und Rechtsprechung vgl. zuletzt vor allem Dütz, ZZP 87, 361 (382 ff.); Böckenförde, Verfassungsfragen der Richterwahl, 1974, S. 87 ff.; Rupp, NJW 73, 1770 ff.; Plassmann, JZ 75, 41 ff.; H. Klein, DRiZ 72, 333 ff.; Ule, in: Demokratie und Verwaltung, 1972, S. 663 ff.; Bachof, H. Huber-Festschrift, 1961, S. 26 (29 ff.); Henke, JZ 74, 729 (731 f.); ders., DRiZ 74, 173 ff.; Eyermann, Die Verwaltung 1975, 7 (8 ff.); Trondle, MDR 75, 617 ff.; $W$. Geiger, Schäfer-Festschrift, 1975, S. 79 (80, 91 f.); vgl. auch W. Zeidler, DVBl. 71, 565 ff.; ders., MDR 70, $713 \mathrm{ff}$. 


\section{B. Strukturen und Grundfunktionen von Verwaltungsverantwortung und Verwaltungsrechtsschutz}

\section{Die Verwaltungsverantwortung}

1. Als Verwaltungsverantwortung sind diejenigen Verantwortlichkeiten und Verfahren, Zuständigkeiten und spezifischen Handlungsspielräume zu verstehen, die das System „öffentliche Verwaltung" rechtlich und politisch verfassen"). Die Empirie dieses Systems ist an der realen politischen und sozioökonomischen Entwicklung orientiert. Sie definiert die Verwaltung nicht abstrakt, vermittelt aber konkrete Erkenntnisse von den typischen und legitimen Strukturen verwaltungsmäßiger Kompetenz und verwaltungsförmiger Entscheidung. Wesensbestimmendes Kernstück dieses Systems ist die Eigenverantwortung ${ }^{10}$ ). Sie besteht unter der grundgesetzlichen Gewaltenteilung als prinzipaler Funktionsvorbehalt, ausgefüllt durch die einzelne Verwaltungskompetenz und ihre verantwortliche Wahrnehmung ${ }^{11}$ ).

2. Verfahrensmäßig erscheint die Verwaltungsverantwortung als ProzeB umfassender Informationsverarbeitung, komplexer Problemanalyse und Problemlösung, kurz: als Entscheidungsprozeß. Dieser Prozeß setzt sich aus dem Verfahren der Ent-

9) Zu Begriff und Dimensionen der "Verwaltungsverantwortung" vgl. eingehend und mit umfassenden "Nachweisen Wilke, DOV 75, 509 ff. - Zentraler Aspekt der Verantwortung ist die Kompetenz (vgl. auch Kröger, Die Ministerverantwortlichkeit in der Bundesrepublik Deutschland, 1972, S. 4; von Pestalozza, JuS 75, 366 (371 f.). Zur öffentlichen Verwaltung als politischem System vgl. zuletzt Bartlsperger, VVDStRL 33, 221 (246 ff.).

10) $\mathrm{Zu}$ ihr und ihrer Legitimation vgl. z. B. Peters, Die Verwaltung als eigenständige Staatsgewalt, S. 6 ff.; ders., H. Huber-Festschrift, 1961, S. 206 (207 ff.); Ossenbuhl, Verwaltungsvorschriften und Grundgesetz, 1968, S. $187 \mathrm{ff}$; Ryffel, in: Morstein-Marx, Verwaltung, 1965, S. 456 ff.; Bülck, ebenda, S. 52 (57 ff.); Ehmke, „Ermessen" und "unbestimmter Rechtsbegriff" im Verwaltungsrecht, 1960, S. 7 ff., 35 ff.; Oettl, Grenzen der Gerichtsbarkeit im sozialen Rechtsstaat, 1971, S. 64 ff.; in grundsätzlich entgegengesetzter, aber gelegentlich mißdeuteter Position Rupp, Grundfragen der heutigen Verwaltungsrech tslehre, 1965, S. 104 ff., 273 f.

ZurVerantwortung in diesem Sinne gehört auch die (verwaltungsrechtliche Eigen-)Kontrolle als Nebenfunktion der (verwaltungsrechtlichen) Entscheidung (vgl. Brunner, Kontrolle in Deutschland, 1972, S. $74 \mathrm{ff}$.) und materieller Konnex von Verantwortung als organisierter Verantwortlichkeit (vgl. z. B. Ryffel, a. a. O., S. 457 f.; Scheuner, G. Müller-Festschrift, 1970, S. 379 (391 f.).

11) Vgl. z. B. Ossenbuhl, Verwaltungsvorschriften und Grundgesetz, S. $187 \mathrm{ff}$; Peters, Verwaltung als eigenständige Staatsgewalt, S. 12 ff., 29 f.; Oettl, a. a. O., S. 66 ff., 78 ff. 
scheidungsfindung und der Entscheidung als formalisiertem Verfahrensabschluß zusammen ${ }^{12}$ ). Funktionell bilden beide Entscheidungsphasen eine Einheit; eine Einheit, die die prozessuale Forderung begründet hat, Verwaltungsverantwortung nicht nur im formalen Verfahrensabschluß, sondern im kompletten Entscheidungsvorgang zu kontrollieren ${ }^{13}$ ). So berechtigt diese Forderung ist, juristische Kontrollfähigkeit bedingt den Entscheid als meßbaren Verfahrensabschlu $\left.\beta^{14}\right)$. Kontrollfähige Verwaltungsverantwortung muß demgemäß phasenmáßig gegliederter bzw. zu gliedernder („formeller") Entscheidungspro$z e \beta$ heißen.

Die innere Organisation dieses Entscheidungsprozesses ist weitgehend offen; denn der Kanon der verwaltungsrechtlichen Handlungs- und Organisationsmittel ist nicht geschlossen. Die konkrete Handlungsform der Verwaltung folgt ihrer konkreten Handlungskompetenz. Ist sie mit dieser nicht gesetzlich fixiert, so liegt ihre Bestimmung beim prinzipiellen Zweckmäßigkeitsentscheid der eigenverantwortlichen Verwaltung ${ }^{15}{ }^{16}$ ).

12) Zur in diesem Sinne organisations- und entscheidungstheoretischen Struktur der Verwaltungsverantwortung vgl. u. a. Luhmann, Theorie der Verwaltungswissenschaft, 1966, S. 67 ff.; ders., Zweckbegriff und Systemrationalität, 1968/1973, S. 88 ff., 166 ff., 257 ff.; Naschold, PVS Sonderheft 1972, S. 13 ff.; ders., Systemsteuerung, 1969; Schlink, in: Rechtstheorie als Grundlagenwissenschaft der Rechtswissenschaft, 1972, S. 322 ff.; Reinermann, Programmbudgets in Regierung und Verwaltung, 1975, S. 67 ff., 295 ff.; Gäfgen, Theorie der wirtschaftlichen Entscheidung, 3. Aufl. 1974, S. 95 ff., 240 ff., 461 ff.; Cornides, Rechtstheorie 1974, 11 ff.; Brohm, VVDStRL 30, 245 (276, 286 f.); Schmitt-Glaeser, VVDStRL 31, 179 (193 ff.); W. Schmidt, VVDStRL 33, 183 (200 ff.); ders., AöR 96, 321 (327 ff., 336 ff.); Bartlsperger, VVDStRL 33, 221 ff.; Brunner, Kontrolle, S. $54 \mathrm{ff}$.

13) Vgl. Brohm, VVDStRL 30, 261, 280 ff., 289 ff.; Blümel, DVBl. 73, 441; 75, 695 (706 f.); ders., Forsthoff-Festgabe, 1967, S. 133 (157 ff.) Ossenbihl, Gutachten 50. DJT, Verhandlungen des 50. Deutschen Juristentages, Band I, 1974, B 36, 177, 193 f.; W. Schmidt, VVDStRL 33, 200 f.; Schmidt-ABmann, DOV 74, 541 (545); F. Wagener, AfK 70, 47 (51); Schwarze, Der funktionale Zusammenhang von Verwaltungsverfahrensrecht und verwaltungsgerichtlichem Rechtsschutz, 1974, S. 71 ff.; Wahl, DOV 75, 373 (377 ff.); vgl. auch Forsthoff-Blümel, Raumordnungsrecht und Fachplanungsrecht, 1970, S. 22 f.; Hoppe, DVBl. 75, 689 f.; vgl. dazu weiter noch unten sub II 2 mit Nachw. N. 53.

14) Vgl. in richtiger Differenzierung zwischen verwaltungswissenschaftlichem und rechtswissenschaftlichem Verwaltungsbegriff Wimmer, Die Verwaltung 75, 141 (158).

15) Zur Formen- und Organisationsfreiheit der Verwaltung vgl. mit weiteren Nachweisen $u$. a. Wolff-Bachof, Verwaltungsrecht I, S. $104 \mathrm{ff}$; Neumann, Wirtschaftslenkende Verwaltung, 1959, S. 19 ff.; $R$. Scholz, Wesen und Entwicklung der gemeindlichen offent- 
3. Materiell folgt die Verwaltungsverantwortung dem Verwaltungszweck und seiner kompetenziellen Gestaltung. Die spezifische "Gemeinwohlverantwortung" der Verwaltung ${ }^{17}$ ) basiert auf ihrem rechtlichen (gesetzlichen) und politischen Amtsauftrag. Beide formulieren den normativ gültigen Verwaltungszweck, wobei dem Element politischer Verwaltungsverantwortung heute zunehmend mehr Bedeutung anfällt ${ }^{18}$ ). Mit dem Zurückweichen der gesetzgeberischen Ordnungsfunktion übernimmt die Verwaltung einen breiten Part in der aktiven und verantwortlichen Gestaltung von staatlicher und gesellschaftlicher Ordnung ${ }^{19}$ ); ein Befund, der die Verwaltungsrechtstheorie zwingt, mehr auf die systembildende Kraft der Verwaltungszwecke, statt - wie bisher zumeist geübt - auf die bloß instrumentellen Funktionen verwaltungsrechtlicher Handlungsformen abzustellen ${ }^{192}$ ).

Das System der Verwaltungszwecke ist zwar, wie das der Staatsaufgaben im sozialen Rechtsstaat überhaupt ${ }^{20}$ ), nicht ge-

lichen Einrichtungen, 1967, S. 22 ff.; zur Kritik vgl. bes. von Pestalozza, FormenmiBbrauch des Staates, 1973, S. 123 ff., 166 ff.; Burmeister, WiR 72, 311 ff.

16) Letzteres offenbart sich beispielsweise auch im Streit um die verwaltungsrechtliche Planungskompetenz. Als instrumentale "Technik vorwegnehmender Koordination" (Scharpf, Die Verwaltung 1971, 1 (4)) birgt auch die Planung eine legitime und originäre Handlungskompetenz eigenverantwortlicher Verwaltung, die entweder als instrumentelle Annexkompetenz oder richtiger noch als Form (materieller) Kompetenzausubung zu verstehen ist (vgl. Ossenbühl, Gutachten 50. DJT, B 62 ff., 72; Schmidt-Aßmann, DOV 74, 541; vgl. auch Kaiser, 50. DJT, II, 1974, I 9 (15)).

17) $\mathrm{Zu}$ ihr vgl. bes. Häberle, „Offentliches Interesse“ als juristlsches Problem, 1970, S. $71 \mathrm{ff}$., $95 \mathrm{ff}$., $101 \mathrm{ff}$., $193 \mathrm{ff}$., $246 \mathrm{ff}$., $453 \mathrm{ff}$., 475 ff., 595 ff., 678 ff.; ders., JZ 75, 297 (303); vgl. auch W. Schmidt, VVDStRL 33, 196 ff.; Steiger, Wolff-Festschrift, 1973, S. 385 ff.

18) Zur politischen Verantwortung der Verwaltung vgl. z. B. Friedrich, Zur Theorie und Politik der Verfassungsordnung, 1963, S. $121 \mathrm{ff}$.

${ }^{19)}$ Vgl. näher hierzu $H$. Schneider, G. Müller-Festschrift, 1970, S. 421 ff.; Eichenberger, Schweiz.JZ 65, 285 (286 f.); Scheuner, G.-Müller-Festschrift, 1970, S. 379 (384, 394 ff.); Bäumlin, Schweiz.JurVerein 1966, S. 165 (171 ff.); Vogel, VVDStRL 24, 125 (172 f.); Herzog, VVDStRL 24, 183 (197 ff.); Builck, in: Morstein-Marx, Verwaltung, S. 63 f.; vgl. auch Diedrichsen, Die Flucht des Gesetzgebers aus der politischen Verantwortung im Zivilrecht, 1974; ders., ZRP 74, 53 ff.

${ }^{\left.18^{\mathrm{a}}\right)}$ Vgl. grundlegend hier Badura, Verwaltungsrecht im liberalen und sozialen Rechtsstaat, 1966, S. 22 ff.

20) Vgl. näher z. B. Bull, Die Staatsaufgaben nach dem Grundgesetz, 1973, S. 90 ff., 369 ff. 
schlossen und zweckinhaltlich somit schwer $z \mathfrak{u}$ definieren ${ }^{21}$ ). Nicht ausgeschlossen ist aber eine methodenkategoriale Erfassung der (typischen) Verwaltungszwecke, die den einzelnen Zweck weniger in seiner kompetenziellen als in seiner disziplinären Typik anhand derjenigen (zweckhaften) Methoden verfolgt, die die Gestaltung und Erfüllung verwaltungsrechtlicher Aufgaben funktionell leitet und damit auch inhaltlich präformiert. Nach einer solchen disziplinären Methodik hat man bisher freilich kaum gefragt. Im Bezugsfeld eines dominant-normativen Verwaltungsverständnisses dominierte mit der Vorstellung von der Verwaltung als Rechtsverwirklichung (Gesetzesvollzug) auch die juristische Methode ${ }^{22}$ ). Verwaltung ist jedoch nicht ausschließlich Rechtsverwirklichung oder (subsumtionsmäßige) Rechtsanwendung ${ }^{23}$ ). Verwaltung ist vielmehr Verwirklichung von Staatszwecken rechtlicher wie außerrechtlicher Art; Verwaltungsverantwortung bedeutet maßgebend auch metajuristische, d. h. politische, ökonomische, soziale, technologische und kulturelle Verantwortung ${ }^{24}$ ). Das (methodenkategorial gegliederte) System der Verwaltungszwecke ist m.a. W. multi- und zum großen Teil auch interdisziplinär beschaffen.

Diese Multidisziplinarität ist gegenständlich gemeint, wenn von der "komplexen Verwaltung" gesprochen wird. Gerade Verwaltungsaufgaben wie die der Raum-, Wirtschafts-, Bauund Sozialplanung, der wirtschaftlichen, sozialen und ökologischen Vorsorge, aber auch der Bildung und Wissenschaft, offenbaren diese Komplexität, die in Wirklichkeit nur die ohnehin vorgegebene Multidisziplinarität der Verwaltungszwecke ${ }^{25}$ )

21) Vgl. Ellwein, Regierung und Verwaltung, 1. Teil, 1970, S. 88 ff.; $R$. Scholz, in: Leisner, Das Berufsbeamtentum im demokratischen Staat, 1975, S. 179 (186 f.); zu Schwierigkeit und Ansätzen der empirisch-verwaltungswissenschaftlichen Bestimmung administrativer Handlungs- und Entscheidungsspielräume vgl. u. a. GrottianMurswieck, Handlungsspielräume der Staatsadministration, 1974, bes. S. $15 \mathrm{ff}$.

22) Grundlegend O. Mayer, Deutsches Verwaltungsrecht, I, 3. Aufl. 1924, S. 21 u. a.; weitere Nachweise vgl. bei Bachof, VVDStRL 30, 193 (215 ff.).

23) Vgl. Bachof, VVDStRL 30, $216 \mathrm{ff}$.

24) Vgl. auch Bachof, VVDStRL 30, 207 ff., 215 ff.; K. Meyer, DOV $69,162$.

25) An typischen Beispielen vgl. etwa die komplexen und hochspezialisierten Aufgabenstellungen von Raumordnung (vgl. dazu anschaulich bes. Raumordnungsbericht der Bundesregierung 1974, BT-Drucks. 7/3582) und Umweltschutz (vgl. mit Bezug gerade zur rechtlichen (Verwaltungs-)Verantwortung Umweltgutachten 1974, BT-Drucks. 7/2802; Bullinger, W. Weber-Festschrift, 1974, S. 665 ff.; Bullinger-Oberhauser-Rincke-Schmıdt, Das Verursacherprinzip und 
und ihres hohen Bedarfs an professionalisiertem Sachverstand ausdrückt ${ }^{26}$ ). Diese methodenmäßige Verwaltungsvielfalt bereitet dem Verwaltungsrechtsschutz erhebliche Probleme; denn die richterliche Verantwortung ist nicht multi-27), sondern monodisziplinär (juristisch) verfaßt ${ }^{28}$ ).

seine Instrumente, 1974; Wäldle, AöR 99, 585 ff.; Freitag-HansenMarkert-Strauch, Umweltschutz in der Wettbewerbsordnung, 1973, S. 3 ff., 24 ff., 54 ff.; Kloepfer, Zum Umweltschutzrecht in der Bundesrepublik Deutschland, o. J., S. 31 ff.; Wegener, DVBl. 75, $176 \mathrm{ff}$; W. Müller, Umweltschutz und kommunale Bauleitplanung, 1975; Doran-Hinz-Mayer-Tasch, Umweltschutz - Politik des peripheren Eingriffs, 1974, S. 14 ff.); zum Verhältnis von Technik und (Verwaltungs-)Recht vgl. bes. klar Denninger, Universitas 1970, $1135 \mathrm{ff}$.

26) Die Organisation solchen Sachverstands fuhrt zur partiellen "Pluralisierung der Verwaltung" (vgl. Brohm, VVDStRL 30, 263), zur Einschaltung Privater (vgl. dazu bes. Dagtoglou, Der Private in der Verwaltung, 1964, bes. S. $30 \mathrm{ff}$.), zur Institutionalisierung wissenschaftlicher Fachberatung (vgl. dazu bes. Albach, BöhmFestschrift, 1975, S. 45 ff.; Brohm, Forsthoff-Festschrift, 1972, S. 37 ff.; ders., VVDStRL 30, 261 ff.; Habermas, in: Krauch-Kunz-R2ttel, Forschungsplanung, 1966, S. 130 ff.; Ritter, Vom Wohlfahrtsausschuß zum Wohlfahrtsstaat, 1973, S. 69 (72 ff.); Borner, Wissenschaftliche Okonomik und politische Aktion, 1975; Lompe, Wissenschaftliche Beratung der Politik, 1966; Sievert, in: Grundsatzprobleme wirtschaftspolitischer Beratung, Schriften des Vereins für Socialpolitik n. F. Bd. 49, 27 ff.; $R$. Scholz, DOV 73, 843 ff.; Erichsen, VerwArch 1974, 311 ff.) und vor allem zur Relativierung des hierarchisch-bürokratischen Verwaltungssystems. An seine - und an die Stelle seiner funktionellen Orientierung an der weisungsmäßig - hierarchisch zu sichernden Entscheidungsrichtigkeit (zur amtsrechtlichen Funktion der Weisung vgl. hier recht klar Hansen, Fachliche Weisung und materielles Gesetz, 1971, S. $229 \mathrm{ff}$.) bzw. "einzig richtigen Verwaltungsentscheidung " (juristische Verwaltungsmethode!) - Stelle treten teilweise (unabhängige) Kollegialgremien ("Teams") zwecks interdisziplinărer Sachverstandsumsetzung - mit der Konsequenz nicht nur organisationsrechtlicher Probleme, sondern vor allem mit der Folge "pluralisierter" (mehrheitlicher oder alternativer) Entscheidungsrichtigkeit (vgl. dazu u. a. Schnur, in: Demokratie und Verwaltung, 1972, S. 557 ff.; Laux, in: Aktuelle Probleme der Ministerialorganisation, 1971, S. 317 ff.; ders., Führung und Führungsorganisation in der öffentlichen Verwaltung, 1975, S. 12 ff., 19 ff., 35 ff., 94 ff.; Lepper, Die Verwaltung 1972, $141 \mathrm{ff}$.; Meinhold, in: Sachverstand und Verantwortung in der öfentlichen Verwaltung, 1966, S. 122 ff.; Dagtoglou, Kollegialorgane und Kollegialakte in der Verwaltung, 1960; Schmidt-Jortzig, Die Pflicht zur Geschlossenheit der kollegialen Regierung (Regierungszwang), 1973, S. 12 ff.; W. Hoffmann, Rechtsfragen der Währungsparität, 1969, S. 146 ff.; Rauschning, Die Sicherung der Beachtung von Verfassungsrecht, 1969, S. 77 ff.; Bachof, VVDStRL 30, 234 f.; Hartfiel, Ideologie und Arbeitsplatzstruktur der öffentlichen Verwaltung zwischen technischem Fortschritt und sozialem Wandel, 1971, S. 6 ff., $12 \mathrm{ff.;}$ R. Scholz, VSSR 73, $283 \mathrm{ff}$.).

${ }^{27}$ ) Vgl. allerdings auch Wannagat, SGb. 74, 361 (365 f.), der von der "interdisziplinären Ausrichtung der sozialgerichtlichen Arbeit" 


\section{Der Verwaltungsrechtsschutz}

1. Die Verwaltungsgerichtsbarkeit kontrolliert die Verwaltung nach Maßgabe der subjektiv-rechtlich individualen Rechtsschutzgewähr ${ }^{29}$ ). Prozessual im Ausschluß der Popularklage versinnbildlicht ${ }^{30}$ ), kennt der Verwaltungsrechtsschutz die objektiv-rechtliche Verwaltungskontrolle grundsätzlich nur als Inzidentkontrolle ${ }^{31}$ ). Verfahrensmäßig funktioniert der Verwaltungsrechtsschutz prinzipiell repressiv ${ }^{82}$ ). Seine Kontrollfunktion schließt an die konkrete Verwaltungsentscheidung und ihre Handlungsform an; den Verwaltungszweck kontrolliert das Verwaltungsgericht meist nur mittelbar.

spricht und hiermit die umfassende (freilich instrumentelle!) Einschaltung metajuristischen Sachverstandes in der modernen Sozialrechtsprechung beschreibt.

28) Der Richter darf sich daher legitim auf die ihm ausbildungsund funktionsmäßig vermittelten (,juristischen“) Gedankenoperationen beschränken (vgl. Diederichsen, ZRP 74, 55). Der Verwaltung obliegt die spezifisch "sachverständige" (metajuristische) Verantwortung; und dies nicht nur kraft eines "faktischen Sachkundemonopols", wie Eichenberger, Schweiz.JZ 1965, 288, meint, sondern kraft legitimer Kompetenz (vgl. auch Ritter, Vom Wohlfahrtsausschuß zum Wohlfahrtsstaat, S. 70 ff.; Forsthoff, Lehrbuch, S. 74 ff.). Nicht unproblematisch sind demgemäß Bestrebungen, sogenannte "Informationsmängel" oder "Sachverstandsdefizite" der Rechtsprechung etwa durch gemeinsame bzw. für Verwaltung und Gerichtsbarkeit einheitliche (metajuristische) Informationssysteme zu überwinden (zu Uberlegungen dieser Art vgl. z. B. Bender, ZRP 73,134 ff.).

29) Vgl. z. B. Bettermann, Schima-Festschrift, 1969, S. 71 (73 ff.); ders., VVDStRL 17, 118 (168); Ule, Verwaltungsprozeßrecht, S. 5; Mühl, Bärmann-Festschrift, 1975, S. 687 (690); Becker, VVDStRL 14, 114; Rumpf, VVDStRL 14, 136 (137 ff.); Bachof, VVDStRL 14, $177 ; H$. Bauer, Gerichtsschutz als Verfassungsgarantie, 1973, S. 50 ff.; Menger, Grundrechte III/2, 1959, S. 717 (727 ff.).

30) Vgl. z. B. BVerwGE 17, 87 (91); 19, 269 (271); 27, 181 (182); Bettermann, Imboden-Gedenkschrift, 1972, S. 37 ff.; Ule, in: Zehn Jahre Verwaltungsgerichtsordnung, 1970, S. 20 (35); Ossenbïhl, Gutachten 50. DJT, B 172; Eyermann, BayVBl. 74, 237 (243).

31) Vgl. Becker, VVDStRL 14, 114; Ule, Verwaltungsprozeßrecht, S. 5; Menger, a. a. O.; vgl. auch Bachof, VVDStRL 14, 177; König, in: Studien über Recht und Verwaltung, S. 65; Hesse, in: Forsthoff, Rechtsstaatlichkeit und Sozialstaatlichkeit, 1968, S. 557 (564);Brohm, VVDStRL 30, 299 ff.

32) Vgl. z. B. Bettermann, Imboden-Gedenkschrift, S. 37; ders., VVDStRL 17, 172; ders., in: Zehn Jahre Verwaltungsgerichtsordnung, 1970, S. 185 (191); Ossenbïhl, Gutachten 50. DJT, B 165, 191; Menger, System des verwaltungsgerichtlichen Rechtsschutzes, S. 259; Kopp, Verfassungsrecht und Verwaltungsverfahrensrecht, 1971 , S. 2, 149, 240; Brunner, Kontrolle in Deutschland, S. 255 ff.; BVerwGE 40, 323 (326). 
Im Gegensatz zur Verwaltungsverantwortung bedeutet Verwaltungsrechtsschutz primär Rechtsanwendung und -verwirklichung (durch konkrete Streitentscheidung). Auch die Verwaltung trifft zwar konkret verbindliche Rechtsentscheidungen ${ }^{33}$ ); deren Funktion ist aber primär die der - auch metajuristischen - Zweckverwirklichung ${ }^{34}$ ). Die gerichtliche Entscheidung hat nur juristischen, die Verwaltungsentscheidung hat auch metajuristischen Richtigkeitsansprüchen $\mathrm{zu}$ genügen. Soweit die Verwaltung Zuständigkeiten namentlich mit metajuristischem Regelungsauftrag besitzt, verfügt sie über eigenverantwortliches und legitimes Ermessen. Verwaltung und Verwaltungsgerichtsbarkeit sind demgemäß kompetenziell geschieden. Vor allem im metajuristischen bzw. ermessensmäßigen Gestaltungsbereich verfügt die Verwaltung über die prinzipielle Entscheidungsprärogative ${ }^{35}$ ). Im Bereich juristischer Richtigkeitsgewähr gilt dagegen der (kompetenzielle) Vorrang der richterlichen Entscheidung. Er erfüllt sich im streitigen Prozeß als jenem hochformalisierten - und deshalb vom Verwaltungsverfahren prinzipiell geschiedenen - Verfahren ${ }^{36}$ ), das die Grundlage und Garantie für eine konfliktlösende und verbindliche Rechtsverwirklichung bildet ${ }^{37}$ ). In der Verwaltung ist die Rechtsanwen-

33) Die Entscheidung des Verwaltungsgerichts legt für den individuellen Streitfall autoritativ fest, was in Anwendung des geltenden Rechts auf einen bestimmten Sachverhalt konkret Rechtens ist (Becker, VVDStRL 14, 105).

34) Vgl. z. B. Peters, Lehrbuch der Verwaltung, 1949, S. 5 f.; $K$. Meyer, DOV 69, 162; E. Becker, VVDStRL 14, $101 \mathrm{ff}$.

s5) Nicht aber, mit Ossenbühl, DVBl. 74, 309 ff. gesprochen, über das Recht zur „letztverbindlichen“ Entscheidung.

so) Zur Methodik und (formalisierten) Struktur des gerichtlichen (Erkenntnis-)Verfahrens vgl. z. B. den interessanten Versuch Rödigs, Die Theorie des gerichtlichen Erkenntnisverfahrens, 1973, bes. S. 3 ff., 32 ff., $148 \mathrm{ff}$., $252 \mathrm{ff}$. (vgl. dazu auch die eingehende Rezension von Grunsky, JZ 74, 750 ff.); zur Technik prozessualer Formstrenge vgl. zuletzt Vollkommer, Formenstrenge und prozessuale Billigkeit, 1973, bes. S. 12 ff., 247 ff.

37) Das Prinzip der rechtlıchen Richtıgkeit ist dabei weniger $1 \mathrm{~m}$ Sinne materialer Einzigrichtigkeit als im Sinne kompetenzieller Verbindlichkeit zu verstehen (Vorrang richterlicher „Richtigkeits“erkenntnis, legitimiert durch entsprechende Erkenntnisverfahren). Zur Kritik an der Vorstellung materialer Einzigrichtigkeit vgl. m. w. Nachw. zuletzt z. B. Dreier, Rechtstheorie 1974, 189 (191 ff.); Hoffmann-Riem, Staat 74, 335 (347 f.); W. Schmidt, AöR 96, 349 f.; Rupp, NJW 73, 1773; Mes, Der Rechtsschutzanspruch, 1970, S. 63; vgl. auch Soell, Das Ermessen der Eingriffsverwaltung, 1973, S. 89 ff., sowie BVerwGE 39, 197 (205 f.); zum richterlichen „Beurteilungsspielraum" vgl. bes. Larenz, Methodenlehre der Rechtswissenschaft, 3. Aufl. 1975, S. 279 ff.). Da auch die Verwaltung für Rechtsverwirklichung und Rechtmäßigkeit zuständig ist, können sich 
dung dagegen nicht Hauptzweck ${ }^{88}$; hier erfüllt sie sich nur innerhalb jener Verfahren und nach jenen Sachgesetzlichkeiten, die fưr die spezielle $Z$ weckverwirklichung maßgebend $\operatorname{sind}^{30}$ ).

2. Auf diese kompetenziellen und verfahrensmäßigen Unterschiede zwischen Verwaltungsverantwortung und Verwaltungsgerichtsbarkeit ${ }^{40}$ ) gründen sich - neben der Befürchtung, daß eine allzu extensiv verstandene Gerichtsverantwortung die Eigen- und Zweckverantwortung der Verwaltung gefährde - die Befürchtungen eines partiell defizitären Rechtsschutzes.

Wo früher, verkörpert im Verwaltungsakt, die klassischpunktuelle Einzelfallentscheidung dominierte, dort wirken in der heutigen Verwaltung vielfältig veränderte Entscheidungs-, Handlungs- und Eingriffsmuster, namentlich in der planenden und gestaltenden Verwaltung. Die Vorstellungen von individual meßbarer Unmittelbarkeit und adressatenmäßiger Rechtsbetroffenheit fangen die Typik heutiger Verwaltungseingriffe nicht mehr in voller Bandbreite ein. Denn Verwaltungseingriffe wirken heute ebenso mittelbar (und das in vielfältiger Vermittlung) wie unmittelbar, ebenso individual wie kollektiv und ebenso gezielt wie „zufällig"-anonym ${ }^{41}$ ).

Verwaltungsverantwortung heißt heute verstärkt nicht nur mikro-, sondern auch makroadministrative Zuständigkeit, und die Erfüllung solcher Zuständigkeit fordert den Einsatz verstärkt generalisierender und typisierender Verfahren. Ein-

zwischen gerichtlicher und verwaltungsmäßger Rechtserkenntnis "Richtigkeitskonkurrenzen" ergeben; deren Lösung obliegt dem richterlichen Entscheid kraft kompetenzıellen Vorrangs. Etwas anderes gilt nur in jenen Bereichen, in denen die Verwaltung selbst rechtsetzende Maßstabsbefugnisse besitzt (vgl. dazu unten IV 1). Hier muß sich das kontrollierende Verwaltungsgericht auf die Kontrolle rechtlicher "Vertretbarkeit" bzw. maßstabsimmanenter „Richtigkeit" beschränken (vgl. näher dazu noch unten N. 136, 268).

${ }^{38}$ ) Vgl. die Nachweise N. 34.

s9) In diesem Sinne ist „jede Norm des Verwaltungsrechts für die Verwaltungsbehörde Verhaltensnorm, nicht Beurteilungsnorm “ wie für die Verwaltungsgerichtsbarkeit (Bettermann, VVDStRL 17, 120).

${ }^{40}$ ) An dieser Stelle werden weiterhin die - aus Zeitgründen nicht $\mathrm{zu}$ verfolgenden - Fragen von juristischer Ausbildung der Verwaltungsrichter und von partiell interdisziplinärer Besetzung richterlicher Spruchkörper akut (vgl. hierzu bes. Rudolph, JZ 75, 316 ff.; Ullrich, GRUR 64, 292 ff.; Zeller, GRUR 53, 459 ff.; 60, 213 ff.; Faber, DRiz 75, 49 ff.; J. Blomeyer, ZRP 70, 153 ff.; Rasehorn, ZRP 71, 52 f.). Zur Funktionsfrage der ehrenamtlichen Verwaltungsrichter vgl. die aufschlußreichen Daten bei Schiffmann, Die Bedeutung der ehrenamtlichen Richter bei Gerichten der allgemeinen Verwaltungsgerichtsbarkeit, 1974; vgl. dazu auch Presting, DOV 75, 155 ff.

41) Vgl. dazu unten D I 1. 
griffsrechtlich korrespondieren solchen Verfahren aber „Breiten-" und "Tiefenwirkungen"42), deren vollständige, individualrechtliche Folgenrelevanz kaum vorab zu kalkulieren ist ${ }^{43}$ ). Im Zuge dieser Tendenz droht auch das subjektiv-öffentliche Recht seinen systematischen Stellenwert als vorab bestimmbare, bewußt-gewollte Individualbegünstigung $\mathrm{zu}$ verlieren ${ }^{44}$ ). Gerade allgemeinere und kollektive Rechtsbetroffenheiten begründen den Ruf nach mehr kollektiv- und objektivrechtlich angelegtem Rechtsschutz ${ }^{45}$ ).

Zwischen den von mehrseitig wirksamen Verwaltungsmaßnahmen betroffenen Bürgern entwickeln sich - wie im „Planungsverbund ${ }^{(46)}$ ), Nachbarschut $z^{47}$ ), Konkurrentenschutz ${ }^{48}$ ) usw. - verwaltungsrechtlich vermittelte Rechtsbeziehungen ${ }^{40}$ ), die die für den Verwaltungsrechtsschutz evidente, individuale Staat-Bürger-Beziehung relativieren $\left.{ }^{50}\right)$. Begriffsschöpfungen wie die vom Verwaltungsakt mit Doppelwirkung erweisen sich als begriffstheoretische Krücken, die das Gerüst jenes Relationsverständnisses nur mühsam aufrechterhalten ${ }^{51}$ ).

42) Vgl. R. Scholz, Wirtschaftsaufsicht und subjektiver Konkurrentenschutz, 1971, S. 46.

43) Vgl. auch Brohm, VVDStRL 30, 259 ff.; Schmidt-ABmann, DVBl. 72, 627 (633); ders., Grundfragen des Städtebaurechts, 1972, S. 157 (166); Götz, Recht der Wirtschaftssubventionen, 1966, S. 251 ff.; R. Schmidt, AöR 99, 529 (553 ff.); Bartlsperger, VDStRL 33, 253; Badura, BayVerfGH-Festschrift, 1972, S. 157 (166).

4) Vgl. dazu unten D II 1, 2.

4) Vgl. dazu D I 3, II 3.

10) Vgl. BVerwGE 27, 29 (33); 32, 173 (176 f.); Schmidt-Aßmann, Grundfragen des Städtebaurechts, S. 97 f.; Redeker, JZ 68, 537 (542); vgl. auch Badura, BayVerfGH-Festschrift, S. 166; Imboden, VVDStRL 18, 113 (123 ff.).

17) Vgl. näher z. B. Timmermann, Der baurechtliche Nachbarschutz, 1969, S. 25 ff., 99 ff.; Bartlsperger, VerwArch 1969, 35 ff.; Weyreuther, BauR 75, 1 ff.; Laubinger, Der Verwaltungsakt mit Doppelwirkung, 1967, S. 43 ff.; Sendler, WiR 72, $453 \mathrm{ff}$.

49) Vgl. dazu $R$. Scholz, Wirtschaftsaufsicht, S. $104 \mathrm{ff}$., $172 \mathrm{ff}$.; ders., WiR 72, 35 ff.; Zuleeg, Subventionskontrolle durch Konkurrentenklage, 1974; Ruber, NJW 71, 2097 ff.; Buhren, DVB1. 75, 328 ff.; BVerwGE 30, 191 (192 ff.).

19) Vgl. zuletzt auch Bothe, JZ 75, 399 ff., und von Pestalozza, JZ 75, 625 ff., der sogar zur Anerkennung einer Kategorie des „Privatverwaltungsrechts" neigt.

so) Vgl. Badura, Verwaltungsrecht im liberalen und sozialen Rechtsstaat, S. 24.

51) Uberdies entwickeln sich die Beziehungen zwischen Verwaltung und Bürger immer stärker zu Dauerbeziehungen, weshalb zu Recht die Forderung nach dogmatisch stärkerem Abstellen auf das Verwaltungsrechtsverhailtnis erhoben wird (vgl. z. B. Henke, VVDStRL 28, 149 (159 ff.); Rüfner, VVDStRL 28, 183 (215 f.); Bachof, VVDStRL 30, 231 f.; Zacher, DOV 70, 3 (11 f.); Schmidt- 
Rechtsschutzprobleme werfen weiterhin gestufte Entscheidungsprozesse auf, wie sie mit Teilgenehmigungs- und bestimmten Planungsverfahren ${ }^{52}$ ) akut geworden sind ${ }^{53}$ ). Hier kommt eine am verfahrensbeendenden Verwaltungsentscheid haftende Rechtskontrolle zeitlich oft zu spät und gewährt kraft Präklusion ${ }^{54}$ ) ebenso oft nur inhaltlich beschränkten Schutz ${ }^{55}$ ). Denn richtiger Rechtsschutz bedingt prinzipiell auch rechtzeitigen Schutz ${ }^{56}$ ).

Im System der gestaltenden Verwaltung stellen sich weiterhin die Probleme der gerichtlichen Kontrolle des Planungsermessens ${ }^{57}$ ), das überwiegend als Phänomen eigener Art gedeu-

Aßmann, Grundfragen des Städtebaurechts, S. 65 f.). Auch solchen Dauerbeziehungen gegenüber kann ein allein am punktuellen Rechtsentscheid haftender Rechtsschutz schnell ins Defizit geraten.

52) Vgl. z. B. die Verfahren gemäß $\$ \S 7 \mathrm{ff}$. AtomG, 4 ff. BImSchG, $6 \mathrm{ff}$. LuftVG, $16 \mathrm{ff}$. BFStrG, $3 \mathrm{ff}$. StBFG, $5 \mathrm{ff}$., $8 \mathrm{ff}$. BBauG, $13 \mathrm{ff}$. BWaStrG, 6, 56 ff. FlurBG.

s3) Vgl. näher bes. Blümel, Forsthoff-Festgabe, 1967, S. 133 (139 ff.); ders., DVBl. 72, 796 ff.; 73, 436 (442 f.); Forsthoff-Blümel, Raumordnungsrecht und Fachplanungsrecht, S. 22 ff.; Schwarze, Der funktionale Zusammenhang von Verwaltungsverfahrensrecht und verwaltungsgerichtlichem Rechtsschutz, S. $71 \mathrm{ff}$; Wahl, DOV 75, 373 ff.; aus der Rechtsprechung vgl. bes., wenngleich mit überwiegender Verneinung stufenmäßig vorverlegten Rechtsschutzes: BVerwG, NJW 69, 340 (341 f.); DVB1. 72, 678 ff.; 73, 34 (35 ff.); 73, 448 ff.; 74, 562 (563 ff.); OVG Lüneburg, DVBl. 72, 795 f.; 75, 190 (191 ff.); BayVGH, DVBl. 72, 790 (792); VG Freiburg, DVB1. 75, 343 ff.

54) Vgl. z. B. $\$ \S 7$ b AtomG, 14 FlurBG, 21, 22, 24 bis 26 AbfG, 18, 18 a BFStrG, 10, 11, 14 BImSchG, 6, 9 LuftVG.

55) Daß Rechtsschutz auch gegenüber "faktischem Planvollzug“ bzw. gegenüber der „Neigung, es bei dem einmal Verlautbarten zu belassen", gewbihrt werden muß, erkennen immerhin im Grundsatz an BVerwGE 17, 269 (281 f.); 40, 323, (326 f.).

$\left.{ }^{56}\right)$ Oder genauer anders ausgedrückt: Schwere und Inhalt eines Eingriffs lassen sich nie ohne Rücksicht auf die Zeit erfahren und beheben. Zum Erfordernis des rechtzeitigen Rechtsschutzes vgl. bes. BVerfGE 35, 263 (273 f.); BVerwGE 17, 279 (281 f.); 40, 323 (326 f.); Kaiser, 50. DJT II, I 18 ff.; ders., NJW 71, 585 (588); Bliimel, Forthoff-Festgabe, 1967, S. 137 ff.; Ossenbïh, Gutachten 50. DJT, B 165, 191 ff.; Schmidt-Aßmann, DOV 74, 547; Lerche, ZZP 78, 1 (17); $R$. Scholz, Wirtschaftsaufsicht, S. 118; H. Bauer, Gerichtsschutz als Verfassungsgarantie, 1973 , S. $97 \mathrm{ff}$; vgl. allgemein auch und besonders Kloepfer, Staat 74, 457 ff.; ders., Vorwirkung von Gesetzen, 1974, S. 213 ff., 251 ff.; Häberle, ZfPol 74, 111 (114 ff.); Kirchhof, Verwalten und Zeit, 1975, S. 12 ff.; zum spezifischen $\mathrm{Zu-}$ sammenhang von Planung und Zeit vgl. bes. Ipsen, in: Kaiser, Planung II, 1966, S. 63 (79 f.); Kaiser, in: Kaiser, Planung II, 1966, S. 11 (23); ders., 50. DJT, II, I 18 ff.; zum Verhältnis von Rechtsschutzeffektivität und Zeit vgl. weitere Nachweise in N. 63.

${ }^{87}$ ) Zu seiner Struktur, Legitimation und therprüfbarkeit vgl. bes. BVerwGE 34, 301 (304 ff.); 36, 352 (356); 42, 331 (338); 45, 112 (113 
tet wird $^{88}$ ), und des prognostischen Entwicklungsspielraums ${ }^{58}$ ), der der Verwaltung das - mit legislativen Einschätzungsbefugnissen vergleichbare ${ }^{60}$ ) - Recht zur verbindlichen Ein- und Abschätzung künftiger Tatsachen einräumt ${ }^{61}$ ). Im gleichen Zuge stellen sich die alten Probleme von (Rechtsfolge-)Ermessen und Beurteilungsspielraum in neuerem Lichte ${ }^{62}$ ).

3. Solange die Verwaltungsgerichtsbarkeit auf diese hier nur grob skizzierten Problemstellungen keine adäquate Antwort

ff.); 45, 309 (312 ff.); BVerwG, DVBl. 72, 895 f.; OVG Lüneburg, BRS 17, 14 (15); 20, 1 f.; 22, 16 (17); 23, 43 (44 f.); HessVGH, BRS 23, 7; BayVGH, BayVBl. 75, 168 (169); Hoppe, DVBl. 74, 641 ff.; ders., Scupin-Festschrift, 1973, S. 121 ff.; Schmidt-Aßmann, DOV 74, 541 ff.; Ossenbiihl, Gutachten 50. DJT, B 183 ff.; Redeker, DVBl. 71, 369 (372); ders., JZ 68, 537 ff.; Badura, BayVerfGH-Festschrift, S. 160 ff.; Kaiser, 50. DJT, II, I 9 ff.; Rietdorf, 50. DJT, II, 1974, I 25 ff.; Blümel, Forsthoff-Festgabe 1967, S. 137 ff.; ders., DVBl. 75, 699 ff., M. Schröder, DOV 75, $308 \mathrm{ff}$.

B8) Vgl. Badura, BayVerfGH-Festschrift, S. 167; Ossenbühl, a. a. O., B 184 ff.; Schmidt-Aßmann, Grundfragen des Städtebaurechts, $S$. 161 ff.; vgl. allerdings auch Hoppe, DVB1. 74, 644.

$\left.{ }^{69}\right)$ Vgl. hierzu bereits R. Scholz, Wirtschaftsaufsicht, S. $107 \mathrm{ff}$.

00) Vgl. hier bes. BVerfGE 16, 147 (181 ff.); 18, 315 (332); 25, 1 (12 f.); 30, 250 (263 f.); BVerfG, NJW 75, 31 (33 f.); vgl. hierzu näher auch R. Scholz, a. a. O.; Philippi, Tatsachenfeststellungen des Bundesverfassungsgerichts, 1971, S. 28 ff., 56 ff., 124 ff.; Seetzen, NJW $75,429 \mathrm{ff}$.

61) Vgl. R. Scholz, a. a. O.; Ossenbühl, Gutachten 50. DJT, B 160, 188 ff.; ders., DVBl. 74, 313; BVerwG, DVBl. 72, 895 f.; BVerwGE 16, 285 (287); 41, 1 (4 ff.); 45, 112 (113 ff.); BayVGH, BayVBl. 75, 168 (170); vgl. auch BadWüStGH, NJW 75, 1205 (1213); DOV 73, 163 (166); NrwVerfGH, OVGE 25, 310 (315); zur planerischen Prognose vgl. z. B. Lompe, Gesellschaftspolitik und Planung, 1971, S. 234 ff.

62) In organisationsrechtlicher Richtung potenzieren sich die Rechtsschutzprobleme dort, wo wesentlich metajuristische Angelegenheiten durch fachspezifische oder gesellschaftlich-repräsentativ besetzte, unabhängige (ministerialfreie) Kollegialgremien entschieden werden. Als Beispiele vgl. bes. Filmbewertungsstelle, Bundesprüfstelle, Prüfungsausschüsse etc. Zum Sonderstatus der Bundesbank vgl. Faber, Wirtschaftsplanung und Bundesbankautonomie, 1970; Uhlenbruck, Die verfassungsmäßige Unabhängigkeit der Deutschen Bundesbank und ihre Grenzen, 1968; von MangoldtKlein-Wilke, GG, 2. Aufl. 1970, Art. 88 Anm. IV 3; Samm, Die Stellung der Deutschen Bundesbank im Verfassungsgefüge, 1967, S. 76 ff., 122 ff., 148; R. Schmidt, Zeros-Festschrift, II, 1973, S. 655 ff.; $R$. Scholz, ZHR 133, 276 ff.; - weitere Beispiele vgl. z. B. bei Laux, Führung und Führungsorganisation in der öffentlichen Verwaltung, S. 94 ff.; $E$. Klein, Die verfassungsrechtliche Problematik des ministerialfreien Raums, $1974, \mathrm{~S} .73 \mathrm{ff}$.

Zum Ganzen vgl. allgemein schon oben N. 26; unter den hiesigen Aspekten vgl. năher vor allem BVerwGE 39, 197 (203 ff.); Ossenbïhl, DVBl. 74, 309 (311 ff.); VG Berlin, NJW 73, $1148 \mathrm{ff}$.; vgl. weiterhin zum ganzen unten sub D III. 
gefunden hat, solange bleibt eine defizitäre Rechtsschutztendenz unabweisbar. Die Rechtsschutzgarantie des Art. 19 IV GG verspricht zwar effizienten Rechtsschutz, Rechtzeitigkeit und Fairneß im Verfahren eingeschlossen ${ }^{63}$ ). Dieses Versprechen genügt jedoch nicht. Denn ein verfassungsgerechter Verwaltungsrechtsschutz hat nicht nur - dem Bürger gegenüber - effizienzgerecht, sondern - der kontrollierten Verwaltung gegenüber auch kompetenzgerecht $\mathrm{zu}$ sein.

\section{Verwaltungsverantwortung und Verwaltungsrechtsschutz im System des gewaltenteiligen Rechtsstaates}

\section{Allgemeines}

1. Den (auch) kompetenzgerechten Verwaltungsrechtsschutz fordert das Prinzip der Gewaltenteilung (Art. 20 II 2 GG). Seine Ordnungsidee unterstellt die drei Staatsgewalten keinem System statischer Trennung oder rein mechanischer Balance, sondern einem System wechselseitiger Zuordnung, gegenseitiger Kooperation und beweglicher Dekonzentration $\left.{ }^{64}\right)$. Die gemeinsame Verantwortung für die rechtsstaatlich-demokratische Einheit des Staates ${ }^{65}$ ) verpflichtet sämtliche Staatsgewalten zur gegenseitigen Anpassung, wechselseitigen Kompensation sowie zum prinzipiellen Offensein für Wandlungen bei der jeweils anderen Staatsgewalt.

2. Diese Grundsätze verfassen den Verwaltungsrechtsschutz - im Zusammenwirken mit der Rechtsschutzgarantie des Art. 19 IV GG - zum effizienz- und kompetenzgerechten Rechtsschutz. Kompetenziell wird dieser durch die Eigenverantwortung der Verwaltung begrenzt; auf die Wirkungsformen der

*) Vgl. BVerfGE 35, 382 (401); 38, 105 (111); BVerfG, NJW 75, 1597; Lorenz, Rechtsschutz, S. 16 f., 150 f.; Lerche, ZZP 78, 16 ff.; Ossenbühl, Gutachten 50. DJT, B 147, 165, 191 ff.; Blümel, Forsthoff-Festgabe, 1967, S. 137 ff.; $R$. Scholz, JZ 72, 725 (729 f.); ders., Wirtschaftsaufsicht, S. 118 ff.; $H$. Bauer, Gerichtsschutz als Verfassungsgarantie, S. 60 ff., 97 ff.; Dutz, Rechtsstaatlicher Gerichtsschutz im Privatrecht, 1970, S. 115 ff.

64) Vgl. näher sowie auch zum folgenden Hesse, Grundzüge des Verfassungsrechts der Bundesrepublik Deutschland, 8. Aufl. 1975, S. 194 ff.; Bäumlin, Schweiz. JurVerein 1966, S. 228; Kägi, H. Huber-Festschrift, 1961, S. 151 (164 ff.); Ossenbïhl, Verwaltungsvorschriften und Grundgesetz, S. 187 ff.; Bóckenförde, Verfassungsfragen der Richterwahl, S. 62 ff., Jarass, Politik und Bürokratie als Elemente der Gewaltenteilung, 1975, S. 6, 10 f., 99; W. Geiger, Schäfer-Festschrift, S. 79 ff.; vgl. in gleicher Richtung auch die Vorstellung $H$. Krügers von der Gewaltenteilung als „Richtigkeitsgewähr" (Allgemeine Staatslehre, 2. Aufl. 1966, S. 869 f.); vgl. weiterhin schließlich Pötter, Peters-Gedächtnisschrift, 1967, S. $007 \mathrm{ff}$.

os) $\mathrm{Zu}$ ihr vgl. bes. Hesse, a. a. $O$. 
Verwaltung hat er aber adäquat zu reagieren. Der Verwaltungsrechtsschutz muß somit flexibel sein und seine Verfahren an den Wirkungsformen der zu kontrollierenden Verwaltung ausrichten (Verwaltungsrechtsschutz als „akzessorische Funktion“). Denn erst solche Beweglichkeit im System gewährleistet über das dauerhaft "sachgerechte Verfahren"*8) den wirklich effizienten Rechtsschutz. Die Erreichung und Sicherung solcher Systembeweglichkeit ist vornehmlich Aufgabe des rechtsschutzgestaltenden Gesetzgebers, zugleich aber Aufgabe der rechtsschutzgewährenden Verwaltungsgerichtsbarkeit.

\section{Verwaltungsverantwortung, Verwaltungsrechtsschutz und Gesetz}

1. Verwaltung und Verwaltungsgerichtsbarkeit unterstehen dem Gesetz; seine Entscheide haben sie in konkretisierender Rechtsanwendung $\mathrm{zu}$ verwirklichen. Normstrukturell verläuft dieser Prozeß der konkretisierenden Rechtsanwendung stets auf die gleiche und für Verwaltung wie Rechtsprechung einheitliche Weise ${ }^{67}$ ): Als subsumtionsmäßige Erkenntnis wird abstrakt-generelles Recht vollzogen, und als sachverhaltsbezogene Dezision wird konkret-individuelles Recht geschöpft $\left.{ }^{88}\right)$. Dieser rechtstheoretische Befund weist in jeder richterlichen wie exekutivischen Entscheidung die Setzung konkreten (Rich-

00) Lerche, ZZP 78, 6.

In diesem Sinne läßt sich die Vorstellung des „due process“ für das System des deutschen Verwaltungsrechtsschutzes fruchtbar machen. Zum amerikanischen System des due process in der Verwaltungskontrolle und $\mathrm{zu}$ seinen Unterschieden zum System der deutschen Verwaltungskontrolle vgl. Scharpf, Die politischen Kosten des Rechtsstaats, 1970, S. 15 ff.

67) Vgl. Merkl, Allgemeines Verwaltungsrecht, 1927, S. 144; Starck, Der Gesetzesbegriff des Grundgesetzes, 1970, S. 265; Bettermann, VVDStRL 17, 138; auch W. Schmidt, Gesetzesvollziehung durch Rechtsetzung, 1969, S. 114 ff.

68) Vgl. Kriele, Theorie der Rechtsgewinnung, 1967, S. 27 ff., 47 ff., 197 ff.; Esser, Grundsatz und Norm in der richterlichen Fortbildung des Rechts, 2. Aufl. 1964, S. 283 ff.; ders., Methodik des Privatrechts, in: Enzyklopädie der geisteswissenschaftlichen Arbeitsmethoden, S. 7 ff., 27 ff.; W. Schmidt, Gesetzesvollziehung, S. 114 ff.; Säcker, ARSP 72, 215 (216 ff., 218 ff.); Starck, Gesetzesbegriff, S. 257 ff., 260 ff.; ders., JZ 72, 609 (612); Dütz, ZZP 87, 366 ff.; $R$. Scholz, DB 72, 1771 (1776 ff.); Buchner, Dietz-Gedächtnisschrift, 1973, S. 175 (184 ff.); Leibholz, Das Verbot der Willkür und des Ermessensmißbrauchs im völkerrechtlichen Verkehr der Staaten, 1964, S. 43; vgl. auch BVerfGE 34, 269 (287).

Zum Verhältnis von Entscheidung und Erkenntnis vgl. allgemein z. B. Michaelis, E. R. Huber-Festschrift, 1973, S. 311 ff.; Albert, Traktat über kritische Vernunft, 2. Aufl. 1969, S. 55 ff. 
ter- bzw. Verwaltungs-)Rechts nach ${ }^{6 \theta}$ ). Die Schöpfung solchen (konkreten) Rechts vollendet den Prozeß der Rechtsbildung insgesamt, indem sie den abstrakten Gesetzesentscheid rechtlich aktualisiert und damit auch (konkret-)tatbestandlich komplettiert'0) ${ }^{71}$ ).

2. Dieser Prozeß von abstrakter und konkreter Rechtsbildung überlagert das formale Begriffsschema von (abstrakt-genereller) Normsetzung sowie (konkret-individueller) Normvollziehung ${ }^{72}$ ) und beschränkt dessen Geltung auf die Abgrenzung von Gesetzgebung, Verwaltung und Rechtsprechung im Prozeß

Bo) Zum Richterrecht vgl. bes. Esser, Grundsatz und Norm, S. 14 ff.; Kriele, Theorie, S. 243 ff.; Canaris, Systemdenken und Systembegriff in der Jurisprudenz, 1969, bes. S. 86 ff.; Fischer, Die Weiterbildung des Rechts durch die Rechtsprechung, 1971; Sacker, ARSP 72, 215 ff.; H. P. Schneider, Richterrecht, Gesetzesrecht und Verfassungsrecht, 1969, S. 10 ff.; ders., DOV 75, 443 ff.; Meyer-Cording, Die Rechtsnormen, 1971, S. 63 ff.; Werner, Recht und Gericht in unserer Zeit, S. 139 ff., 176 ff., 196 ff.; Engisch, Die Idee der Konkretisierung in Recht und Rechtswissenschaft unserer Zeit, 1953, S. 181 ff.; Redeker, NJW 72, 409 ff.; A. Kaufmann, Rechtsphilosophie im Wandel, 1972, S. 135 ff.; Buchner, a. a. O.; Richardi, DietzGedächtnisschrift, 1973, S. 269 (272 ff.); Starck, Gesetzesbegriff, S. 256 ff., 260 ff.; ders., JZ 72, 609 ff.; Larenz, Methodenlehre der Rechtswissenschaft, 3. Aufl. 1975, S. 350 ff.; ders., E. R. HuberFestschrift, 1973, S. 291 (292 ff.); ders., Henkel-Festschrift, 1974, S. 33 ff.; Wannagat, SGb. 74, 361 (362 ff.); Ditz, ZZP 87, 366 ff.; Hilger, Larenz-Festschrift, 1973, S. 109 ff.; Rüthers, JZ 74, 625 ff.; Kruse, Das Richterrecht als Rechtsquelle des innerstaatlichen Rechts, 1971; H. H. Klein, DRiZ 72, 333 ff.; Badura, in: Rechtsfortbildung durch die sozialgerichtliche Rechtsprechung, 1973, S. 40 ff.; J. Ipsen, Richterrecht und Verfassung, 1975; Rottleuthner, Richterliches Handeln. Zur Kritik der juristischen Dogmatik, 1973, S. 11 ff.; R. Scholz, DB 72, 1776 ff.

70) Vgl. Kriele, Theorie, S. 27 ff., 47 ff., 197 ff., 203 ff.; Esser, Grundsatz und Norm, S. 283 ff.; Sacker, ARSP 72, 224 ff.; Geitmann, Bundesverfassungsgericht und "offene Normen", 1971, S. 48 ff., 149 ff., 163; H. P. Schneider, DOV 75, 450; Starck, Gesetzesbegriff, S. 268 ff.; Zippelius, NJW 75, 914 f.; Bäumlin, Staat, Recht und Geschichte, 1961, S. 35 f.; R. Scholz, DB 72, 1777 f. Vgl. in diesem Sinne auch die Vorstellung der „individuellen Norm“ Kelsens (vgl. Nipperdey-Festschrift, I, 1965, S. 57 (69 f.); Reine Rechtslehre, 1934, S. 79 f.; Internationale Zeitschrift für Theorie des Rechts 1934, S. 9 (10 ff.)); entsprechend aus rechtssoziologischer Sicht $T h$. Geiger, Vorstudien zu einer Soziologie des Rechts, 1964, S. 242 ff.

71) Zur verfassungsrechtlichen Legitimation des konkreten (Richter-)Rechts vgl. BVerfGE 34, 269 (286 ff.) mit Anm. von Kübler, JZ 73, 667 f.; Schwabe, DVBl. 73, 788 ff., und Menger, VerwArch 1974, 195 ff.; BVerfG, NJW 75, 968 (969).

72) Zum Bedeutungsverlust des Schemas Normsetzung - Normvollzug vgl. Scheuner, DOV 69, 585 (589 f.); Badura, BayVerfGHFestschrift, S. 167 f. 
abstrakter Rechtsetzung. Hier ist die Legislative prärogativis); im übrigen ist der Proze $B$ der Rechtserzeugung aber funktionsund arbeitsteilig verfaBt ${ }^{74}$ ). Im System der grundgesetzlichen Gewaltengliederung tragen alle drei Staatsgewalten in kompetenzieller und kooperativer Gliederung die Verantwortung für das Recht und seine Gestaltung ${ }^{75}$ ).

\section{Verwaltungsverantwortung und Verwaltungsrechtsschutz als kompetenzielle Konkretisierungsverfahren}

1. Verfügen Verwaltung und Verwaltungsgerichtsbarkeit über qualitativ gleichartige Kompetenzen zur Setzung konkreten Rechts, so sind ihre Konkretisierungskompetenzen im übrigen aber verschieden. Denn wo richterliche Konkretisierung Konkretisierung von Rechtszwecken heißt, dort heißt verwaltungsmäßige Konkretisierung nur sekundär Konkretisierung von Rechtszwecken und primär Konkretisierung von Verwaltungszwecken, gleichgültig, ob diese rechtlicher oder außerrechtlicher Art sind.

Anerkennt man weiterhin, daß Verwaltungsverantwortung primär (eigen)verantwortliche Zweckerfüllung ist, so erweist sich auch die Rechtsform, in der die exekutivische Konkretisierung eines Verwaltungszwecks erfolgt, als sekundär, angefangen von der Rechtsverordnung ${ }^{76}$ ) bis hin zum Verwaltungsakt $^{77}$ ). Als typisches Beispiel exekutivischer Zweck- und Rechts-

73) Vgl. Kriele, Theorie, S. $60 \mathrm{ff}$; vgl. auch $R$. Scholz, DB 72, $\overline{1776}$; H. P. Schneider, DOV 75, 448.

74) Vgl. H. P. Schneider, DOV 75, 449; ders., Richterrecht, S. 33; J. Ipsen, Richterrecht und Verfassung, S. 240; R. Scholz, DB 72, 1777.

${ }^{75}$ ) Vgl. A. Kaufmann, Rechtsphilosophie im Wandel, S. 170; H. P. Schneider, Richterrecht, S. 31 ff.; ders., DOV 75, 449 f.; R. Scholz, DB 72, 1777.

Verwaltung und Rechtsprechung besitzen demgemäß ursprüngliche, legitime Kompetenzen auch im (materiell-)rechtsetzenden Bereich (vgl. Kriele, Theorie, S. 60 ff.; Achterberg, Probleme der Funktionenlehre, S. 93, 149 ff.; Vogel, VVDStRL 24, 166).

76) Vgl. Art. 80 GG als spezıfischen Konkretisierungsauftrag. Für die Satzung ergibt sich prinzipiell Gleiches aus der jeweiligen Selbstverwaltungsermächtigung (z. B. Art. 28 II GG für die kommunale Satzung).

${ }^{77}$ ) In den gleichen Zusammenhang gehören die Verwaltungsvorschriften. Soweit sie die Funktion des normativen „Ordnungssurrogats" (Zacher, VVDStRL 25, 308 (312 f.)) übernehmen, sind sie Form verwaltungsmäßiger Zweckkonkretisierung (so namentlich im Bereich von ermessensleitenden Verwaltungsvorschriften) und zugleıch materielle Rechtsnormen (zum letzteren vgl. - gegen die noch überwiegende Meinung - Ossenbühl, Verwaltungsvorschriften und Grundgesetz, S. 553 ff., 567 f.; ders., AöR 92, 1 (22 f.); 
konkretisierung figuriert in diesem Zusammenhang auch die Planung als strukturelle Einheit von (final-programmierender) Rechtsfindung und (impliziter) Rechtsvollziehung ${ }^{78}$ ).

Die empirisch wie normativ begründete Vorstellung einer derartigen, verfahrensmäßig funktionierenden Zweckkonkretisierung charakterisiert jede Verwaltungsverantwortung. Als spezifischer Konkretisierungsprozeß mit sowohl rechtlichem wie außerrechtlichem Zweckbezug erscheinen demgemäß auch alle Ermessensentscheidungen sowie alle die Entscheidungen, die in "wertender" Auslegung unbestimmter Gesetzesbegriffe „Beurteilungsspielräume" ausfüllen.

2. Dieses Bild der konkretisierenden Verfahren vermittelt im Verwaltungsrecht zwei miteinander verbundene, logisch aber $\mathrm{zu}$ trennende Vorgänge: einmal den Vorgang der realen, $d . h$. auch außerrechtlich wirksamen, Erfüllung von Verwaltungszwecken und zum anderen den Vorgang der Setzung konkreten Rechts durch die rechtsanwendende Verwaltung. Zugleich verdeutlicht das Bild des konkretisierenden Verfahrens den spezifisch prozeßhaften Charakter beider Vorgänge, dem man bisher $\mathrm{zu}$ wenig Beachtung geschenkt hat.

Kennzeichnendes Beispiel dafür ist die tradierte Ermessens$\left.l e h r e^{79}\right)$. Seit Jahrzehnten wird sie fast einseitig vom Streben

Böckenförde-Grawert, AöR 95, 1 (18 ff.); Ipsen, VVDStRL 25, 257 (296); Lorenz, Rechtsschutz, S. 40 ff.; Vogel, VVDStRL 24, 156 ff. - zur Gegenposition vgl. bes. Rupp, Grundfragen der heutigen Verwaltungsrechtslehre, 1965, S. 119 ff.).

78) $\mathrm{Zu}$ dieser Struktur der Planung vgl. u. a. Kaiser, in: Kaiser, Planung I, 1965, S. 11 (19); Planung II, 1966, S. 11 (26); Badura, BayVerfGH-Festschrift, S. 159 ff., 167 ff.; ders., W. Weber-Festschrift, 1974, S. 911 (922 ff.); Schmidt-Aßmann, Grundfragen des Städtebaurechts, S. $161 \mathrm{ff.;}$ Steiger, Wolff-Festschrift, S. 393 ff., 406 f., 422; Hoppe, DVBl. 74, 641 ff.; Blümel, Forsthoff-Festgabe, 1967, S. 143; Redeker, DVBl. 71, 372; Ossenbühl, Gutachten 50. DJT, B 33, 183 ff.; Imboden, VVDStRL 18, 113 ff.; Oberndorfer, Die Verwaltung 1972, 257 (260 ff.); vgl. auch die Vorstellung des Plans als "Vollzugsnorm" (Brohm, Rechtsschutz im Bauplanungsrecht, 1959, S. 52 ff.). Vgl. weiterhin und näher zum Planungsprozeß Klages, Planungspolitik, 1971, S. 76 ff.; Lompe, Gesellschaftspolitik und Planung, 1971, S. 37 ff., 221 ff.; Gresser, Probleme der mehrjährigen öffentlichen Finanzplanung, 1974, S. 70 ff.; Mayntz-Scharpf, Planungsorganisation, 1973, S. 91 ff., 107 ff.; Scharpf, PVS 1972 Sonderheft 4, S. 168 (175 ff.); ders., in: Naschold-Väth, Politische Planungssysteme, 1973, S. 167 (169 ff.) = Die Verwaltung 1971, 1 ff.; Ellwein, Regierung und Verwaltung, 1. Teil, S. $200 \mathrm{ff}$.; Herzog, in: Regierungsprogramme und Regierungspläne, 1973, S. 37 (39 ff.).

79) Aus dem fast unubersehbaren Schrifttum vgl. bes. Soell, Das Ermessen der Eingriffsverwaltung, 1973, S. 63 ff.; Ehmke, „Ermessen" und "unbestimmter Rechtsbegriff" im Verwaltungsrecht, 1960; 
nach möglichst viel Justiziabilität beherrscht. So leugnete man das Tatbestandsermessen zugunsten des bloßen Rechtsfolgeermessen $s^{80}$ ) und verdrängte auch letzte Relikte tatbestandsorientierten Ermessens über die Lehre vom Beurteilungsspielraum auf die Ebene angeblichen Nicht-Ermessens ${ }^{81}$ ). Und doch mußte das kunstvolle Gebäude dieser Doktrin im gleichen Maße schwankend werden wie ihre Prämisse, die Vorstellung von der

W. Schmidt, Gesetzesvollziehung durch Rechtsetzung, S. 114 ff, 149 ff.; ders., NJW 75, 1753 ff.; Bachof, JZ 55, 97 ff.; Jesch, AóR 82, $163 \mathrm{ff}$; Bettermann, Staat 62, 79 ff.; Badura, BayVerfGH-Festschrift, S. 157 ff.; Ule, Jellinek-Gedachtnisschrift, 1955, S. 309 ff.; Kopp, DOV 66, 317 ff.; Ossenbühl, Verwaltungsvorschriften und Grundgesetz, S. 311 ff.; ders., DOV 68, 618 ff.; 70, 84 ff.; 72, 401 ff.; ders., DVBl. 74, 309 ff.; Stern, Ermessen und unzulässige Ermessensausübung, 1964; Schmidt-Salzer, Der Beurteilungsspielraum der Verwaltungsbehörden, 1968; ders., VerwArch 1969, 261 ff.; Rupp, Grundfragen der heutigen Verwaltungsrechtslehre, S. $177 \mathrm{ff}$.; ders., NJW 69, 1273 ff.; ders., ZRP 71, 233 f.; Redeker, DOV 71, 757 ff.; Jarosch, DOV 74, 123 ff.; Lohmann, Die ZweckmäBigkeit der Ermessensausübung als verwaltungsrechtliches Rechtsprinzip, 1972; Schmidt-Eichstaedt, AöR 98, 173 ff.; Bullinger, NJW 74, 769 ff.; ders., Jahrreiß-Festschrift, 1974, S. 19 ff.; Weigel, Beurteilungsspielraum oder Delegationsbegriff?, 1971; Kellner, DOV 69, 309 ff.; 72, 801 ff.; Obermayer, BayVBI. 75, 257 ff.; Rittner, H. KaufmannFestschrift, 1972, S. 307 ff.; Hoppe, DVBl. 74, 641 ff.; Schröder, DOV 75, 308 ff.; Stüer, DVBl. 74, $314 \mathrm{ff.}$

Bo) Vgl. z. B. BVerwGE 1, 138 (139); 3, 279 (283 f.); 15, 207 (208 ff.); 29, 140 (141 ff.); 40, 237 (247); 40, 353 (356 ff.); Bachof, JZ 55, 98; Jesch, AöR 82, 204 ff., 220 ff.; Stern, Ermessen, S. 20 ff.; Kellner, DOV 62, 572 (574); 69, 309 f.; Obermayer, BayVB1. 75, 260; ders., NJW 63, 1177 ff.; Schmidt-Salzer, VerwArch 1869, 262 ff.; Ossenbühl, DOV 70, 86; Menger, System des verwaltungsgerichtlichen Rechtsschutzes, S. 33; Becker, VVDStRL 14, 125 ff.; Korbmacher, DOV 65, 696 (697).

81) Zur Lehre vom prinzipiell voll kontrollfähigen unbestimmten Rechtsbegriff vgl. Bachof, JZ 55, 97 ff.; Rupp, Grundfragen, S. 212 ff.; Schmidt-Salzer, Beurteilungsspielraum, S. 16 ff., $42 \mathrm{ff}$., $90 \mathrm{ff}$.; Kellner, DOV 72, 802 ff.; BVerwGE 5, 153 (162 f.); 15, 39 (40); 16, 116 (129 f.); 23, 112 (114); 26, 65 (74 f.); 29, 279 (280); 35, 69 (75). Zum nicht voll kontrollfähigen Beurteilungsspielraum vgl. bes. Ule, Jellinek-Gedächtnisschrift, S. 309 ff.; Bachof, JZ 55, 98 ff.; Jesch, AöR 82, $230 \mathrm{ff}$; Ossenbühl, Verwaltungsvorschriften und Grundgesetz, S. $328 \mathrm{ff}$.

In diesem Sinne wird ein entsprechender Beurteilungsspielraum von der Rechtsprechung anerkannt für pädagogisch-prüfungsmäßige Beurteilungen (BVerwGE 5, 162 f.; 8, 272 (273 f.); 11, 165 (166 f.); 12, 29 (34); 12, 359 (363); 38, 105 (109 ff.); BadWüVGH, ESVGH 24, 225 (226 ff.)) und dienstliche Eignungsbeurteilungen bzw. Wertungen (vgl. BVerwGE 8, 192 (195); 11, 139 f.; 12, 20 (26 ff.); 12, 29 (34); 15, 3 (5 ff.); 15, 39 (40 f.); 15, 128 (131 f.); 17, 267 (271, 276 ff.); 21, 127 (129); 26, 65 (73 ff.); 32, 237 (238 ff.); 43, 342 (344) - vgl. allerdings auch BVerwGE 18, 298 (299 f.); 29, 279 (281)). 
Verwaltung als gesetzlich programmierter Vollzugsfunktion, ins Schwanken geriet ${ }^{82}$ ). Nur dort, wo der Gesetzgeber der Verwaltung konditionale Entscheidungsprogramme vorgibt ${ }^{83}$ ), lassen sich für eine entsprechend programmierte Verwaltung auch so enge Spielraumvorstellungen wie die vom bloßen Rechtsfolgeermessen und Beurteilungsspielraum aufrechterhalten. Wenn der Gesetzgeber der Verwaltung solche Programme aber nur (noch) begrenzt vorgibt und die Verwaltung im übrigen zur eigenen (finalen) Programmbildung beruft, so muß ihr auch tatbestandliches Ermessen zu eigener Kompetenz eröffnet sein $^{84}$ ).

Zuerst hat sich dies beim sog. Planungsermessen gezeigt. Sein ausholendes Gestaltungsmandat umfaßt Programmbildung wie Programmvollzug ${ }^{85}$ ), ermessensrechtlich gedacht also Tatbestand und Rechtsfolge $\left.{ }^{86}\right)$. Der gleiche Effekt kennzeichnet (beispielsweise) die wirtschaftspolitische - und hier namentlich die makroökonomisch lenkende ${ }^{87}$ ) - Verwaltungsentscheidung. Bei ihr wie bei der Planung spielt zudem die Prognoseentscheidung mit, die der Verwaltung prärogativ auch tatsächliche Entwicklungseinschätzungen erlaubt $\left.{ }^{88}\right)$; auch der hiermit anerkannte „Entwicklungsspielraum“ liegt außerhalb der Begriffskategorien von Beurteilungsspielraum und Rechtsfolgeermes$\operatorname{sen}^{80}$ ). Endlich hat sich die Unterscheidung zwischen Tatbestands- und Rechtsfolgeermessen selbst, weil logisch und normstrukturell nicht genügend vollziehbar, als fiktiv erwiesen ${ }^{00}$ ).

82) Zur Kritik vgl. Ehmke, „Ermessen“, S. 23 ff.; W. Schmidt, Gesetzesvollziehung, S. 133 ff., 149 ff.; ders., NJW 75, 1754 ff.; Jarosch, DOV 74, 124 ff.; Soell, Ermessen, S. 173 ff., 205 ff.; Schmidt-Eichstaedt, AöR 98, 176 ff., 186 ff.; Redeker, DOV 71, 760 ff.; vgl. auch bereits Ossenbühl, DÖV 68, 619 ff.; ders., DVBl. 74, $310 \mathrm{ff}$.

83) Zur Unterscheidung zwischen konditionaler und finaler Programmierung vgl. Luhmann, Theorie der Verwaltungswissenschaft, S. 60 f.; ders., Zweckbegriff und Systemrationalität, S. 100 ff.; ders., VerwArch 1964, 1 ff.; ders., AöR 94, 1 (2 ff.).

84) Vgl. auch Bullinger, NJW 74, 770 f.; Ossenbïhl, DVBl. 74, 310 f.; Hoppe, DVBl. 74, 643 ff.; W. Schmıdt, Gesetzesvollziehung, S. 157 ff., 161 f.; ders., NJW 75, 1754 f., 1757 f.

85) Vgl, die Nachweise oben N. 78.

86) Vgl. auch Steiger, Wolff-Festschrift, S. 422.

87) Vgl. dazu sehr klar Bullinger, NJW 74, $770 \mathrm{f}$.

88) Vgl. z. B. BVerwGE 16, 285 (287); 35, 291 (293); 39, 197 (203 ff.); 45, 112 ff.; BVerwG, DVBl. 72, 895 f.; vgl. weiterhin schon die Nachweise oben N. 59,61 .

80) Vgl. näher schon R. Scholz, Wirtschaftsaufsicht, S. $106 \mathrm{ff}$.

${ }^{\left.{ }^{00}\right)}$ Vgl. Ehmke, „Ermessen“, S. 28, 40; Schmidt-Eichstaedt, AöR 98, 179 ff., 186 ff., 189; Soell, Ermessen, S. 205 ff.; W. Schmidt, Gesetzesvollziehung, S. 157; ders., NJW 75, 1754 ff ; aus rechtstheoretischer Sicht vgl. allgemein Schreiber, Die Geltung von Rechtsnormen, 1966, S. 24 ff. 
Eine flexible Rechtsprechung hat dieser überfälligen Einsicht inzwischen Bahn gebrochen ${ }^{91}$ ) und die Ermessenslehre damit der erforderlichen Gesamtrevision zugeführt.

Diese muß von folgenden Daten ausgehen: Legitimation und Grenzen verwaltungsrechtlichen Ermessens bilden ein Problem des gewaltenteiligen Rechtsstaats ${ }^{\mathbf{2}}$ ). Seine Garantie elgenverantwortlicher Verwaltung gewährleistet auch das Verwaltungsermessen ${ }^{* 3)}$. Hiernach legitimes Ermessen läßt sich nicht auf die Kategorien von Beurteilungsspielraum und Rechtsfolgeermessen reduzieren. Denn Tatbestands- und Rechtsfolgeermessen sind nicht voll voneinander scheidbar und die Differenzierung zwischen Beurteilungsspielraum und Tatbestandsermessen hat sich als Scheinlösung erwiesen; in Wirklichkeit handelt es sich auch bei der „wertenden“ oder „beurteilenden“ Ausfüllung unbestimmter Gesetzesbegriffe um - freilich begrenztes - Tatbestandsermessen ${ }^{94}$ ).

In der Konsequenz führt dies zur Anerkennung eines prinzipiell einheitlichen Verwaltungsermessens, das typologisch unter Aufgabe der Lehre vom Beurteilungsspielraum ${ }^{95}$ ) - in Tatbestands-, Rechtsfolge- und Gestaltungsermessen zu gliedern ist. Diese Kategorien besitzen zwar fließende Grenzen; die allein quantitativen Unterschiede zwischen den einzelnen Er-

Für die Praxis ist dies zuerst am sog. Kopplungstatbestand deutlich geworden (vgl. zu § 131 AO GemSoGB, in: BVerwGE 39, 355 (357 ff.); vgl. weiterhin BVerwGE 45, 162 (164 ff.); vgl. auch Redeker, DVB1. 72, 609).

91) Vgl. bes. GemSoGB, in: BVerwGE 39, 355 ff. zu $\S 131 \mathrm{AO}$; BVerwGE 34, 301 (304 ff.): Planungsermessen; BVerwG, DVBl. 72, $895 \mathrm{f}$. zu § 12 AWG (mit Anm. Redeker); BVerwGE 39, 197 (203 f., $207 \mathrm{ff}$.) gegen BVerwGE 23, 112 ff.; 28, 223 ff. zu § 1 GjS; BVerwGE 41, 1 (4 ff.) zu § 3 WährG; BVerwGE 45, 309 (312 ff.) - Flachglas -.

92) Vgl. Ossenbühl, DOV 68, 626; ders., DVB1. 74, 311; SchmidtEichstaedt, AöR 98, 190 ff.

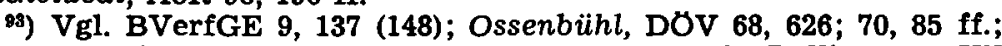
ders., DVBl. 74, 311; Ehmke, "Ermessen“, S. 45 ff.; Bullinger, NJW 74, 770; Bachof, VVDStRL 12, 67 f.; Redeker, DVBl. 71, 369 (371); Kassimatis, Der Bereich der Regierung, 1967, S. 45 f.; im Sinne einer einschränkenden, aber differenziert zu verstehenden Position vgl. vor allem Rupp, Grundfragen, S. $178 \mathrm{ff}$., $193 \mathrm{ff}$., $201 \mathrm{ff}$.

04) Vgl. W. Schmidt, Gesetzesvollziehung, S. 139, 142 f., 157; ders., NJW 75, 1755 ff.; Schmidt-Eichstaedt, AöR 98, 186 ff., 189; Häberle, Offentliches Interesse, S. 595 ff. (691 ff.); Gertmann, Bundesverfassungsgericht und "offene Normen“, S. 52 ff., 57, 108; Ehmke, „Ermessen", S. 23 ff.; Soell, Ermessen, S. 207 ff.; vgl. auch Ossenbühl, DOV 72, 404; Jarosch, DOV 74, 124 ff.; BVerwGE 11, 165 (166 f.).

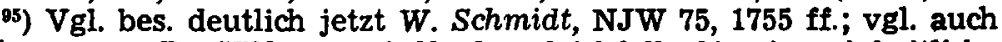
Obermayer, BayVBl. 75, 258 ff., der gleichfalls fúr eine einheitliche Konzeption des Verwaltungsermessens, wenngleich mit engerer Reichweite, eintritt. 
messensermächtigungen fangen sie begrifflich aber auf. Die danach umfassendste Ermessenskompetenz liegt im Gestaltungsermessen, dem das Planungsermessen und die Prognoseentscheidung mit ihrem Entwicklungsspielraum zuzurechnen sind.

Gegen eine solche Bereinigung der Ermessenslehre ließe sich nicht der Einwand erheben, daß damit einseitig oder gar rechtsstaatswidrig der Verwaltungsverantwortung die Vorhand gegenuber dem Verwaltungsrechtsschutz gegeben würde. Im Gegenteil, das Ermessensproblem würde aus der Sackgasse bloßen Strebens nach Justiziabilität heraus- und in die (allein zuständige) Verantwortung des Gesetzgebers zurückgeführt ${ }^{90}$ ). Denn jedes Verwaltungsermessen bedarf der rechtlich ermächtigenden Delegation ${ }^{97}$ ): Der Gesetzgeber beruft die gesetzesanwendende Verwaltung zur konkretisierenden Vervollständigung einer in Tatbestand und/oder Rechtsfolge nicht kompletten (erst von konkretisierender Rechtsanwendung aktuell zu komplettierenden) Gesetzesnorm ${ }^{98}$ ).

Ermessen bedeutet somit konkrete Rechtsetzung ${ }^{90}$ ) im beschriebenen Sinne ${ }^{100}$ ). Der Gesetzgeber hat angesichts dessen

98) Ermessen, unbestimmter Rechtsbegriff etc. sind primär Aufgaben rechtsstaatlicher und demokratischer Gesetzgebung (Rechtsstaatsprinzip, Art. 80 GG) und nicht Aufgaben der gerichtlichen Verwaltungskontrolle (vgl. auch W. Schmidt, Gesetzesvollziehung, S. 133 ff., 159 ff.; für das Planungsermessen vgl. nachdrücklich vor allem Badura, BayVerfGH-Festschrift, S. 175).

${ }^{07}$ ) Vgl. W. Schmidt, Gesetzesvollziehung, S. 142 f., 157; Weigel, Beurteilungsspielraum oder Delegationsbegriff?, S. 168 ff.; SchmidtEichstaedt, AöR 98, 179 ff., 186 ff.

98) Vgl. Soell, Ermessen, S. 173 ff., 204 ff.; W. Schmidt, Gesetzesvollziehung, S. 142 f., 157; ders., NJW 75, 1755; Bäumlin, Staat, Recht und Geschichte, S. 35 f.; Starck, Gesetzesbegriff, S. 263 ff., 277 ff.; Weigel, Beurteilungsspielraum oder Delegationsbegriff?, S. $168 \mathrm{ff}$; Ossenbühl, DOV 72, 403 (für den Beurteilungsspielraum); ders., DOV 70, 86 ff. (für Ermessen und Beurteilungsspielraum); ders. auch DVBl. 74, 310 ff.; Schmidt-Salzer, Beurteilungsspielraum, S. $90 \mathrm{ff}$. (für den Beurteilungsspielraum); vgl. dens. auch VerwArch 1969, 267 ff. für das Ermessen (mit allerdings verfassungsrechtlich unrichtiger Verortung des Ermessens - "Verbot des Einzelfallgesetzes"! - [S. 269] und damit im Ergebnis nicht voll zutreffender Lösung). Vgl. auch Lorenz, Rechtsschutz, S. 23; Selmer, in: SteuerkongreBReport 1974, S. 83 (111); Rupp, Grundfragen, S. 212; Bettermann, Staat 62, 85; Merkl, Allgemeines Verwaltungsrecht, S. $142 \mathrm{ff}$.

"9) Diese Qualifikation des Ermessens als verwaltungsmäßiger Rechtskonkretisierung ist von primärer Bedeutung; sie rangiert dogmatisch noch vor der Qualifikation „Ermessen“; vgl. Bäumlin, Staat, Recht und Geschichte, S. 36, mit der an sich konsequenten, freilich wenig praktikablen Schlußfolgerung, daß „der Ermessenbegriff im Verwaltungsrecht sogar entbehrlich" wäre. 
zu prüfen, welcher Konkretisierungs- oder Ermessensspielraum der Verwaltung im einzelnen offenstehen soll. Wenn er dieser Pflicht nicht immer genügt (hat), so läßt sich ein daraus (etwa) resultierendes Defizit an materieller Rechtsstaatlichkeit nicht über die rechtsprechende Gewalt und ihre juristische Kontrollfunktion ausgleichen. Denn die zu kontrollierende Ermessensentscheidung ist typischerweise metajuristischen Zielen, Wertungen oder Erkenntnissen verpflichtet ${ }^{101}$ ); und die Kompetenz $\mathrm{zu}$ solcher Zweckkonkretisierung liegt im Verhältnis von Verwaltungsgerichtsbarkeit und Verwaltung vorrangig bei der letzteren ${ }^{102}$ ).

100) Bes. beispielhaft etwa in jeder Interessenabwägung im planerischen oder sonstig gestaltenden Bereich dokumentiert. Denn in jeder Interessenabwägung aktualisiert sich der konkret-rechtsetzende und politisch-dezisionäre Entscheid über bestimmte (divergente) Interessen, der sich als solcher den Kategorien von (subsumtionsmäßiger) Rechtsanwendung oder (schlichter) Gesetzesvollziehung entzieht. In diesem Sinne ist die planerische Entscheidung typischerweise Akt prospektiver Interessenkoordination. Vgl. in diesem Sinne und näher BVerwGE 34, 301 (304 ff.); 34, 352 (356); 41, 67 (68 ff.); 42, 331 (338); 44, 1 (6 ff.); 45, 25 (38 f.); 45, 112 (113 ff.); 45, 309 (312 ff.); BVerwG, DVBl. 69, 697 (699); 72, 895 f.; 75, 492 (493 ff.); BVerwG, DOV 75, 101 f.; vgl. zuvor auch schon BVerwGE 4, 284 (285 f.); 10, 202 (205); 18, 247 (250 ff.); vgl. weiterhin OVG Lüneburg, BRS 17, 14 (15); 24, 11 f.; 23, 43 (44 f.); HessVGH, BRS 23, 7; OVG Berlin, BRS 23, 1 (5 f.) - anders vgl. bes. BadWüVGH, BRS 17, 16 (18 f.); 18,2 f.; 20, 14 (15); 22, 27; 24, 37 (38) - Dogmatisch vgl. zur Rechtsnatur und Wirkung der (planerischen) Interessenabwägung bes. Steiger, Wolff-Festschrift, S. 385 ff.; Papier, DVBl. 75, 461 ff.; Badura, BayVerfGH-Festschrift, S. 179 ff.; Hoppe, Scupin-Festschrift, S. 124 ff.; Schmidt-Aßmann, Grundfragen des Städtebaurechts, $S$. 87 ff.; Weyreuther, BauR 75, 1 ff.

101) Vgl. allgemein z. B. Ossenbühl, Verwaltungsvorschriften und Grundgesetz, S. 321 ff.; Redeker, DOV 71, 760; Stüer, DVBl. 74, 317 f.; Jesch, AöR 82, 208, 211; F. Mayer, Das Opportunitätsprinzip in der Verwaltung, 1963, S. 16; Stern, Ermessen, S. 26; Hoppe, Scupin-Festschrift, S. 122, 125 f., 130 f.; vgl. auch Badura, BayVerfGH-Festschrift, S. 164 f.; Kassimatis, Bereich der Regierung, S. 42 ff.

Aus der Rechtsprechung zum Rechtsfolgeermessen und zum Beurteilungsspielraum vgl. u. a. BVerwGE 1, 92 (96); 2, 313 (314); 3, 279 (283 f.); 4, 89 (91 ff.); 4, 298 (300); 6, 186 (187 f.); 8, 272 (273 f.); 9, 284 (285 f.); 15, 251 (253 f.); 21, 187 (188 f.); 32, 148 (155 f.); 39, 197 (202 ff.); 41, 253 (259); 45, 13 (24); 45, 112 ff.; 45, 162 (164 ff); BayVerfGH, VGHE 27, 47 (57 f.); anders allerdings BVerwGE 21, 184 (186 f.); 23, 112 (114); 23, 194 (200 f.); 24, 60 (63 f.); 28, 223 (224).

Zum Verhältnis von Verwaltungsrecht und Technik vgl. richtig OVG Münster, DB 74, 2106 („Einschätzungsspielraum"); zur „padagogischen (Ermessens-)Freiheit des Lehrers" vgl. Evers, VVDStRL 23, 147 (177 ff.); zur geringen Justiziabilität von Lehr- und Bildungsplänen vgl. Wimmer, DVBl. 70, 305 ff.; Dietze, DVBl. 75, 389 (392 ff.). 
Die kompetenzrechtliche Struktur aller verwaltungsrechtlichen Ermessensentscheidungen erweist sich damit als ambivalent: Als Verfahren konkreter Rechtsetzung ist jede Ermessensentscheidung rechtlicher Akt und damit justiziabel. Als Verfahren konkreter Zweckverwirklichung ist sie inhaltlich aber auch außerrechtlicher Akt und daher nur soweit justiziabel, wie die inhaltliche Zweckverfehlung Folge gerade fehlerhafter Rechtskonkretisierung ist. Für den kompetenzgerechten Verwaltungsrechtsschutz bedeutet dies, daß zur Kontrolle von Ermessensentscheidungen nach Maßstäben gesucht werden muß, die methodisch auch beim juristisch meßbaren Entscheidungsverfahren und nicht nur beim häufig injustiziablen Entscheidungsinhalt ansetzen. Dieses Erfordernis wird freilich erst im Lichte jener Ermessensentscheidungen bewußter, die sich nicht in der momentanen Statik punktueller Rechtsfolgebestimmungen erschöpfen, sondern die ganze Dynamik kompletter Zielund Vollzugsprogramme aufnehmen ${ }^{103}$ ).

3. Strukturgesetz der Verwaltungsverantwortung ist die Zweckund Rechtskonkretisierung. Sie buldet die typische Verfahrensform der Verwaltung und zugleich deren kompetenzielle Aufgabe im System der gewaltengegliederten Staatszwecke ${ }^{104}$ ). Das Prinzip des konkretisierenden Verfahrens formuliert damit auch ein materielles Rechtsgebot, nämlich den verfahrensrechtlich organisierten Auftrag zur möglichst ermächtigungs-, sach-

102) Nicht richtig ist daher jene Auffassung, derzufolge auch die "Zweckmäßigkeit" des Verwaltungshandelns - und hinter diesem traditionellen, freilich recht farblosen Begriff verbirgt sich die Summe aller metajuristischen Entscheidungselemente oder Entscheidungsdeterminanten - gerichtlich voll zu überprüfen sei (vgl. so Görlitz, Verwaltungsgerichtsbarkeit in Deutschland, S. $268 \mathrm{f}$.; Lohmann, Die Zweckmäßigkeit der Ermessensausübung als verwaltungsrechtliches Rechtsprinzip, S. 91 ff.; auch Obermayer, BayVBl. 75, 260; zum Begriff der ZweckmäBigkeit und dessen Differenz zur Rechtmäßigkeit vgl. eingehend und kritisch bes. Soell, Ermessen, S. $66 \mathrm{ff} ., 76 \mathrm{ff}$.). Daß die Verwaltungsgerichtsbarkeit nicht zur Zweckmảßigkeitskontrolle zustandig ist, ist mit Recht herrschende Auffassung (vgl. statt vieler nur W. Schmidt, Gesetzesvollziehung, S. 139, 258; Ossenbühl, Gutachten 50. DJT, B 164; differenzierend allerdings auch Brunner, Kontrolle in Deutschland, S. $243 \mathrm{ff}$.).

103) Richtig ist deshalb der vom BVerwG bei der Beurteilung planerischer Interessenabwägungen gewählte, dogmatisch freilich noch auszubauende Ansatz von der Differenzierung zwischen dem Abwägen als Vorgang und dem Abgewogensein als Zustand (vgl. BVerwGE 41, 67 (71); 45, 25 (35 ff); 45, 309 (312 ff.); BVerwG, BauR 74, 181 (184 ff.)).

104) Vgl. auch Peters, Lehrbuch der Verwaltung, 1949, S. 3 ff.; Ossenbühl, Verwaltungsvorschriften und Grundgesetz, S. 189 ff.; Bäumlin, Staat, Recht und Geschichte, S. 35 f. 
verhalts- und individualgerechten $\left.{ }^{105}\right)$ - kurz: maximalen Konkretisierung der gesetzlich aufgegebenen Staatszwecke $\left.{ }^{108}\right)$. Dieser Auftrag verpflichtet jede Verwaltungsfunktion und benennt folglich auch deren prinzipalen Verhaltensmaßstab. Dieser gilt für alle Verwaltungsaufgaben und eröffnet so auch den Weg zum wirksamen Kontrollmaßstab für die Verfahrensweisen verwaltungsmäßiger Verantwortung.

$\mathrm{Daß}$ die gesetzesgebundene Verwaltung ihren gesetzlichen Vollzugsauftrag vollständig erfüllen, $d$. $h$. subsumtionsmäßig abschließend konkretisieren muß, ist selbstverständlich und rechtlich voll überprüfbar. Für die gesetzesfreie, gestaltende und Ermessensverwaltung ist das Maß der rechtlichen Nachprüfbarkeit dagegen beschränkt. Nicht beschränkbar ist aber auch hier die Kontrolle des von der Verwaltung zu leistenden Maßes verfahrensmäßiger Konkretisierung - eine Kontrolle, die bis zum Verdikt des - gegebenenfalls rechtswidrigen Konkretisierungsdefizits führen kann, so z. B. bei Ermessensunter- und Ermessensüberschreitung: Die zur Ermessensentscheidung ermächtigte Verwaltung erfüllt den gesetzlichen Konkretisierungsauftrag nicht, weil sie das Verfahren ermessensmäßiger Zweckkonkretisierung unterläßt oder überdehnt $\left.\left.{ }^{107}\right),{ }^{108}\right)$.

${ }^{105}$ ) Konkretisierung in diesem Sinne bedeutet allerdings nicht nur tatsächliche Individualisierung. Der Verwaltung stehen als Konkretisierungsverfahren auch die (normative) Generalisierung und Typisierung zur Verfügung. Im Verhältnis zum Gesetz funktionieren diese aber als Form und Verfahren der Konkretisierung, bedürfen allerdings prinzipiell der gesetzlichen Ermächtigung. Zur Typisierung bzw. zum Verhältnis von typisierendem Gesetzesvollzug und gesetzmäBiger Verwaltung vgl. Isensee, StuW 73, 199 (201 ff.); vgl. auch Selmer, Steuerinterventionismus und Verfassungsrecht, 1972, S. 285 ff. (Verhältnis von typisierendem Gesetzesvollzug und Ubermaßverbot bzw. rechtsstaatlicher Eingriffskontrolle). Vgl. hierzu auch noch unten N. 108.

106) Verfassungsrechtlich stützt sich das Konkretisierungsgebot auf mehrere Grundlagen: (1) auf das demokratische Prinzip, soweit dies den Vorbehalt und (konkretisierungsrechtlichen) Vollzugsauftrag des Gesetzes konstituiert; (2) auf das rechtsstaatliche Prinzip, soweit dies im Verhältnis von Exekutive und Gesellschaft die moglichst konkret- und individualgerechte Verwaltungs- oder Vollzugsmaßnahme fördert; (3) auf das Gewaltenteilungsprinzip und den ihm immanenten Funktionsauftrag der Verwaltung (Konkretısierung der gesetzlich definierten Staatszwecke).

107) Vgl. in dieser Richtung auch den Versuch W. Schmidts, NJW 75, $1755 \mathrm{f}$., die Kontrolle von Ermessensentscheidungen phasenmäßig zu systematisieren.

${ }_{108}$ ) Als typisches Konkretisierungsdefizit in diesem (verfahrensrechtlichen) Sinne erweist sich auch das planungsrechtliche Abwägungsdefizit (zu ihm vgl. bes. BVerwGE 34, 301 (305 ff.); 42, 331 
Der spezifisch verfahrensmäßige Aspekt des rechtlichen Gebots maximaler Zweck- und Rechtskonkretisierung ermöglicht auch die adäquate Kontrolle ganzer Entscheidungsprozesse in der Verwaltung ${ }^{109}$ ) - unter Einschluß des Faktors Zeit. Dies zeigt sich z. B. bei Entwicklungsplanungen und Prognoseentscheidungen, die bestimmte (faktische) Entwicklungsziele oder -erwartungen zur prospektiven Basis einer momentanen Verwaltungsentscheidung erheben. Bei Fehlprognosen oder entwicklungsbedıngten Zielabweichungen müssen solche Entscheidungen nachträglich zur Korrektur oder angepaßten Fortschreibung verpflichtet werden ${ }^{110}$ ). Die Grundlage dafür bietet das

(338); 45, 25 (35 ff.); 45, 309 (312 ff.); BVerwG, NJW 75, 1373 (1374 ff.); Hoppe, Scupin-Festschrift, S. 125 ff., 133 ff.; ders., DVBl. 74, 644 f.; Papier, DVBl. 75, 461 ff.; Sendler, WiR 72, 454 ff.; Weyreuther, BauR 75, 1 ff.). Soweit die Abwägung unter glechzeitiger wie für den planungsrechtlichen Zusammenklang von Programmbildung und -vollzug typisch - Definition und koordinierender Bewertung von Interessen erfolgt, kann eine wirksame (,immanente“) Kontrolle nur derjenige Maßstab gewährleisten, der wie das Konkretisierungsgebot nach der tatsächlichen Definition und Koordination gegebenenfalls kollidierender Interessen im Planungs- und Abwägungsverfahren selbst fragt. Von vornherein materiell-rechtliche Kontrollen sind nur insoweit möglich, als es um die Kontrolle der konkreten Planentscheidung anhand übergeordneten Verfassungsoder Gesetzesrechts geht.

Als weiteres Beispiel sei auf die Begrenzung von verfahrens- oder ermessensleitenden Verwaltungsvorschriften hingewiesen, sofern diese in allzu einseitiger Sachverhaltstypisierung einen gesetzlichen Auftrag zur konkret-individualen Einzelfallgerechtigkeit verfehlen. $\mathrm{Zu}$ den Grenzen und statthaften Möglichkeiten derart typisierender Verwaltung vgl. bes. Isensee, StuW 73, 199 ff.; Selmer, Steuerinterventionismus, S. 285 ff.; ders., DOV 72, 551 ff.; allgemein zu den Grenzen (gesetzlicher) Typisierung vgl. BVerfGE 25, 236 (251); 30, 292 (327); BVerfG, NJW 74, 1127 (1129); zur Legitimation verwaltungsrechtlicher Typisierung vgl. im übrigen bereits oben N. 105 .

100) Als Beispiel vgl. die im Ergebnis richtige Kontrollfragestellung in BVerwG, NJW 75, 1373 (1374 ff.), derzufolge die planerische Gestaltungsfreiheit für eine Straßenplanung nach dem BFStrG in Verbindung mit dem BImSchG 1. durch die behördeninterne (!) Bindung an die vorbereitende Planentscheidung des Bundesministers für Verkehr, 2. durch das Erfordernis einer der fernstraßenrechtlichen Zielsetzung entsprechenden Rechtfertigung des konkreten Planvorhabens, 3. durch die gesetzlichen Planungsleitsätze und 4. durch die Anforderungen des Abwägungsgebots beschrảnkt wird. Mit diesen, rechtlich wie systematisch differenten, lediglich verfahrensmäßig verbundenen Elementen eines (rechtmäßigen) Planungsvorgangs folgt das BVerwG richtig der Linie, einen kompletten Planungsprozeß nach Maßgabe von dessen verfahrungsmäßigen Konkretisierungsphasen $\mathrm{zu}$ überprüfen.

110) Vgl. für die Entwicklungsplanung Kaiser, 50. DJT, II, I 18 f.; ders., in: Kaiser, Planung II, S. 25 f.; Ossenbühl, Gutachten 50. DJT, 
Konkretisierungsgebot mit seiner Pflicht für die Verwaltung, frühere, auf Zukunftsgestaltung oder -erwartung gerichtete Entscheidungen auch "in die Zeit hinein ${ }^{\text {(111) }}$ hinsichtlich des (noch) bestehenden sach- und gesetzesgerechten Konkretisierungsgehalts zu überprüfen $\left.{ }^{112}\right),{ }^{113}$ ).

Verfahrensrechtlich werden durch solche Utberprüfungs- und konkretisierenden Anpassungspflichten zugleich viele der Mängel an rechtlicher Bestimmtheit kompensiert, die für die gesetzliche Organisation gerade planender oder sonstig gestaltender Verwaltung charakteristisch sind. Der prozeßhafte Charakter von Gestaltungsmaßnahmen der Verwaltung schließt die a priori-gesetzgeberische Bestimmung vorhersehbarer Zweckund Folgeinhalte vielfach aus; denn diese aktualisieren sich erst auf Zeit innerhalb konkretisierender und gegebenenfalls wechselnder Zweck-Mittel- und Folgenrelationen. Der gerichtlichen Kontrolle muß sich dieser Prozeß entziehen, wenn diese nur ex post nach der Rechtmäßigkeit des verfahrensabschließenden Entscheidungsakts, gemessen an der ursprünglichen gesetzlichen Ermächtigungsgrundlage, fragen darf. Der zweck- wie eigentlich folgenbestimmende Konkretisierungsproze $\beta$ droht m. a. W. aus dem disziplinierenden Rahmen von gesetzlicher Vorabbestimmung und gerichtlicher Kontrolle herauszufallen - beispielhaft verkörpert im Kontrolldilemma um stufenförmige Planungs- und Genehmigungsverfahren. Diesem Dilemma wirksam zu begegnen, vermag allein ein kontrollrechtlich verdichtetes Konkretisierungsgebot, das auch die einzelnen Phasen eines Entscheidungsprozesses auf ihre jeweilige Konkretisierungsgerechtigkeit prüft'11).

B 160, 163; für die (sonstige) Prognoseentscheidung vgl. bereits $R$. Scholz, Wirtschaftsaufsicht, S. $105 \mathrm{f}$.

111) Bäumlin, Staat, Recht und Geschichte, S. 15.

112) Die verfahrensrechtliche Konsequenz lautet gegebenenfalls Wiederaufnahme des Verwaltungsverfahrens mit entsprechender Restitution oder Entscheidungsänderung. Vgl. zur Fehlprognose bereits näher $R$. Scholz, a. a. O., mit der prozessualen Forderung auf Zulassung von präventivem Verwaltungsrechtsschutz. Zur Wiederaufnahme von Verwaltungsverfahren vgl. allgemein näher bes. Bettermann, Wolff-Festschrift, 1974, S. 465 ff.; aus der Rechtsprechung vgl. z. B. BVerwGE 15, 155 (156 ff.).

113) Mit dieser kontrollfähigen Erfassung des Faktors Zeit wirkt das Gebot der maximalen Konkretisierung überdies und gleichsam als Ergänzung des - mit Recht aus Art. 19 IV GG abgeleiteten (vgl. Lorenz, Rechtsschutz, S. 14 ff.) - Verrechtlichungsgebots.

114) Vgl. auch Wahl, DOV 75, $375 \mathrm{f}$., der für die Kontrolle mehrstufiger Verwaltungsverfahren ähnlich verfährt und den jeweilıgen "Konkretisierungsproze ${ }^{\text {“ }}$ mit Recht sowohl unter dem Aspekt der stufenförmigen "Verfeinerungsbedürftigkeit" als auch unter dem Aspekt des „Abschneidens von Alternativen" zu überprüfen sucht. 
IV. Verwaltungsrechtliches Konkretisierungsverfahren und gerichtliche Verwaltungskontrolle

1. Die gerichtliche Kontrolle der zweck- und rechtskonkretisierenden Verwaltungsentsche1dungen ist soweit beschränkt, wie deren Gegenstand (auch) außerrechtlich beschaffen ist. Hier stößt die Prüfungskompetenz des Verwaltungsgerichts an die vorrangige Zweckkompetenz der Verwaltung ${ }^{115}$ ). Prozessual äußert sich diese Kontrollbeschränkung in der Bindung des Verwaltungsgerichts an denjenigen Maßstab, den die Verwaltung für ihre metajuristische oder Ermessensentscheidung selbst aufgestellt hat. Die Verwaltung verfügt insoweit über eine legitime Maßstabskompeten $z^{110}$ ), die - verfassungsrechtlich gesehen - typische implied power einer zur konkreten Rechtssetzung ermächtigten Exekutive ist ${ }^{117}$ ).

Die Aufstellung solcher Verwaltungsmaßstäbe erfolgt mittels der den (partiell-) offenen Zweckentscheid des Gesetzes konkretisierenden, $d$. h. (konkret-) rechtlich komplettierenden Verwaltungsentscheidung. Die Rechtsschutzgarantie des Art. 19 IV GG wird durch diese Maßstabskompetenz der Verwaltung nicht berührt; denn in der Anerkennung verwaltungseigener Maßstabsbildung liegt keine Anerkennung rechtsfreier „Maßstabsautonomie". Als konkrete Rechtsetzung muß sich auch die verwaltungseigene Maßstabsbildung an die gesetzliche Ermächtigung (eingeschlossen die Frage nach der richtigen Qualifikation der Außerrechtlichkeit eines Verwaltungszwecks!) und ihre

115) Dies ist auch der - legitıme - Grund, weshalb z. B. Gnadenentscheidungen und sog. „Regierungsakte" nur beschränkt justiziabel sind; denn Gnadenakt und rein politischer Leitungsakt sind wesentlich metajuristisch bestimmt (ungenaue Bezeichnung: „justizfreie Hoheitsakte"). Zur beschränkten Justiziabilität von Gnadenentscheidungen vgl. mit freilich etwas unterschiedlicher Ausrichtung BVerfGE 25, 352 (358 ff.); HessStGH, NJW 74, 791 ff.; Schatzler, NJW 75, 1249 ff.; Petersen, JuS 74, 502 ff.; Bettermann, AöR 96, 537 ff.; Lorenz, Rechtsschutz, S. 157 ff.; H. Bauer, Gerichtsschutz als Verfassungsgarantie, S. 150 ff.; zum Regierungsakt vgl. z. B. Lorenz, a. a. O.; H. Schneider, Gerichtsfreie Hoheitsakte, 1951; F. Klein, VVDStRL 8, 108 ff.; Becker, VVDStRL 14, 115 f.; H. Bauer, a. a. O., S. $144 \mathrm{ff}$.

110) Vgl. auch BVerwGE 6, 177 (182); W. Schmidt, Gesetzesvollziehung, S. 139, 161, 258 f.; Ossenbühl, DOV 68, 622; 70, 87; allgemeiner vgl. z. B. E. Stein, Die Wirtschaftsaufsicht, 1967, S. 114 ff.; zur Maßstabskompetenz z. B. der Bundesbank vgl. Herzog, VVDStRL 24, 183 (191).

117) Zur implied-powers-Lehre als Rechtfertigung entsprechender Funktionsverschränkungen vgl. Achterberg, Probleme der Funktionenlehre, S. 213 ff., 220 ff.; Böckenförde, Die Organisationsgewalt im Bereich der Regierung, 1964, S. 87. 
„Ermessensdirektiven“118) halten. Ob sie dem genügt, kontrolliert das Verwaltungsgericht ebenso wie es im übrigen - in Anwendung des verwaltungseigenen Maßstabs - prüft, ob die Verwaltung selbst maßstabskonform gehandelt hat. Die verwaltungsgerichtliche Kontrolle namentlich von Ermessens- und Planungsentscheidungen zerfällt mithin (1.) in die Kontrolle der konkreten Maßstabsbildung (Frage nach dem verfassungs- und gesetzeskonformen Maßstab) und (2.) in die maßstabsimmanente Kontrolle der konkreten Verwaltungsentscheidung (Frage nach der maßstabskonformen Entscheidung). Je weiter die gesetzliche Ermächtigung der Verwaltung zur Selbstprogrammierung ${ }^{119}$ ) oder metajuristischen Zweckverfolgung reicht ${ }^{120}$ ), desto enger fällt die gerichtliche Kontrolle des verwaltungseigenen Handlungsmaßstabs aus. Besonders eng gesteckte Kontrollmöglichkeiten bestehen demgemäß bei den komplexen Zielformeln der Raum- ${ }^{121}$ ), Wirtschafts-122) und Entwicklungs-

118) $\mathrm{Zu}$ diesem Begriff vgl. Ossenbïhl, Verwaltungsvorschriften und Grundgesetz, S. 319; ders., DOV 68, 626; Badura, BayVerfGHFestschrift, S. 174.

119) Zur Technik gesamtwirtschaftlicher Zielprojektion in der Wirtschaftsplanung vgl. Schlecht, in: Kaiser, Planung III, 1968, S. 111 ff.; aus ökonomischer Sicht vgl. z. B. H. K. Schneider, WesselsFestschrift, S. 37 ff.

120) Vgl. hier bereits die Nachweise oben N. 101.

121) Vgl. im Bundesrecht nur z. B. \$§ 1, 2 I/2 II RaumOG, 1 FlurBG, Bundesraumordnungsprogramm (BT-Drucks. 7/3584); im Landesrecht vgl. z. B. \$§ 1 I HessLPIG vom 4. 7. 62 (GVBl. I, S. 311) i. d. F. vom 28. 1. 75 (GVBl. I, S. 19), 1 I lit. a SchlHLPIG vom 13. 4. 71 (GVBl. S. 152), 1 BadWüLPlG i.d. F. vom 25. 7. 72 (GB1. S. 460), 1 NdsRLPlG vom 30. 3. 66 (GVBl. S. 69) i. d. F. vom 24. 1. 74 (GVBl. S. 49), 1 I, 2 RhPfRLPIG vom 14. 6. 66 (GVBl. S. 177), 2 BayLPIG vom 6. 2. 70 (GVBl. S. 9) - etwas anders lediglich \& 1 I NrWLPIG vom 7. 5. 62 (GVBl. S. 229) -.

Rechtsschutzmäßig sind hier vor allem die Fragen des gemeindlichen Bestandsschutzes gegenuber staatlichen Neugliederungsmaßnahmen aktuell geworden. Die Rechtsprechung hat dem Staat hier einen breiten Gestaltungsspielraum zuerkannt und sich wesentlich auf die Kontrolle der Frage beschränkt, ob die planerischen „Wertungen und politischen Erwägungen“ „eindeutig widerlegbar oder offensichtlich fehlerhaft sind oder der verfassungsrechtlichen Wertordnung widersprechen" (BadWüStGH, NJW 75, 1205 (1207); BadWüStGH, DOVV 73, 163 (166); entspr. NrwVerfGH, OVGE 25, 310 [315]) bzw. der gesetzlichen Ermächtigung widersprechen (vgl. BayVGH, BayVBl. 75, 168 (169 f.); entspr. VG Freiburg, DVBl. 74, 916 (917) mit Anm. Ule). - Zum Ganzen vgl. näher und $\mathrm{m}$. w. Nachw. Hoppe-Rengeling, Rechtsschutz bei der kommunalen Gebietsreform, 1973, S. 7 ff., 31 ff., 35 ff., 64 ff., 78 ff., 85 ff., 134 ff., 167 ff.; Hoppe, Hefermehl-Festgabe, 1972, S. 91 ff.; Ule, G. Müller-Festschrift, 1970, S. 529 (535 ff.); ders., VerwArch 1969, 101 ff.; F. Mayer, Geiger-Festschrift, 1974, S. 735 ff.; Seibert, Selbstverwaltungsgaran- 
planung ${ }^{128}$ ), bei den offenen Ermächtigungen zur planerischen Interessenabwägung ${ }^{124}$ ), bei den makroökonomischen Prozeßbegriffen im StWG $\left.{ }^{125}\right)$, GWB ${ }^{126}$ ) usW. ${ }^{127}$ ), bei allen kompetenziel-

tie und kommunale Gebietsreform, 1971, S. $58 \mathrm{ff}$; Schnur, Die Verwaltung 1970, 257 ff.; Tettinger, JR 73, 407 ff.; Stüer, DVBl. 74, $314 \mathrm{ff}$.

122) Vgl. im Bundesrecht z. B. \$§ 1 I, II, 2 I, II Gesetz über die Gemeinschaftsaufgabe „Verbeserung der regionalen Wirtschaftsstruktur" vom 6. 9. 69 (BGBl. I, S. 1861); $\$ \$ 1$ I, 2 Gesetz über die Gemeinschaftsaufgabe „Verbesserung der Agrarstruktur und des Küstenschutzes" vom 3. 9. 69 (BGBl. I, S. 1573) in Verbindung mit dem 4. Rahmenplan der Gemeinschaftsaufgabe „Verbesserung der regionalen Wirtschaftsstruktur" für den Zeitraum 1975 bis 1978 (BTDrucks. 7/3601) und dem Rahmenplan der Gemeinschaftsaufgabe „Verbesserung der Agrarstruktur und des Küstenschutzes“ fur den Zeitraum 1975 bis 1978 (BT-Drucks. 7/3563); zum Ziel- und Begrıffssystem des Rechts der regionalen Strukturpolitik vgl. vor allem $R$. Schmidt, AöR 1974, Beiheft 1 Deutsche öffentlich-rechtliche Landesberichte zum IX. Internationalen Kongreß für Rechtsvergleichung, S. 86 ff.; ders., AöR 99, 529 (547 ff.) mit der richtigen Kritik an der bisherigen Ermessens- und Beurteilungsspielraumslehre, deren undifferenzierte Anwendung zu "absoluten Ungereimtheiten" führe (AöR 99, 552). Vgl. weiterhin § 1 II InvestitionszulagenG vom 18. 8. 69 (BGBl. I, S. 1211) i. d. F. vom 30. 12. 74 (BGBl. I, S. 3726); zur Auslegung der hiesigen Zielformel ,volkswirtschaftlich besonders förderungswürdig“ vgl. nicht richtig OVG Münster, GewArch 74, 244 (245 ff.); VG Köln, BB 72, 870 (871 f.): keine Beurteilungsermächtigung, sondern prinzipiell volle Justiziabilität; vgl. weiterhın zu eng noch Heinze, WiR 72, 267 (280 ff.): unbestimmter Rechtsbegriff"; richtig dagegen $R$. Schmidt, AöR 99, 548 ff.; vgl. weiterhin hierzu Pfeifer, DVBl. 75, 323 ff., und jetzt auch mit richtiger Tendenz, BVerwG, DVBl. 75, $723 \mathrm{ff}$. - Vgl. weiterhin $\$ \$ 1 \mathrm{I}, 18$ SteinkohleAnpG vom 15. 5.68 (BGBl. I, S. 365) i. V.m. \$§ 1 ff. VO über die Maßstäbe für die Ermittlung der optımalen UnternehmensgröBen im Steinkohlenbergbau vom 7. 1. 69 (BGBl. I, S. 16); vgl. hierzu richtig Seidler, Rechtsschutz bei staatlicher Wirtschaftsplanung, 1973, S. 57 ff., 88 ff.: nicht unbestimmte Rechtsbegriffe, sondern (ermessensmäßige) „Prozeßbegriffe" wie im Falle des \& 1 StWG; vgl. weiterhin mit richtiger Fragestellung auch Streckel, Die RuhrkohleAG. Entstehungsgeschichte und Zulässigkeit, 1973, S. 132 ff.; zu eng dagegen $H$. Schneider, BB 69 Beilage 2, S. 1 (5 ff.).

123) Vgl. im Bundesrecht z. B. \$\$ 1 I-IV, 3 I-III, 10 I StBFG, 1 I, IV-V, 5 I-IV, VI, 8 I BBauG, 2, 7 AbfG.

124) Vgl. dazu mit Nachweisen schon oben N. 100.

125) Vgl. § 1 StWG - Die Begriffe des "gesamtwirtschaftlichen Gleichgewichts" sind ökonomische Prozeß- oder Ablaufsbegriffe, weil sie auf eine bestimmte Dynamik wirtschaftlich-realen Geschehens wie wirtschaftspolitischer Steuerung Bezug nehmen (vgl. Friauf, VVDStRL 27, 1 (37 f.); Scheuner, H. Schäfer-Festschrift, 1975, S. 109 (116 f.); Biedenkopf, BB 68, 1005 (1006 f.); Seidler, Rechtsschutz bei staatlicher Wirtschaftsplanung, S. 62 f.; Kitterer, DOV 75, 23 (32 f.); vgl. auch Schmidt-Preuß, DVBl. 70, 535 ff.; aus ökonomischer Sicht vgl. z. B. Enke, in: Gahlen-H. K. Schnerder, Grundfragen der Stabilitätspolitik, 1974, S. 3 (11 ff.)). Für sie paßt daher der „un- 
bestimmte Rechtsbegriff" im liberkommenen (oft zu statischen) Begriffsverständnis nicht (vgl. anders allerdings Stern-Münch-Hansmeyer, StWG, 2. Aufl. 1972, Einfuhrung C III 2 d, \$ 1 Erl. VIII 2, $\S 15$ Erl. II 2, § 19 Erl. II 2; Möller, StWG, 2. Aufl. 1969, § 1 Rdnr. 13; Wrebel, Wirtschaftslenkung und verwaltungsgerichtlicher Rechtsschutz des Wirtschafters nach dem Erlaß des Stabilitätsgesetzes, 1971, S. 74). § 1 StWG konstituiert vielmehr eine wirtschaftspolitische (makroökonomische) Gestaltungsermächtigung, der ein breites (metajuristisches Gestaltungs-)Ermessen der zuständigen Organe zu eigen ist, mit der Folge entsprechender Justiziabilitätsgrenzen (vgl. auch Vogel, Finanzverfassung und politisches Ermessen, 1972, S. 28 ff.; Vogel-Wiebel, Bonner Kommentar, Art. 109 Rdnr. 140).

126) Vgl. bes. \$§ 8 II, 24 III GWB - Das GWB setzt in $§ 70$ IV 2 auch ausdruicklich eine Grenze in der Justiziabilität von Ermessensentscheidungen, indem es erklärt, daß „die Würdigung der gesamtwirtschaftlichen Lage und Entwicklung ... der Nachprüfung des Gerichts entzogen" ist. Zu dieser Bestimmung vgl. bes. Soell, Ermessen, S. 26 ff.; $R$. Scholz, Wirtschaftsaufsicht, S. 106 ff.; Gleiss, WuW 70, 39 ff.; Halbey, WRP 68, 349 ff.; Würdinger, Rechtskontrolle der Verfügungen der Kartellbehörden durch die Gerichte (\$ 70 Abs. 4 GWB), 1958; Rittner, H. Kaufmann-Festschrift, S. $310 \mathrm{ff}$. So wenig glücklich diese Bestimmung gefaßt ist, bringt sie doch ein grundsätzlich legitimes Ziel zum Ausdruck: nämlich der Kartellaufsicht dort ein gestaltungspolitisches Ermessen einzuräumen, wo es um makroökonomische Zusammenhänge geht, und ihr zugleich einen prognostischen Entwicklungsspielraum zu sichern (zum ersteren vgl. bes. Soell, a. a. O., S. 54 ff., 377; zum letzteren vgl. R. Scholz, a. a. O.).

Zur Justiziabilität und kontrollpolitischen Problematik der Regelungen aus $\$ \$ 8$ II, 24 III GWB vgl. R. Scholz, Konzentrationskontrolle und Grundgesetz, 1971, S. 91 ff.; Rittner, DB 70, 669 ff., 717 ff.; vgl. auch Hoppmann, Jb. f. Nationalökonomie und Statistik, Bd. 184, S. 397 ff. mit der scharfsinnigen, aber wohl zu weitgreifenden Analyse staatlicher Wettbewerbspolitik als potentieller bzw. übermäßiger Mikrosteuerung.

127) Vgl. weiterhin bes. \& 3 WährG mit der richtigen Qualifikation in BVerwGE 41, 1 (4 ff.) zugunsten eines breiten (ermessensmäßigen) Handlungsspielraums der Verwaltung; § 12 AWG mit der gleichfalls richtigen Beurteilung in BVerwG, DVBl. 72, $895 \mathrm{f}$. (mit Anm. Redeker), derzufolge der Begriff „Berücksichtigung der handels- und sonstigen wirtschaftspolitischen Erfordernisse" wegen seiner entwicklungsmäßigen Offenhert einen Ermessens- und keinen unbestimmten Rechtsbegriff enthalte (vgl. auch BVerwGE 21, 187 (188 ff.)); \& 42 S. 1 BVFG mit BVerwGE 45, 13 (24): agrarpolitische Ermessenserwägungen; § 4 IZHVO mit der Qualifikation des Tatbestandmerkmals "zur Wahrung der Interessen der Gesamtwirtschaft des Bundesgebiets" als Ermessensermächtigung in BVerwGE 18, 336 (338 ff.); zu den $\$ \S 13$ II Nr. 1 u. 2, IV PBefG i.d. F. vom 13. 6. 74 (BGBl. I, S. 1281), 7 I-II, 13 a II GüKG i.d. F. vom 10. 3. 75 (BGBl. I, S. 685) vgl. richtig im Sinne gestaltungspolitischer Ermessensermächtigungen $K$. Lange, Verkehr und öffentliches Recht, 1974, S. 129 ff. m. Nachw. (N. 5 S. 129) zu entgegengesetzter Rechtsprechung (unbestimmte Rechtsbegriffe); vgl. weiterhin schon $\$ 9$ I PBefG a. F. mit richtiger Wurdigung durch BVerwGE 9, 284 (285 f.). 
len "Gemeinwohl"-Entscheidungen ${ }^{128}$ ) sowie bei Entscheidungen über pädagogische und wissenschaftlich-künstlerische Zweckgehalte ${ }^{129}$ ).

Die rechtliche Kontrolle solcher verwaltungseigenen Maßstabsbildung kann freilich am System eines Verwaltungsrechtsschutzes scheitern, dessen juristische Relationstechnik die individuell meßbare Rechtsfolge voraussetzt und kontrollmäßig erst auf der Ebene der exekutivischen Maßstabsanwendung einzusetzen pflegt. Unproblematisch ist dies nur dann, wenn Maßslabsbildung und Maßstabsanwendung in der konkreten Verwaltungsentscheidung, z. B. im angefochtenen Verwaltungsakt, unmittelbar zusammenfallen. Ist dies aber, wie namentlich bei vollzugsmäßig „gleitenden“ Planungsverfahren, nicht der Fall, so drohen bei bloßer Kontrolle der Maßstabsanwendung nicht nur zeitlicher Kontrollverzug ${ }^{130}$ ), sondern auch inhaltlich-präkludierende Kontrollbegrenzung ${ }^{131}$ ). Ein effizienter Verwaltungsrechtsschutz muß daher auch die (vorangegangene) Maßstabsbildung der Verwaltung erfassen.

Neben der Frage nach der inhaltlichen Reichweite solcher gerichtlichen Kontrollkompetenzen (metajuristische Zweckkompetenzen der Verwaltung!) stellt sich die Frage nach dem gerichtlichen Kontrollmaßstab. Das hierzu meist bemühte Übermaßverbot bietet allein wenig Kontrolleffizienz; denn seine Maßstabstechnik fordert die individual meßbare Rechtsfolge ${ }^{132}$ ), greift also erst bei der Maßstabsanwendung. Wirksamer ist dagegen das verfahrensrechtliche, also rechtsfolgenunabhängige

128) Zur kompetenzrechtlichen Struktur des (offenen) Begriffs des „öffentlichen Interesses" oder "Gemeinwohls" vgl. bes. Häberle, Offentliches Interesse, S. $60 \mathrm{ff}$., $71 \mathrm{ff}$., 85 ff., $193 \mathrm{ff}$., $453 \mathrm{ff}$., 595 ff., 691 ff.; ders., AöR 92, 259 (271); 95, 86 ff., 260 ff. (279 ff.); Martens, Offentlich als Rechtsbegriff, 1969, S. 186 ff.; Lerche, AöR 90, 341 (367 f.); Ossenbuhl, DOV 70, 87; R. Scholz, Wirtschaftsaufsicht, S. 88; ders., Konzentrationskontrolle und Grundgesetz, S. 83 ff. Zum ermessensrechtlichen Kompetenzgehalt von "öffentlichem Interesse“ und "Gemeinwohl“ vgl. BVerwGE 10, 202 (205); 18, 247 (250 ff.); BVerwG, NJW 75, 180 f.; BadWüStGH, NJW 75, 1205 ff.; NrwVerfGH, OVGE 25, 310 (314); NrwVerfGH, DVBl. 70, 794 (796); VG Freiburg, DVBI. 74, 916 (917) mit zust. Anm. Ule; Häberle, Offentliches Interesse, S. 193 ff., 595 ff., 691 ff.; Ossenbiihl, DOV 70, 87; R. Scholz, Konzentrationskontrolle und Grundgesetz, S. 84; W. Schmidt, NJW 75, 1753.

129) Vgl. dazu bereits die Nachweise oben N. 101.

130) Zum Parallelerfordernis der „begleitenden" Plankontrolle vgl. Schmidt-Aßmann, DOOV 74, 541 (547).

131) Vgl. dazu bereits die Nachweise oben N. 53, 54.

132) Vgl. Lerche, Ubermaß und Verfassungsrecht, 1961, S. $140 \mathrm{ff}$; Selmer, Steuerinterventionismus, S. 286 f.; Grabitz, AöR 98, 568 (581, 600 f.); Schröder, Planung auf staatlicher Ebene, 1974, S. 41 ff. 
Kriterium der maximalen Zweck- und Rechtskonkretisierung. Seine Kontrolle begleitet den gesamten Prozeß der exekutivischen Maßstabsbildung und kann die Frage nach dem Grad erreichter bzw. erreichbarer Konkretisierung der zum Vollzuge vorgegebenen Gesetzesentscheidung auf Dauer und in justiziabler Form stellen ${ }^{139}$ ), ohne die inhaltliche Zweckkompetenz der Verwaltung und deren "autonome" bzw. zweckorientierte Richtigkeitsgewähr anzutasten. Auch die Ermessensentscheidung hat zwar den juristischen Richtigkeitsanspruch des Gesetzes zu wahren. Dessen Justiziabilität vermittelt aber erst das verfahrensrechtliche Konkretisierungsgebot. Uber- oder unterschreitet die Verwaltung ihr Ermessen, so verletzt sie den ihr obliegenden Konkretisierungsauftrag, mißachtet deshalb das Gesetz und untersteht daher der aufhebenden Entscheidung des Verwaltungsgerichts ( $\$ 114$ VwGO) $\left.{ }^{134}\right)$. Dies kassiert dabei auch den verwaltungseigenen (ermessensmäßigen) Handlungsmaßstab, darf dies aber nur kraft seiner Kompetenz zur verfahrensmäßigen Konkretisierungskontrolle. Denn wie das Verwaltungsgericht sein inhaltliches Ermessen nicht positiv an die Stelle des inhaltlichen Ermessens der Verwaltung setzen darf ${ }^{135}$ ), so darf es dies auch negativ nicht. Die inhaltliche Kassation einer Ermessensentscheidung rechtfertigt sich erst mittelbar als (implizite) Folge des gerichtlich festgestellten (und kompetenziell feststellbaren) Fehlers im Konkretisierungsverfahren $^{136}$ ).

133) Vgl. in ähnlicher Richtung auch Wahl, DOV 75, $375 \mathrm{f}$.

134) Anders im Falle des inhaltlichen Verstoßes gegen übergeordnetes Recht; hier besteht einmal der (verfahrensrechtliche) Versto $B$ gegen den gesetzlichen Konkretisierungsauftrag bzw. „innerhalb“ desselben und daneben der materiell-rechtliche Versto $B$ gegen jenes Recht (Konkretisıerung gleichsam „außerhalb“ des gesetzlichen Konkretisierungsauftrages).

135) Unstreitig - vgl, nur z. B. GemSoGB in: BVerwGE 39, 355 (369); BVerwGE 11, 95 (98); Bettermann, Wacke-Festschrift, 1972, S. 233 (238 ff.) zugleich zur Sonderregelung der \$\$ 96 I 1 FGO/217 AO, derzufolge den Finanzgerichten Schätzungsermessen hinsichtlich der „Besteuerungsgrundlagen“ eröffnet ist.

136) Grundlage dieser Prüfung ist die angefochtene Verwaltungsentscheidung auf der Grundlage ihrer Begrúndung. Der Begründungszwang erfüllt in diesem Sinne nicht nur eine rechtsstaatl Schutzfunktion im Verhältnis zum betroffenen Bürger (vgl. z. B. BVerfGE 6, 32 (44 f.); BVerwGE 10, 37 (43 f.); 22, 215 (217 f.); WolffBachof, Verwaltungsrecht I, S. 420 f.), sondern auch eine kompetenzielle Abgrenzungsfunktion im Verhältnis zum Verwaltungsgericht: Dessen Kontrolle ist auf den speziellen Begründungszusammenhang beschränkt, es sei denn, daß dieser evident fehlerhaft ist, d. h. die betreffende Entscheidung offensichtlich nicht zu tragen oder rechtfertigen vermag (im Sinne einer entsprechenden Evidenzkontrolle gerade gegenüber planerischen Maßnahmen vgl. z. B. BVerwGE 45, 
Diese Differenzierung zwischen inhaltlicher und verfahrensmäßiger Ermessenskontrolle hat man bisher kaum beachtet; aus kompetenziellen Gründen ist dies aber geboten. Die Rechtsprechung scheint dies neuerdings zu spüren, wenn sie (bestimmte) Ermessensentscheidungen einer bloßen Vertretbar-

25 (36); BayVerfGH, VGHE 27, 14 (27); NrwVerfGH, OVGE 25, 310 (312 ff.); BadWuiStGH, NJW 75, 1205 (1211 ff.); BayVGH, BayVBl 75, 168 (169 f.); Papier, DVBl. 75, 465; Ossenbühl, Gutachten 50. DJT, B 190 f.; allgemein vgl. Kaiser, 50. DJT, II, I 12). Diese Einschränkung ergibt sich daraus, daß auch die (dogmatische) Begründung noch keine (absolute) Richtigkeitsgewähr vermittelt (vgl. Esser, Vorverständnis und Methodenwahl in der Rechtsfindung, 1970, S. 168); auch die „plausible“ Begründung vermittelt nur relative Richtigkeit (vgl. zum Ganzen bes. Esser, a. a. O., S. 168 ff.). Ist diese aber offenkundig nicht gegeben, so kann auch das Verwaltungsgericht nicht entsprechend gebunden sein. Seine Entscheidungskompetenz ist aber erneut begrenzt: Das Verwaltungsgericht darf die betreffende Verwaltungsentscheidung lediglich kassieren oder als nichtig qualifizieren, zu deren Rechtfertigung aber nicht eigene, die Entscheidung eventuell tragende Begründungen entwickeln.

Vor allem eln ohne Begründung verkundeter Plan ist danach rechtswidrig bzw. nichtig; denn gerade der Plan bedarf der (finalprogrammierenden) Begründung (vgl. bes. BVerwGE 45, 305 (330 f.); vgl. weiterhin dazu BVerwG, DVBl. 68, 276 f.; BayVGH, GewArch 75, 160 (161); Schmidt-Aßmann, Grundfragen des Städtebaurechts, S. 81 f.; ders., DOV 74, 546; Forsthoff, in: Kaiser, Planung III 1968, S. 21 (30 f.)). Die Evidenzkontrolle der einem Plan oder einer sonstigen Verwaltungsentscheidung beigegebenen Begründung ist rechtsmethodisch aber und zunächst verfahrensmäßig angelegt. Denn den Zusammenhang von Verwaltungsentscheidung und Begrundung auf seine immanente Plausibilität zu befragen, heißt nichts anderes, als nach dem (verfahrensrechtlichen) Kontrollmaßstab "vertretbarer" Konkretisierung vorzugehen.

$\mathrm{DaB}$ auch materiell das Prinzip der „rechtlich einzig richtigen Entscheidung“ anfechtbar ist bzw. nur relative Gultigkelt besitzt (vgl. oben N. 37), ist nur von sekundärem Belang. Denn das Verhältnis von entscheidender Verwaltung und kontrollierender Verwaltungsgerichtsbarkeit ist zunächst kompetenzrechtlich bestimmt; und die kompetenzielle Abgrenzung beider führt zunächst zum (verfahrensrechtlichen) Prinzip von entscheidungsrechtlicher Zweckkonkretisierung bzw. kontrollrechtlicher Konkretisierungsgerechtigkeit. Entsprechend ist die Sachlage bei der Kontrolle von Ermessensentscheidungen; Pflicht und Befugnis der Verwaltungsgerichte zur Aufklärung und Spruchreifmachung gem. \$ $86 \mathrm{I}, 113 \mathrm{IV}$ VwGO beschränken sich hier auf die Umstände, die die Verwaltung ihrer Ermessensentscheidung selbst zugrunde gelegt hat (vgl. BVerwGE 3, 279 (281 f.); 10, 202 (204); 11, 95 (98 ff.)).

Der verfahrensrechtliche Charakter der Vertretbarkeitskontrolle wird noch deutlicher dort, wo sich die "Unvertretbarkeit" der verwaltungsrechtlichen Entscheidung schon aus dem spezifischen Verfahren der Entscheidungsfindung durch (partiell) unabhängige Prüfungs-, Fach- bzw. Kollegialausschüsse ergibt (vgl. bes. BVerwGE 39, 197 (203 ff.); VG Berlin, NJW 73, 1148 (1149 f.); vgl. dazu vor allem Ossenbïhl, DVB1. 74, 311 f. m. w. Nachw.). 
keitskontrolle, also keiner inhaltlich vollen Richtigkeitskontrolle unterstellt ${ }^{137}$ ). Eine solche Vertretbarkeitskontrolle kann nach der rechtlichen „Plausibilität“ der angefochtenen Verwaltungsentscheidung fragen; wegen des kompetenziellen Vorbehalts verwaltungseigener Ermessens- und (metajuristischer) Zweckhoheit darf sie jedoch nie qualitativ gleichartige Maßstabs- oder Inhaltskompetenzen von Verwaltung und Gericht behaupten. Wenn der von der Verwaltung ermessensmäßig bestimmte Handlungsmaßstab den gesetzlichen Konkretisierungsauftrag wahrt, muß die verwaltungsgerichtliche Entscheidungskontrolle maßstabsimmanent erfolgen; und dies bedeutet, daß das Verwaltungsgericht die Entscheidung der Verwaltung als (inhaltlich) „richtig“, weil kraft verwaltungseigener Maßstabskompetenz verbindlich, zu akzeptieren hat. Maßstabsimmanente Verwaltungskontrolle heißt Kontrolle verwaltungseigener Maßstabsgerechtigkeit. Selbst wenn das Verwaltungsgericht - angesichts der Bandbreite möglicher, maßstabskonformer Entscheidungen - auch andere Entscheidungsalternativen erkennt, muß es doch die von der Verwaltung vorgezogene Entscheidungsalternative als (allein) gültig anerkennen, sofern sich diese im Rahmen übergeordneten Rechts hält und deshalb vor Gesetz und Verfassung "zu vertreten “ ist.

Im übrigen bedarf die Kontrolle verwaltungseigener Maßstabsgerechtigkeit erneut vermittelnder Kriterien, die die maßstabsımmanente Urteilsfindung erlauben. Kriterien dieser Art finden sich in Begriffsbildern wie denen von Sach-138) und $S y$ stemgerechtigkeit ${ }^{130}$ ), Folgerichtigkeit ${ }^{140}$ ) und Marktkonformi-

137) Vgl. BVerwGE 39, $203 \mathrm{ff}$; 45, 25 (35 ff.); 45, 305 (326); OVG Münster, GewArch 75, 243 (245); BayVGH, BayVBl. 75, 168 (169 f.); VG Berlin, NJW 73, 1149 f.; BayVerfGH, VGHE 27, 14 (27).

138) $\mathrm{Zu}$ Begriff und Funktion der "Sachgerechtigkeit" in Verwaltung und Verwaltungsrecht vgl. informativ Kunze, in: MorsteinMarx, Verwaltung, 1965, S. $229 \mathrm{ff}$.

130) Zur mangelnden Rechtsgutqualität (keine absolute Maßstabsqualität) der Systemgerechtigkeit vgl. $K$. Lange, Die Verwaltung 1971, 259 ff.; Hoppe-Rengeling, Rechtsschutz, S. 114 ff.; R. Scholz, Konzentrationskontrolle und Grundgesetz, S. 27 ff.; Lerche, Fernsehabgabe und Bundeskompetenz, 1974, S. 54 ff.; ders., DOV 61, 486 ff.; Evers, Städtebund 1970, 235 ff.; Seibert, Selbstverwaltungsgarantie und kommunale Gebietsreform, S. 74 f.; vgl. auch BVerfGE 13, 215 (224); 18, 315 (334); 24, 112 (118 f.); 30, 367 (388); BadWüStGH, DOV 73, 163 (165); BadWüStGH, NJW 75, 1205 (1213).

140) Für die Vorstellung der Folgerichtigkeit gilt als Inhalt maßnahmeimmanenter Rationalität zunächst das Gleiche wie für die Vorstellung der Systemgerechtigkeit; vgl. allerdings auch Forsthoff, ın: Kaiser, Planung III, S. 35. 
tät bzw. -inkonformität'141). Solche Kriterien bergen keine für sich stehenden Rechtsgüter ${ }^{142}$ ), da keine abstrakte (absolute) Pflicht der Verwaltung zur System- oder Sachgerechtigkeit etc. besteht ${ }^{143}$ ). System-144) und Sachgerechtigkeit ${ }^{145}$ ), Folgerichtigkeit und ordnungspolitische Maßnahmekonformitä $t^{146}$ ) können aber mit Rechtsgütern wie dem Willkürverbot ${ }^{147}$ ), dem Vertrauensschutz ${ }^{148}$ ), der Gleıchbehandlung ${ }^{149}$ ), dem Verhältnıs-

141) $\mathrm{Zu}$ dieser vgl. demnächst $R$. Scholz, in: Der Staatssektor in der sozialen Marktwirtschaft; vgl. auch BayVerfGH, VGHE 27, 14 (27): "Konzeptionskonformität" raumordnender Maßnahmen.

142) Es handelt sich um typische - Normativitat und Faktizitat gegebenenfalls „konkret" vermittelnde Zwischen- oder Kontaktbegriffe (vgl, zu dieser Interpretationskategorie bereits R. Scholz, ZHR 132, 97 (119 N. 118, 129); vgl. auch Oberndorfer, Die Verwaltung $1972,257(261))$.

143) Dementsprechend gibt es auch keine hinreichend justiziable Bindung der Verwaltung an Kriterien wie die von Optimalität, Rationalität oder Effektivität; vgl. auch z. B. Badura, BayVerfGH-Festschrift, S. 165; Papier, DVBl. 75, 466 f. Zur Effizienz als (relativem) Rechtsprinzip vgl. allgemein namentlich Lersner, Effizienz als Rechtsprinzip, 1971, S. 6 ff.; Derlien, Die Verwaltung 1974, $1 \mathrm{ff}$;; Häberle, AöR 98, 625 ff ; zur Effizienz als dienstrechtlıches und verwaltungsinternes Rechtsprinzip vgl. z. B. Bettermann-Papier, Die Verwaltung 1975, 23 (30 f.); Isensee, JZ 71, 73 (75); ders., Beamtenstreik, 1971, S. 153; R. Scholz, in: Offentlicher Dienst und Gesellschaft - eine Leistungsbilanz, 1974, S. 170 (179 ff.).

144) Vgl. K. Lange, Die Verwaltung 1971, $268 \mathrm{ff}$; vgl. auch den von Bullinger, Jahrreiß-Festschrift, S. $27 \mathrm{f}$, mit Recht hervorgehobenen Aspekt von Systemgerechtigkeit einmal als Maßstab widerspruchsfreier und gleichmäßiger Programmanwendung und zum anderen als Maßstab zur pflichtweisen Programm(fort-)entwicklung. Vgl. hier auch BadWüStGH, NJW 75, 1205 (1213) mit richtiger Abgrenzung zur nicht schematisch-starren Systembindung raumordnender Maßnahmen. Vgl. weiterhin auch Lerche, in: Freiheit und Bindung im Recht der sozialen Sicherheit, 1972, S. 94 (108); Martens, WolffFestschrift, 1973, S. 429 (438).

145) Vgl. richtig die Fragestellung in BVerwG, NJW 75, 841 (843), derzufolge das Verwaltungsgericht gegenüber Abwägungsakten gem. \$ 1 IV, V BBauG zu prüfen habe, „ob sachgerechte, d. h. an den Planungsleitsätzen orientierte ... Grüde es rechtfertigen, den einen Belang hinter den anderen zurucktreten zu lassen".

${ }^{146)}$ Vgl. näher demnächst $R$. Scholz, in: Der Staatssektor in der sozialen Marktwirtschaft.

147) Vgl. zum Zusammenhang von Willkurverbot, Sach-, Systemgerechtigkeit und Maßnahmekonformitat BVerfGE 6, $55(70,77) ; 12$, 151 (164); 18, 315 (334); 26, 1 (10 f.); R. Scholz, Konzentrationskontrolle und Grundgesetz, S. 28 ff.; Püttner, Die öffentlichen Unternehmen, 1969, S. 152, 208 ff.; Lerche, DOV 61, 488; Götz, Recht der Wirtschaftssubventionen, S. 267 f.; Badura, BayVerfGH-Festschrift, S. $180 \mathrm{f}$.

148) Zum Verhàltnıs von Vertrauensschutz und Sachgerechtigkeit vgl. BVerwGE 46, 89 (90 ff.); vgl. dazu auch Lerche, Maunz-Festgabe, 1971, S. 292 ff.; ders., Fernsehabgabe, S. 56; R. Scholz, Konzen- 
mäßigkeits-150) und Eignungsgebot ${ }^{151}$ ) konkrete Verbindungen eingehen und gemeinsam mit diesen die volle Justitiabilität von Verwaltungsentscheidungen auch im maßstabsimmanenten Bereich gewährleisten ${ }^{158}$ ).

2. Bei der Kontrolle planerischer Entscheidungen unterstützt das Gebot der maximalen Zweck- und Rechtskonkretisierung die Forderung auf einen etappenmäßig gestuften Rechtsschutz ${ }^{153}$ ), weil erst die Fixierung derart verfahrensmäßiger Zwischenstufen den effizienten Rechtsschutz verspricht ${ }^{154}$ ).

trationskontrolle und Grundgesetz, S. 29 f.; vgl. weiterhin BGHZ 45, 83 (87 ff.).

149) Vgl. die Nachweise N. 147; vgl. weiterhin z. B. BVerfGE 19, 101 (111); 18, 224 (233); 21, 54 (65); Lerche, Fernsehabgabe, S. 56. Vgl. für das Verhältnis von Gleichbehandlung und Folgerichtigkeit bei der Planung auch Imboden, VVDStRL 18, 119 ff., 123 ff., mit der wesentlichen Feststellung, daß im Plan die Zweckrationalität die rechtssatzmäßige Folgerıchtigkeit formaler Gleichheit uberlagert. Allerdings ist damit die Anwendung des Gleichheitssatzes nicht, wie Imboden wohl annimmt, verdrängt. Sie erfolgt vielmehr modifiziert und in verschiedenen Phasen nach folgendem Kontrollmuster: (1) Vereinbarkeit der Planaufstellung mit Art. 3 GG? Hier ergeben sich für die Vergleichbarkeit von Planbetroffenen und Nicht-Planbetroffenen wenig Ansatze. Der Gleichheitssatz kommt voll zum Tragen erst in Kontrollstufe (2), d. h. auf der Stufe der vollzugsmäßigen Einzelfallreduktion: Vereinbarkeit der planungsmäßigen Rechtsfolgen immanent mit Art. 3 GG?

150) $\mathrm{Zu}$ ihm gehört $\mathrm{z}$. B. die Im Planungsbereich mitunter praktizierte Schaden-Nutzen-Kontrolle (vgl, in deren Sinne z. B. BadWüStGH, NJW 75, 1205 (1212); Stuer, JR 73, 409). Nicht justiziabel ist dagegen die Kosten-Nutzen-Analyse (vgl. aber auch Hoppe, DVB1. 74, 644; Schmidt-Aßmann, DOV 74, 546; Wrmmer, Die Verwaltung 1974, 465 (477)).

151) Zum Eignungsgebot als inhaltlichem (aber beschränktem) Kontrollmaßstab im wirtschaftspolitischen Bereich vgl. z. B. Kloepfer, NJW 71, 1585 ff.; vgl. weiterhin den auch im Verwaltungsrecht fruchtbaren Ansatz einer "Economical-Question-Doctrin“, wie ihn Spanner, DƠ 72, 217 (220) für das Verhältnis von wirtschaftspolitischer Gesetzgebung und Verfassungsgerichtsbarkeit vorgestellt hat.

152) Vgl. weiterhin auch den verwandten Systematisierungsversuch von Hoppe-Rengeling, Rechtsschutz, S. $106 \mathrm{ff}$., 124 ff., $130 \mathrm{ff}$., die zwischen finalen Maßstäben, wie Systemgerechtigkeit, Sachgerechtigkeit usw., instrumentalen Maßstäben, wie Verhältnismäßigkeit, Eignung etc., und prozeduralen Maßstäben, wie Abwägung etc., zu differenzieren suchen.

153) Vgl. dazu die Nachweise oben N. 13.

$\left.{ }^{154}\right) \mathrm{Zu}$ solcher Stufenbildung liegen Vorschläge bereits vor, erprobt sind diese bisher jedoch kaum. Am praktikabelsten erscheint hier das von Ossenbuihl entwickelte Dreiphasenmodell mit den Hauptstufen von Planaufstellung, Planausführung und Erfolgskontrolle sowie Rückkopplung (vgl. Gutachten 50. DJT, B 36; zu sehr aufgespalten erscheint dagegen das von Wagener vorgeschlagene 
Besonderheiten ergeben sich bei der Kontrolle von planerischen wie (sonstigen) Prognoseentscheidungen. Hier fordert das Konkretisierungsgebot zunächst die richtige Diagnose zum gegebenen Sachverhalt, d. h. zur auch gerichtlich voll nachprüfbaren Sachlage ( $\$ 86$ I VwGO) ${ }^{185}$ ). Die hieran anschließende Prognose läßt sich - vergleichbar mit der gesetzgeberischen Prognose ${ }^{166}$ ) - aber nur auf offensichtliche Fehlsamkeit (evidenter Fehlschluß) prüfen (prinzipiell freier Entwicklungsspielraum) ${ }^{157}$ ). Vor der Fehlprognose i. ü. kann nur der präventive

Modell (vgl. AfK 70, 47 (50 ff.); vgl. allerdings auch Schmidt-A $\beta-$ mann, DOV 74, 545). Prozessual sind in dieses Verfahrensschema die rechtsschutzfähigen Bügerpositionen einzubauen. Mit dem verfahrensrechtlichen Pflichtengehalt des Konkretisierungsgebots sind auch diese zunächst verfahrensrechtlicher Natur. Sie fallen in den weiteren Rahmen von Anhorung und rechtlichem Gehor. Auch diese verfahrensrechtlichen Gewährleistungen eröffnen dem angerufenen Verwaltungsgerıcht aber die Möglichkeit, potentielle Konkretisierungsdefizite, z. B. in der Sachverhaltsaufklarung wie in der Interessenabwägung, festzustellen (zu entsprechenden Verfahrensbeteiligungen und deren Folgen vgl, noch unten sub D II 2, III). Ob es im weiteren der Entwicklung einer eigenstandigen planungsrechtlichen Fehlerlehre bedarf (vgl. in diesem Sinne und mit viel erwägenswerten Vorschlägen Hoppe, DVBl. 74, 644; ders., Scupin-Festschrift, S. 128; Hoppe-Rengeling, Rechtsschutz, S. 43 ff., 106 ff., $130 \mathrm{ff}$; vgl. auch Badura, BayVerfGH-Festschrift, S. 167) oder ob nicht die allgemeinen Kontrollaspekte namentlich des $\S 114$ VwGO ausreichen (In diesem Sinne offenkundig BVerwGE 34, 301 (304)), mag offenbleiben. Gewisser eigenständiger Systembildung bedarf es aber jedenfalls bei der Vermittlung immanenter Kontrollen anhand verwaltungseigener Maßstabsbildung. Im ubrigen ergeben sich deutliche Parallelen zur Ermessenskontrolle, insbesondere in Gestalt von Willkür- und Evidenzkontrolle.

155) Wenn die Diagnose oft die fachlich-wissenschaftliche Beurteilung fordert, so muß das Verwaltungsgericht seine Prüfung mit den Mitteln und Methoden des modernen (anerkannten) Wissenschaftsstandes vornehmen (vgl. richtig z. B. Belke, ZHR 139, 129 (132 f.) zu wirtschaftspolitischen Diagnosen im Rahmen der Kartellaufsicht und deren gerichtlicher Kontrolle). Nicht richtig dagegen BVerwG, DVBl. 72, $678(680)$ - Würgassen -, das auf den Wissenschaftsstand im Zeitpunkt der Verwaltungsentscheidung zurückgreift; insofern geht es namlich nicht um den „maßgeblichen Zeitpunkt der Sachlage", sondern um den methodischen Stand gegebener - gegebenenfalls fortentwickelter - Erkenntnismittel (richtiger deshalb OVG Luineburg, DVBl. 75, 190 (195 ff.)).

Als Methode der Sachverhaltsbewertung funktionieren ähnlich auch metajuristische Auslegungsgebote im Gesetz, wie etwa die "wirtschaftliche Betrachtungsweise“ (vgl. näher Teichmann, Bartholomeyczik-Festschrift, 1973, S. 377 (388 ff.)).

156) Vgl. hier BVerfGE 16, 147 (181 ff.); 18, 315 (332); 25, 1 (12 f.); 30, 250 (263); BVerfG, NJW 75, 31 (33 f.); vgl. dazu weiterhin auch Philippi, Tatsachenfeststellungen des Bundesverfassungsgerichts, 1971, S. 28 ff., 56 ff., 124 ff.; R. Scholz, Wirtschaftsaufsicht, S. 107 ff. 
Rechtsschutz in Gestalt von vorbeugender Feststellungs- oder Unterlassungsklage schützen - jeweils auf Einschätzungs- und Plankorrektur ${ }^{158}$ ) sowie Unterlassen von entwicklungswidrigen Vollzugsmaßnahmen gerichtet ${ }^{159}$ ).

\section{Sicherung des effizienten Rechtsschutzes im Verwaltungsprozeß}

\section{Verwaltungsrechtsschutz, Verwaltungseingriff und Handlungsform der Verwaltung}

1. Das Kontrollsystem der Verwaltungsgerichtsbarkeit schließt an die konkrete Verwaltungsmaßnahme an und mißt deren Folgen am betroffenen (subjektiven) Recht. Als zentrale Handlungsform der Verwaltung galt und gilt danach der Verwaltungsakt; auf seine Kontrolle konzentrierte sich folgerichtig das System von verwaltungsgerichtlicher Anfechtungs- und Verpflichtungsklage ( $\$ 42$ VwGO). Aus der Sicht effizienten

157) NrwVerfGH, OVGE 25, 310 (315); 26, 286 (293 f.); BadWüStGH, NJW 75, 1205 (1213); BayVGH, BayVBl. 75, 168 (170); R. Scholz, Wirtschaftsaufsicht, S. 107 ff.; Schmidt-Aßmann, DOV 74, 546; Ossenbühl, Gutachten, 50. DJT, B 160, 188 ff.; Stüer, DVBl. 74, 320.

${ }^{158}$ ) Vgl. R. Scholz, Wirtschaftsaufsicht, S. 112 f.

150) Vgl. Brohm, Rechtsschutz im Bauplanungsrecht, S. 75 ff : „Vollzugsunterlassungsklage“.

Vgl. weiterhin richtig BVerwG, DOV 71, 639 f. mit der prinzipiellen Eröffnung der vorbeugenden Unterlassungsklage gegen erwartete Baugenehmigungen aufgrund eines mit \& $1 \mathrm{IV}, \mathrm{V}$ BBauG für unvereinbar erachteten Bebauungsplans; kritisch hierzu Eyermann, BayVBl. 74. 237 (240 f.), in entsprechender Richtung aber bzw. auch Redeker, DVBl. 68, $7 \mathrm{ff}$.

In positiver Richtung stellt sich das Problem einer Planerfüllungsklage in Gestalt des materiellen Plangewährleistungsanspruchs (zum letzteren vgl. bes. Ipsen, in: Kaiser, Planung I, S. 62; Planung II, S. 106 ff.; Oldıges, Grundlagen eines Plangewảhrleistungsrechts, 1970, bes. S. 174 ff., 186 ff., 199 ff.; Kriele, DOV 67, 531 (532 ff.); Egerer, Der Plangewährleistungsanspruch, 1971; Burmeister, Die Verwaltung 1969, 21 ff.; Ossenbühl, Gutachten 50. DJT, B 196 ff.; $\boldsymbol{R}$. Scholz, Konzentrationskontrolle und Grundgesetz, S. 29 f.). Angesichts der planerischen Gestaltungsfreiheit der Verwaltung kann ein solcher Anspruch nur kraft voll konkretisierter Planung mit entsprechend beschränktem Gestaltungsspielraum in Betracht kommen; vgl. in dieser Richtung zutreffend BVerwG, DVBl. 70, 61. Zur mangelnden und als solche justiziablen Fortgeltung von (Flächennutzungs-)Plänen mangels "Brauchbarkeit" vgl. in richtiger Fragestellung BVerwGE 45, 25 (35 ff.). Wie Ossenbühl, a. a. O., gezeigt hat, wird sich die weitere Theorie um das Plangewährleistungsrecht weniger um die Entwicklung von planbedingten Schadensersatz- oder Entschädigungsansprüchen als um die Entwicklung positiver Ansprïche auf Plananpassung etc. bemühen müssen. 
Rechtsschutzes steht jedoch jede Prozeßordnung unter dem Vorbehalt der funktionsfähigen Eingriffswehr ${ }^{100}$ ). Die Rechtsschutzgarantie des Art. 19 IV GG überläßt die prozessuale Organisation des Verwaltungsrechtsschutzes zwar dem Gesetzgeber. Uber die materiell gebotene Eingriffskontrolle darf dieser jedoch ebensowenig wie die Verwaltung disponieren. Wenn Form und Technik der potentiell eingriffswirksamen Verwaltungsmaßnahme im Zweckmäßigkeitsentscheid von Gesetzgeber und Verwaltung liegen, so muß auch das System der verwaltungsprozessualen Rechtsschutzmöglichkeiten flexibel sein und auf veränderte Eingriffsformen der Verwaltung reagieren ${ }^{181}$ ).

Solange im Verwaltungsrecht der Verwaltungsakt als unmittelbar und individuell wirksame Regelung im sog. Außenverhältnis Staat-Bürger dominierte, durfte das geltende Rechtsschutzsystem der VwGO als effektiv gelten. Im System der gestaltenden Verwaltung häufen sich jedoch Eingriffe, die nicht individuell (punktuell), sondern generell, die nicht unmittelbar, sondern mittelbar und die nicht nur im Außenverhàltnis, sondern auch im verwaltungsmäßigen Innenverhältnis wirksam sind. Verwaltungseingriffe erfolgen ebenso durch aktives Tun wie durch schlichtes Unterlassen ${ }^{162}$ ), sie geschehen ebenso durch rechtliche Anordnungen wie durch faktische Einwirkungen ${ }^{183}$ ); als Beispiel für Eingriffe letzterer Art sei nur an die sich häufenden Rechtsbeeinträchtigungen durch staatliche Konkurrenz ${ }^{164}$ ) oder verwaltungswirtschaftlich genutzte Marktmacht ${ }^{165}$ ) erinnert.

100) Vgl. auch Maunz-Dürig-Herzog, GG, Art, 19 IV Rdnr. 18; Maurer, Kern-Festschrift, 1968, S. 275 (285).

101) Vgl. bereits oben sub C I 2.

162) Dies ist das Grundsatzproblem der leistenden Verwaltung. Ihr begegnet man nach wie vor bzw. vorrangig mit dem Maßstab der Gleichheit. (Formale) Gleichbehandlung wehrt jedoch den materiellen Unterlassungseingriff nicht $a b$. Hier bedarf es anderer Maßstabe, für die - neben sozial- bzw. leistungsrechtlich relevanten Grundrechtstatbeständen - das Ubermaßverbot den richtigen, von Lerche (vgl. Ubermaß und Verfassungsrecht, 1961, S. $276 \mathrm{ff}$.) schon lange aufgewiesenen Ansatz bietet (vgl. auch $R$. Scholz, Wesen und Entwicklung der gemeindlichen öffentlichen Einrichtungen, S. 223, 231 ff.).

163) Vgl. dazu vor allem und mit weiteren Nachweisen Gallwas, Faktische Beeinträchtigungen im Bereich der Grundrechte, 1970, S. 125 ff., 139 ff.; Gronefeld, Preisgabe und Ersatz des enteignungsrechtlichen Finalitätsmerkmals, 1972, S. 36 ff., 117 ff.; $R$. Schotz, Wirtschaftsaufsicht, S. 39 ff., 46 ff.

104) Vgl. näher bereits $R$. Scholz, AòR 97, 301 (305 f.); ders., WRP 68,315 (317); R. Scholz (-Isensee), Zur Krankenversicherung der Studenten, 1973, S. 7 ff , 12 ff.; vgl. auch Friauf, VVDStRL 27, 19; zu 
2. Vor allem mittelbare und faktische Rechtseingriffe fordern den verstärkten Einsatz von Leistungs-, Unterlassungs- und Feststellungsklage $\left.{ }^{106}\right)$. Die Verwaltungsgerichte zögern indessen, ihr prozessuales Instrumentarium voll zugunsten einer solchen allgemeineren Eingriffskontrolle einzusetzen. Ihr Aufgabenverständnis haftet oft $\mathrm{zu}$ sehr am tradierten Begriffsbild des Verwaltungsakts ${ }^{167}$ ) und seiner kontrollpolitischen Dominanz. Eben diese sind jedoch fraglich geworden ${ }^{188}$ ).

Als hoheitlicher Einzelakt ist der Verwaltungsakt zunächst vom Rechtssatz abzugrenzen; die Grenzen zwischen beiden sind inzwischen aber so flüssig geworden, daß allseits sichere Diffe-

verwaltungsprozessualen Konsequenzen vgl. etwa Lerche, JurA 70, 821 ff.; im Sinne der prinzipiell entgegengesetzten Position vgl. etwa Bettermann, Hirsch-Festschrift, 1968, S. 1 ff.

Eine Wende bedeutet jetzt BVerfG, NJW 75, 1265 (1266): Anerkennung des (potentiellen) Grundrechtseingriffs durch Konkurrenz im Falle der Einrichtung staatlicher Arbeitskammern.

165) Die bisherige Rechtsprechung von Verwaltungsgerichten (vgl. bes. BVerwGE 39, 329 (337 f.)) und Zivilgerichten (vgl. bes. und zuletzt OLG Köln, NJW 74, 802 ff.) führt hier zu echten Rechtsschutzlücken: Die Verwaltungsgerichtsbarkeit verweist unter Berufung auf das wettbewerbliche Agieren staatlicher Verwaltungswirtschaften auf das Wettbewerbsrecht und den fuir dies zustandigen ordentlichen Rechtsweg; die ordentlichen Gerichte verweisen auf den thnen verschlossenen Eingriff in die materiell-hoheitliche Verwaltungsfunktion solcher Wirtschaftseinheiten und wenden das Wettbewerbsrecht nicht oder nur beschrankt an. Diese Rechtsprechung verstößt sowohl gegen Wettbewerbsrecht und materielle Grundrechte wie gegen Art. 19 IV GG (vgl. naher bereits $R$. Scholz, NJW 74, 781 f.). Eine Wende könnte sich allerdings mit dem Vorlagebeschluß des I. Zivilsenats des BGH von 21. 3. 75 abzeichnen (vgl. Leitsatz NJW 75, 1480); vgl. weiterhin BSG, BB 74, 187 ff.; Gerichtshof für Kompetenzkonflikte beim BayOblG, DVBl. 75, $370 \mathrm{ff}$.

${ }^{106)} \mathrm{DaB}$ gegen mittelbare Eingriffe etc. Rechtsschutz gewährt werden muß, entspricht heute wohl schon der überwiegenden Meinung (vgl. z. B. und mit weiteren Nachweisen Gallwas, Faktısche Beeinträchtigungen, S. 125 ff., 139 ff.; Gronefeld, Preisgabe und Ersatz des enteignungsrechtlichen Finalitätsmerkmals, S. $36 \mathrm{ff} ., 117 \mathrm{ff}$.; $R$. Scholz, Wirtschaftsaufsicht, S. 39 ff., 46 ff.; Brohm, VVDStRL 30, 271 ff.). Nur die prozessualen Konsequenzen sind noch wenig geklärt. - Zum negatorischen Rechtsschutz in der Rechtsprechung der Verwaltungsgerichte vgl. die Nachweise bei Martens, Negatorischer Rechtsschutz im öffentlichen Recht, 1973, S. 7 ff., 12 ff., 26 ff., 36 ff.

167) Vgl. \& 31 EVwVfG.

188) Vgl. ausführlich hierzu und mit umfangreıchen Nachweisen $P$. Krause, Rechtsformen des Verwaltungshandelns, 1974, S. 70 ff., 115 ff., 235 ff., 329 ff.; zur Rechtsschutzproblematik der Anfechtung von Verwaltungsakten insgesamt vgl. bes. die umfassende und $\mathrm{kr}-$ tische Bestandsaufnahme von Bettermann, Bötticher-Festschrift, 1969 , S. 13 ff. 
renzierungen kaum noch möglich erscheinen ${ }^{169}{ }^{170}$ ). Nicht nur gesetzgeberische Inkonsequenzen wie im Planungsrecht fordern neue, funktionale Abgrenzungsversuche, die mehr bei der (typischen) Einzelrechtsfolge als bei der (typischen) Einzelregelung ansetzen $\left.{ }^{171}\right)$. Praktisch fordert dies jedoch neben der begrifflichen Revision die prozessuale Offnung in der Zulässigkeit von Anfechtungs- und Verpflichtungsklage (auch typisierende, nicht nur individualisierende Rechtsfolgekontrolle auf der Ebene der Klagezulässigkeit) $\left.{ }^{172}\right)^{173}$ ).

160) Vgl. dazu z. B. Brohm, VVDStRL 30, 281 ff.; ders., Strukturen der Wirtschaftsverwaltung, 1969, S. 229 ff.; von Mutius, Wolff-Festschrift, 1973, S. 167 ff.; Volkmar, Allgemeiner Rechtssatz und Einzelakt, 1962, S. $149 \mathrm{ff}$., $165 \mathrm{ff} ., 176 \mathrm{ff}$.

170) Dies gilt auch hinsichtlich möglicher Doppelnaturen von Verwaltungsakt einerseits und Normsetzung andererseits (vgl. hierzu BVerwGE 16, 83 ff. und einerseits Bettermann, Nipperdey-Festschrift II, 1965, S. 723 ff., sowie Bachof, W. Weber-Festschrift, 1974, S. $515 \mathrm{ff}$. andererseits).

171) Vgl. in dieser Richtung überzeugend von Mutius, a. a.O., S. 187 ff., 216 ff.

172) Das typische Beispiel hierfur bildet der makroadministrative, aber konkrete Akt, wie etwa (makrookonomisch lenkende) Akte der Bundesbank. Deren kreditpolitische Beschlüsse sind zwar von einem breiten Raum gestaltungspolitischen Ermessens getragen; dies ändert aber nichts daran, daß diese Akte, sowelt sie verbindliche Rechtsfolgen setzten, grundsätzlich als Verwaltungsakte (Allgemeinverfugungen) zu qualifizieren sind (vgl. BVerfGE 34, 307 (315); BayVGH, BayVBl. 75, 171 f.; Kindermann, Die Anfechtung von kreditpolitischen Beschlüssen der Bundesbank, 1974, S. $82 \mathrm{ff}$., $101 \mathrm{ff} ., 109 \mathrm{ff}$., 113 ff.; Mühl, Bärmann-Festschrift, 1975, S. 687 (702 f.)) und deshalb auch anfechtbar sind (anders allerdings Samm, Die Stellung der Deutschen Bundesbank im Verfassungsgefuge, S. 208 ff.; für die Anweisung uber Mindestreserven auch BVerwGE 41, 334 (337) - dies jedoch zu Unrecht, vgl. Püttner, DOV 73, 642; Stern, JuS 63, 68 (71); Mühl, a. a. O., S. 703); vgl. anders allerdings auch Spindler-BeckerStarke, Die Deutsche Bundesbank, 4. Aufl. 1973, \& 2 Anm. 3, § 16 Anm. 1, 2).

Zur eingriffsrechtlich analogen Problematik von Auf- und Abwertungsmaßnahmen vgl. W. Hoffmann, Rechtsfragen der Währungsparität, 1969 , S. 70 ff.; in grundsätzlich anderer Blickrichtung zu globalsteuernden Maßnahmen Wagner, VVDStRL 27, 47 (63 ff.). Im gleichen Zusammenhang vgl. die Differenzierungen zwischen imperativen, indikativen und influenzierenden Planungsakten (zu dieser Unterscheidung vgl. Ipsen, in: Kaiser, Planung II, S. 81 f.; Kaiser, in: Kaiser, Planung I, 1965, S. 23 f.; Brohm, Strukturen der Wirtschaftsverwaltung, S. 234 ff.; Redeker, JZ 68, 537). Alle diese Wirkungsmechanismen sind prinzipiell nur graduell sowie nach Unmittelbarkeit bzw. Mittelbarkeit voneinander geschieden. An der Möglichkeit verwaltungsaktmäßiger Rechtsfolgenwirksamkeit ändert dies aber und prinzipiell nichts.

Vgl. weiterhin als aktuelles Problembeispiel die verwaltungsmäßige "Information" mit (potentiellem) Eingriffscharakter, relevant geworden z. B. im Kartellrecht (= anfechtbare „Verfugung“?) - vgl. 
Ähnliche Probleme offenbart der sog. Verwaltungsakt mit Doppelwirkung ${ }^{174}$ ). Hinter seiner Begriffsfigur steht weniger die mehrseitig wirksame Einzelfallregelung als die komplexe Regelung differenter Rechtsbeziehungen, deren Verbindungsstück die mehrseitige Rechtsfolge ist.

Das Begriffselement der rechtlichen „Regelung“ weist den Verwaltungsakt als verbindlichen Abschluß eines Verwaltungsverfahrens aus. Auch diese Funktion des Verwaltungsakts besitzt indessen nur noch partielle Geltung. Denn Verwaltungsverfahren tendieren verstärkt zur Begründung von Dauerbeziehungen ${ }^{175}$ ) und - bedingt durch höhere Problemkomplexität - zu Formen gestufter Entscheidung ${ }^{178}$ ). Stichworte wie Teilgenehmigung, Vorbescheid, Zweitbescheid, Zusage usw. dokumentieren dies äußerlich; Begriffsbildungen wie die eines „Verwaltungsvorakts" und "Verwaltungsendakts"177) oder eines „Kettenverwaltungsakts“178) reflektieren diese Entwicklung dogmatisch ${ }^{170}$ ).

Für den Verwaltungsrechtsschutz resultieren aus alledem erhebliche Probleme. Deren Lösung scheint mir jedoch weder

dazu Kloepfer, Information als Intervention in der Wettbewerbsaufsicht, 1973; R. Scholz, NJW 73, 481 ff.; Erlinghagen-Zippel, NJW 73, 10 ff.; zum Problem der Information als rechtsrelevanter Maßnahme in noch allgemeinerer Sicht vgl. auch $R$. Scholz, DOV 73, 843 ff.; Scheuner, W. Weber-Festschrift, 1974, S. 369 (370).

17s) Die Popularklage wehrt das Kriterium der (tatsächlichen) $\mathrm{Be}$ schwer ab, deren Voraussetzung fur die Klagebefugnis gem. \$ 42 II VwGO Bettermann (vgl. in: Staatsbürger und Staatsgewalt, II, 1963, S. 449 (464 ff.); ders., Schima-Festschrift, S. 80 ff.; vgl. auch dens., Die Beschwer als Klagevoraussetzung, 1970) nachgewiesen hat (vgl. weiterhin auch BVerwGE 28, 131 (132 f.); BVerwG, DVB1. 69, 263 (264); BSGE 26, 237 (238 f.); R. Scholz, Wirtschaftsaufsicht, S. 76 ff.; ders., WiR 72, 50 f.).

Die Beschwer vermittelt die individuelle Komponente der Klagebefugnis. Die typisierende Rechtsfolgekontrolle setzt die konkret verletzte (als verletzt gerïgte) Norm hierzu in Bezug (rechtliche Komponente der Klagebefugnis).

174) Zu ihm vgl. bes. Laubinger, Der Verwaltungsakt mit Doppelwirkung, 1967, S. 1 ff., 5 ff., 28 ff.; Fromm, VerwArch 1965, 26 ff.; Dörffler, NJW 63, 14 ff.; Sellmann, NJW 64, 1545 ff.; Friauf, JurA (OffR) 69, 3 (4 ff.); R. Scholz, Wirtschaftsaufsicht, S. 44 ff.

175) Aus diesem Grunde ist die Forderung, dogmatisch wie verfahrensrechtlich mehr auf das Verwaltungsrechtsverhältnis als auf die (punktuelle) Verwaltungsentscheidung abzustellen, unbedingt begrundet (vgl. in diesem Sinne schon die Nachweise oben N. 51).

176) Vgl. hierzu die Nachweise oben N. 52, 53.

177) Achterberg, DOV 71, 397 ff.; vgl. auch Merten, VSSR 73, 66 (78 ff.).

178) Kloepfer, DVB1. 72, $371 \mathrm{ff}$.

170) Vgl. ausführlich zum ganzen $P$. Krause, Rechtsformen, $S$. 288 ff., 329 ff. 
beim Verzicht auf den Verwaltungsakt noch bei seiner begrifflichen Reduktion auf einen „für die Verwaltung verbindlichen“ Entscheidungsabschluß ${ }^{180}$ ) zu liegen. Wechseln muß allein der begriffsausschließende Kontext von (bezweckter) „Regelung“ und „Einzelfall" zugunsten einer funktionalen Verbindung von "Maßnahme" und individual-typischer "Rechtsfolge". Wann eine solche Rechtsfolge anzuerkennen ist, beantwortet das strukturelle Verfahrensprinzip von der maximalen Konkretisierung: Eine individualtypische Rechtsfolge in der Regelungsform des Verwaltungsakts ist gegeben, wenn ein Verwaltungsverfahren seinen spezifischen Endpunkt abschließender und höchstmöglicher Konkretisierung im Verhältnis zum Einzelnen erreicht hat; und dies ist auch auf der „bloßen Verfahrensstufe" der Fall - sofern diese einen rechtlich eigenständigen Konkretisierungsvorgang verkörpert.

Das Begriffsmerkmal der rechtlichen „Außenwirkung“ des Verwaltungsakts ist gleichfalls fragwürdig geworden. Denn auch verwaltungsinterne Einzelakte lösen relevante Individualrechtsfolgen aus, bedürfen also verwaltungsgerichtlicher Anfechtbarkeit ${ }^{181}$ ). Dies ist schon beim besonderen Gewaltverhältnis der Fall, das vom allgemeinen Gewaltverhältnis grundrechtlich ${ }^{182}$ ) und damit auch rechtsschutzmäßig nicht mehr (völlig) abgeschieden werden $\mathbf{k a n n}^{183}$ ). Die überkommene Unterscheidung zwischen Verwaltungsakt und verwaltungsinternem (innerdienstlichem) Rechtsakt läßt sich in allgemeinerer Form

180) So Brohm, VVDStRL 30, 285 ff. in Anlehnung an Begriffsmaterial der Entscheidungstheorie.

181) Vgl. als bes. charakteristisches Beispiel die Anfechtbarkeit von einzelnen (Schul-)Zensuren, die frùher als unselbständige und interne Maßnahmen fur nicht gesondert anfechtbar erachtet wurden (vgl. z. B. OVG Rheinland-Pfalz, DOV 56, 631; VG Wiesbaden, NJW 63, 2140; vgl. auch VG Berlin, NJW 64, 939; VGH Bebenhausen, JZ 59,67 (69)). Heute zeigt sich, daß diese Qualifikation nicht voll aufrechtzuerhalten ist (vgl. i. S. d. Anfechtbarkeit von Einzelzensuren richtig OVG Berlin, DOV 75, 570 f.; HessVGH, DVBl. 74, 469 f.; i.S. d. allgemeinen Leistungsklage ebenso OVG Münster, DOV 75, 358 f.). Vgl. zum Ganzen m. w. Nachw. auch Schramm, Beurteilungen im Prufungs-, Schul- und Beamtenrecht, 1975, S. 3 ff., 38 ff.; vgl. auch Pietzcker, Verfassungsrechtliche Anforderungen an die Ausgestaltung staatlicher Prufungen, 1974, S. 66 ff.; Stier, JR 74, 445 ff.

182) Grundlegend BVerfGE 33, 1 (9 ff.); 34, 165 (192 ff.); an verwaltungsgerichtlich relevant gewordenen Einzelfällen vgl. z. B. BVerwG, DOV 75, 347 (348 f.); 75, 349 f.; vgl. weiterhin z. B. OVG Muinster, DOVV 75, 360; BayVerfGH, BayVBl. 75, 298 ff.

${ }^{183}$ ) Vgl. näher und $\mathrm{m}$. w. Nachw. hierzu Lorenz, Rechtsschutz, S. 29 ff. (35 ff.). 
nicht mehr aufrechterhalten ${ }^{184}$ ); dementsprechend müssen Anfechtungs- und Verpflichtungsklage auch für solche Einzelakte - bei entsprechend relevanter Rechtsfolge bzw. prozessual gesprochen: Beschwer - zulässig sein. Das gleiche gilt für die Anfechtung von verwaltungsinternen Organisationsakten, sofern diese relevante Folgen für den individualen Rechtsstatus äußern ${ }^{185}$ ). Solche Fälle häufen sich sehr - angefangen von Regelungen auf dem Gebiet schulischer Organisation ${ }^{186}$ ) bis $\mathbf{z u}$ inneruniversitären Kollegialentscheidungen und ihren Auswirkungen für einzelne Hochschul- oder Kollegialmitglieder ${ }^{187}$ ). Den prozessual richtigen Weg weist auch hier § 42 VwGO vermittelt durch ein entsprechend modifiziertes Verständnis des Verwaltungsakts.

3. Nicht nur begriffliche Probleme zwischen Verwaltungsakt und Rechtssatz fordern die prinzipale Normenkontrolle gegenüber materiellen Rechtsetzungsakten der Verwaltung $\left.{ }^{188}\right)$. Von

184) Unterschiede ergeben sich allein auf der Ebene der (grund-) rechtsrelevanten Rechtsfolgen. Hier kann ein verwaltungsinterner Einzelakt bestimmte Duldungspflichten implizieren; diese müssen aber im Wege der üblichen Anfechtbarkeit definitiv festgestellt werden - mit der Konsequenz der gegebenenfalls unbegründeten, aber nicht unzulässigen Anfechtungsklage. Vgl. an tatsächlichem Material weiterhin etwa P. Krause, Rechtsformen, S. $301 \mathrm{ff}$.

186) Vgl. auch bereits Brohm, VVDStRL 30, 286 ff.; ders., DOV 64, 238 (240 ff.); BVerwGE 18, 40 (41 ff.) - zu den grundsàtzlichen Grenzen subjektiv-rechtlicher Beeinflussung staatlicher Organisationsformen vgl. BVerfGE 11, 310 (321).

186) Vgl. im Schulrecht z. B. BVerwGE 18, 40 (41 f.); BVerwG, DOV 75, 347 (348 f.); 75, 349 f.; BadWüVGH, DƠV 74, 858 (859 f.); 75, 568 (569 f.); VG Hamburg, XV G 874/75; vgl. zum Ganzen auch Löhning, Der Vorbehalt des Gesetzes im Schulverhältnis, 1974, S. $84 \mathrm{ff}$., $141 \mathrm{ff}$.

187) Vgl. hierzu bes. Kimminich, WissR 1970, Beiheft 4, S. 119 ff.; Fuß, WissR 72, 97 ff.; Hoffmann-Becking, DVBl. 72, 299 ff.; an Einzelfällen vgl. z. B. BVerwGE 45, 39 (41 ff.); BadWüStGH, DOV 74, $632 \mathrm{f}$; OVG Berlin, DOV 75, 571 f.

Zum Kollegialverfassungsstreit als grundsätzlich auszubauendem Klageinstitut vgl. R. Scholz, DOV 73, 843 (845 f.).

Je mehr der Private in verwaltungsrechtliche Organisationsverhältnisse eingebunden wird, desto mehr muß sich der VerwaltungsprozeB - auch in seinem Verständnis von subjektiv-öffentlichem Recht und Klagebefugnis - den organisationsrechtlich gebundenen oder vermittelten Bürgerpositionen öffnen. Vgl. die richtigen Ansätze hierzu bei Lorenz, AöR 93, 308 (324 ff.); Hoppe, Organstreitigkeiten vor den Verwaltungs- und Sozialgerichten, 1970, S. $82 \mathrm{ff}$., 132 ff., 166 ff., 177 ff.; Böckenförde, Wolff-Festschrift, 1973, S. 269 (277 ff.).

189) Im Sinne dieses Erfordernisses vgl. z. B. Stern, Schäfer-Festschrift, 1975, S. 59 (61 ff.); von Engelhardt, Der Rechtsschutz gegen Rechtsnormen, 1971, S. 145 ff., 244 ff.; K. Meyer, AöR 97, 12 (28 f.); Ossenbiihl, Gutachten 50. DJT, B 176 ff.; Bartlsperger, DVB1. 67, 360 
der Ermächtigung des $\S 47$ VwGO haben jedoch nur einige Bundesländer Gebrauch gemacht; für die übrigen stellt sich der Streit um ein verfassungsrechtliches Normenkontrollerfordernis bzw. um die Entwicklung eventueller Rechtsschutzsurrogate ${ }^{189}$ ). Das Prinzip des effizienten Rechtsschutzes fordert heute die Eröffnung der prozessualen Eingriffswehr gegen Verwaltungsnormen, soweit diese ihren Vollzug schon implizieren bzw. einen bereits rechtsfolgerelevanten Konkretisierungsgrad erreicht haben $\left.{ }^{100}\right)$. Der - auch vom BVerfG' ${ }^{191}$ ) - angestellte Gegenverweis ${ }^{102}$ ) auf die inzidente Normenkontrolle bei der Anfechtung des normvollziehenden Einzelakts ist bei Normen wie dem Bebauungsplan und der den Anschluß- und Benutzungszwang verfügenden Gemeindesatzung etc. ${ }^{103}$ ) nicht haltbar; denn er verweist in Wahrheit auf vollzugsmäßig schon Geschehenes. Das Argument, daß die Legislative nicht zur öffentlichen Gewalt im Sinne des Art. 19 IV GG gehöre ${ }^{104}$ ), hat der rechtsetzenden Verwaltung gegenüber keine Geltung ${ }^{105}$ ); denn diese könnte sonst mit der Wahl der Eingriffsform über die eigene Kontrolle entscheiden $\left.{ }^{106}\right)$. Art. 19 IV GG garantiert zwar nicht die rechtsschutzeffektivste Handlungsform der Verwaltung ${ }^{107}$ ),

(368 ff.); Wilken, DVBl. 69, 532 ff.; Blümel, Forsthoff-Festgabe, 1967, S. $160 \mathrm{f}$; Lorenz, Rechtsschutz, S. $153 \mathrm{ff}$.

189) Vgl. näher vo . Engelhardt, Der Rechtsschutz gegen Rechtsnormen, S. 145 ff., 244 ff.; Maurer, Kern-Festschrift, S. 275 ff.; Siemer, Normenkontrolle durch Feststellungsklage?, 1971; Stern, SchäferFestschrift, S. 59 ff.; Bettermann, AöR 86, 129 (157 f.); Bachof, AöR 86, 186 (188 ff.); Bartlsperger, DVBl. 67, 360 ff.; Wilken, DVBl. 69, $532 \mathrm{ff}$; Oldiges, WiR 74, 277 ff.; Obermayer, in: Zehn Jahre Verwaltungsgerichtsordnung, 1970, S. 143 ff.; $K$. Meyer, in: Zehn Jahre Verwaltungsgerichtsordnung, 1970, S. 161 ff.; ders., AöR 97, 12 (28 f.); Renck, JuS 66, $273 \mathrm{ff}$.

190) denn dann ist das (beschränkte) Rechtsetzungsermessen des Verordnungsgebers kompetenzgerecht gewahrt (vgl. auch z. B. Lerche, in: Staatsbürger und Staatsgewait, II, 1963, S. 59 (81)). (401).

191) BVerfGE 31, 364 (367 ff.); auch BVerfGE 24, 33 (49 ff.); 24, 367

192) Vgl. BVerwG, DOV 74, 426 f.; BVerwGE 26, 251 (252 f.); 30, 287 (290 ff.); Bettermann, AöR 86, 157 f.; 96, 528 (531 ff.); F. Klein VVDStRL 8, 106 f.

108) Weitere Beispiele z. B. bei Stern, Schäfer-Festschrift, S. 66.

194) Vgl. BVerfGE 24, 49 ff.; 24, 401; offenlassend für die exekutivische Rechtsetzung BVerfGE 31, 368.

195) Vgl. in richtiger Kritik u. a. Renck, JuS 66, 273 ff.; Lorenz, DVBl. 69, 145; Stern, Schäfer-Festschrift, S. $61 \mathrm{ff}$.

106) Dagegen schützt auch der vom BVerwG angeführte, prinzipiell richtige Gesichtspunkt der mißbräuchlichen Formenvertauschung (vgl. DOV 74, 426) nicht hinreichend. Vgl. auch Stern, Schäfer-Festschrift, S. 63 f.; Blümel, DVBI. 72, 122 ff.; Maurer, Kern-Festschrift, S. 285; Obermayer, DVBl. 65, 625 (627).

107) BVerfGE 10, 89 (105); BVerwG, DOV 74, 426 (427). 
garantiert aber gegenüber jeder Handlungsform den adäquaten - vom ProzeBrechtsgesetzgeber zu realisierenden - Rechtsschutz ${ }^{108}$ ). Art. 19 IV GG eröffnet die prinzipale Normenkontrolle daher nicht selbst, fordert aber ihre gesetzliche Instituierung ${ }^{100}{ }^{200}$ ).

Die prinzipale Normenkontrolle verspricht auch verwaltungspolitisch den zweckmäßigsten Rechtsschutz. Denn sie konzentriert den Rechtsschutz ${ }^{201}$ ), öffnet ihn der Prävention ${ }^{202}$ ) und sorgt über die Rechtskraft inter omnes für ein $\mathrm{MaB}$ an objektivrechtlicher Sicherheit, das neben dem rechtsschutzsuchenden Bürger auch der Verwaltung, etwa im planerischen Gestaltungsprozeß, wesentlich zustatten kommt. Effizienteren Rechtsschutz verspricht eine solche objektiv-rechtliche Verwaltungskontrolle, weil die "Vollzugsnorm" typischerweise kollektive, d. h. allgemeinere Rechtsbetroffenheiten auslöst, denen der rein individual- oder subjektiv-rechtliche Gerichtsschutz, wie die verschiedentlich empfohlene Feststellungsklage, nicht vergleichbar gewachsen ist ${ }^{208}$ ).

109) Deshalb müssen auch Verwaltungsvorschriften im Bereich von Selbstbindung und Ermessensgestaltung materiell als „Rechtssätze qualifiziert und entsprechendem Rechtsschutz (namentlich auch aus $\$ 47$ VwGO) unterstellt werden (vgl. Ossenbühl, Verwaltungsvorschriften und Grundgesetz, S. 553 ff.; K. Meyer, in: Zehn Jahre Verwaltungsgerichtsordnung, S. 165; Redeker, JZ 68, 538 f.).

199) Inhaltlich brauchte diese nicht soweit wie \& 47 VwGO zu gehen; es genügte auch die subsidiäre Normenkontrolle gegenüber Normen mit nachgewiesenem Selbstvollzug.

200) Rechtsschutzsurrogate wie die vielfach vertretene Feststellungsklage (vgl. Maunz-Dürig-Herzog, GG, Art. 19 IV Rdnr. 18; Renck, JuS 66, 278 f.; Maurer, Kern-Festschrift, S. 305 ff.; Bachof, AöR 86, $188 \mathrm{ff}$.) versprechen keinen adäquaten Rechtsschutz. Denn sie verfügen weder über das nach \$ 43 I VwGO erforderliche „Rechtsverhältnis" (vgl. Stern, Schäfer-Festschrift, S. 67 f.; BVerwG, DOV 64, 169; sehr klar zuletzt auch Oldiges, WiR 74, 305), noch führen sie darüber hinweg, đaß die rechtskräftige Entscheidung inter partes eine relative (vgl. Bettermann, AöR 86, 165 f.; ders., in: Zehn Jahre Verwaltungsgerichtsordnung, S. 200 f.; Maurer, Kern-Festschrift, S. 303 f.) oder partielle (Bachof, AöR 86, 191; Oldiges, WiR 74, 307) Geltungseinschränkung der Norm verfügte, die aus Gründen der Rechtssicherheit kaum zu vertreten wäre. Auch die präventive Feststellungsklage hilft hierüber nicht hinweg (vgl. allerdings auchi BVerwGE 26, 252 f.; 30, 292).

201) Vgl. Schmedt-Aßmann, DVBl. 72, 627 (633 mit N. 51); Ossenbiihl, Gutachten 50. DJT, S. 195.

Vgl. Bettermann, in: Zehn Jahre Verwaltungsgerichtsordnung, S. $187 \mathrm{f}$.

ros) Von wesentlicherer Bedeutung ist aber, daB die prinzipale Normenkontrolle neben der Effektivität im Rechtsschutz auch der verwaltungspolitischen Zweckmäßigkeit dienlich sein kann. Die Beachtung solcher Interessenkoinzidenz sichert die kompetenzielle 
4. Einer interessenmäßigen Zusammenschau von Verwaltungsrechtsschutz und Verwaltungsverantwortung bedarf es auch beim präventiven und vorläufigen Rechtsschutz $z^{204}$ ). Beide unterstehen zwar der Garantie des Art. 19 IV GG205), geben aber zunehmend mehr Probleme auf. Einerseits wächst das Bedürfnis, den Bürger vor unzumutbaren Gefährdungen und irreparablen Eingriffen rechtzeitig zu schützen ${ }^{206}$ ); andererseits verstärken sich Tendenzen, durch vorbeugende Rechtsschutzgewährung allgemein-bedeutsame Verwaltungsverfahren übermäßig zu verzögern ${ }^{207}$ ). Konflikte dieser Art erwachsen gleichermaßen bei der vorbeugenden Unterlassungs- und Feststellungsklage wie bei der Suspendierung bzw. sofortigen Vollziehung angefochtener Verwaltungsakte ( $\$ 80$ VwGO).

Vorbeugender wie vorlaufiger Rechtsschutz orientieren sich, der Grundtypik des individualen Rechtsschutzes gemäß, am punktuellen und unmittelbar wirkenden bzw. drohenden Eingriff. In der Kontrolle solcher Eingriffe leisten die Institute

Ausgewogenheit von Verwaltungsverantwortung und Verwaltungsrechtsschutz und wahrt die Prinzipien von flexiblem Rechtsschutz und kooperativer Verantwortung im gewaltenteiligen Rechtsstaat.

204) Zum strukturellen Zusammenhang bzw. zur mehr formalen Differenz von vorbeugendem und vorläufigem Rechtsschutz vgl. Lorenz, Rechtsschutz, S. 143.

${ }^{205)}$ Vgl. für den vorbeugenden Rechtsschutz z. B. Naumann, Jellinek-Gedächtnisschrıft, 1955, S. 391 (405); Ruckdäschel, DOVV 61, 675 (682); Renck, DOV 64, 651 (655); Ule, VerwArch 1974, 291 (299 ff.); Lorenz, Rechtsschutz, S. 138 ff.; H. Bauer, Gerichtsschutz als Verfassungsgarantie, S. $97 \mathrm{ff}$.

Für den vorläufigen Rechtsschutz vgl. z. B. BVerfGE 35, 263 (272 ff.); 35, 382 (402); BVerfG, DVB1. 74, 79 (81) - zu eng aber BVerfG, NJW 74, 1079 f. fur den Rechtsschutz im Verfahren nach §§ 23 ff. EGGVG -; Lorenz, Rechtsschutz, S. 138 ff.; H. Bauer, a. a. O.; Finkelnburg, Vorlaufiger Rechtsschutz im Verwaltungsstreitverfahren, 1973, S. 1; Maunz-Durig-Herzog, GG, Art. 19 IV Rdnr. 14; Wieseler, Der vorläufige Rechtsschutz gegen Verwaltungsakte, 1967, S. 25 ff.

206) Vgl. z. B. BVerfGE 35, 263 (272 ff.); BayVGH, VGHE 22, 91 (94); OVG Berlin, JR 73, 518 f.; OVG Hamburg, DVBl. 75, 207 ff.; OVG Lüneburg, DVBl. 75, 190 (192 ff.); VG Freiburg, DVBl. 75, 343 (347); vor allem vgl. Blümel, Forsthoff-Festgabe, 1967, S. $134 \mathrm{ff}$.; vgl. allgemein hierzu auch schon die Nachweise oben N. 56.

207) Dies gilt namentlich für Raumplanungen und für die Zulassung beispielsweise von Flughäfen (vgl. dazu BVerwG, NJW 69, 340 ff.; BVerwG, DVBl. 73, 448 ff.; OVG Lüneburg, DVBl. 72, 795 f.; BayVGH, DVBl. 72, $790 \mathrm{ff}$.) und von Kernkraftwerken (vgl. hierzu vor allem die Fälle Würgassen - BVerwG, DVBI. 72, $678 \mathrm{ff}$. Wyhl, VG Freiburg, DVBl. 75, 343 ff. -, Bayernwerk - BayVGH, DVBl. 75, 199 ff., bes. S. 205 f. -, Stade - OVG Lüneburg, DVBl. 75, 190 ff., bes. 195 ff. -). Vgl. weiterhin den Fall Reynolds (OVG Hamburg, DVBl. 75, 207 ff.). 
des vorbeugenden und vorläufigen Rechtsschutzes - die einstweilige Anordnung gemäß $\S 123$ VwGO eingeschlossen - inzwischen einen recht effizienten Rechtsschutz ${ }^{208}$ ). Kompetenzielle Probleme im Verhältnis zur Verwaltung treten relativ selten auf ${ }^{209}$ ). Häufiger ist dies dagegen bei gestuften und mehrseitigen Verwaltungsrechtsverhältnissen der Fall; hier drohen bei

208) Zum vorbeugenden Verwaltungsrechtsschutz vgl. bes. die Grundsätze in BVerwGE 26, 23 (25); 34, 69 (73); 40, 323 (326 f.); 45, 99 (105); BVerwG, DVBl. 71, 746; 73, 448 f.; vgl. weiterhin und grundlegend Naumann, Jellinek-Gedächtnisschrift, S. 391 ff.; Ule, VerwArch 1974, 294 ff.; Schenke, Aor 95, 223 (226 ff.); Ruckdäschel, DOV 61, 675 ff.; vgl. einschränkend zuletzt allerdings Bettermann, in: Zehn Jahre Verwaltungsgerichtsordnung, S. 185 (188 ff.).

Zum vorläufigen Verwaltungsrechtsschutz vgl. näher und $\mathrm{m}$. w. Nachw. Obermeyer, Peters-Gedächtnisschrift, 1967, S. 875 ff.; Quaritsch, VerwArch 1960, $210 \mathrm{ff}$; Finkelnburg, Vorläufiger Rechtsschutz, S. $3 \mathrm{ff}$., $13 \mathrm{ff}$., $25 \mathrm{ff}$., $91 \mathrm{ff}$., $147 \mathrm{ff}$;; Wieseler, Vorläufiger Rechtsschutz, bes. S. 34 ff., 77 ff., 174 ff., 213 ff.; Leipold, Grundlagen des einstweiligen Rechtsschutzes, 1971, S. $187 \mathrm{ff}$.

209) Derartige Probleme können freilich unter dem Aspekt der Vorwegnahme der endgültigen Entscheldung auftreten. In diesem Sinne findet der vorläufige Rechtsschutz an einer solchen Vorwegnahme seine prinzipielle Grenze (vgl. BVerwGE 33, 42 (44); HessVGH, ESVGH 10, 125 (127); 10, 154 (155); 20, 30 (32); 23, 215 (216); HessVGH, VerwRspr. 74, 940 f.; BadWüVGH, VerwRspr. 75, 145; BadWüVGH, ESVGH 18, 31 (38); BayVGH, VGHE 17, 34 (35); BayVGH, BayVBl. 75, 419 (420); OVG Lüneburg, AS 18, 387 (388f.); OVG Saarland, AS 9, 32 (34); OVG Bremen, DOV 75, 280 f. - nicht haltbar dagegen BayVGH, BayVBl. 75, 144). Dieser Grundsatz besteht jedoch nicht ohne Ausnahme. Er gilt namentlich dort nicht, wo ein effektiver Rechtsschutz auch eine vorläufige Regelung mit dem Inhalt einstweiliger Endgultigkeit fordert (vgl. richtig HessVGH, ESVGH 11, 10 (11); 12, 97 (98); 14, 240 (241 f.); BadWüVGH, ESVGH 10, 73 (74); 14, 131 (133 ff.); 16, 102 (103); BayVGH, VGHE 22, 91 (94); OVG Lüneburg, AS 18, 387 (390 f.); OVG Berlin, AS 7, 144 (147); 11, 210 (211); OVG Berlin, DVBl. 75, 266 f.; OVG Berlin, JR 73, 518 ff.; VG Freiburg, NJW 75, 1089 ff.).

Zwischen repressivem, pràventivem und vorläufigem Rechtsschutz ist in diesem Sinne nicht statisch zu differenzieren. Entscheidend ist die effektive Sicherung des geschützten materiellen Rechtsguts; sein Schutz entscheidet prinzipiell über die adäquate Rechtsschutzform und ihre prozessuale Reichweite. Aus kompetenziellen Gründen müssen der präventive und der vorläufige Rechtsschutz zwar dort zurücktreten, wo das Verwaltungsgericht die Entscheidung der Verwaltung vorwegnehmen würde. Wo dies aber nicht der Fall ist, gelten nur noch die Aspekte des effektiven Rechtsschutzes. Partielle Vorwegnahmen endgültiger Gerichtsentscheidungen sind vor allem dort zuzulassen, wo es um die Regelung von verwaltungsrechtlichen Dauerbeziehungen geht; denn hier gilt zunächst deren zeitliche Dimension; sie kann rechtsschutzmảßig nicht auf die „Momentaufnahme" punktueller Entscheidung und "augenblicklicher Entscheidungsvorwegnahme" reduziert werden (unzulässige Entscheidungsvorwegnahme erst bei vorweggenommener Dauerentscheidung). 
voll durchgesetzter Rechtsschutzpräventivität auch Ubergriffe in laufende (nicht abgeschlossene) oder mehrseitig wirksame Verwaltungsverfahren.

Der Anfechtungsproblematik des Verwaltungsakts mit Doppelwirkung wird die Praxis inzwischen zwar - sei es über $\S 80^{210}$ ), sei es über $\S 123$ VwGO'11) - einigermaßen gerecht $\left.{ }^{212}\right)^{213}$ ). Bei der Anfechtung von Teilgenehmigungen setzt sich die richtige, pragmatische Tendenz durch, den Konflikt zwischen individualem Rechtsschutz- und verwaltungsmäßigem Vollzugsinteresse weniger über die (zeit- und problemverschiebende) Zwischenlösung einer Interessenabwägung strıkt nach $\S 80 \mathrm{II}$ Nr. 4 VwGO als über die summarische Prüfung der klägerischen Erfolgsaussicht zu lösen ${ }^{214}$ ); unter dem Aspekt koinzidenter Verfahrensinteressen von Rechtsschutz und Verwaltung ein legitimes Vorgehen, weil auch der Verwaltung an moglichst frühzeitiger Information über die Rechtmäßigkeit des von $\mathrm{hhr}$ beabsichtigten Handelns gelegen sein muß (kann).

Ansonsten tendiert man gegenüber stufenförmigen Planungsund Genehmigungsverfahren - im an sich richtigen Bestreben, nicht zu fruh auf Entscheidungsprozesse der Verwaltung einzuwirken - eher zur Zurückdrängung präventiven Rechtsschutzes. Die Anfechtung etwa späterer Planfeststellungsbe-

210) Vgl. hier und hiesiger Auffassung richtig z. B. BVerwG, NJW 69, 202 (203); BayVGH, VGHE 11, 83 f.; BadWuVGH, ESVGH 18, 65 f.; OVG Berlin AS 10, 103 (104 f.); vgl. auch BVerfGE 35, 263 (278 ff.).

211) Vgl. hier z. B. OVG Münster, NJW 66, 2181 ff.; OVG Koblenz, BRS 18 Nr. 140; HessVGH, NJW 66, 2183 (2184); HessVGH, DOV 68, 504 f.; vgl. auch den wohl praktikablen, aber gesetzlich kaum vorgezeichneten Zwischenweg des OVG Lineburg, NJW 70, 963.

214) Vgl. systematisch hierzu u. a. Wreseler, Vorläufiger Rechtsschutz, S. 219 ff.; Finkelnburg, Vorläufiger Rechtsschutz, S. 152 ff.; Gelzer, NJW 70, 1352 ff.; ders., in: Zehn Jahre Verwaltungsgerichtsordnung, 1970, S. 203 ff.; Papier, VerwArch. 1975, 283 ff., 399 ff.; Schenke, NJW 70, $270 \mathrm{ff}$.

213) Zur Antragsbefugnis eines Genehmigungsempfangers auf sofortige Vollziehbarkeitserklärung gem. $\S 80 \mathrm{~V}$ VwGO als komplettierender Rechtsschutzkonstellation im Bereich vorläufigen Drittinteressentenrechtsschutzes vgl. richtıg Papier, VerwArch. 1975, 413 If. - kritisch dagegen Eyermann, BayVBl. 74, 237 (239 f.).

214) Vgl. bes. OVG Hamburg, DVBl. 75, 207 ff.; OVG Lüneburg, DVBl. 75, 190 (192 ff.); OVG Saarland, AS 12, 420 ff.; BayVGH, BayVBl. 75, 273 (275 f.); OVG Bremen, DOV 75, 280 (281) - vgl. im Weg uber \& 123 VwGO ähnlich auch OVG Rheinland-Pfalz, GewArch. 75, $165 \mathrm{f}$.

Strukturell wird damit eine gewisse Harmonisierung der Entscheidungen nach $\S 80$ und $\S 123$ VwGO hergestellt; zur immanenten Sachgerechtigkeit dessen vgl. Leipold, Grundlagen, S. 207 ff. 
schlüsse im mehrstufigen Planungsverfahren kommt indessen oft zu spät ${ }^{215}$ ). Folglich muß auch hier ein Rechtsschutz gewährleistet sein, der rechtzeitig, also präventiv, und auch kompetenzgerecht im Verhältnis zur entscheidungsverantwortlichen Verwaltung ist. Der richtige Lösungsansatz liegt im Zusammenhang von präventivem Rechtsschutz und hinreichender Eingriffsbestimmtheit. Dieser Bestimmbarkeit bedarf es zur inhaltlichen Rechtmäßigkeitskontrolle $\left.{ }^{216}\right)$ sowie auch aus kompetenziellen Gründen. Wenn die zu kontrollierende (künftige) Verwaltungsentscheidung nämlich nicht wenigstens práfixiert 1st, fehlt es schon an der kompetenziell ausgeübten Verwaltungsverantwortung und damit am rechtlichen Kontrollobjekt. Den Maßstab für eine kompetenzgerechte Präfixierung vermittelt das Verfahrensprinzip der Rechts- und Zweckkonkretisierung: Hat die Verwaltung die Richtung der von ihr konkret vorgesehenen Entscheidung bereits inhaltlich offenbart, oder ist offenkundig nur eine einzige Konkretisierungsalternative denkbar, so ist die präventive Gerichtskontrolle auch kompetenzmäßig eröffnet ${ }^{217}$ ).

Unter diesen Voraussetzungen ist ein vorbeugender Rechtsschutz prinzipiell gegen jeden Eingriff statthaft, gleichgültig, in welcher Rechtsform und auf welcher Verfahrensstufe ${ }^{218}$ ) dieser droht. Das gilt auch für die prinzipale Normenkontrolle des § 47 VwGO: Wenn die Verwaltung ihr (beschränktes) Rechtsetzungsermessen nämlich schon so weit (vor)konkretisiert hat,

218) Vgl. hierzu nach wie vor maßgebend und mit unwiderlegten Belegen, Blümel, Forsthoff-Festgabe 1967, S. $137 \mathrm{ff}$.

216) In dieser Blickrichtung vgl. die Nachweise zum vorbeugenden Rechtsschutz N. 208.

217) Effektive Gerichtskontrolle ist auch institutionell nie ohne Bezug zum Faktor Zeit zu verstehen. Aus diesem Grunde bedarf es des vorbeugenden und vorläufigen ("vorwirkenden ") Rechtsschutzes ebenso, wie es des zeitlich fortwirkenden ("nachwirkenden“) Rechtsschutzes bedarf. Der Gesetzgeber hat dem mit der Fortsetzungsfeststellungsklage des $\$ 113$ I 4 VwGO Rechnung getragen; und die Rechtsprechung neigt mit Recht zur auch erweiternden Praktizierung dieser Form „nachwirkenden Rechtsschutzes“ (vgl. bes. BVerwGE 16, 194 (196 ff.); 26, 161 (165 f.); 28, 233 (234 ff.)).

218) Ein wichtiges Beispiel hierfür bildet der (präventive) Rechtsschutz (von Gemeinden) gegen Maßnahmen gem. \$\$ 6 LuftVG, 16 BFStrG, 13 BWaStrG, die dem Planfeststellungsverfahren vorgelagert sind (vgl. Blümel, DVBl. 72, 796 ff.; ders., Forsthoff-Festgabe, 1967, S. 159, gegen BVerwG, NJW 69, 340 (341 f.); BVerwG, DVBl. 73, 448 ff.; BayVGH, DVBl. 72, 790 (791 ff.); OVG Lüneburg, DVBl. 72, 795 f. zu § 6 LuftVG).

Entsprechend ist vorläufiger Rechtsschutz gegen Tellgenehmigungen statthaft (vgl. richtig OVG Lüneburg, DVBl. 75, 190 (192 ff.); VG Frelburg, DVBl. 75, 343 ff.). 
daß das Maß rechtsbeeinträchtigenden "Selbstvollzuges“ für den Richter bereits abschatzbar ist, dann ist die Normsetzungskompetenz der Verwaltung (inhaltlich) gewahrt (präventiver Rechtsschutz allein gegen „Vollzugsnormen" bzw. entsprechend unmittelbar wirksame Rechtsetzungsakte) ${ }^{219}$ ) ${ }^{220}$ ).

\section{Verwaltungsrechtsschutz und rechtlicher Bügerstatus}

1. Verfassung ${ }^{221}$ ) und Gesetz ${ }^{222}$ ) verpflichten den Verwaltungsrechtsschutz den Prinzipien von individualer Eingriffswehr und (primär) subjektiv-rechtlicher Verwaltungskontrol$\left(e^{223}\right)$. Diese Ausrichtung der Verwaltungsgerichtsbarkeit funk-

219) Vgl. Kloepfer, Vorwirkung von Gesetzen, 1974, S. 269 ff.; vgl. mit richtigem Ansatz auch BVerwG, DVB1. 73, 34 (35 f.) und VG München, BayVBl. 74, 198 (199 f.).

A. A. allerdings die h. M.; vgl. nur z. B. Bettermann, in: Zehn Jahre Verwaltungsgerichtsordung, S. 193; BVerwG, DVBI. 63, 441 (442); BadWüVGH, ESVGH 12, 152 (154); BayVGH, VGHE 17, 57 (65); OVG Lüneburg, DVBl. 71, 322 (323 f.); VG Ansbach, DVB1. 75, 150 (151 f.); Schmitt, BayVBl. 74, 253 (259).

Im gleichen Sinne ist im Rahmen der prinzipalen Normenkontrolle gemäß \& 47 VwGO vorläufiger Rechtsschutz nach Maßgabe des $\S 123$ VwGO zu gewähren; vgl. so BadWüVGH, ESVGH 13, 81; BayVGH, VGHE 24, 126 (127); Sojka, MDR 74, 448 (449 ff.); Redeker-von Oertzen, VwGO, 5. Aufl. 1975, § 47 Anm. 24; Engelken, DOV 71, 331 (332 ff.); Klotz, DOV 66, 186 (188 f.); Quaritsch, VerwArch. 1960, 210 - a. A. allerdings HessVGH, NJW 70, 1619; BadWüVGH, ESVGH 16, 31 (33); Eyermann-Fröhler, VwGO, 6. Aufl. 1974, \& 47 Rdnr. 37, $\S 123$ Rdnr. 16; Czermak, BayVBl. 74, $612 \mathrm{f}$.

220) Das gleiche gilt im Ergebnis für den präventiven Rechtsschutz im Bereich von Drittinteressentenklagen.

221) Dies ist die Systemwirkung des Art. 19 IV GG. - Vgl. näher bes. Lorenz, Rechtsschutz, S. 11 ff., 51 ff., 133 ff.

222) Vgl. \& 42 II VwGO.

223) Zur Systemfunktion des subjektiv-öffentlichen Rechts vgl. eingehend z.B. Lorenz, Rechtsschutz, S. 51 ff.; vgl. weiterhin z. B. $R$. Scholz, Die Koalitionsfreiheit als Verfassungsproblem, 1971, S. 78 f.; Brohm, VVDStRL 30, 299; aus rechtssoziologischer Sicht vgl. namentlich J. Schmidt, in: Die Funktion des Rechts in der modernen Gesellschaft, Jahrbuch für Rechtssoziologie und Rechtstheorie 1970, S. 300 (306 ff); Luhmann, ebenda, S. 322 (323).

Auf dem subjektiv-öffentlichen Recht ist auch gegenüber jenen Bestrebungen zu beharren, die statt seiner lieber auf das „rechtlich geschützte Interesse" abstellen wollen (vgl. z. B. Scheuner, VVDStRL 11, 1 (56, 63); Redeker-von Oertzen, VwGO, 5. Aufl. 1975, $\S 42 \mathrm{Anm}$. 125). Denn dessen Begriff ist entweder - im Verhältnis zur unzulässigen Popularklage - zu farblos oder er bezeichnet im Grunde nichts anderes als eben ein subjektiv-öffentliches Recht. Für dessen begriffliche und funktionelle Beibehaltung vgl. demgemäß z. B. Bachof, VVDStRL 12, 72 ff.; $R$. Scholz, WiR 72, 51 f.; vgl. richtig auch z. B. BVerwG, DVBl. 74, 910 (912); BVerwGE 30, 135 (136 f.); - nicht richtig dagegen BVerwGE 10, 122 (123); 30, 191 (197). Hiermit wird naturgemaß nicht die begriffliche und funktionelle 
tioniert allerdings nur so lange, wie die grundsätzliche Distanz zwischen staatlicher und gesellschaftlicher Funktion, zwischen verwaltungsrechtlichem Ordnungsmandat und bürgerlichem Freiheits- oder Teilhaberecht bzw. zwischen öffentlichem und privatem Interesse besteht $\left.{ }^{224}\right)$. Denn das juristische Instrument "subjektiv-öffentliches Recht" ist Ausfluß und Vermittler eben dieser grundsätzlichen Dichotomien. Erst sie erlauben, das subjektiv-öffentliche Recht - im Gegensatz zum objektiven Recht - als gesetzlich "gewollte" Individualbegünstigung oder gesetzgeberisch "ausgegrenztes“ Privatinteresse zu begreifen ${ }^{225}$ ).

Im System des sozialen Rechts- und Verwaltungsstaates lassen sich diese strukturellen Voraussetzungen indessen nur noch bedingt aufrechterhalten. Denn mit der relativierten Distanz

Offnung des subjektiv-öffentlichen Rechts ausgeschlossen. Sie ist, wie im folgenden zu zeigen sein wird, erforderlich, und im Einklang mit der instrumentellen Systemfunktion des subjektiv-öffentlichen Rechts als formaler Statuskategorie möglich (anschaulich zu letzterer vgl. $P$. Hofmann, Subjektives Recht und Wirtschaftsordnung, 1968, bes. S. 4 ff., $10 \mathrm{ff}$. mit der vergleichenden Projektion der Begriffsfigur des subjektiven Rechts auf das Wirtschafts- und Rechtssystem der Bundesrepublik Deutschland einerseits und auf das planwirtschaftliche System der DDR andererseits - zum insoweit analog wirksamen Begriff des „Interesses“ vgl. auch Pleyer, Reinhardt-Festschrift, 1972, S. 291 ff.).

Die These vom "rechtlich geschützten Interesse" könnte sich nưr dann wirklich vom subjektiv-öffentlichen Recht lösen, wenn sie den Begriff des "Interesses" etwa rein prozessual als spezifisches Rechtsschutzinteresse außerhalb des subjektiv-öffentlichen Rechts verstünde (vgl. in dieser Richtung für den Schweizer Verwaltungsprozeß Gygi, Verwaltungsrechtspflege und Verwaltungsverfahren im Bund, 2. Aufl. 1974, S. 40). Dies wäre jedoch mit der gegebenen Systematik des deutschen Verwaltungsrechtsschutzes kaum zu vereinbaren.

224) Zum rechtsstaatlichen Erfordernis prinzipieller - in sich zwar beweglicher und relativer - Distanzierung von Staat und Gesellschaft in dieser Art vgl. Böckenförde, Die verfassungstheoretische Unterscheidung von Staat und Gesellschaft als Bedingung der individuellen Freiheit, 1973, S. 7 ff.; ders., Hefermehl-Festgabe, 1972, S. $12 \mathrm{ff}$; $R$. Scholz, in: Materialien zum Bericht zur Lage der Nation 1974, Kap. II, Tz. 266; ders., Die Koalitionsfreiheit als Verfassungsproblem, S. 151 ff.; in teilweise anderer Richtung vgl. zuletzt hierzu Hesse, DOV 75, $437 \mathrm{ff}$.

$\left.{ }^{225}\right)$ So die herrschende „Schutznormtheorie ${ }^{\alpha}$ - vgl. z. B. BVerwGE 2, 290 (294); 10, 122 (123 f.); 27, 29 (33); BVerwG, DVBl. 58, 391 (392); BVerwG, DOV 58, 558; BGHZ 51, 61 (66); Bachof, Die verwaltungsgerichtliche Klage auf Vornahme einer Amtshandlung, 2. Aufl. 1968, S. 63; Bühler, Jellinek-Gedächtnisschrift, 1955, S. 269 (274 ff.); Bettermann, NJW 61, 1097 (1098) - zur parallelen Sicht des subjektiven Rechts im Zivilrecht vgl. mit kritischer Bestandsaufnahme zuletzt Schmiedel, Deliktsobligationen nach deutschem Kartellrecht, 1. Teil, 1974, bes. S. 138 ff.; zur Struktur des subjektiven Rechts allgemein 
von Staat und Gesellschaft weicht auch die Divergenz von öffentlichem und privatem Interesse deren partieller (latenter) Konvergen $\left.z^{228}\right)$; und der Gegensatz von objektivem und subjektivem Recht rückt von der Ebene abstrakter Tatbestandlichkeit auf die Ebene konkreter Rechtsfolgen oder - anders ausgedrückt - auch auf die Ebene vor allem verfassungsrechtlicher Eingriffs- und Gesetzesanwendungskontrolle227). Das Beispiel der mehrseitigen Verwaltungsrechtsverhältnisse kraft Verwaltungsakts mit Doppelwirkung hat diesen Vorgang wohl zuerst verdeutlicht; unter Rückgriff auf grundrechtliche Eingriffsschranken und eine hieran anschließende Zulassung von Drittinteressentenklagen ${ }^{228}$ ) (Nachbar-, Konkurrentenklagen etc. ${ }^{229}$ ) vgl. m. w. Nachw. bes. Kasper, Das subjektive Recht - Begriffsbildung und Bedeutungsmehrheit, 1967.

220) Vgl. näher Haberle, Offentliches Interesse ais juristisches Problem, S. 60 ff., 95 ff.; Leisner, DOV 70, 217 ff.; R. Scholz, Wirtschaftsaufsicht, $S .87$ ff.

227) Vgl. dazu bereits $R$. Scholz, Wirtschaftsaufsicht, S. 122 ff., 152 ff., $172 \mathrm{ff}$.; ders., WiR 72, $49 \mathrm{ff}$., 56; vgl. weiterhin Brohm, VVDStRL 30, 272 ff.; vgl. grundsätzlich in dieser Richtung auch, wenngleich mit unterschiedlicher Akzentsetzung, Lorenz, Rechtsschutz, S. 54 ff.; Henke, Das subjektive öffentliche Recht, 1968, S. 60 ff.; ders., W. Weber-Festschrift, 1974, S. 495 (501 ff., 509 ff.); Bartlsperger, VerwArch. 1969, 35 (47 ff.); ders., VVDStRL 33, $252 \mathrm{ff}$. - zu diesen letzteren Auffassungen vgl. auch bereits $R$. Scholz, Wirtschaftsaufsicht, S. $123 \mathrm{ff}$.

Die für das subjektiv-öffentliche Recht maßgebende Eingriffsbzw. Gesetzesanwendungskontrolle greift freilich erst sekundär. Primär Ist nach dem „objektivierten" Willen einer gesetzlichen Norm zur Individualbegünstigung $\mathrm{zu}$ fragen (Schutzzweck der Norm). Ist dieser nicht feststellbar, was vor allem bei massenmäßig wirksamen Rechtsnormen oft der Fall ist (hier verzichtet auch das BVerfG, NJW 75, 31 (32 f.) folgerichtig auf die Bestimmbarkeit des (begünstigten) Adressaten), so muß die individuale Rechtsfolgenrelevanz der Norm anhand vor allem der Grundrechte gemessen werden; aus ihnen folgt gegebenenfalls die Anerkennung des subjektiv-öffentlichen Rechts auf der Ebene des konkreten Gesetzes bzw. seiner Anwendung. Als Grundrecht in diesem Sinne kann freilich nicht ein zur allgemeinen "Eingriffsfresheit" uminterpretiertes (formelles Haupt-)Grundrecht aus Art. 2 I GG verwandt werden; denn die Folge dessen wäre der subjektiviert-allgemeine Gesetzesvollziehungsanspruch 0 . ä., den das System der grundgesetzlichen Grunđrechtsgarantien nicht intendiert bzw. anerkennt (vgl. näher dazu bereits R. Scholz, AöR 100, 88 ff., 265 ff. (111 ff. m. N. 174)).

228) Zu diesem Begriff vgl. $R$. Scholz, WiR 72, 39; vgl. auch Bettermann, Schima-Festschrift, S. 91, und Lerche, JurA 70, 862 f.: Interessentenklage.

${ }^{229}$ ) Zur Nachbarklage vgl. näher bes. sowie $m$. w. Nachw.: Timmermann, Der baurechtliche Nachbarschutz, 1969, S. 25 ff., 99 ff.; Laubinger, Verwaltungsakt mit Doppelwirkung, S. 43 ff.; Henke, Recht, S. 81 ff.; Bartlsperger, VerwArch. 1969, 35 ff.; Weyreuther, BauR 75, 1 ff.; Sendler, WiR 72, 453 ff.; Grundei, NJW 70, 833 ff.; Evers, JuS 62, 87 ff.; ders., DVBl. 70, $12 \mathrm{ff}$. 
fand sich jedoch der richtige Lösungsansatz $\left.{ }^{230}\right)$. Dessen prozessuale Durchsetzung fiel nicht schwer, weil die Drittinteressentenklage sich noch zwanglos in das Ordnungsschema eines individual-rechtlich konzipierten Rechtsschutzsystems einfügen ließ. Ungleich schwerer fällt dies hingegen dem Bereich planerischer und sonstig makroadministrativer Gestaltung. Hier werden die meßbaren Rechtsfolgen individualer Eingriffsbetroffenheit von einer oft unübersehbaren Vielfalt kollektiver Betroffenheit (rechtlicher wie faktischer Art)231) oder allgemeiner Interessiertheit überlagert ${ }^{232}$ ); zum Beleg seien nur die Stichworte "Masseneinwendungen“ und "Massenverfahren“ genannt ${ }^{233}$ ).

Zur Konkurrentenklage vgl. bes. $R$. Scholz, Wirtschaftsaufsicht, S. 104 ff., 172 ff.; ders., WiR 72, 35 ff.; Zuleeg, Subventionskontrolle durch Konkurrentenklage, 1974; Mössner, JuS 71, 131 ff.; Rüber, NJW 71, 2097 ff.; Buhren, DVBl. 75, 328 ff.; Weinhardt, Die Klagebefugnis des Konkurrenten, 1974; zum Europarecht vgl. bes. Weidinger, Der Rechtsschutz betroffener Dritter im Kartellverwaltungsrecht der Europäischen Wirtschaftsgemeinschaft, 1968, bes. S. $10 \mathrm{ff} ., 109 \mathrm{ff}$.

2s0) Aus der Rechtsprechung vgl. zur Nachbarklage bes. BVerwGE 11, 95 ff.; 45, 309 ff.; BVerwG, DVBl. 69, 754 f.; 70, 57 ff.; 70, 60; 70, 61 f.; 70, 66; BVerwG, NJW 75, 1373 (1374 ff.); zur Konkurrentenklage vgl. bes. BVerwGE 30, $191 \mathrm{ff}$; vgl. zuletzt auch VG Berlin, DOV 75, 134 ff. m. Anm. $R$. Scholz = DVBl. 75, 272 ff. m. Anm. Henke zur pressesubventionsrechtlichen Konkurrentenklage.

2s1) Vgl. allgemein auch Brohm, VVDStRL 30, $280 \mathrm{ff}$; R. Scholz, Wirtschaftsaufsicht, S. 39 ff.; ders., demnăchst in: Der Staatssektor in der sozialen Marktwirtschaft; zu Gruppenbetroffenheit und fehlendem Gruppenrecht im Subventionswesen vgl. Gotz, Recht der Wirtschaftssubventionen, S. 251 ff.; zum Planungswesen etc. vgl. anschließend N. 232.

232) In materiell-rechtlicher Hinsicht lassen sisch schon aus den gesetzlichen Tatbeständen oft keine abgrenzbaren Adressatenkreise, geschweige denn Inhalte individualisierbaren Rechtsgüterschutzes, ausmachen. Am wohl eklatantesten ist dies im Bereich des Fachplanungsrechts (vgl. näher Forsthoff-Blümel, Raumordnungsrecht und Fachplanungsrecht, S. 30, $67 \mathrm{ff}$., $162 \mathrm{ff}$.; Blümel, DVB1. 75, 706 ff.; Wahl, DOV 75, 373 (377)) der Fall.

In verfahrensrechtlicher Hinsicht verstärkt diesen Vorgang das mehrstufige Planungs- oder Genehmigungsverfahren, wenn dies sich nur um stufenmäßige Zweckrationalität, nicht aber um auch stufenmäßigen Interessenschutz bemuht (vgl. naher wiederum Wahl, a. a. O.; Blümel, a. a. O.; Schmidt-Aßmann, DOV 74, 547), und die Rechtsprechung schließlich noch auf eine angeblich gebotene, in Warheit aber die Rechtsschutzeffektivitàt ernsthaft gefährdende „Rechtsschutzkonzentration" zugunsten einer Gerichtskontrolle erst auf der letzten oder einer der letzten Stufen (z. B. Planfeststellungsbeschluß) verweist bzw. drangt (vgl. so z. B. BVerwG, NJW 69, $340 \mathrm{ff}$.; auch BVerwG, DVB1. 72, 678 (679 f.) - zur Kritik vgl. Wahl, DOV 75, 374 ff.; Blümel, DVBl. 72, 798 f.; 73, 441 f.).

In tatsächlicher Hinsicht stellen sich schlieBlich die Probleme der realen Abgrenzung materiell-rechtlich relevanter Betroffenheit. Als 
Beispiel sei etwa auf die An- und Umlieger eines projektierten Atomkraftwerks hingewiesen, deren Betroffenheit sich naturgemäß nicht nach exakten räumlichen Abständen bestimmen läßt; vgl. paradigmatisch dazu die Problemstellungen in BVerwG, DVBl. 72, $678 \mathrm{f}$. - Würgassen - Klagebefugnis für Anlieger von ca. $4 \mathrm{~km}$ Entfernung zum Atomkraftwerk; VG Frelburg, DVBl. 75, 343 (344) - Klagebefugnis fur Landwirte b1s zu ca. $8 \mathrm{~km}$ Entfernung vom Atomkraftwerk Wyhl bejaht -; BayVGH, DVBl. 75, 199 (203 ff.) ebenso für ca. $7,5 \mathrm{~km}$ Abstand, zweifelnd aber für $50 \mathrm{~km}$ Abstand; vgl. weiterhin OVG Luneburg, DVBl. 75, 190 (193) - Stade - und OVG Hamburg, DVB1. 75, 207 ff. - Reynolds -

Gegenüber dieser Sachlage bedarf es mehrerer Vorkehrungen: Einmal ist die rechtliche Schutzwirkung der zugrunde liegenden Gesetze durch Ruckgriff auf solche Verfassungswerte (Grundrechte) zu konkretisieren, die durch die betreffenden Maßnahmen rechtlich berührt werden können (Frage nach der typisch-möglichen Eingriffsfolge). Denn wenn der Gesetzgeber, wie unstreitig ist, vor der Verfassung nicht über Bestand und Zuerkennung von subjektiven Rechten (frei) disponieren kann, dann darf er dies auch nicht indirekt, indem er den gesetzlichen Regelungs- bzw. Planungszweck so vage und offen faßt, daß jegliche Schutz- bzw. (potentielle) Eingriffswirkungen unbestimmbar bleiben. Planungsgesetze sind zwar auf derart "offene" Tatbestande angewiesen; lhre Zielbestimmung erfolgt wesentlich erst auf der Ebene der Rechtsanwendung. Dementsprechend muß aber auch mit der subjektiv-rechtlichen Schutzwirkung solcher Gesetze verfahren werden. Auch diese ist gegebenenfalls erst auf der Ebene der Rechtsanwendung bzw. ihrer gerichtlichen Durchsetzung (Kontrolle) zu konstituieren - und zwar, wie im folgenden zu zeigen sein wird (vgl. sub 2), durch entsprechend (interpretatorische) typisierende Rechtsfolgekontrollen.

$\mathrm{Zu}$ deren Zwecken bedarf es weiterhin der Pflicht der (gesetzesanwendenden, planenden oder teilgenehmigenden) Verwaltung zur möglichst konkretisierungsgerechten (Stufen-)Entscheidung (vgl. bereits oben und speziell hierzu Wahl, DOV 75, 375 f.). Denn erst von hier aus gelingt es, dem Erfordernis eines - nach Planungsbzw. Genehmigungsstufen differenzierenden - „Stufensystems der Betroffenheit" (Ossenbühl, Gutachten 50. DJT, B 177) gerecht zu werden. Eine solche Stufenbestimmung kann nicht abstrakt bzw. a priori vorgenommen werden; sie muß vielmehr konkret, d. h. je nach konkretem Gesetz und nach konkret-möglicher Rechtsfolge, erfolgen. "Stufenmäßige Betroffenheit" bedeutet in diesem Sinne nichts anderes als einen formalen Kontrollmaßstab, der jeweils erst im Einzelfall zu aktualisieren ist. - Auf das Problem ,tatsächlicher" Betroffenheitsunterschiede kann es schließlich nur insoweit ankommen, als sich nach typisierender Rechtsfolgekontrolle (Prüfung der Frage, welche Rechtsfolgen sind typischerweise zu erwarten oder möglich?) gegebenenfalls bestimmte Betroffenheiten definitiv ausschließen lassen. Daß es hierbei - dem summarischen Charakter einer solchen Prufung ebenso wie dem Gebot eines möglichst effizienten Rechtsschutzes gemảß - sehr großzugiger Kriterien bedarf, liegt auf der Hand (namentlich bei den vorstehenden Beispielen von Atomkraftwerken oder Industrieansiedlungen mit entsprechenden, schwer kalkulierbaren Umweltgefährdungen).

Vgl. zum Ganzen weiter auch noch im Folgenden N. 240.

233) Vgl. hierzu bes. Blümel, W. Weber-Festschrift, S. 539 ff. 
2. Ein Verzicht auf das subjektiv-öffentliche Recht und seine Systemfunktion scheidet dennoch ${ }^{234}$ ) aus. Die Krise des subjektiven Rechts ist vielmehr über dessen funktionsgerechte Offnung zu lösen ${ }^{236}$ ): Wo das (einfache) Gesetz das subjektiv-öffentliche Recht nicht mehr allseits verbindlich abzugrenzen vermag, dort ist das einseitige Beharren auf den Kriterien der sog. Schutznormtheorie unstatthaft. Wo ein konkreter Eingriff sich häufig erst im Rahmen objektiv-rechtlicher Gesetzesanwendung aktualisiert, dort ist das subjektiv-öffentliche Recht aus der Relation von subjektiver Rechtsfolge und verfassungsrechtlicher (grundrechtlicher) Eingriffskontrolle zu bestimmen. Verstärkt gilt dies dort, wo eine zur (partiellen) Eigenprogrammierung berufene Verwaltung selbst individuale Schutzpositionen aufbauen und beseitigen kann. Das subjektiv-öffentliche Recht schützt zwar das private Interesse, kann (latent) aber auch öffentliche Interessen vertreten oder diesen bei inhaltlicher Kongruenz dienlich sein. Im Gegensatz zur Schutznormtheorie darf solche Kongruenz nicht zur Verneinung subjektiver Rechte führen. Das subjektiv-öffentliche Recht kann vielmehr und legitimerweise auch öffentliche Interessen repräsentieren und begrifflich aufnehmen, wenn diese Repräsentation als inhaltlich typische Rechtsfolge eines Gesetzes nicht nur Ausdruck faktischer Zufälligkeit, sondern Ausdruck einer auch grundrechtlichen Begünstigung des jeweils betroffenen Individuums ist $\left.{ }^{236}\right)$.

Diese funktionale Erweiterung des subjektiven Rechts bietet die Grundlage zur erforderlichen Offnung des individualen Rechtsschutzes: Der einzelne kann auch klagebefugt sein, wenn ihn objektiv-rechtliche Zweckmaßnahmen - in grundrechtsrelevanter Weise - als „Repräsentanten“ eines öffentlichen

254) Selbst so massives Argumentationsgeschütz wie das vom subjektiv-öffentlichen Recht und von der individualen Beschwer als angeblich traditionalistischem Anachronısmus o. ä. (vgl. so DoranHinz-Mayer-Tasch, Umweltschutz - Politik des peripheren Eingriffs, 1974, S. 47) öffnet keinen Weg zum objektıv-rechtlichen oder popular-klägerischen Rechtsschutz. Im Kompetenzsystem der grundgesetzlichen Gewaltenteilung und ihrer Rechtsschutzorganisation bleibt das Prinzip der subjektiv-rechtlichen Verwaltungskontrolle maßgebend.

285) Vgl. auch Bartlsperger, VVDStRL 33, 252 ff.

286) Als subjektiv-öffentliches Recht gilt danach nicht nur die willentliche und tatsächliche Begünstigung eines bestimmten Privatinteresses durch das Gesetz, sondern im Rahmen objektiven und nur tatsächlich privatbegünstigenden Rechts auch die Repräsentation öffentlicher Interessen bel entsprechender grundrechtlicher Legitimation oder grundrechtlichem Eingriffsschutz zugunsten eines tatsächlich (mit-)begünstigten Prıvatinteresses (vgl. bereits $R$. Scholz, Wirtschaftsaufsicht, S. 164 ff ; ders., WiR 72, 55 f.). 
Interesses treffen, das mit seinem Privatinteresse inhaltlich übereinstimmt ${ }^{237}$ ). Als Beispiel sei etwa auf eigentumsrelevante Konstellationen im Bereich von Bau-, Raum- oder Wirtschaftsplanung verwiesen ${ }^{288}$ ). Im Rahmen derart geschützter Individualbelange kann das Verwaltungsgericht auch allgemeine oder drittbetreffende Belange berücksichtigen, soweit sie der klägerisch-individuale Interessenschutz inhaltlich mit zu repräsentieren vermag ${ }^{239}$ ). Selbst für die Masseneinwendung zeichnen sich von hier aus Lösungsansätze $a b$, die den Einzelnen auch

297) Vgl. näher und m. w. Nachw. R. Scholz, Wirtschaftsaufsicht, S. $164 \mathrm{ff}$.

238) Vgl. bes. eindeutig anerkannt bzw. praktiziert im baurechtlichen Nachbarschutz; vgl. z. B. die Fallbildungen in BVerwG, DVBl. 70, 57 ff.; 70, 60; 70, 61 f.; 70, 66; BVerwG, BauR 75, 191 ff.; BVerwGE 45, 309 (312 ff.); weitere Nachweise bes. bei Weyreuther, BauR 75, 1 ff.

Im Bereich der Wirtschaftsplanung bestehen vorerst nur Ansätze, die wie im Bau- und Raumrecht auf der Ebene mikroadministrativer ("eingriffsrechtlich meßbarer") Ausführung ansetzen (vgl. z. B. im Subventionsrecht BVerwGE 30, $191 \mathrm{ff}$; im Verkehrsrecht BVerwGE 2, 141 f.; 9, 340 ff.; 10, 310 ff.; 16,187 ff.; 30, 347 ff.; 30,352 ff.; 31 , 133 ff.; 31,184 ff.); im makroökonomischen Lenkungsbereich typisch für die Verneinung von individualen Klagebefugnissen VGH Mannheim, NJW 74, 2150.

${ }^{230}$ ) Vgl. in richtigem Ansatz danach BVerwGE 2, 141 f.; 9, 340 (341 f.); 16, 187 ff.; 27, 176 (180); 30, 347 (348 ff.); 30, 352 (353 ff.); 31, 133 (135 ff.); 31, 184 (185 ff.); BayVGH, BayVBl. 75, 273 (274 ff.); nicht richtig bzw. zu eng dagegen z. B. BVerwGE 21, 338 (340); 30, 135 (136 ff.); 39, 345 (349); BVerwG, DVBl. 72, 678 (679 f.); BVerwG, NJW 75, 1373 (1374 f.); VGH Mannheim, NJW 74, 2150. - Dies bedeutet nicht den Schritt zur Popularklage, weil der einzelne nur kraft seiner individualen Beschwer klagebefugt ist (vgl. im Gegensatz dazu in tatsächlich popularklägerischer Richtung RehbinderBurgbacher-Knieper, Bürgerklage im Umweltrecht, 1972, S. $118 \mathrm{ff}$.). $\mathrm{DaB}$ sich die Rechtsordnung derartige Interessenkoinzidenzen von privatem und öffentlichem Interesse zur Durchsetzung gerade auch des öffentlichen Interesses zunutze macht, ist nichts Neues. Dies beweisen z. B. die Fälle wirtschaftsrechtlicher Verbandsklagen (vgl. dazu anschließend sub 3.) oder die Fälle nach Art der \$§ 11 I, II WZG, 13 II, IV PBefG. - Vgl. dazu schon $R$. Scholz, Wirtschaftsaufsicht, S. 72 ff., 83 f., 145 ff.; auch Wäldle, ZRP 75, 105 (106 ff.) und zum Subventionsrecht jetzt Zuleeg, Subventionskontrolle durch Konkurrentenklage, S. $62 \mathrm{ff}$.

Für die beispielhafte Rechtsgütertypik des Kartellrechts und seine bisher zu einseitig "objektiv-rechtliche “ (ordnungspolitische) Handhabung vgl. $R$. Scholz, Wirtschaftsaufsicht, S. 172 ff., und jetzt auch Sondergutachten der Monopolkommission Anwendung und Möglichkeiten der Mißbrauchsaufsicht über marktbeherrschende Unternehmen seit Inkrafttreten der Kartellgesetznovelle, 1975, S. 23 ff.; ungleich offener und rechtsschutzeffektiver vgl. hier auch EuGH, EuR 74,369 (373 f.) zum europäischen Kartellrecht; zum nationalen Kartellrecht vgl. neuerdings auch - als Wende? - BGH, NJW 75, $1223 \mathrm{f}$. 
als mittelbaren "Sachwalter" für allgemeinere oder gruppenmäßig gleichartige Interessen aktivlegitimieren ${ }^{240}$ ).

240) Dabei ist an die Feststellungen oben N. 232 anzuschließen und dementsprechend nach der potentiellen (typischen) Eingriffswirksamkeit der konkreten Maßnahme zu fragen. Dies erkennt auch prinzipiell das BVerwG im Flachglas-Urtell, wenn es für einen Bebauungsplan gegenüber Emissionsgefahren „stets ein hohes $\mathrm{MaB}$ an typisierender Betrachtung“ als „deshalb unerläßlich" erklärt, "weil nach aller Erfahrung nur dadurch Aussicht besteht, eine beginnende Fehlentwicklung frühzeitig in den Griff zu bekommen" (vgl. DOV 75, 92 (98)). In diesem Sinne ist also bei der Typisierung bzw. typisierenden Vorausschau bestimmter, individual-rechtlich relevanter Rechtsfolgen anzusetzen (Gebot der individual-rechtlichen Folgendiskussion). Der entgegengesetzte Weg, lediglich beim gesetzlichen Tatbestand selbst anzusetzen und dessen mögliche Rechtsfolgen außer Betracht zu lassen, verfängt dagegen nicht. Deshalb erweist sich beispielsweise auch der zuletzt von W. Schmidt, VVDStRL 33, 207 f. - noch deutlich in Anlehnung an die Schutznormtheorie angestellte Differenzierungsversuch als nicht tragfähig; Schmidt sucht zwischen den folgenden drei Betroffenheitstypen zu unterscheiden: (1) Inhaber von Individualrechten (z. B. Eigentümer), (2) Entscheidungs- und Planungsbetroffene, die (sonstige) Schutznormen auch $\mathrm{zu}$ eigenen Gunsten anführen können, und (3) sonstige Betroffene, die nur „Einwendungen" erheben können. Auch Schmidt erkennt, daß die Ubergänge hier fließend sind (a. a. O., S. 208). Das Entscheidende ist aber, daß sich die konkret gegebene Form der Betroffenheit eben nicht vorab oder allein am gesetzlichen Tatbestand, sondern erst auf der Ebene der verwaltungsmäßigen Rechts- und Zweckkonkretisierung bzw. auf der Ebene der Rechtsfolgen gleichsam rückschließend - feststellen läßt. Deshalb erscheint jeder Versuch, der vom gesetzlichen Tatbestand her nach dem Grad der Begünstigung Einzelner bzw. privater Interessen fragt, zu eng und damit ungeeignet. Stattdessen sollte umgekehrt verfahren werden und der einzelne Rechts- oder Einwendungsträger auch in seiner potentiell repräsentativen Stellung für alle in rechtlich relevanter Form Betroffenen gesehen und gegebenenfalls als klagebefugt anerkannt werden. Einen demgemäß mchtıgeren Weg beschreit der Abgrenzungsversuch in: K. Adenauer-Stiftung (Hrsg.), Stadtentwicklung - Von der Krise zur Reform, 1973, S. 186 ff. Dieser stuft inhaltlich "nach Sachgebieten" (S. 187 f.) sowie nach der "Intensität der Planbetroffenheit" (S. 188 ff.) ab und erschließt sich so eine recht umfassende Anwendbarkeit namentlich des Verhăltnismäßigkeitsgrundsatzes. Dieser (richtige) Grundansatz wird jedoch nicht durchgehalten; es wird dann doch zu schnell bzw. wieder zwischen "vorhandenen Besitzständen“ etc. und „allgemeinen Bürgerinteressen“ unterschieden; und dies, obwohl beispielsweise richtig erkannt wird, daß gerade das StBFG diese (traditionelle) Differenzierung als Schutzgütermaßstab (mit Recht) aufgegeben hat (vgl. a. a. O., S. 189). Ubersehen wird überdies das Erfordernis des eingriffskontrollierenden Rückgriffs auf die Grundrechte und ihrer konkreten Wirkung fur die jeweilige Betroffenheit. Maßgebend ist danach zunächst das konkrete Gesetz und seine gegebenenfalls planerische Umsetzung. Aus ihr und ihren Wirkungen für die tatsächliche Position des Einwendungsführers ergibt sich der rechtliche Bezug zu Gesetz und 
Sogar institutionelle Verbindungen von öffentlichem und privatem Interesse kennzeichnen das subjektiv-öffentliche Recht in jenen Bereichen, in denen der Gesetzgeber verstärkt auf Verwaltungsermessen und verwaltungseigener Programmbildung vertraut, namentlich also im planerischen Bereich. Hier wechselt das subjektive Recht - häufig und durchaus konsequent - aus der Dimension der materiellen Rechtsgewährleistung in die der bloB formellen Verfahrensbeteiligung über ${ }^{241}$ ).

Dem betroffenen und interessierten Bürger werden Rechte auf Anhörung, Einwendung, Information oder sonstige Beteiligung (Beiladung) im Verwaltungsverfahren gewährt; und dies geschieht zum Schutze privater wie zur Unterstützung öffentlicher Interessen. Privatnützig sind solche Verfahrensrechte, wenn sie den Verlust und die mangelnde Fixierung materieller

Grundrecht (beispielsweise Art. 14 GG). Aus der Relation beider unter Einschluß einer gegebenenfalls auch nur hypothetisch - typisierenden Eingriffskontrolle - ergibt sich das Maß rechtlich zulàssiger Betroffenheit. Das tatsächlich betroffene Eigentumsrecht eines Eigentümers steht dabei naturgemäß im spezifischen Zusammenhang mit anderen, gleichermaßen betroffenen Eigentumsrechten („Planungsverbund“); es repräsentiert diese mit wie umgekehrt diese es selbst mitrepräsentieren. Und dieser repräsentative Betroffenheitsgehalt ist maßgebend mit Betroffenheitsmaßstab; er wird prozessual zum Bestandteil der klägerischen Aktivlegitimation. Den Weg zur interpretativen Umsetzung dessen zeichnet z. B. die Rechtsprechung zum situationsbefangenen Eigentum und seiner legitimen wie illegitimen Beschränkungsmöglichkeiten vor (vgl. hier namentlich BVerwGE 4, 57 (60 f.); 5, 143 (144 f.); 26, 111 (119); 29, 357 (364); 32, 173 (178 f.); 35, 256 (260 f.) u. a.; zur Planung als Aktualisierung gerade dieser Situationsgebundenheit des Grundeigentums vgl. Badura, BayVerfGH-Festschrift, S. 182).

241) Denn wenn das Gesetz mit der konkreten Zielsetzung auch die schutzwürdigen Interessen des Individuums nicht verbindlich präfixiert, dies vielmehr der verwaltungsmäßigen Programmkonkretisierung überläßt, muß dem Bürger als Kompensation verstärkt die Verfahrensbeteiligung zwecks eigener Interessenartikulation eingeräumt werden. Dieser Vorgang bildet weniger eine Form radikaldemokratischer Partizipation, sondern viel eher und prinzipiell eine Form rechtsstaatlich-kompensatorischer Rechtsgewährleistung (vgl. hierzu noch weiter unten sub III).

Als Beispiel sei auf die kommunale Raumordnung verwiesen (Anhörungsrecht der betroffenen Gemeinden): vgl. z. B. BayVerfGH, DVB1. 75, 28 (35); SaarVerfGH, DVBl. 75, 35 f.; Hoppe-Rengeling, Rechtsschutz bei der kommunalen Gebietsreform, S. $149 \mathrm{ff}$. - Im Wirtschaftsrecht vgl. z. B. R. Scholz, Wirtschaftsaufsicht, S. 120 ff.; ders., Konzentrationskontrolle und Grundgesetz, S. 101. Allgemein vgl. bes. Kopp, Verfassungsrecht und Verwaltungsverfahrensrecht, S. $75 \mathrm{ff}$;; Schwarze, Der funktionale Zusammenhang von Verwaltungsverfahrensrecht und verwaltungsgerichtlichem Rechtsschutz, 1974, S. 108; weitere Nachweise vgl. schließlich unten N. 260. 
Rechte kompensieren oder antezipierten Rechtsschutz gewähren sollen. Dem öffentlichen Interesse dienen solche Verfahrensrechte, wenn es um Effizienzfragen im Verwaltungsverfahren, wie umfassende Sachaufklärung und beschleunigte Sachentscheidung kraft Präklusion späterer Einwendungen, geht. Die interpretative Unterscheidung zwischen derart öffentlichen und privaten Interessen hat praktisch jedoch wenig Bedeutung. Vor allem inhaltlich offene (ermessensmäßige, planerische etc.) Verwaltungsverfahren bauen häufig auf die Kombination oder gar Substitution von öffentlichen und privaten Interessen ${ }^{242}$ ). Wenn der Gesetzgeber dafür, in Gestalt verfahrensrechtlicher Bürgerbeteiligung, organisatorische Voraussetzungen schafft, so müssen diese auch vom Verwaltungsgericht in ihrer interessenmäßigen Ambivalenz praktiziert werden. Der Versuch, hier zwischen privatem und öffentlichem Interesse zu differenzieren, würde den Zweck solcher Verfahrensrechte verkennen und damit auch zur inhaltlichen Rechtsschutzverkürzung beitragen. Denn wenn das Gesetz dem Bürger Rechte auf Beteiligung im Verwaltungsverfahren gewährt, so sind diese Rechte in ihrer spezifischen Offentlichkeits- und Privatinteresse verbindenden Sinnrichtung einklagbar $\left.{ }^{243}\right)^{244}$ ).

242) Vgl. z. B. die Beteiligungsrechte In \$§ 1 IV 3 u. 4, 4 I 2, II, 8 II, 9 I-IV, 10 IV StBFG; \& 18 IV, V BFStrG, § 14 PBefG, §§ 10, 11 BImSchG, \& 10 III-VII LuftVG, \& 7 b AtomG, \& 3 AtomAnivo, $\S 31$ WHG. Vgl. dazu im Zusammenhang bes. $K$. Lange, DVBl. 75, 130 (131 ff.); Battis, Partizipation im Städtebaurecht, Habilitationsschrift Berlin (MS); Kopp, Verfassungsrecht und Verwaltungsverfahrensrecht, S. 24 ff., 217 ff.; Blümel. W. Weber-Festschrift, S. 548 ff.; R. Scholz, Wirtschaftsaufsicht, S. 79 ff., 120 f.; Mayntz, in: Demokratie und Verwaltung, 1972, S. 341 ff.; vgl. in richtiger Blickrichtung auch z. B. BayVGH, DVBl. 75, 199 (202).

${ }^{243}$ ) Dies gilt auch dann, wenn die Beiladung zum Verwaltungsverfahren im Ermessen der Verwaltung steht (so § 13 II EVwVfG, § 51 II Nr. 4 GWB). Vgl. bereits $R$. Scholz, Wirtschaftsaufsicht, S. $79 \mathrm{ff}$., $197 \mathrm{f}$. (in verfassungskonformer Auslegung des § $51 \mathrm{II} \mathrm{Nr.} 4$ GWB); aus anderer Blickrichtung vgl. auch Soell, Wahl-Festschrift, 1973, S. 439 (440 ff.); ders., Die Verwaltung 1973, 499 (503 f.); vgl. weiterhin - aber zu pauschal - Kopp, Verfassungsrecht und Verwaltungsverfahrensrecht, S. 22 ff. (Anspruch auf Beiladung im Verwaltungsverfahren kraft Art. 1 I GG); vgl. weiterhin richtig sowie weiterführend die Vorstellung einer "Partizipationsklage“, wie sie Battis, Partizipation im Städtebaurecht, a. a. O., ders., ZRP 75, 111 (112 f.), vorgestellt hat. Nicht richtig dagegen BVerwG, DOV 75, 92 (93); $75,99 \mathrm{f}$.

Verfassungswidrig ist die Regelung der $\$ \S 48,60$ III 2 FGO, soweit diese die Klagebefugnis beschränkt (vgl. Entwurf eines Verwaltungsgerichtsgesetzes, 1969 , S. 223 f. m. w. Nachw.).

Aus dem spezifischen Sinnzusammenhang von privatem und öffentlichem Interesse entsprechender Beteiligungsrechte folgt zugleich, $\mathrm{da} B$ diese nicht aus einer erweiternden - auf das Verwaltungsver- 
3. Durch die Offnung des subjektiv-öffentlichen Rechts zur legitimen Repräsentation auch öffentlicher Interessen und durch die verwaltungsverfahrensmäßige Verbindung von privatem und öffentlichem Interesse gelingt es dem individualen Verwaltungsrechtsschutz, auch kollektive Rechtsschutzanliegen zu vermitteln. Die grundsätzliche Berechtigung solcher Anliegen steht mit der Zunahme gruppenmäßiger Rechtsbetroffenheit und den wachsenden Schwierigkeiten individualer Rechtsverfolgung außer Streit. Problematisch sind jedoch die aktuell diskutierten Rechtsschutzformen von Popular- und Kollektiv- bzw. Verbandsklage ${ }^{245}$ ).

fahren erstreckten - Anwendung des Prinzips des rechtlichen Gehörs (Art. 103 I GG) zu erklären sind. Denn abgesehen davon, daß das Gebot des Art. 103 I GG nur im Ausnahmefall des quasi-just1ziell gestalteten Verwaltungsverfahrens angewandt werden kann (vgl. weitergehend allerdings z. B. Kopp, Verfassungsrecht und Verwaltungsverfahrensrecht, S. 75 ff.; Maunz-Dirig-Herzog, GG, Art. 103 I Rdnr. $92 \mathrm{~m}$. w. Nachw.; zuletzt vgl. dazu Schickedanz, ZRP 75, 182 ff. - vgl. dazu auch schon $R$. Scholz, Wirtschaftsaufsicht, S. 121 m. N. 60), der eigentliche Standort derartiger Beteiligungsrechte liegt aus Rechtsschutzsicht bei der Rechtsschutzgarantie des Art. 19 IV GG bzw. deren Effektulerung oder Kompensation (vgl. Lerche, ZZP 78, 2 ff., 23 ff., und weiter noch anschließend sub 3).

Aus der Rechtsprechung vgl, richtig vor allem BVerwGE 2, 141 f.; 9, 340 (341 1.); 16, 187 (188 f.); 30, 347 (348).

244) Die spezifische Verbindung von öffentlichem und privatem Interesse gestattet dem Verwaltungsgericht erneut auf die Pflicht der Verwaltung zur Beachtung aller verfahrens- wie materiellrechtlich relevanten Unstände $z u$ erkennen, soweit die klägerische Anhörung, Einwendung oder Belladung diese (mit-)zurepräsentieren vermag.

245) Vgl. näher $M$. Wolf, Die Klagebefugnis der Verbände, 1971; Faber, Die Verbandsklage im VerwaltungsprozeB, 1972; RehbinderBurgbacher-Knieper, Bürgerklage im Umweltrecht, 1972; Bleckmann, VerwArch 1972, 183 ff.; Rupp, ZRP 72, 32 ff.; Naumann, DOV 71, 378 ff.; Blümel, W. Weber-Festschrift, S. 564 f.; Bettermann, ZZP 85, 133 ff.; ders., AöR 99, 501 ff.; Redeker, DVBl. 73, 744 ff.; R. Scholz, ZHR 137, 266 ff.; ders., Wirtschaftsaufsicht, S. 83 ff.; Brohm, VVDStRL 30, 300 f.; W. Schmidt, VVDStRL 33, 210 f.; Bartlsperger, VVDStRL 33, 259 ff.; Stelkens, DVBl. 75, 137 ff.; Hofmann, BayVBl. 72, 524 ff.; 73, 265 f.; von Mutius, VerwArch 1973, 311 ff.; Wäldle, ZRP 75, 105 ff.; Lorenz, Rechtsschutz, S. 72 ff.; $H$. Krüger, MDR 53, 518 ff.; Ule, VerwaltungsprozeBrecht, 6. Aufl. 1975, S. 158 f.; Streckel, in: Rehbinder, Recht im sozialen Rechtsstaat, 1973, S. 329 (352 ff.); Eyermann, BayVBl. 74, 237 (242 f.); Doran-Hinz-MayerTasch, Umweltschutz - Politik des peripheren Eingriffs, S. $41 \mathrm{ff}$.

Aus der Rechtsprechung vgl. bes.: VGH Mannheim, NJW 72, 1101 ff.; OVG Koblenz, ZBR 73, 109 ff.; BayVGH, BayVBl. 75, 420 f.; OVG Lüneburg, $\mathrm{KStZ} 75,56 \mathrm{f}$. (mit dem - nicht verallgemeinerungsfähigen - Kriterium der Verbandsvertreterbefugnis in „berufsstandsspezifischen Angelegenheiten"). 
Für die Popularklage sollte rechtsschutzpolitisch nur dort Raum sein, wo es um die prozessuale Durchsetzung gesetzlichpopularer Einwendungsrechte im Verwaltungsverfahren selbst geht $\left.^{246}\right)$. Für eine allgemeine bzw. materiell-rechtlich orientierte Popularklage spricht hingegen wenig(47). Sie wäre vor allem nicht geeignet, die drohenden Massenklageverfahren zu bewältigen $^{248}$ ). Dies vermöchte eher die Verbandsklage. Auch gegen diese sprechen jedoch zumindest insoweit viele Gründe, als es um "altruistische“ (nicht "egoistische“) Kollektivklagen geht. Denn sie vertreten keine subjektiv-rechtliche Klageposition ${ }^{248}$ ); und eine demokratisch-partizipative Klagebefugnis ist dem System von Verwaltungsproze $B$ und Rechtsschutzgarantie fremd $\left.{ }^{250}\right)$. Verbandsklagen setzen ein rechtlich, nicht nur fak-

240) Vgl. z. B. die Einwendungsrechte aus $\$ 18$ III, IV BFStrG 1t. BT-Ausschuß für Verkehr (BT-Drucks. 7/1828, S. 5).

Vgl. in dieser Richtung auch den erwägenswerten Vorschlag von Blümel, W. Weber-Festschrift, S. 564 f., die Verbandsklage an das förmliche Verwaltungs- und Planfeststellungsverfahren als kollektive Verfahrensbeteiligung anzubinden; vgl. ebenso Hofmann, BayVBl. 72, 525.

247) Dies gilt auch für den Umweltschutz. Die hiesigen Befürworter der Popularklage (vgl. bes. Rehbinder-Burgbacher-Knieper, Bürgerklage im Umweltrecht, passim; Doran-Hinz-Mayer-Tasch, Umweltschutz, S. 41 ff.) übersehen vor allem, daß solche Klagen den Umweltschutz kompetenziell weitgehend auf die Verwaltungsgerichte uberwälzen würden; und diese sind für eine solche, wesentlich metajuristische Verantwortung kaum geeignet (vgl. richtig Bartlsperger, VVDStRL 33, 263). Zur Individual-Popularklage im Wettbewerbsrecht vgl. skeptisch juingst Schricker, ZRP 75, 189 ff.

249) Solche Verfahren drohen vor allem im Rahmen von Planfeststellungsverfahren jedweder Art, von Immissionsschutz und Genehmigungsverfahren zur Errichtung von Atomkraftwerken. Zur tatsächlichen Breitenwirkung namentlich von Finanzprozessen vgl. Voß, DRiZ 75, 70 (71); für die Sozialgerichtsbarkeit vgl. entsprechend Wannagat, SGb. 74, 361 (363) - in kritischer Distanz vgl. hierzu auch Larenz, Henkel-Festschrift, 1974, S. 33 (35 ff.).

${ }^{249}$ ) Sondern nur faktisch gebündelte Interessen, die nicht in entsprechend subjektive Rechtspositionen „umschlagen" (vgl. bereits $R$. Scholz, ZHR 137, 267 ff.; Bettermann, ZZP 85, 134 ff. gegen M. Wolf, Klagebefugnis der Verbände, S. 7 ff., und Bettermann, AöR 99, 502 ff. gegen Faber, Verbandsklage, S. 59 ff.).

Auch aus dem Status der "Offentlichkeit" von Verbänden ergibt sich nichts Gegenteiliges (a. A. aber H. Krüger, MDR 53, 520); denn "Offentlichkeit" in diesem Sinne impliziert kein rechtlich legitimierendes Repräsentationsmandat der Verbände (vgl. näher und $\mathrm{m}$. $w$. Nachw. hierzu R. Scholz, Koalitionsfreiheit als Verfassungsproblem, S. 195 ff.).

250) Vgl. allgemein dazu und bes. Blümel, Forsthoff-Festschrift, 1972, S. 23 ff.; Schmitt-Glaeser, VVDStRL 31, $217 \mathrm{ff}$., $221 \mathrm{ff} ., 240 \mathrm{ff}$.; Rupp, NJW 73, 1769 (1772); vgl. in dieser Richtung wohl auch BVerfG, JZ 74, 377 (378 f.) - a. A. insbes. Faber, Verbandsklage, S. 
tisch legitimiertes Repräsentationsmandat sowie dessen prozessuale Umsetzbarkeit - etwa durch Rechtskrafterstreckung auf die Verbandsmitglieder - voraus ${ }^{251}$ ). Beides ist jedoch nicht gewährleistet ${ }^{252}$ ); und für ein Institut nach Art der amerikanischen class action ${ }^{253}$ ) fehlen hiesigen Orts fast alle Voraussetzungen $^{254}$ ). Soweit das geltende Recht dennoch Verbandsklagen anerkennt ${ }^{255}$ ), handelt es sich um objektive Beanstandungsklagen, die als tatsächliche Popularklagen neben dem individualen Rechtsschutz stehen ${ }^{256}{ }^{267}$ ). Solche Verbandsklagen ließen sich

59 ff. (vgl. dagegen bereits $R$. Scholz, JR 72, 397); vgl. hier auch W. Schmidt, VVDStRL 33, 210.

251) Vgl. R. Scholz, ZHR 137, 267 f.; Bettermann, ZZP 85, 144; von Mutius, VerwArch 1973, 315 ff.

Zum Verhältnis des Rechtsschutzbedürfnisses eines Verbandes und dem seiner Mitglieder vgl. außerordentlich problematisch OLG Hamburg, MDR 75, 321.

252) Dem läßt sich auch nicht über die gesetzliche Zwangsverbandsbildung abhelfen. Denn selbst wenn man solche Zwangsorganisationen im Falle einer sog. "legitimen öffentlichen Aufgabe" mit der Rechtsprechung des Bundesverfassungsgerichts (vgl. BVerfGE $10,89(102) ; 10,354(363) ; 15,235$ (241) u. a.) zulassen wollte (zur Kritik vgl. m. w. Nachw. bereits $R$. Scholz, Koalitionsfreiheit als Verfassungsproblem, S. $270 \mathrm{ff}$.; ders., AöR 100, $124 \mathrm{ff}$.), so wäre eine solche doch jedenfalls dort nicht gegeben, wo kollektiv-rechtliche Klagebefugnisse zu Lasten oder unter (partieller) Verdrängung individual-rechtlichen Rechtsschutzes eingeführt werden sollten; und dies wäre bei (vorrang1ger und rechtlich verbindlicher) Repràsentation wie bei zwingender Rechtskrafterstreckung der Fall. Anders wären entsprechende Zwangszusammenschlüsse nur dort zu beurteilen, wo sie lediglich neben oder im Vorfeld des individualen Rechtsschutzes fungierten (vgl. in dieser Richtung auch BlümelRonellenfitsch, Die Planfeststellung in der Flurbereinigung, 1975, S. 82 ff.).

253) Vgl. Rule 23, Federal Rules of Civil Procedure for the US District Courts. Die Besonderheit der class action besteht vor allem in der Rechtskrafterstreckung auf die class-Angehörigen und im partiellen Verzicht auf die Dispositionsmaxime (vgl. nảher an deutschem Schrifttum Witzsch, JZ 75, 277 ff.; Sterndorff, ZHR 138, 504 (511 ff.); Wäldle, ZRP 75, 107 ff.; Buxbaum, Die private Klage als Mittel zur Durchsetzung wirtschaftspolitischer Rechtsnormen, 1972, S. $18 \mathrm{ff}$.).

254) $\mathrm{Zu}$ entsprechenden Reformüberlegungen im Wettbewerbsrecht vgl. allerdings Steindorff, a. a. O.

255) Vgl. \$§ 8 IV HandwO, 13 I UWG, 35 II GWB, 2 I ZugabeVO, 12 I RabattG. Zur wirtschaftsrechtlichen Verbandsklage nach diesen Regelungen vgl. bes. Schricker, GRUR Int. 73, 453 (454 ff.); E. von Hippel, Verbraucherschutz, 1974, S. 72 ff., 87; Hadding, JZ 70, 305 ff.; Bußmann, Mitteilungen der deutschen Patentanwälte 1969, S. 312 ff.; R. Scholz, Wirtschaftsaufsicht, S. 83 f.

${ }^{250}$ ) Vgl. R. Scholz, Wirtschaftsaufsicht, S. 83 f.; Rupp, ZRP 72, 35.

${ }^{257}$ ) Eine weitere Frage ist, inwieweit gemeindliche "Verbandsklagen" zugunsten der Gemeindeeinwohner gegenuber staatlichen Planungsmaßnahmen oder staatlıchen Umweltgefährđungen zugelassen 
auch im Verwaltungsrecht denken, namentlich in planerischen, umweltschützenden, wettbewerbs- und konsumpolitischen Ordnungsbereichen. Die Probleme des individualen Verwaltungsrechtsschutzes lösten solche Kollektivklagen indessen nicht. Mehr Rechtsschutzeffektivität und Systemkonformität verspricht ein Abstellen auf den individualen Rechtsträger und seine potentielle Repräsentanz auch gruppentypischer Rechtsgefährdungen ${ }^{258}$ ).

\section{Kompensatorischer Rechtsschutz in der Verwaltung}

Gestatten Sie zum Schluß noch einige Bemerkungen zum kompensatorischen Rechtsschutz in der Verwaltung.

Ein solcher Rechtsschutz ist vor allem dort zu diskutieren, wo - wie im planerischen, gestaltenden und metajuristischen Zweckbereich - gerichtliche Ex-post-Kontrollen zeitlich oft zu spät kommen oder inhaltlich zu eng ausfallen ${ }^{259}$ ). Hier können

werden. Da die Gemeinden insoweit auch über ein verfassungsrechtlich legitimiertes, demokratisches Repräsentationsmandat verfügen (vgl. dazu m. w. Nachw. $R$. Scholz, Wesen und Entwicklung der gemeindlichen öffentlichen Einrichtungen, S. 42 ff.), können solche Klagen durchaus - jenseits der rechtsstaatlichen Verteidigung subjektiver (Individual-)Rechte - in Betracht kommen (vgl. auch Schmidt-Aßmann, DOV 74, 547; Papier, DVBl. 75, 463; zu eng BayVGH, BayVBl. 75, 114 ff.; offener dagegen VG Freiburg, DVB1. 75, 343 (344); zum Ganzen vgl. auch Pankoke, Die Verwaltung 1971, $395 \mathrm{ff}$.). In diesem Zusammenhang ist weiterhin auch die Zulassung zwischengemeindlicher Planungsnachbarklagen zu sehen, zugelassen durch BVerwG, DVB1. 73, $34 \mathrm{ff}$. mit dem richtigen Ansatz einer subjektiv-rechtlichen Klagebefugnis (vgl. dazu näher auch noch Hoppe, Wolff-Festschrift, 1973, S. 307 ff.).

${ }^{258}$ ) Dies zeigt sich auch beim Umweltschutz. Da ein Verband (juristische Person) als solcher nicht subjektiv-rechtlich betroffen ist, dies nur seine Mitglieder kraft individualer Berechtigungen sein können, sollte prinzipiell von deren (zugleich "repräsentierender") Klagebefugnis - gegebenenfalls durch prozessuale Erleichterungen unterstützt (im Kostenrisiko etc. - vgl. hier vor allem die Grundlage im Würgassen-Urteil des BVerwG, DVBl. 72, 678 (682); auch BayVGH, BayVBl. 75, 273 (276 f.) - ausgegangen werden. Vgl. in dieser Richtung auch Kloepfer, Zum Umweltschutzrecht in der Bundesrepublik Deutschland, o. J., S. 29 f. mit dem insoweit richtigen Plädoyer für ein (Individual-)Grundrecht auf ungefährdete Umwelt; zu einem solchen Grundrecht vgl. kontrovers im übrigen BVerwG, DOV 75, 605; Umweltprogramm der Bundesregierung (BT-Drucks. VI/2710); H. Klein, W. Weber-Festschrift, 1974, S. 643 ff.; E. Rehbinder, ZRP 70, $250 \mathrm{ff}$; Rupp, JZ 71, $401 \mathrm{ff}$; zur im übrigen wesentlich analogen Fragestellung des Art. 141 III BayVerf. vgl. BayVGH, BayVBl. 75, 420 f. (kein Recht juristischer Personen; ebenso VG Ansbach, DVBl. 75, 150 (151 f.)), BayVGH, DVBl. 75, 545 ff. mit kritischer Anm. Bettermann; BayVerfGH, BayVBl. 75, $419 \mathrm{f}$.; VG München, BayVB1. 75, $421 \mathrm{ff}$; 75, $425 \mathrm{ff}$.

${ }^{250}$ ) Vgl. hierzu schon die Nachweise oben N. 54, 55, 56. 
quasi-justiziell gestaltete Verwaltungsverfahren und bürgerliche Rechte auf Anhörung, Einwendung oder Beiladung im Verwaltungsverfahren antezipatorischen Rechtsschutz gewähren und so einige Effizienzverluste im gerichtlichen Rechtsschutz ausgleichen ${ }^{280}$ ). Ein derart antezipatorischer Rechtsschutz findet in den Grundsätzen des effektiven Rechtsschutzes und der offenen, funktionsteiligen Gewaltengliederung seine prinzipielle Legitimation, zugleich aber auch seine zwingende sprich kompetenzrechtliche - Begrenzung ${ }^{261}$ ). Denn jedes Verwaltungsverfahren ist zunächst der zweckrationalen Erfüllung einer Verwaltungsaufgabe verpflichtet. Dem Rechtsschutz kann es nur insoweit und inzident dienen, wie dies die konkrete Zweckverantwortung erlaubtear).

Diese kompetenzrechtlichen Grenzen jedes kompensatorischen Rechtsschutzes in der Verwaltung werden freilich oft übersehen. Vor allem die Faszinationen einer nicht nur demokratie-, sondern auch rechtsstaatlich begründeten Partizipationsidee ${ }^{263}$ ) haben hier manchen Blick getrübt ${ }^{204}$ ). Reduziert

20v) Vgl. mit allerdings unterschiedlicher Ausrichtung Blümel, Forsthoff-Festschrift, 1972, S. 23 ff.; Lerche, ZZP 78, 2 ff.; Battis, Partizipation im Städtebaurecht, a. a. O.; Haberle, VVDStRL 30, 43 (86 ff., 125 ff.); ders., JZ 75, 297 (303 f.); Schmitt-Glaeser, VVDStRL 31, 200, 204 ff., 240 ff.; W. Schmidt, VVDStRL 33, 207 ff., $210 \mathrm{ff}$; Seidler, Rechtsschutz bei staatlicher Wirtschaftsplanung, S. $144 \mathrm{ff}$., 147 ff.; Schmidt-Aßmann, DOV 74, 547; Soell, Wahl-Festschrift, S. 454 f.; Schwarze, Der funktionale Zusammenhang von Verwaltungsverfahrensrecht und verwaltungsgerichtlichem Rechtsschutz, $\mathbf{S}$. $58 \mathrm{ff}$.; R. Scholz, Wirtschaftsaufsicht, S. $109 \mathrm{ff}$., $120 \mathrm{ff}$.

261) Vgl. dazu bereits oben C I 1 .

Zur verfassungsrechtlichen (grundrechtlichen) Position und Strukturierung der Kompensation vgl. allgemein $\boldsymbol{R}$. Scholz, Paritätische Mitbestimmung und Grundgesetz, 1974, S. $110 \mathrm{ff}$. m. w. Nachw.

262) Deshalb gehört auch die Staatsaufsicht, selbst wenn sie (auch) Rechtmäßigkeitskontrolle ist, nicht in den Kontext des kompensatorischen Rechtsschutzes. Denn RechtmäBigkeitsverantwortung dieser Art in der Verwaltung ist zweckorientierte Selbstkontrolle und kann allein indirekt auch den Interessen betroffener Bürger dienen. Rechtsschutzkompensatorische Intendanzen bestehen daher nicht. Verwaltungsinterne Kontrollen haben generell zunächst die Aufgabe, eine verantwortliche und als solche auch rechtmäßige Exekutive zu sichern (vgl. richtig Schwarze, DVBl. 74, 893 (899)). Eine Rechtsschutzfunktion übernimmt die Staatsaufsicht lediglich dort, wo sie (gleichzeitig) Widerspruchsinstanz gemäß $\$ 68 \mathrm{ff}$. VwGO ist.

263) Vgl. näher bes. Walter, VVDStRL 31, $147 \mathrm{ff}$; Schmitt-Glaeser, VVDStRL 31, 179 ff.; Blümel, Forsthoff-Festschrift, 1972, S. 9 ff.; Rupp, NJW 72, 1537 ff.; Battss, Partizipation im Städtebaurecht, a. a O.; W. Schmidt, VVDStRL 33, $207 \mathrm{ff}$., $210 \mathrm{ff}$; Ossenbühl, Gutachten 50. DJT, B 119 ff., 130 ff., 192 ff.; Grauhan, PVS 1972 Sonderheft 4, S. 84 ff.; Dienel, Die Verwaltung 1971, 151 ff.; Dagtoglou, DVB1. 72, 712 ff.; Mayntz, in: Demokratie und Verwaltung, 1972, S. 341 ff ; Riedl, Städtetag 73, 207 ff. 
man die Vorstellung der Partizipation aber auf ihren verfassungsrechtlich tragfähigen (allein grundrechtlichen) Kern, so zeigt sich bald, daß die Gleichungen effektiver = antezipatorischer Rechtsschutz und antezipatorischer $=$ partizipatorischer Rechtsschutz nicht aufgehen.

Einen ungleich effektiveren sowie kompetenzgerechteren Rechtsschutzansatz versprechen dagegen Verwaltungsverfahren, in denen sich die Verwaltung schon aus eigenen, zweckautonomen Gründen quasi-justizieller Verfahrensformen bedient ${ }^{265}$ ). Dies geschieht vor allem dort, wo die Nutzung metajuristischen („unvertretbaren“) Sachverstandes kollegiale und (partiell) unabhängige Verwaltungseinheiten fordert. Organisationen dieser Art finden sich ebenso in unabhängigen Prüfungsausschüssen wie in den speziellen Beschlußeinheiten der Patent-, Kartell- und Versicherungsaufsicht $\left.{ }^{208}\right)$. Status und Verfahren dieser Organisationen werfen zwar andere Rechts- und Verfassungsprobleme - wie die Frage nach Statthaftigkeit und Grenzen ministerialfreier Räume ${ }^{287}$ ) - auf; unter dem Aspekt antezipatorischen Rechtsschutzes tragen sie aber gerade dort, wo die Kontrollkompetenz der Verwaltungsgerichte an die Grenzen metajuristischer Verwaltungsverantwortung stößt, zu

204) Vgl. im Ergebnis auch Ossenbïhl, Gutachten 50. DJT, B $125 \mathrm{ff.}$ 174 f., 193 f.; Blümel, Forsthoff-Festgabe, 1967, S. 157 ff.; ders., Forsthoff-Festschrift, 1972, S. 26 ff.; Rupp, NJW 73, 1769 (1772); R. Scholz, Wirtschaftsaufsicht, S. 121; vgl. auch Bettermann, VVDStRL 17, 170; Bartlsperger, VVDStRL 33, 260 ff.; W. Zeidler, DVBl. 73. 719 (720).

205) Zum entsprechenden Zusammenhang von Verwaltungsprozeß und Verwaltungsverfahren bzw. zur prinzipiellen Möglichkeit gegenseitiger Ergänzung vgl. mit freilich unterschiedlicher Akzentuierung Bettermann, VVDStRL 17, 168 ff.; Ule, DVBl. 57, 597 ff.; 58, 9 f.; Schwarze, Der funktionale Zusammenhang von Verwaltungsverfahrensrecht und verwaltungsgerichtlichem Rechtsschutz, $S$. 35 ff., 44 ff., 50 ff., $58 \mathrm{ff}$; Schmitt-Glaeser, VVDStRL 31, 241; auch Bachof, DVBl. 58, $6 \mathrm{ff}$.

206) Vgl. \$§ 17, 18, 26 ff. PatG l. d. F. v. 2. 1.68 (BGBl. I, S. 2), §§ 48, 51 ff. GWB i. d. F. v. 4. 4. 74 (BGBl. I, S. 869), \$§ 1 ff. BAG v. 31. 7. 51 (BGBl. I, S. 480) in Verb. $\mathrm{m}$. $882 \mathrm{ff}$. DVO-BAG vom 25. 3. 53 (BGBl. I, S. 75).

Zum Verfahren von Versicherungsaufsicht und Kartellaufsicht siehe vergleichend z. B. Rittner, H. Kaufmann-Festschrift, 1972, S. 307 (315 ff.); zur Offentlichkeit dieser Verfahrensformen als „Instrument präventiver Rechtmäßigkeitskontrolle" vgl. Martens, Offentlich als Rechtsbegriff, S. 57; $R$. Scholz, NJW 73, 481 (485).

207) Vgl. dazu BVerfGE 9, 268 (282); BremStGH, NJW 74, 2223 (2228 ff.); E. Klein, Die verfassungsrechtliche Problematik des Ministerialfreien Raums, 1974, S. 36 ff., 43 ff., 58 ff., 73 ff., 144 ff.; Fichtmüller, AöR 91, 297 ff.; Dahlgrün, in: Demokratie und Verwaltung, 1972, S. 317 ff.; Loening, DVBl. 54, 173 ff. 
wirksamer und kompetenzgerechter Rechtsschutzkompensation bei $\left.{ }^{268}\right)^{280}$ ).

289) Vgl. näher Schwarze, Der funktionale Zusammenhang von Verwaltungsverfahrensrecht und verwaltungsgerichtlichem Rechtsschutz, S. 62 f.; Bachof, VVDStRL 30, 235; Ossenbihl, DVBl. 74, 311 ff.; BVerwGE 39, 197 (203 ff.) - nicht richtig dagegen die Blickrichtung bei Rittner, H. Kaufmann-Festschrıft, S. 320 ff.

Das Entscheidende ist hier allerdings nicht die "Unvertretbarkeit" der kollegialen Entscheidung, die das BVerwG in seiner Entscheidung zur Bundesprüfstelle betont hat (BVerwGE 39, $203 \mathrm{f}$.). Denn organisatorisch ist jedes Verwaltungsverfahren anders als das Gerichtsverfahren gestaltet - ohne damit für dessen Kontrollkompetenz "unvertretbar" zu werden. Sollte damit aber die spezifische Unabhängigkeit und Kollegialität des entscheidenden Verwaltungsgremiums gemeint sein, so darf erst recht nicht auf "Unvertretbarkeit" im Sinne von Kontrollbeschränkung geschlossen werden; denn die Rechtsschutzgarantie des Art. 19 IV GG wüde jede Organisationsmaßnahme dieser Art dann als potentielle Umgehung ihrer selbst ansehen. Die Kontrollbeschränkung ergibt und legitimiert sich allein aus der (partiell-)metajuristischen Maßstabskompetenz der Verwaltung. Aus ihr folgt, vom juristischen Kontrollmaßstab her gesehen, in der Tat die vom BVerwG in AnschluB an Redeker, DOV 71, 757 (762) beschworene „Bandbreite der (vom Gericht zu akzeptierenden) Entscheidungsmöglichkeiten" (vgl. a. a. O., S. 203). Innerhalb dieser Entscheidungsalternativen ist jede Entscheidung rechtmäßig, wenn sie sich im Rahmen der gesetzlichen Entscheidungsermächtigung hält (begrifflich nicht genau BVerwGE 39, 205: "mehrere rechtmäßige Entscheidungen (sind) möglich"); hierauf ist jedoch jede konkret getroffene Entscheidung überprüfbar. Deshalb kommt es hier auf eine besonders sorgfältıge Begründung der Verwaltungsentscheidung an (dies betont zu Recht für Entscheidungen der Filmförderung VG Berlin, NJW 73, 1148 (1149 f.)).

Im metajuristischen Entscheidungsbereich soll das Verfahren der spezifisch kollegialen Sachverstandsumsetzung die möglichst sachgerechte („zweckrichtige") Entscheidung gewahrleisten. Hierin liegt der spezifisch kompensatorische Effekt. Ungeklärt ist jedoch noch die Frage, inwieweit die Einführung derartiger Verfahren und Organisationsformen ihrerseits auf deren Eignung kontrollierbar ist. Vgl. weiterhin die auch demokratiestaatlichen Bedenken von Papier, DVBl. 75, 463, die gleichfalls nicht ohne weiteres übergangen werden dürfen.

269) Nicht sachgerecht erscheint daher der Vorschlag im Zwischenbericht der Enquête-Kommission für Fragen der Verfassungsreform, das Widerspruchsverfahren in der Verwaltung einer Widerspruchsinstanz zu überantworten, die mit richterlicher Unabhängigkeit und (doch) voller Verwaltungskompetenz fur das beanstandete Verhalten Recht- und Zweckmaßßgkeit kontrollieren kann (vgl. BT-Drucks. VI/3829, S. 34). Denn hiermit wird kein Mehr an rechtlicher Verantwortung und kein höheres $\mathrm{MaB}$ an fachlicher Verantwortung erreicht. Im Gegenteil, das System verantwortlicher Verwaltungsorganisation wird in gerade verantwortungshindernder Weise relativiert. Das Prinzip der Unabhängigkeit hat hier nicht den spezıfısch legitimierenden Gehalt wie beim Gericht gemäB Art. 97 GG (zum legitimatorischen Gehalt richterlıcher Unabhängigkeit vgl. bes. Erchen- 
Im übrigen liegt die Verantwortung für den juristischen Rechtsschutz prinzipiell bei den Gerichten und ihren institutionellen, gegebenenfalls fortzuentwickelnden, d. h. nicht $\mathrm{zu}$ ersetzenden Verfahren spezifischer Rechtsverwirklichung. Zwischen gerichtlichem und verwaltungsmäßigem Rechtsschutz besteht kein Verhältnis gegenseitiger Substituierbarkeit und kein Verhältnis der Subsidiarität ${ }^{270}$ ). Der Rechtsschutz in der Verwaltung kann einzig unterstützende Funktionen im Vorfeld des gerichtlichen Rechtsschutzes übernehmen (Verhältnis der Supplementarität). Denn Verwaltungsrechtsschutz und Verwaltungsverantwortung stehen im Verfassungsstaat nebeneinander und bedingen einander gegenseitig. Ihr "Spannungsverhältnis muß" - um mit einem Worte Fritz Werners ${ }^{271}$ ) zu schließen, dessen Name über dem heutigen Thema gestanden haben könnte - "durchgestanden werden" und dieses Spannungsverhältnis wird sich stets als "fruchtbar" erweisen, „wenn es auf Seiten der Verwaltung nicht zu Ressentiments der unterlegenen Prozeßpartei und auf Seiten der Verwaltungsgerichte nicht zur richterlichen Hybris führt."

berger, Die richterliche Unabhängigkeit als staatsrechtliches Problem, 1960, S. 83 ff.).

270) $\mathrm{Zu}$ weitgehend insofern Schwarze, DVB1. 74, 901; ohne Aussagekraft insoweit BVerfGE 30, 1 (24f.) - vgl. richtig Ossenbühl, Gutachten 50. DJT, B 174.

271) Vgl, in: Recht und Gericht in unserer Zeit, S. 318. 
Leitsätze des Berichterstatters über:

\title{
Verwaltungsverantwortung und Verwaltungsgerichtsbarkeit
}

\author{
I.
}

1. Die Verwaltungsverantwortung umfaßt diejenigen Verantwortlichkeiten und Verfahren, Zuständigkeiten und spezifischen Handlungsspielräume, die das System der öfentlichen Verwaltung rechtlich und politisch verfassen.

2. Kernstück der Verwaltungsverantwortung ist der Verwaltungszweck. Funktionsmäßig ist das System der Verwaltungszwecke nicht geschlossen (Offenheit der Verwaltungszwecke); in der Methodik ist es multi- (und teilweise) interdisziplinär (Methodenvielfalt oder Pluralität der Verwaltungsdisziplinen).

3. Als - organisations- und verfahrensrechtlich prinzipiell offener - Entscheidungsproze $\beta$ hat das Verwaltungsverfahren den konkreten Verwaltungszweck zu verwirklichen.

Im Gegensatz zum verwaltungsgerichtlichen Verfahren dient das Verwaltungsverfahren primär der Konkretisierung von (juristisch wie metajuristisch bestimmten) Verwaltungszwecken und nur sekundär der Konkretisierung von (juristischen) Rechtszwecken.

4. Im Gegensatz zum verwaltungsgerichtlichen Verfahren hat das Verwaltungsverfahren nicht nur juristischen, sondern auch metajuristischen Richtigkeitsansprüchen zu genügen.

Im Bereich metajuristischer Richtigkeitsgewähr gilt der kompetenzielle Vorrang der Verwaltungsentscheidung; im Bereich juristischer Richtigkeitsgewähr gilt der kompetenzielle Vorrang der gerichtlichen Entscheidung.

II.

5. Die verfassungsrechtliche Rechtsschutzgarantie des Art. 19 IV GG gewährleistet im Verhältnis Bürger - Staat den effizienten Rechtsschutz. Das Verfassungsprinzip der Gewaltenteilung fordert im Verhältnis Verwaltungsgerichtsbarkeit - Verwaltung den kompetenzgerechten Rechtsschutz.

6. Verwaltungsrechtsschutz heißt grundsätzlich subjektivrechtliche (nur inzident objektiv-rechtliche), individuale (,punktuelle") und repressive Rechtsschutzgewähr. 
Der Verwaltungsrechtsschutz orientiert sich prinzipiell an den konkreten Entscheidungsformen der Verwaltung.

7. Das Prinzip des effizienten Verwaltungsrechtsschutzes fordert den flexiblen Rechtsschutz. Die Verwaltungsgerichtsbarkeit muß auf veränderte Wirkungsformen und Eingriffsmuster in der öffentlichen Verwaltung reagieren und die Typik ihrer Klagesysteme entsprechend offenhalten.

8. Das Prinzip des effizienten Verwaltungsrechtsschutzes fordert ebenso die Kontrolle makro- wie mikroadministrativer Verwaltungsentscheidungen; auch gestaltende, planende, "mittelbare“, "verwaltungsinterne" und „gruppenförmige“ (kollektive) „Eingriffe" der öffentlichen Verwaltung bedürfen der effektiven Gerichtskontrolle.

9. Kompetenziell wird der Verwaltungsrechtsschutz durch die eigene (politische) Zweckverantwortung der Verwaltung und den Maßstab allein juristischer (nicht auch metajuristischer) Verwaltungskontrolle beschränkt. Im Bereich (auch) metajuristischer, gestaltender und planender Verwaltungsentscheidungen etc. endet die (juristische) Kontrollkompetenz der Verwaltungsgerichtsbarkeit an der prinzipiell vorrangigen Zweckkompetenz der Verwaltung.

\section{III.}

10. Offentliche Verwaltung und Verwaltungsgerichtsbarkeit unterstehen dem Gesetz. Seinen Entscheid "vollenden" sie in konkretisierender Rechtsverwirklichung.

Konkretisierende Rechtsverwirklichung impliziert stets konkrete Rechtsetzung (konkretes „Richter“- und „VerwaltungsRecht").

11. Das Verfahren konkreter Rechtsetzung überlagert - verfassungsgerecht - das formale Schema von Normsetzung und Normvollzug.

Als Verfahren konkreter, die (partielle) Offenheit gesetzlicher Tatbestände (ermächtigungskonform) schließender Rechtsetzung stellen sich namentlich auch Verwaltungsentscheidungen mit Ermessens- oder sog. Beurteilungsspielraum dar.

12. Im Bereich eigener Verantwortung verfügt die öffentliche Verwaltung über legitimes Ermessen (vor allem bei Zuständigkeiten mit metajuristischem Zweckgehalt).

Legitimes Verwaltungsermessen erschöpft sich nicht im bloBen Rechtsfolgeermessen. Die öffentliche Verwaltung verfügt auch über Tatbestandsermessen - vornehmlich in der Zone gestaltungsrechtlicher Zuständigkeiten („Planungsermessen" etc.) sowie auch im Bereich unbestimmter Rechtsbegriffe („Be- 
urteilungsspielraum" als begrenztes Tatbestandsermessen). Daneben kennt die öffentliche Verwaltung das Recht zur prognostischen Entscheidung mit entsprechendem „Entwicklungsspielraum".

Dogmatisch ist eine einheitliche Ermessenskompetenz der öffentlichen Verwaltung anzuerkennen. Die Lehre vom „Beurteilungsspielraum" im Rahmen unbestimmter Gesetzesbegriffe sollte aufgegeben werden.

Das (einheitliche) Verwaltungsermessen gliedert sich in gradueller Abstufung in die Ermächtigungsformen von Rechtsfolge-, Tatbestands- und Gestaltungsermessen.

13. Die rechtsstaatliche Begrenzung des Verwaltungsermessens obliegt dem Gesetzgeber. Rechtsstaatswidrige Ermächtigungsdefizite sind deshalb weder durch Leugnung oder kompetenzwidrige Begrenzung legitimen Verwaltungsermessens noch - mittels zu weit vorgerückter Justiziabilitätsgrenzen durch die Verwaltungsgerichtsbarkeit zu kompensieren.

14. Namentlich im gestaltenden und ermessensrechtlichen Entscheidungsbereich verfügt die öffentliche Verwaltung über die (konkret-rechtsetzende) Kompetenz zur Aufstellung eigener Handlungsmaßstäbe. Die ermächtigungs-(gesetzes- und verfassungs-)konforme Ausübung dieser Maßstabskompetenz bindet auch die Verwaltungsgerichtsbarkeit; die verwaltungsgerichtliche Kontrolle maßstabsvollziehender Verwaltungsentscheidungen kann prinzipiell nur maßstabsimmanent erfolgen (Kontrolle verwaltungseigener Maßstabsgerechtigkeit).

IV.

15. Zentrales Strukturprinzip der Verwaltungsverantwortung ist die - empirisch wie normativ begründete - Vorstellung des zweck- und rechtskonkretisierenden Verfahrens. Sie kennzeichnet jede Form sowie jeden Inhalt verwaltungsmäßiger Verantwortung und bildet daher den prinzipalen Verfahrenswie Handlungsmaßstab der Verwaltung.

16. Die formal-verfahrensförmige Qualität dieses Handlungsmaßstabs ist materiell-rechtlich mit dem Auftrag der öffentlichen Verwaltung zur möglichst ermächtigungs-, sachverhaltsund individualgerechten - "maximalen" - Konkretisierung der aufgegebenen Verwaltungszwecke verbunden; sie aktualisiert diesen Auftrag im Wege der verfahrensrechtlichen Umsetzung.

17. Der verfahrensrechtliche Maßstab der „maximalen Konkretisierung" vermittelt die dogmatische Grundlage für den 
kompetenz- und effizienzgerechten Verwaltungsrechtsschutz (auch kontrollrechtliche Maßstabsqualität).

18. Kontrollrechtlich überprüft das Prinzip der „maximalen Konkretisierung" den gesamten Prozeß konkreter Verwaltungsentscheidung im Hinblick auf eventuelle Konkretisierungsdefizite.

Unter dem Aspekt des rechtzeitigen Verwaltungsrechtsschutzes ermöglicht das Prinzip der "maximalen Konkretisierung“ die Kontrolle kompletter (auch gestufter oder mehrphasiger) Entscheidungsprozesse bzw. deren dauerhaft begleitende Kontrolle.

Unter dem Aspekt des inhaltlich kompetenz- und effizienzgerechten Verwaltungsrechtsschutzes ermöglicht das Prinzip der "maximalen Konkretisierung" auch die wirksame Kontrolle metajuristischer, gestaltender (planender), prognostischer und (sonstig) ermessensmäßiger Verwaltungsentscheidungen.

19. Als objektiver Kontrollmaßstab vermittelt das Prinzip der "maximalen Konkretisierung" keine subjektiv-rechtlich geschützten (unmittelbar rechtsschutzfähigen) Rechtspositionen.

V.

20. Die Organisation der Verwaltungsgerichtsbarkeit und die Gestaltung ihrer Klagetypen unterstehen dem verfassungsrechtlichen Vorbehalt einer funktionsfähigen Eingriffswehr (Art. 19 IV GG).

21. Die funktionsfähige Eingriffswehr fordert die begriffliche Offnung des Verwaltungsakts; neben das Kriterium der (typischen) Einzel-(fall-)regelung muß das Kriterium der (typischen) Einzelrechtsfolge treten.

Die funktionsfähige Eingriffswehr fordert die allgemeine Einführung der prinzipalen Normenkontrolle i.S.d. \& 47 VwGO.

Die funktionsfähige Eingriffswehr fordert den adäquaten, d. $h$. den effizienz- und kompetenzgerechten Ausbau von vorbeugendem und vorläufigem Verwaltungsrechtsschutz.

22. Als Form prinzipiell individualer Eingriffswehr und subjektiv-rechtlicher Verwaltungskontrolle darf der Verwaltungsrechtsschutz auf die Systemfunktion des subjektiv-öffentlichen Rechts nicht verzichten; der Weg zum objektiv-rechtlichen oder allgemein popularklägerischen Verwaltungsrechtsschutz ist nicht eröffnet.

23. Die Begriffsfigur des subjektiv-öffentlichen Rechts ist in systemgerechter und rechtsschutzeffektvver Weise zu erwei- 
tern; die Kriterien der sog. Schutznormtheorie erweisen sich als zu eng.

Wo sich konkrete Rechtseingriffe häufig erst im' Rahmen objektiv-rechtlicher Gesetzesanwendung aktualisieren, dort mu $\beta$ das subjektiv-öffentliche Recht (auch) aus der Relation von subjektiver Rechtsfolge (Betroffenheit) und grundrechtlicher Eingriffskontrolle bestimmt werden.

Angesichts vielfältiger Kongruenzen von öffentlichem und privatem Interesse (nur relativer Gegensatz von öffentlichem und privatem Interesse) ist das subjektiv-öffentliche Recht aus dem einseitigen Begriffsbezug zur („bewußt-gewollten“) Begüstigung von privaten Interessen zu lösen. Auch das ein öffentliches Interesse inhaltstypisch repräsentierende Privatinteresse kann subjektiv-rechtlich legitimiert sein.

24. Der Forderung nach mehr kollektivem Verwaltungsrechtsschutz läßt sich mangels repräsentationsrechtlicher Legitimation von Verbänden etc. nur in Ausnahmefällen über die Anerkennung von Verbandsklagen oder sonstigen Kollektivklagen entsprechen.

Als Typus objektiver Beanstandungsklagen vermag die („altruistische ") Verbandsklage den individualen und subjektiven Verwaltungsrechtsschutz nicht zu substituieren.

Mehr systemkonforme Rechtsschutzeffektivität verspricht die individuale Klagebefugnis und deren Repräsentanz auch gruppentypischer Rechtsbeeinträchtigungen.

25. Ein kompensatorischer Rechtsschutz innerhalb der öffentlichen Verwaltung kann den gerichtlichen Verwaltungsrechtsschutz weder kompetenziell noch verfahrensmäßig ersetzen. Institute antezipatorischen Rechtsschutzes in der Verwaltung können nur supplementäre Funktionen im Vorfeld des gerichtlichen Verwaltungsrechtsschutzes übernehmen. 


\section{Verwaltungsverantwortung und Verwaltungsgerichtsbarkeit}

\section{Mitbericht von Professor Dr. Eberhard Schmidt-Aßmann,}

Bochum

Erster Abschnitt:

Inhalt

Seite

Komplexe Verwaltungsentscheidungen als Brennpunkte derzeitiger Verwaltungssituation und des Rechtsschutzauftrages (Bestandsaufnahme) . . . . . . . . . . . . . . . . . 222

I. Komplexe Verwaltungsentscheidungen: Strukturen und Genese . . . . . . . . . . . . . . . 223

II. Rechtsschutzprobleme komplexer Verwaltungsentscheidungen

Zweiter Abschnitt:

Verwaltungsverantwortung und verwaltungsrichterliche Verantwortung (verfassungsrechtlicher Standort, Wesensmerkmale, Beziehungen) . . . . . . . . . . . . . . . . . . . . . 227

I. Die Verantwortung der Zweiten Gewalt . . . . . . 229

1. Verwaltung als eigenständige Staatsgewalt . . . 229

2. Typologie zur Verwaltungsverantwortung . . . . 231

II. Die verwaltungsrichterliche Verantwortung , . 233

1. Das normative Denken des Verwaltungsrichters . . 234

2. Art. 19 Abs. 4 GG: Gerichtsschutz und polygonaler Rechtsschutz . . . . . . . . . . . . 234

3. Die Bezogenheit der Verwaltungsgerichtsbarkeit auf die Zweite Gewalt . . . . . . . . . . . . 237

4. Außergerichtlicher Rechtsschutz . . . . . . . . . 238

III. Aufgaben und Entscheidungssituation als Kriterium administrativ-richterlicher Verantwortungsverteilung . 239

Dritter Abschnitt:

Konkrete Zuordnungsprobleme . . . . . . . . . . . . . . 239

A. Kontrollzugänglichkeit und Kontrollverfahren . . . 239

I. Rechtsform und Rechtsschutzform . . . . . . . . 239

1. Prinzipale Normenkontrolle, $\$ 47$ VwGO . . . . 240

2. Rechtsschutz gegen Einzelakte . . . . . . . . 243

II. Individualrechtsschutz und andere Rechtsschutzverfahren 245

1. subjektives öffentliches Recht . . . . . . . . . 245

2. Massenverfahren .. . . . . . . . . . . 248

3. Verbandsklagen, Körperschaftsklagen . . . . . 250

B. Intensität verwaltungsgerichtlicher Kontrolltätigkeit (Ermes-

sen und Beurteilungsspielraum) . . . . . . . . . . 251

I. Programmbegriffe als Abwägungsdirektiven . . . . 254

II. Kontrolle des Abwägungsvorgangs und des Abwägungsergebnisses 
Seite

C. Sicherung und Begrenzung der Urteilswirkungen . . . . 259

I. Die Sicherung rechtzeitigen Rechtsschutzes . . . . . 259

II. Urteilswirkungen und administrative Folgenverantwortung ................. . . 261

1. Urteilsbegrenzende Folgenverantwortung (Kapazitätsprobleme) . . . . . . . . . . . . . 261

2. Urteilsergänzende Folgenverantwortung (Entschädigungsausgleich) ............... 263

Vierter Abschnitt:

Komplementäre Rechtsschutzeinrichtungen und Ånderungen der Gerichtsorganisation . . . . . . . . . . . . . . . . 264

I. Die Komplementärfunktion des Verwaltungsverfahrens 265

II. Anderungen der Gerichtsorganisation (Sachverständigenproblem) ............... 267

Erster Abschnitt: Komplexe Verwaltungsentscheidungen als Brennpunkte derzeitiger Verwaltungssituation und des Rechtsschutzauftrages (Bestandsaufnahme)

Die Berichterstattung zum Verwaltungsrechtsschutz, mit der unsere Vereinigung seit ihrer Jenaer Tagung über 50 Jahre hin die Verwaltungsgerichtsbarkeit begleitet hat ${ }^{1}$ ), kann heute mit der Feststellung fortgeführt werden, daß die Verwaltungsgerichte auf das Ganze gesehen ihren Standort im Spannungsfeld zwischen Bürger und Verwaltung gefunden haben²). Die

1) Referate von Walter Jellinek und Gerhard Lassar zum Thema: Der Schutz des öffentlichen Rechts durch ordentliche und durch Verwaltungsgerichte, VVDStRL 2 (1925), 9 ff., 81 ff.; ferner Erich Becker und Helmut Rumpf, Verwaltung und Verwaltungsrechtsprechung, VVDStRL 14 (1955), 96 ff., 136 ff. Rechtsschutzfragen jeweils themenbezogen sind auf nahezu jeder Tagung der Vereinigung besprochen worden.

2) Menger, Rechtsschutz im Bereich der Verwaltung, DOV 1969, $153 \mathrm{ff}$; K. Meyer, Betrachtungen über die Verwaltung aus der Sicht der Rechtsprechung, DOV 1969, 102 ff.; $K$. Zeidler, Einige Bemerkungen zum Verwaltungsrecht und zur Verwaltung in der Bundesrepublik seit dem Grundgesetz, Staat 1 (1962), 321 ff., 326. Blümel, Planung und Verwaltungsgerichtsbarkeit, DVBl. 1975, 696, spricht davon, $\mathrm{da} B$ sich „das Pendel zwischen Verwaltung und Verwaltungsgerichtsbarkeit im allgemeinen auf eine vernunftige Mittellage" eingestellt habe. Für die Eingriffsverwaltung konnte Becker, VVDStRL 14, $96 \mathrm{ff}$., 99, schon $1955 \AA$ Annliches feststellen. Inzwischen darf das positive Urteil auf die seinerzeit noch wenig entwickelte Rechtsprechung zur Leistungsverwaltung ausgedehnt werden. Heute hat sich das Interesse den gleichermaßen hinter der Eingriffs- wie der Leistungsverwaltung stehenden administrativen Gestaltungs- und Verteilungsentscheidungen zuzuwenden. 
Phase des Ausbaus einer umfassenden gerichtlichen Verwaltungsrechtspflege mit ihren koordinatensetzenden Entscheidungen liegt hinter uns. Auf insgesamt gesicherter Basis gewähren die Gerichte dem Bürger Schutz, ohne daß es zu der früher befürchteten Lähmung der Administration gekommen wäre ${ }^{3}$ ). Von einer akuten Krise der Verwaltungsgerichtsbarkeit kann nicht die Rede sein!

\section{Komplexe Verwaltungsentscheidungen: Strukturen und Genese}

Es sind in den letzten Jahren allerdings zunehmend Urteile eines Typs ergangen, der fern aller punktuellen Kritik die Frage nach wirkungsvollem Rechtsschutz und nach angemessener Verantwortungsaufteilung zwischen Justiz und Verwaltung erneut aufgeworfen und gewisse Symptome struktureller Mängel im Verhältnis der Zweiten zur Dritten Gewalt freigelegt hat. Hierher gehören die Industrieansiedlungs- und Straßenbaufälle ebenso wie Urteile zu Raumordnungsverfahren, zur Wirtschaftsförderung, zur Verteilung von Hochschulkapazitäten und zu staatlichen Organisationsakten.

3) Es geht uns hier um ein Gesamturteil. Nicht übersehen werden sollen kritische Punkte in einzelnen Rechtsprechungsgebieten, z. B. die Zersplitterung der Judikatur zum Erschließungsbeitragsrecht, vgl. Thierfelder, Einige Grundprobleme der Verwaltungsgerichtsbarkeit, DOV 1967, 900 ff. Nicht übersehen werden soll ferner die Verbesserungsbedürftigkeit einer Reihe prozeßrechtlicher Vorschriften; dazu Maetzel, Zehn Jahre Verwaltungsgerichtsordnung, DOV 1970, $28 \mathrm{ff}$., der aber die VwGO insgesamt als "bewährt" bezeichnet (S. 33). Nicht übersehen werden sollen die von der „Krisenliteratur" der sechziger Jahre herausgestellten Gravamina: das InstanzenübermaB, die Rechtswegzersplitterung und die Dauer der Prozesse. Dazu Ehrig, Die Krise der Verwaltungsgerichtsbarkeit, NJW 1959, 217 ff. und NJW 1961, 196 ff.; G. Brunner, Kontrolle in Deutschland, 1972, 283 ff. m. w. Nachw. Fn 522 ff. Auf das Ganze gesehen aber hat die Behutsamkeit der Verwaltungsrechtsprechung die in Art. 19 Abs. 4 GG angelegten Gefahren extremer Justizstaatlichkeit gebannt, so daß es selbst in Zeiten großer Kontrollfreudigkeit, wie sie am zeitweisen Abbau des administrativen Ermessens und Beurteilungsspielraums ablesbar sind (vgl. Ossenbïhl, Tendenzen und Gefahren der neueren Ermessenslehre, DOV 1968, 618 ff.), zu nachhaltigen Verletzungen des verwaltungseigenen Verantwortungsbereichs nicht gekommen ist; W. Weber, VVDStRL 14, 193 (Diskussionsbeitrag); Ule, Gerichtliche Kontrolle in: Verwaltung (hrsg. v. Morstein-Marx), 1965, 433 ff., 451-454; Häberle, Offentliches Interesse als juristisches Problem, 1970, $691 \mathrm{ff}$; ferner die Vorträge und Diskussionsbeiträge der 38. Staatswissenschaftlichen Fortbildungstagung der Hochschule fur Verwaltungswissenschaften Speyer: Zehn Jahre Verwaltungsgerichtsordnung - Bewährung und Reform, 1970. Kritischer dagegen Scharpf, Die politischen Kosten des Rechtsstaates, 1970 bes. 38 ff. 
Gemeinsam ist allen diesen Urteilen ihr Bezug auf hochkomplexe Verwaltungsvorgänge: Das gilt einmal für den vom Gericht beurteilten engeren Sachverhalt, den Begriffe und Daten außerjuristischer Wissenschaften besetzt halten und komplizierte technische Prognosen unüberschaubar machen. Komplex vor allem aber ist der weitere Sachverhalt, von dem der eigentliche Prozeßstoff nur einen Ausschnitt, gleichsam die Spitze des Eisbergs, bildet. Vorentscheidungen, flankierende Maßnahmen, Richtzahlen und Rahmenprogramme erweisen sich als ein engmaschiges Netz, in das der engere Sachverhalt eingespannt ist und das in einzelnen Punkten nicht aufgeknotet werden kann, ohne weitläufige Folgewirkungen zu bedenken. Der verwickelten materiellen Fallstruktur entspricht die Vielzahl der Beteiligten: Nicht einzelne Adressaten mit gleichgerichteten oder schlicht gegenläufigen - jedenfalls aber überschaubaren - Interessen, sondern Gruppen privater Beteiligter mit vielfach verschränkten Belangen sind hier betroffen, und dieser Breitenwirkung korrespondiert auf Seiten der Verwaltung eine Tiefenwirkung, die hinter der letztentscheidenden Behörde andere Verwaltungsträger sichtbar macht und so Verwaltungsorganisation und Verwaltungsinnenbereich in den Blick rückt.

Vorgänge solcher Art werden die Gerichte künftig in steigendem Maße beschäftigen; denn sie erweisen sich als die Brennpunkte der derzeitigen Verwaltungssituation überhaupt. Diese Situation wird gekennzeichnet durch eine stärkere Berücksichtigung der Interdependenzen allen Verwaltungshandelns - eine Veränderung gegenüber früherem Vorrang punktuellen Entscheidens ${ }^{4}$ ), die die einzelnen Eingriffs- und Leistungsvorgänge bereichsweise in größere Zusammenhänge stellt: Ausdruck administrativer Gestaltungs- und Verteilungsaufgaben.

4) W. Weber, Planende Verwaltung als Aufgabe der Gegenwart, Forschungs- und Sitzungsberichte der Akademie für Raumforschung und Landesplanung, Bd. 78, 1972, 9 ff.; Brohm, Die Dogmatik des Verwaltungsrechts vor den Gegenwartsaufgaben der Verwaltung, VVDStRL 30, $245 \mathrm{ff}$., bes. $258 \mathrm{ff}$.; Ipsen, Verwaltung durch Subventionen, VVDStRL 25, 257 ff., 264 ff.; Ossenbühl, Welche normativen Anforderungen stellt der Verfassungsgrundsatz des demokratischen Rechtsstaates an die planende staatliche Tätigkeit, dargestellt am Beispiel der Entwicklungsplanung?, Gutachten für den 50. DJT, Bd. 1 (Gutachten) 1974, Teil B, 25 ff.; Scheuner, Zur Entwicklung der politischen Planung in der Bundesrepublik Deutschland, in: Festschrift für W. Weber, 1974, 369 If.; Schmidt-Aßmann, Planung unter dem Grundgesetz, DOV 1974, 541 ff. 
Bewirkt ist diese Veränderung primär durch eine Verknappung der Verwaltungsmittel, die die faktischen Grenzen des Verwaltens spürbar macht und Raum, Zeit, Finanzen und Personal in ein System kommunizierender Röhren gebracht hat ${ }^{5}$ ). Bewirkt ist sie zweitens durch eine stärkere Verwissenschaftlichung des praktischen Verwaltungshandelns $\left.s^{6}\right)$. Bewußt wird sie schließlich durch einen Rückstand der Verfassungsentwicklung, die die immer deutlicher hervortretende planende Staatstätigkeit bisher nicht angemessen zwischen Parlament und Exekutive aufteilt ${ }^{7}$ ). So bleibt die Zweite Gewalt einstweilen belastet mit ausgreifenden Entscheidungen, die komplex eben auch deshalb erscheinen, weil die entflechtende Wirkung parlamentarischer Leitlinien $\mathrm{zu}$ gering ist.

\section{Rechtsschutzprobleme komplexer Verwaltungsentscheidun- gen}

Die den komplexen Verwaltungsentscheidungen anhaftende Unüberschaubarkeit hat unter den Schlagworten vom „Rechtsstaats- und administrativen Legitimationsdefizit" den Ruf nach dem Richter verstärkt $\left.{ }^{8}\right)$. Die Verwaltungsgerichte sehen sich so Kontrollaufgaben gegenüber, die die Routine, die Ausstattung, vor allem aber die mit dem einzelnen Prozeß gegebenen Erkenntnis- und Steuerungsmöglichkeiten weit überschreiten. Die Schwierigkeiten lassen sich mit fünf Punkten umreißen:

5) Joseph H. Kaiser: „Planung als Tochter der Krise“ in Planung III (hrsg. von Joseph H. Kaiser), 1968, 7; Forsthoff, Der Staat der Industriegesellschaft, 1971 bes. $30 \mathrm{ff}$; Dürig, VVDStRL 30, 291 (Diskussionsbeitrag) zur Verwaltung des Mangels.

6) Brohm, VVDStRL 30, $258 \mathrm{f}$.

7) Zusammenfassend Ossenbüh, DJT-Gutachten (Fn 4), $56 \mathrm{ff}$.

9) Görlitz, Verwaltungsgerichtsbarkeit in Deutschland, 1970, 260 ff.; Rehbinder-Burgbacher-Knieper, Bürgerklage im Umweltrecht, 1972, pass.; Wälde, Recht und Umweltschutz, AöR 99 (1974), 585 ff., 624 ff.; Schmidt-Salzer, DVBl. 1972, 391 f. (Urteilsanmerkung); Blïmel, DVBl. 1975, 695 ff. Referierend ferner: Schmitt Glaeser, Partizipation an Verwaltungsentscheidungen, VVDStRL 31 (1972), 179 ff.; 204-207, der jedoch zutreffend die Grenzen der Justiz gegenüber der gestaltenden Verwaltung betont, bes. S. 244 ("Gerichtskontrolle als ultima ratio"); W. Schmıdt, Organisierte Einwirkungen auf die Verwaltung, VVDStRL 33 (1974), 183 ff., 205 f. mit Kritik der "Defizit"-Lehren in Anm. 68. Roters, Kommunale Mitwirkung an höherstufigen Entscheidungsprozessen, 1975, 77. Hierherzurechnen sind auch die vielen Neugliederungsprozesse, von denen die meisten allerdings wegen der Gesetzesform der Neugliederungsmaßnahmen vor den Verfassungsgerichtshöfen der Länder ablaufen. $\mathrm{Zu}$ Versuchen, im Rahmen solcher Prozesse dem Richter immer wieder eine möglichst weitreichende Überprüfung der Neugliederungsentscheidung anzuempfehlen, vgl. Hoppe-Rengeling, Rechtsschutz bei der kommunalen Gebietsreform, 1973. 
(1) Als Ausdruck gestaltender Verwaltung basieren komplexe Entscheidungen regelmäßig auf nur grobmaschig vorgeformten gesetzlichen Grundlagen, deren Weitläufigkeit durch die Dynamik der Vorgänge noch gesteigert wird, weil die Statik juristischer Begriffsbildung und die filternde Wirkung der Rechtssprache ${ }^{\theta}$ ) verloren gehen.

(2) Der Rechtsschutz setzt gegenüber den sich fortlaufend entwickelnden Verwaltungsvorgängen zu spät ein, weil Gericht und Verwaltung nicht mehr nur phasenverschoben, sondern phasenverzerrt arbeiten ${ }^{10}$ ) (Probleme der zeitlichen Dimension).

(3) Die von Verteilungsentscheidungen betroffenen privaten Interessen divergieren schon unter sich so $\operatorname{sehr}^{11}$ ), daß sie in den Formen einfachen zweipoligen Prozeßrechts, gebildet etwa nach einem ,in dubio pro civi“"12), nicht angemessen verfaßt werden (Probleme polygonalen Rechtsschutzes).

(4) In den Verflechtungen begegnen sich die Institute des klassischen "Außenrechts" mit Rechtsakten und Organisationsformen des Verwaltungsinnenbereichs. Gerichtsschutz verlangt hier, den Vordergrund der Eingriffs- und Leistungsverwaltung zu durchschreiten, den dahinterliegenden, die Verflechtungen

9) Zur Bedeutung der Rechtssprache Hans Huber, Niedergang des Rechts und Krise des Rechtsstaats, Festgabe für Giacometti, 1953, 59 ff., 79 ff.; $F$. Werner, Verwaltungsrecht als konkretisiertes Verfassungsrecht (1959), in: $F$. Werner, Recht und Gericht in unserer Zeit, 1971, 212 ff., $214 \mathrm{f}$.

10) Grundlegend Blümel, Raumplanung, vollendete Tatsachen und Rechtsschutz, Festgabe für Forsthoff (1967), 133 ff., ders., DVBl. 1975, 695 ff.; zur Diskrepanz von Sachgehalt und Rechtsgehalt vorzüglich Wahl, Der Regelungshaushalt von Teilentscheidungen in mehrstufigen Planungsverfahren, DOV 1975, $373 \mathrm{ff} ., 376 \mathrm{f}$.

11) Die Auseinandersetzungen, die sich in der Offentlichkeit mittlerweile um jeden größeren Anlagenbau abspielen, zeigen diese Divergenzen recht deutlich: da streiten Umweltschützer gegen Bauherren, betroffene Nachbarn gegen verkaufswillige Eigentümer, Arbeitnehmer, denen es um nahe und gesicherte Arbeitsplätze geht, gegen Rentner, Betroffene alternativer Standorte untereinander. Dazu Knopfle, Organisierte Einwirkungen auf die Verwaltung, DVBl. 1974, 709 ff., 714. Zu den Divergenzen privater Interessen bei städtebaulichen Sanierungen z. B. Herlyn-Schaufelberger, Innenstadt und Erneuerung, 1971.

12) Falle solcher in-dubio-Rechtsprechung: zur Rechtsform und Rechtsschutzform (BVerwGE 18, 154 ff.); zur fraglichen öffentlichrechtlichen Natur einer Maßnahme (BVerwG, DOV 1961, 148); zu Mißverständlichkeiten von Erklärungen (BVerwG, DOV 1972, 759 f.; BVerwG Bucholz $238.90 \mathrm{Nr}$. 47); zur Auslegung des $\$ 80$ Abs. 6 VwGO (BVerfGE 35, 263 ff.), dazu Lichtenberg, Der Grundsatz der Waffengleichheit auf dem Gebiet des Verwaltungsprozeßrechts, Diss. Múnster, 1974, $58 \mathrm{ff}$. 
konstituierenden Innenbereich $\mathrm{zu}$ erfassen ${ }^{13}$ ) und die Verbindungsstücke zwischen beiden Sphären ${ }^{14}$ ) dogmatisch zu durchdringen (Gerichtsschutz im makroadministrativen ${ }^{15}$ ) Bereich).

(5) Die Verflechtungen des Sachverhalts steigern die Urteilswirkungen in einem vom einzelnen Prozeß her kaum überschaubaren, geschweige denn steuerbaren Ausmaß. Wird durch diese Potenzierung ein ganzes Verwaltungsprogramm von einem gesetzlich nicht sicher unterfangenen Urteil gefährdet, so erscheinen Konflikte zwischen Zweiter und Dritter Gewalt künftig nicht ausgeschlossen (Problem der Steuerbarkeit).

Utbertragen auf das Prozeßrecht werden diese fünf Punkte Utberlegungen erfordern

- zu den Rechtsschutzformen (Normenkontrolle, Verwaltungsakt, Anfechtungslast und Präklusion)

- zum gerichtlichen Verfahren (Klagebefugnis, Beiladung, Massenverfahren, Sachverständige)

- zur Kontrolldichte (Ermessensüberprüfung, administrative Definitions- und Beurteilungsspielräume, Evidenzvorbehalt)

- zu den Kontrollergebnissen (Kapazitätsverteilung und Prioritätensetzung, Sicherung rechtzeitigen Gerichtsschutzes, komplementärer Rechtsschutz durch Verwaltungsverfahren).

Zweiter Abschnitt: Verwaltungsverantwortung und verwaltungsrichterliche Verantwortung - verfassungsrechtlicher Standort, Wesensmerkmale, Beziehungen

Diese Fragen führen dazu, das Verhältnis der Zweiten zur Dritten Gewalt von ihren jeweiligen Verantwortungsbereichen her zu überdenken. Verantwortung wird dabei dem allgemeinen Wortsinne folgend ${ }^{16}$ ) als Begriff verstanden, der sich zu-

13) Zur Notwendigkeit einer Beschäftigung mit dem Organisationsrecht Bachof, Die Dogmatik des Verwaltungsrechts vor den Gegenwartsaufgaben der Verwaltung, VVDStRL 30, 193 ff., 233 f.; Rupp, Grundfragen der heutigen Verwaltungsrechtslehre, 1965, $19 \mathrm{ff}$.

14) Z. B. Raumordnungsklauseln ( $\$ 1$ Abs. 3 BBauG), Ableitungsklauseln (\$ 8 Abs. 2 S. 1 BBauG) mit dem Begriff des „Entwickelns", dazu jüngst BVerwG, Urt. vom 28. 2. $1975=$ BauR 1975, $257 \mathrm{ff}$.

15) Begriff bei Bullinger, Ermessen und Beurteilungsspielraum, NJW 1974, 769 ff., 771.

16) Dazu mit zahlreichen Varianten der Formulierungen Hauschildt, "Verantwortung", in: Handwörterbuch der Organisation (hrsg. von Grochla), 1969, Sp. 1693; Beck, „Verantwortung“, in: Lexikon der Pädagogik, Bd. 4, 1971, 283; Ryffel, Eigenverantwortlichkeit, in: Verwaltung (hrsg. von Morstein-Marx), 1965, $456 \mathrm{ff}$.; grundlegend Weischedel, Das Wesen der Verantwortung, 1933. 
sammensetzt aus den Elementen der Aufgabe, der Eigenständigkeit und der Einstandspflicht im Sinne einer Kontroll- und Steuerungsabhängigkeit. In diesem Sinne etwa benutzt ihn das Grundgesetz in Art. 28 Abs. 2 und Art. 65 ${ }^{17}$ ), ohne ihm einen definitorisch exakten Inhalt zuzuweisen ${ }^{18}$ ). Verantwortung ist kein normativer Begriff, sondern kennzeichnet ein differenziertes Ausgleichssystem, in dem sich Rechtssätze, Sachgesetzlichkeiten und Institutionen mit ihrem Selbstverständnis begegnen: ein heuristischer Begriff also. Auf Verfassungsebene ist er überall dort angesiedelt, wo es um die Zuordnung von Gewalten geht, mit Vorrang bei den Maximen föderaler Ordnung und einem als Leitsatz funktionsgerechter Organisation ${ }^{10}$ ) verstan-

17) $K$. Kröger, Die Ministerverantwortlichkeit in der Verfassungsordnung der Bundesrepublik Deutschland, 1972, S. 4: „Ohne Aufgabe und Befugnis kennt die freiheitlich-rechtsstaatliche Ordnung keine Verantwortung, wie sie umgekehrt ohne Verantwortlichkeit keine Kompetenz und Befugnis duldet". $K$. unterscheidet dann die Rechenschafts- und die Prästationspflicht als Teilinhalte der Ministerverantwortlichkeit (S. $17 \mathrm{ff}$.). Beide setzen prinzipielle Eigenstandigkeit" voraus (S. 18, $22 \mathrm{ff}$.). Die Einstandspflicht knüpft „eng an die Rechenschaftspflicht" an. Sie bedeutet, daß man sich "Versäumnisse, Fehler und Mißerfolge als eigenes politisches Versagen anrechnen lassen" muB, was unvermeidlich eine "politische Vertrauenseinbuße" bedeutet (S. 23). Die unter rechtsdogmatischen Gesichtspunkten auffällige Unbestimmtheit dieser Formulierungen nimmt Rucksicht auf die Flexibilitat und Sensibilitat der Zentralbegriffe der Verfassungsordnung die eben primär gelebte, und erst sekundär geschriebene Verfassung wiederzugeben haben. Letzter Gesichtspunkt besonders deutlich bei Scheuner, Verantwortung und Kontrolle in der demokratischen Verfassungsordnung, in: Festschrift für Gebhard Müller, 1970, 379 ff. Folglich sucht man auch in den Kommentierungen zu Art. 65 GG vergeblich nach einer zusammenfassenden Definition der Verantwortung. Ahnlich steht es mit den Erläuterungen zu Art. 28 Abs. 2 GG. Das im Begriff der Verantwortung angelegte Spannungsverhältnis von Aufgabe, Eigenständigkeit und Bindung wird deutlich am ehesten in der Umschreibung, die Becker, Kommunale Selbstverwaltung, in: Bettermann-Nipperdey, Die Grundrechte Bd. IV 2. Halbband, 1962, 673 ff., 718 f. gibt: „Die Eigenverantwortlichkeit ist das Kernstück der kommunalen Selbstverwaltung. Sit erstreckt sich auf die Entschlußfreiheit der kommunalen Gemeinwesen, die Aufgaben, die zur Verbandskompetenz gehören, ohne Weisung und Vormundschaft des Staates so zu erfüllen, wie dies nach Maßgabe der Rechtsordnung zweckmäßig erscheint." Ebenso Stern, Bonner Kommentar, Art. 28 Rdnr. 94. Zum gleichen Aspekt allgemein Schmitt Glaeser, VVDStRL 31 (1972), 244.

1v) D. Wilke, Uber Verwaltungsverantwortung, DOV 1975, $509 \mathrm{ff}$., 511: „Verantwortung oder Verantwortlichkeit stellt kein festgefügtes Rechtsinstitut oder auch nur einen halbwegs klaren Begriffskomplex dar." Dort Nachw. zur Verwendung des Begriffs in der Gesetzes- und Verwaltungssprache; zur heuristischen Funktion dort 514.

19) Hesse, Grundzüge des Verfassungsrechts der Bundesrepublik Deutschland, 8. Aufl., 1975, 194 ff.; Achierberg, Probleme der Funk- 
denem Gewaltenteilungsschema und verdeutlicht hier Befugnisse, Bindungen und Entlastungen $\left.{ }^{20}\right)$. Als einen Zentralbegriff des letzteren, des Gewaltenteilungsschemas, haben wir Verantwortung in der vom Thema vorgegebenen Relation $\mathrm{zu}$ verstehen, als externe Verantwortung, als Beziehung zu den anderen Gewalten und zum Träger der Staatsgewalt selbst.

\section{Die Verantwortung der Zweiten Gewalt}

1. Verwaltung als eigenständige Staatsgewalt

Verwaltungsverantwortung ist verfassungsrechtlich gegrundet in der Position der Zweiten Gewalt als einer eigenständigen Staatsgewalt, wie sie das Grundgesetz in Art. 20 Abs. 2, 91 a, 109, und für den wichtigsten Teilbereich der kommunalen Verwaltung in Art. 28 Abs. 2 konstituiert'12). Verwaltung als System zur tagtäglichen Verwirklichung der sozialrechtsstaatlichen Verfassung, als "Arbeit" und Leistung, an der sie als Institution wiederum gemessen wird und von der sie eine starke institutionelle Legitimation ${ }^{22}$ ) empfängt.

tionenlehre, 1970; Böckenförde, Verfassungsfragen der Richterwahl, $1974,86 \mathrm{f}$.

20) Zur Entlastungsfunktion der Verantwortung Luhmann, Funktionen und Folgen formaler Organisation, 1964, $172 \mathrm{ff}$.

21) H. Peters, Die Verwaltung als eigenständige Staatsgewalt, 1965; Bullinger, Vertrag und Verwaltungsakt, 1962, 93 f.; Badura, Auftrag und Grenzen der Verwaltung im sozialen Rechtsstaat, DOV 1968, 446 ff., 452; Vogel, Gesetzgeber und Verwaltung, VVDStRL 24, 125 ff., bes. 156 ff.; Herzog, Gesetzgeber und Verwaltung, dort S. $193 \mathrm{ff}$., bes. 191 f.; Kaufmann, dort 219 (Diskussionsbeitrag); Ipsen, dort 222 (Diskussionsbeitrag); Ossenbühl, Verwaltungsvorschriften und Grundgesetz, 1968, 187 ff.; W. Weber, Planende Verwaltung als Aufgabe der Gegenwart, (Fn 4), 9 ff.; Kopp, Verfassungsrecht und Verwaltungsverfahrensrecht, 1971, 234; Oettle, Grenzen der Gerichtsbarkeit im sozialen Rechtsstaat, 1871, $65 \mathrm{ff}$.; W. Schmidt, VVDStRL 33, 195 mit Anm. 36; Bartlsperger, Organisierte Einwirkungen auf die Verwaltung, VVDStRL 33, 221 ff., 246 ff.; Böckenförde, dort 297 ff. (Diskussionsbeitrag); Bachof, dort 312 ff., 315 (Diskussionsbeitrag); Wimmer, Der juristische und der verwaltungswissenschaftliche Verwaltungsbegriff, Verwaltung 1975, 141 ff. Speziell zur kommunalen Verwaltung Stern, Bonner Kommentar Art. 28 Rdnr. 98.

22) Zur institutionellen Legitimation Ossenbühl, Verwaltungsvorschriften (Fn 22), $196 \mathrm{ff}$. Es ist zwar richtig, daB die Gemeinwohlverantwortung der öffentlichen Verwaltung die administrative Legitimation noch nicht hinreichend vermittelt (Böckenförde, VVDStRL 33, 299), doch ist gerade für die leistende, vorausplanende und spontane Verwaltungstätigkeit Effektivität ein wesentliches Element dafür, wie Verwaitung vom Bürger „angenommen“ wird. Dazu etwa Laux, Kommunale Selbstverwaltung im Staat der siebziger Jahre, AfK 1970, 217 ff., 226 f.; W. Weber, Planende Verwal- 
Verwaltungsverantwortung ist wirksam nicht nur in den Hauptzügen der Staats- und Kommunalverwaltung, sondern ebenso in der wirtschaftlichen, kulturellen und sozialen Selbstverwaltung, in den Ausschüssen und Sachverständigengremien, in den Verschränkungen föderaler und instantieller Art. Wie dieses Gefüge für die Verwaltung neben der parlamentsabgeleiteten zahlreiche zusätzliche Legitimationsquellen erschließen kann $^{23}$ ), so gliedert es Verantwortung in ihren Bezügen zu den umgebenden Funktionsträgern, aber auch nach innen hin dergestalt auf, daß der externen Verantwortung innewohnende Geltungsanspruch von der internen Verantwortungserfüllung24) vielfältı mitbestimmt wird.

Am deutlichsten sichtbar werden die Arten der Verwaltungsverantwortung im Spiegel des Gesetzes. Vierfach prägt das Gesetz das Verwaltungshandeln ${ }^{25}$ ): als Organisations- und Verfahrensregelung, als Rahmen, als Richtpunkt und materielle Leitlinie und schließlich als Eingriffsermächtigung. In ihren Steuerungwirkungen sind diese Aufgaben des Gesetzes wenigstens teilweise wechselseitig substituierbar $\left.{ }^{26}\right)$. Gesetzesfreie

tung (Fn 4), 12. Wichtig z. B. fúr den Gebietszuschnitt der kommunalen Selbstverwaltungskörperschaften ( $\$ 5$ GemeindeO/NW). Allgemein zu Leistung und Effizienz Häberle, Grundrechte im Leistungsstaat, VVDStRL 30, 43 ff., 53 ff.; ders., Effizienz und Verfassung, AöR 98 (1973), 625 ff. als Besprechung von Leisner, Effizienz als Rechtsprinzip, 1971.

23) W. Weber, Staats- und Selbstverwaltung in der Gegenwart, 2. Aufl., 1967, bes. 142 ff. mit velfaltigen Differenzierungen, wie sie allein der historischen Entwicklung, den Aufgaben und Verfassungsbezugen der genannten Institution entsprechen und wie sie auch hier der Textausgabe zugrunde gelegt sein sollen. Brohm, Strukturen der Wirtschaftsverwaltung, 1969, 243 ff.; ders., VVDStRL 30, 1971, 245 ff., 269 f.; BVerfGE 33, 125 ff., bes. 156-158 (Verleihung von Satzungsautonomie, um bestımmten gesellschaftlichen Gruppen die Regelung der sie betreffenden Angelegenheiten „eigenverantwortlich" zu überlassen, dazu Häberle, "Berufsständische" Selbstverwaltung und staatliche Gesetzgebung, DVBI. 1972, 909 ff. Zur sozialen Selbstverwaltung Henke, Die Rechtsformen der sozialen Sicherung und das allgemeine Verwaltungsrecht, VVDStRL 28, 149 ff., 163-172. Ablehnend hinsichtlich der Legitimation durch ein „Verbandsvolk" Schmitt Glaeser, VVDStRL 31, $217 \mathrm{f}$.

24) Bis hin zur innerbehordlichen Verantwortung; dazu Beispiele aus der Gesetzespraxis bei Wilke, DOV 1975, $509 \mathrm{ff}$.

$\left.{ }^{25}\right)$ Grundlegend Scheuner, Das Gesetz als Auftrag der Verwaltung, DOV 1969, $585 \mathrm{ff}$; instruktiv die Typologie der Leistungsgesetze bei Háberle, VVDStRL $30,43 \mathrm{ff} ., 49 \mathrm{ff}$.

${ }^{26)}$ Besonders die Richtlinien materiellen Verwaltens, die die Haushaltsordnungen des Bundes und der Lander heute geben, mussen wegen der Schlusselposition des Fınanzwesens hier stärker einbezogen werden, als das bisher geschehen ist: dazu die Aussagen 
Räume kennt die heutige Verwaltung nicht mehr, sondern nur unterschiedliche Dichtegrade, inwieweit ihr Handeln gesetzlich vorgezeichnet ist ${ }^{27}$ ): gesetzesdirigierte Verwaltung ${ }^{28}$ ). Darunter möchten wir ein der heutigen Verwaltung durchgängig zukommendes Attribut verstehen.

Administratives Handeln kann soweit gesetzlich vorgezeichnet sein, daß alle anderen Aspekte in der Norm bereits mit eingeschlossen sind, die Entscheidung demnach mittels rechtswissenschaftlichen Verfahrens aus dem Gesetz zu gewinnen ist. Die Ubergänge zu lockeren Formen gesetzlicher Vorzeichnung sind gleitend ${ }^{29}$ ). Spätestens in den Höhenlagen verdünnter gesetzlicher Luft, dort wo die gestaltende Verwaltung angesiedelt ist, treten Uberlegungen ökonomischer, sozialer und organisatorischer Art als eigenständige hervor, mit gesetzlichen Linien und Richtpunkten verflochten zwar, nicht aber absorbiert. Diese Vielfalt der Zwecke und Aspekte prägt das normative Denken der Verwaltung ebenso wie sie es transzendiert - auch insoweit aber abgesichert durch die verfassungsrechtliche Einsetzung der Verwaltung zu umfassender Aufgabenerfüllung.

2. Typologie zur Verwaltungsverantwortung

Eine aufgabenbezogene Typologie der Verwaltungsverantwortung ${ }^{30}$ ) nimmt diese Vielfalt der Zwecke und Bedingungen auf:

des HaushaltsgrundsätzG vom 19. 8. 1969 (BGBl. I, S. 1273), z. B. § 6 Abs. 1 (Grundsätze der Wirtschaftlichkeit und Sparsamkeit), § 6 Abs. 2 (Kosten-Nutzen-Analysen), $\$ 26$ (Bindungen bei Zuwendungen), \& 40 (öffentliche Ausschreibung), Ânderung und Aufhebung von Verträgen (\$31).

27) Bachof, Neue Tendenzen in der Rechtsprechung zum Ermessen und zum Beurteilungsspielraum, JZ 1972, $641 \mathrm{ff.,} 642$.

${ }^{28}$ ) Wir übernehmen diesen Ausdruck von Ossenbuhl, Vom unbestimmten Gesetzesbegriff zur letztverbindlichen Verwaltungsentscheidung, DVBl. 1974, 309 ff., möchten ihn aber nicht auf die planende Verwaltung beschränkt wissen (so dort Anm. 6), sondern jeder Art von Verwaltungstätigkeit zuordnen, also auch der streng gesetzlich gebundenen: Eingriffsermächtigungen als präziseste Art gesetzlicher Direktiven.

${ }^{29}$ ) Das soll gegenüber der im Anschluß an Luhmann, z. B. Rechtssoziologie, 1972, 227 ff. und 234 ff., heute zuweilen überbetonten Trennung von gesetzlich „konditional" und „final“ programmierter Verwaltung deutlich herausgestellt werden. Zur Erklàrung konkreter Vorgänge herangezogen, läuft gerade diese Trennung Gefahr, die Gesetzgebungspraxıs $\mathrm{zu}$ verkennen und Lösungsansảtzen Zäsuren zugrundezulegen, die es in Wrklichkeit nicht gibt. Krit. zu Luhmanns Trennung Esser, Vorverständnis und Methodenwahl, 1972, 142 ff.; Badura, Die Verwaltung als soziales System, DOV 1970, 18 ff., 21; Schmidt-Aßmann, DOV 1974, 541 ff., 546. Zu Programm- 
- Verwaltungsverantwortung ist einmal Vollzugsverantwortung in den Bindungen des Gesetzes. Verantwortung für gleichmäßigen, rechtmäßigen aber auch rechtzeitigen Vollzug, für effektiven Vollzug.

- Verwaltungsverantwortung bedeutet weiter Entfaltungsverantwortung dort, wo ein gesetzgeberisches Programm nur in Umrissen vorgezeichnet ist; Verantwortung, wirksam durch Normen und Pläne in den Formen der originären und derivativen Rechtssetzung, in Rechtsverordnungen, Satzungen und Verwaltungsverordnungen.

- Verwaltungsverantwortung ist ferner Verantwortung für Programmverwirklichung mit den Untergliederungen der Prognoseverantwortung, der Verantwortung für die Methodenwahl, Stimmigkeits- und Ausgleichsverantwortung bei konnexen Maßnahmen, Kontinuitätsverantwortung bis hin zu Vertrauensschutz, Entschädigungspflichten und Ausgleich bei Härtefällen.

- Verwaltungsverantwortung umschließt Initiativverantwortung ${ }^{31}$ ) im Angesicht neuer Lagen und in der vorausschauenden Erfassung von Veränderungen: Aktion, nicht nur Reaktion! Spontaneität, Pflicht des ersten Zugriffs, der Selbstprogrammierung bis hin zur Schaffung eigener Handlungsinstrumente ${ }^{32}$ ); aber auch Verantwortung für

verschränkungen König, Programmsteuerungen in komplexen politischen Systemen, Verwaltung 1974. $137 \mathrm{ff.,} 141 \mathrm{f}$.

30) Zu entwickeln primär nach einem System öffentlicher Aufgaben; dazu die KGSt-Gutachten: Verwaltungsorganisation der Gemeinden, Teil 1 (Aufgabengliederungsplan), 4. Aufl., 1967, Verwaltungsorganisation der Kreise, Tell 1 (Institutionelle Organisation), 1972. Pflichtaufgaben der Kreise in Nordrhein-Westfalen (Aufgabenkatalog), hrsg. vom Landkreistag, NW 1967; Bericht der Interministeriellen Projektgruppe zur "Zuständigkeitsverteilung zwischen Kreisen und kreisangehörigen Gemeinden in Nordrhein-Westfalen und Abschluß der kommunalen Neugliederung", Düsseldorf 1974 (hektographiert). Ellwein, Einführung in die Regierungs- und Verwaltungslehre, 1966, 31 ff.; ders., Zur Entwicklung der öffentlichen Aufgaben, DOV 1972, 13 ff.; Becker, Verwaltungsaufgaben in: Verwaltung (hrsg. v. Morstein-Marx), 1965, $187 \mathrm{ff}$; ders., Die vollziehende Gewalt nach der demokratischen Verfassung des Grundgesetzes, in: Demokratie und Verwaltung, 25 Jahre Hochschule fur Verwaltungswissenschaften Speyer, 1972, 497 ff.; König, Offentliche Verwaltung und soziale Differenzierung, VerwArch, 1973; Mäding, Aufgaben der öffentlichen Verwaltung, Verwaltung 1973, $257 \mathrm{ff}$; Wimmer, Verwaltung 1975, 141 ff.

s1) Dazu Ellwein, Politik, Regierung, Verwaltung, Bd. 1 (1966), 80 ff. und 195 f.; Schmitt Glaeser, VVDStRL 31, 201, 213.

32) Z.B. die Ausbildung eines differenzierten Durchfuhrungsinstrumentariums der Wirtschaftsplanung dazu Ipsen, Rechtsfragen der Wirtschaftsplanung, in: Joseph H. Kaiser (Hrsg.), Planung Ir, 
die Vorbereitung gesetzgeberischer Entscheidungen, für Information, und damit überhaupt Vermittlungsverantwortung zwischen den Staatsfunktionen, indem daraufhingearbeitet wird, staatlicher Aufgabenerfüllung gesetzliche Strukturen einzuziehen, die Impuls, Leitlinie und Kontrollmaßstab bieten: Verantwortung für Verrechtlichung.

- Verwaltungsverantwortung hat schließlich zu sehen auf die Eingliederung der Einzelmaßnahmen in den Zusammenhang und erweist sich gerade bei komplexen Entscheidungen als Verpflichtung auf das Ganze - Gesamtverantwortung.

Das alles sind keine festen Begriffe der Dogmatı; aber sie kennzeichnen die Situation des Verwaltungshandelns und wirken hinein bis in die administrative Handhabung des Rechts ${ }^{32^{2}}$ ).

\section{Die verwaltungsrichterliche Verantwortung}

Die verwaltungsrichterliche Verantwortung wird konstituiert durch Art. 92, 97 und 19 Abs. 4 GG: durch Unabhängigkeit also und durch Aufgaben und Bindungen in der Verpflichtung zu positiver Wahrung des Rechts ${ }^{33}$ ).

1966, 63 ff., bes. 82-86; W. Haase, Formen regionaler Wirtschaftsförderung im Zusammenhang mit der Grundung der Ruhrkohle AG, 1972; ferner im Bereich kommunaler öffentlicher Einrichtungen, dazu Scholz, Das Wesen und die Entwicklung der gemeindlichen öffentlichen Einrichtungen, 1967; bis hin zu den Formen interkommunaler Zusammenarbeit; Rothe, Das Recht der interkommunalen Zusammenarbeit in der Bundesrepublik Deutschland, 1965.

s2a) Zum eigenständigen normativen Denken der Verwaltung und gegen eine simple Philosophie der Einheit des juristischen Denkens eindringlich König, Erkenntnisinteressen der Verwaltungswissenschaft, 1970, 73 ff. und 206 ff.; auch schon Becker, VVDStRL 14, 101 f.; zum Topos der "Sachzugewandheit" wohlfahrtsstaatlicher Verwaltung Badura, DOV 1968, 446 ff., 453.

33) Grundlegend Eichenberger, Die richterliche Unabhängigkeit als staatsrechtliches Problem, 1960; Bettermann, Die Unabhängigkeit der Gerichte und der gesetzliche Richter, in: Bettermann-Nipperdey-Scheuner, Die Grundrechte, 3. Bd. 2. Halbband, 1959 (zit.: Grundrechte III/2), S. 523 ff. "Aktive Wahrung des Rechts" umfaßt beides: die Bindung an das Gesetz, aber auch die „Eigenverantwortl1chkeit der Justiz fur die Positivierung des Rechts" von der Esser, Vorverständnis und Methodenwahl in der Rechtsfindung, 1972, 192 spricht; s. dort auch S. 17 ff. Speziell zur aktiven Wahrung des Rechts durch die Verwaltungsgerıchtsbarkeit Forsthoff, Begriff und Wesen des sozialen Rechtsstaates, VVDStRL 12, 8 ff., 39; Redeker, Fragen der Kontrolldichte verwaltungsgerichtlicher Rechtsprechung, DOV 1971, 757 ff. 
1. Das normative Denken des Verwaltungsrichters

Verwaltungsrichterliches Denken ist Denken von Recht her ${ }^{34}$ ), ist Bemühen, den Sachverhalt mit dem speziellen rechtswissenschaftlichen Instrumentarium in den Griff zu bekommen. Richterliches Handeln bedeutet methodengeprägtes Handeln ${ }^{35}$ ). Der Richter bedarf dieser Rückbindung. Sie ist das Korrelat seiner Unabhängigkeit und seine zweite Legitimationsbasis $\left.{ }^{36}\right)$. Hier zeigt sich, daß das im Grundgesetz verankerte Berufsrichtertum, das den Kern der Verwaltungsgerichtsbarkeit ausmacht, nicht ein die politische Situation frei gestaltendes Richtertum sein kann $^{37}$ ). Hier zeigt sich ferner, daß jene Modelle ${ }^{38}$ ) zu kurz greifen, die der Justiz Legitimationseffekte gerade dort zuwelsen wollen, wo die gesetzlichen Einbindungen der Verwaltung nachlassen; denn sie eignen sich die Erscheinungsform einer Institution an, ohne ihr Essentiale, die Rechtsbindung, zu respektieren.

2. Art. 19 Abs. 4 GG: Gerichtsschutzund polygonaler Rechtsschutz

Verwaltungsgerichtsbarkeit wird geprägt vom Rechtsschutzauftrag des Art. 19 Abs. 4 GG, der zwar nicht der einzige, wohl

34) Bettermann, Die Rechtsweggarantie des Art. 19 Abs. 4 GG in der Rechtsprechung des Bundesverfassungsgerichts, AöR 96, 1971, 528 ff., 551; Krüger, Allgemeine Staatslehre, 1964, 750; Becker, VVDStRL 14, 105; Eichenberger, Richterliche Unabhängigkelt (Fn 33), 174, s. aber auch 184; Lorenz, Der Rechtsschutz des Bürgers und die Rechtsweggarantie, 1973, 11, 17, s. aber auch 151 f.; H.-P. Schneider, Die Gesetzmäßigkeit der Rechtsprechung, DOV 1975, 443 ff., 448.

s5) Wieacker, Gesetz und Richterkunst, 1958, 8 ff.; ders., Uber strenge und unstrenge Verfahren der Rechtsfindung, Festschrift für W. Weber, 1974, $421 \mathrm{ff}$; W. Zendler, Richter und Verfassung, DOV 1971, 6 ff., 12 ff.; Badura, Grenzen und Möglichkeiten des Richterrechts - Verfassungsrechtliche Uberlegungen - Schriftenreihe des Deutschen Sozialgerichtsverbandes Bd. X, 1973, 40 ff., 49; Bockenförde, Verfassungsfragen der Richterwahl, 1974, $87 \mathrm{ff}$., $89 \mathrm{mit}$ Anm. 4 und 94 und die Referate von Roellecke und Starck in diesem Heft.

36) Zusammenfassend J. Ipsen, Richterrecht und Verfassung, 1975, bes. $196 \mathrm{ff}$.

37) Esser, Vorverstandnis (Fn 33), 21; Kruse, Das Richterrecht als Rechtsquelle des innerstaatlichen Rechts, 1971, 14; H. H. Klein, Richterrecht und Gesetzesrecht, DRiZ 1972, $333 \mathrm{ff}$; Badura, Richterrecht (Fn 35), 56; Lorenz, Rechtsschutz (Fn 34), 184; Böckenforde, Verfassungsfragen (Fn 35) 71, 87 ff.; etwas weitergehend Redeker, Legitimation und Grenzen richterlicher Rechtssetzung, NJW 1972, 409 ff., der aber ebenfalls betont, daß es eine „rechtliche Gestaltungsaufgabe“ (DOV 1971, 757 ff., 760) sei.

38) Görlitz (Fn 8), 260 ff. bes. 265: Legitimations-, Partizipationsund Entdifferenzierungsgarantıe“; Wälde, AöR 99 (1974), 585 ff., 624 ff. 
aber der Hauptpfeiler der gesamten Institution ist. $\mathrm{Zu}$ leisten ist danach primär der Schutz subjektiver Rechte, während der Schutz des objektiven Rechts, erheblich in seiner Bedeutung zwar, regelmäßig nur inzidenter erbracht wird, insofern subjektives und objektives Recht ein gutes Stück gemeinsamen Weges gehen ${ }^{30}$ ). $\mathrm{Zu}$ leisten ist Schutz gegen erkennbare ${ }^{40}$ ) Rechtsverletzungen. Die Verwaltungsgerichtsbarkeit arbeitet grundsätzlich reaktiv ${ }^{41}$ ), und sie arbeitet nur auf individuellen

39) Becker, VVDStRL 14, 144; Rumpf, dort S. 159; Ule, Verwaltungsprozeßrecht, 6. Aufl., 1975, 1 ff.; Menger, Der Schutz der Grundrechte in der Verwaltungsgerichtsbarkeit, Grundrechte III/2, 727-732; Krüger, Allgemeine Staatslehre, 749. Lorenz, Rechtsschutz (Fn 34) 130 ff., der betont, daß die Alternative subjektiver-objektiver Rechtsschutz sich in voller Schärfe gar nicht stellt. Auf diese zweite objektiv-rechtswahrende Funktion weisen besonders hin Scheuner, VVDStRL 14, 186 (Diskussionsbeitrag); Bachof, dort 197 ("doppeltes Gesicht der Verwaltungsgerichtsbarkeit"); Ossenbuhl, Verwaltungsvorschriften (Fn 23), 192 Anm. 29. Weitergehend Ipsen, VVDStRL 14, 193 (Diskussionsbeitrag), der der Verwaltungsgerichtsbarbeit „mit gleicher Legitimierung" die Funktionen der Verwaltungskontrolle zuerkennen will; ferner Eichenberger, Richterliche Unabhängigkeit (Fn 33), 166. Im Grunde sollte an der Zweispurigkeit der verwaltungsrechtlichen Aufgabenerfullung kein Zweifel bestehen. Sie fügt die Entwicklungslinien des norddeutschen und süddeutschen Systems (dazu Menger, Grundrechte III/2, 723 ff.; Erichsen, Verfassungs- und verwaltungsgeschichtliche Grundlagen der Lehre vom fehlerhaften belastenden Verwaltungsakt und seiner Aufhebung im ProzeB, 1971, 280 ff.) auch historisch sinnvoll zusammen. Nur scheint im Augenblick die subjektiv-rechtsschützende Komponente der Hervorhebung bedurftig, nachdem sie als Relikt bürgerlicher „Privatisierungsstrategie" (so Rehbinder-BurgbacherKnieper, Bürgerklage - Fn $8-$ ) abgewertet worden ist; für objektive Kontrolle des Verwaltungshandelns, für die die Privatinitiative nur als AnstoB „mobilisiert" wird, auch Manfred Wolf, Die Klagebefugnis der Verbände, 1971, 50. Dagegen zutreffend Lorenz, Rechtsschutz (Fn 34), 131 mit Hinweis auf die grundlegende Entscheidung der Verfassung fúr den materiellen Rechtsstatus des Individuums.

40) Das sind bereits eingetretene und sichtbar bevorstehende Rechtsverletzungen; dazu Ule, Vorbeugender Rechtsschutz im Verwaltungsproze $B$, VerwArch 1974, 291 ff., $298 \mathrm{f}$.

41) Unter diesem Begriff werden der „repressive Standardrechtsschutz" (Lorenz, Rechtsschutz, S. 136) und die Fálle anerkannter präventiver Klagemöglichkeiten (dazu unten $S$. $259 \mathrm{f}$.) zusammengefaßt. Auch diese präventiven Klagen lassen den Richter reaktiv handeln, und heben seine Distanz zum Verwaltungsgeschehen nicht auf. Das Gleiche gilt schließlich fur die wenigen Fälle eines „Richtervorbehalts" (Bettermann, Grundrechte III/2, 872 ff.), z. B. in Art. 13 Abs. 2, Art. 104 GG, der sich, gemessen an den präventiven Klagen, zwar als eine weitere Vorverlagerung des Rechtsschutzes in den Ablauf des Verwaltungshandelns hinein darstellt, den Richter aber trotzdem nicht in dieses Handeln inkorporiert. Die besondere Schutzwirkung dieser Vorbehalte beruht gerade in der Einschaltung 
Anstoß hın in einer Weise, die dem Kläger die Disposition über den Streitgegenstand erhält. Auch das gehört zu ihrem verfassungsfesten Bilde; denn ihr Schutzeffekt beruht eben nicht nur auf der organisatorischen Trennung von der Zweiten Gewalt, sondern auch auf jener Distanz zum Verwaltungsgeschehen ${ }^{42}$ ), die nur ein repressives Verfahren gewährt. Eigenständige Verfahren ausschließlich objektiver Rechtskontrolle bleiben zulässig $^{43}$ ), sofern sie nicht typusverändernd wirken. Nicht möglich dagegen ist es, die Verwaltungsjustiz als Institution in eine objektive, verfahrensbegleitende, aktive Kontrollinstanz umzudeuten ${ }^{44}$ ).

Verwaltungsgerichtsbarkeit zielt auf Effektivität subjektiver Rechte. Das heißt aber nicht notwendig exzessives Prozessieren gerade um klägerische Rechte. Die für zweipolige Prozeßverhältnisse oft übertriebene Konstruktion immer neuer Rechtsschutzfinessen muß aufhören in Anbetracht polygonaler Verwaltungsverhältnisse ${ }^{45}$ ), in denen subjektive Rechte auch untereinander in Frontstellung stehen. Wenn Rechtsverwirklichung heute zunehmend von administrativer Verteilung abhängt, wenn sie termingebunden und mehr als Erhaltung eines status

eines Organs „institutionalisierter Distanz“. Sie zu wahren, muß ein Leitpunkt aller rechtsschutzorganisatorischen Uberlegungen sein. $\mathrm{Zu}$ Recht wurden die Richtervorbehalte des Grundgesetzes als abschließend normierte Ausnahmeregelungen angesehen (Bettermann, AöR 96, 1971, 528 ff., 558 f.)

42) $\mathrm{Zu}$ den Begriffen der Distanz, Passivität, Unbeteiligtheit als Bausteine richterlicher Unabhängigkeit nachdrücklich immer wieder Bettermann, Gedächtnisschrift für Jellinek, 1955, 361 ff., 371 f.: "Vielmehr sind Initiative und Aktivität fur die Verwaltung typisch, wie es Passivität für die Rechtsprechung ist"; ders., Grundrechte III/2, 525 ff. und AöR 92 (1967), 496 ff. Allgemein zum Richter als „unbeteiligten Dritten“ BVerfGE 27, 312 ff., 322; Lorenz, Rechtsschutz (Fn 34), 202 ff.

43) BVerfGE 22, 106 ff., 110 mit dem Hinweis, Art. 19 Abs. 4 GG garantiere ein Minimum an subjektiven Rechtsschutz, schließe aber daneben „In-Sich-Prozesse" der Verwaltung nicht aus. Bisher sind solche Verfahren auf Randpositionen beschränkt, vgl. die Aufstellung bei Ule, VerwaltungsprozeBrecht (Fn 39), \& 33 V. Zur Entwicklung der verwaltungsgerichtlichen Normenkontrolle vom vorwiegend objektiven Kontrollverfahren (Menger, Grundrechte III/2, 729) über ein Mischinstitut subjektiv-objektiver Prägung (v. Engelhardt, Der Rechtsschutz gegen Rechtsnormen, 1971, 160 ff.); zum vorwiegend subjektıven Rechtsschutzverfahren ohne Behördenantragsrecht, wie es im Referentenentwurf zur Anderung des $\$ 47$ VwGO (Stand 1975) erscheint.

${ }^{44}$ ) $\mathrm{Zu}$ den sehr begrenzten Möglichkeiten eines „vorverlegten“ verfahrensbegleitenden Gerichtsschutzes vgl. Ossenbühl, DJT-Gutachten (Fn 4), $191 \mathrm{f}$. Zutreffend der Hinweis bei Kopp, Verwaltungsverfahrensrecht (Fn 22), 248 mit Anm. 692.

45) $\mathrm{Zu}$ diesem Phänomen Háberle, VVDStRL 30, 43 ff., 87. 
quo ist, dann können prozeßbedingte Verzögerungen, dann können Umfang und Dauer eines gerichtlichen Verfahrens nicht rechtsneutral bleiben. Dann wird man sich an den Gedanken gewöhnen müssen, daß Art. 19 Abs. 4 GG als Gerichtsschutzanspruch des einen durch materiell-grundrechtliche Rechtsverwirklichungsansprüche anderer Beteiligter Einschränkungen erfahren kann. Effektiver Schutz aller beteiligten Rechte wird hier nicht durch Steigerung, sondern durch angemessene Verteilung gerichtlicher Kontrollansätze gewährt ${ }^{46}$ ).

3. Die Bezogenheit der Verwaltungsgerichtsbarkeit auf die Zweite Gewalt

Verwaltungsgerichtsbarkeit ist zum anderen geprägt durch ihre spezielle Bezogenheit auf die Zweite Gewalt. Dieses Merkmal hebt sie aus dem Kreis der Gerichtszweige heraus und gebietet Vorsicht dort, wo es um die Ubernahme von Rechtsanwendungslehren geht, die für andere Gerichte, insbesondere für die Zivilgerichtsbarkeit entwickelt worden sind. Rechtsanwendung des Verwaltungsrichters ist stets ein dreipoliges Kompetenzproblem.

Verwaltung und Verwaltungsgericht begegnen sich in ihrer gemeinsamen Verantwortung für das Recht, die sie arbeitsteilig wahrnehmen ${ }^{47}$ ). Das geschieht in einem Zusammenspiel, das Züge gleichartiger, gegensätzlicher und komplementärer Aufgabenerfüllung trägt.

(a) Antinomisch wirkt dabei vor allem die unterschiedliche Entscheidungssituation; denn der Richter erhält den Sachverhalt:

46) Gerade unter den Bedingungen eines Massenrechtsschutzes erweist sich Bachofs These als zutreffend (VVDStRL 12, 37 ff., 76): "Rechtsstaatlichkeit heißt zu einem ganz wesentlichen Teil: geordnetes, klares und übersichtliches, leicht zugängliches und mit größtmöglicher Beschleunigung zum Ziele führendes Verfahren.“ Zum verfassungswidrig eingerichteten, da grundrechtshindernden $\mathrm{Ge}$ richtsschutz die Entscheidung des BVerfG vom 23. 4. $1974=$ BVerfGE 37, 132 ff.: Dem Richter steht es nicht frei, das materielle Recht mit Hilfe verfahrens-rechtlicher Vorschriften zu ändern. Effektiver Rechtsschutz gebietet es, die sich unmittelbar aus dem betroffenen Grundrecht ergebende Interessenabwägung nachzuvollziehen (148).

6) Häberle, Offentliches Interesse (Fn 3), 692; Bullinger, Unbestimmte Gesetzesbegriffe in der neueren deutschen und französischen Verwaltungsrechtsprechung, Festschrift für JahrreiB, 1974, 19 ff., 32. Zum parallelen Problem der Zuordnung von Legislative und richterlicher Gewalt H.-P. Schneider, DOV 1975, $443 \mathrm{ff}$., 449 („Prinzip koordinierter Arbeitsteilung“); J. Ipsen, Richterrecht und Verfassung, 1975, 240; Badura, Richterrecht (Fn 35), 42. 
- vorgeprägt durch einen anderen staatlichen Funktionsträger,

- occasionell und segmentarisch, im Umfang bestimmt durch den Kläger,

- zur Beurteilung ex post,

- in einem Verfahren, das auf die Dimensionen des Einzelfalles zugeschnitten ist, deshalb weder alle Beteiligten noch alle Bezüge des größeren Zusammenhangs aufnimmt und diesen auch nur begrenzt steuern kann, weil Parallel- und Divergenzfälle nicht Gegenstand des Prozesses sind.

Daraus folgt eine mediatisierte Situation richterlıchen Entscheidens, die die Ausmaße der im Grundfall wirkenden administrativen Verantwortung weder in Initiative, Information und Prognose, noch in Selbstprogrammierung, Abwicklung oder Folgen erreichen kann ${ }^{48}$ ).

(b) Auf der anderen Seite vermag der Richter durch das $\mathrm{Me}-$ dium des Rechts Entlastungsfunktionen für die Verwaltung auszuüben, indem er Standards entwickelt und größere Entscheidungszusammenhänge durch sukzessive Teilprüfungen stabilisiert $\left.^{49}\right)$. Mehr noch, selbst nicht Empfänger der Verwaltungsverantwortung, aktualisiert der Richter doch das der Verantwortung innewohnende Pflichtenmoment und schafft der Zweiten Gewalt dadurch „legitimierende Fundierung im Recht" ${ }^{(30}$ ). Hier manifestiert sich die von Werner Weber hervorgehobene Wirkungseinheit von Verwaltung und Verwaltungsgerichtsbarkeit $\left.{ }^{\mathrm{s}}\right)$.

\section{AuBergerichtlicher Rechtsschutz}

Wesentlich für das Bild der Verwaltungsjustiz ist schließlich, daß sie kein universales Rechtsschutzorgan darstellt. Sie steht vielmehr in einem Verbund mit anderen öffentlichen Rechts-,

49) Dazu auch Kopp, Verwaltungsverfahrensrecht (Fn 22), 153; H.-P. Schneider, DOV 1975, $443 \mathrm{ff} ., 447,450 \mathrm{f}$.

49) W. Weber, Staats- und Selbstverwaltung (Fn 24), 13; Scheuner, Die neuere Entwicklung des Rechtsstaats in Deutschland, Festschrift zum hundertjährigen Bestehen des Deutschen Juristentages, 18601960, Bd. 2, 1960, 229 ff., jetzt auch in: Rechtsstaatlichkeit und Sozialstaatlichkeit (hrsg. von Forsthoff), 1968, $461 \mathrm{ff}$., (danach hier zit.); Badura, Richterrecht (Fn 35), 48. Eichenberger, Richterliche Unabhängigkeit (Fn 33), 165 ff.; Hoppe, Verwaltungsverantwortung und Verwaltungsrechtsschutz, DVBl. 1975, $648 \mathrm{ff}$.

60) Eichenberger, Richterliche Unabhäng1gkeit (Fn 33), 166; vgl. K. Meyer, DOV 1969, 162 ff., 169.

s1) W. Weber, VVDStRL 14, 188 ff., 191 (Diskussionsbeitrag). 
Verwaltungs- und Finanzkontrollen ${ }^{52}$ ). Erst der richtig verfaßte Zusammenhang aller dieser Institutionen als spezifisch, überlappend und ergänzend tätiger Systemteile macht den Rechtsschutz insgesamt aus, innerhalb dessen der Verwaltungsgerichtsbarkeit eine ihren Besonderheiten entsprechende, institutions-spezifische Rolle zufällt.

III. Aufgaben und Entscheidungssituation als Kriterium administrativ-richterlicher Verantwortungsverteilung

Die weitaus meisten verwaltungsgerichtlichen Urteile haben die administrativ-richterliche Verantwortungsverteilung durchaus zutreffend im Sinne einer Angleichung der Entscheidungsstrukturen erfaßt. Das ist möglich, weil das Gros der Fälle in Sachverhalt, Beteiligten und Folgen ubersichtlich ist und bei Sachverhaltsreihungen schon die Singularität der klagbar gewordenen Fälle nachhaltige Beeinträchtigungen des administrativen Verantwortungsbereichs ausschließt. Wo die Gerichte dagegen über verflochtene Verwaltungsentscheidungen $\mathrm{zu}$ befinden haben, gehen die Grundlagen dieser Angleichung verloren, da die Uberschaubarkeit, die Einsichtigkeit der Wertungen und die Filterwirkung der Sachverhaltsreihung nachlassen und dadurch die Unterschiede der Entscheidungssituationen aufbrechen. Wenn heute nach angemessenem Rechtsschutz gerade gegenüber komplexen Vorgängen gesucht wird, dann müssen primär Uberschaubarkeit und Einsichtigkeit zurückgewonnen, dann müssen die Strukturen des richterlichen und des administrativen Entscheidens in den Kontrollgegenständen und -verfahren wieder angenähert werden.

Ich möchte das an einigen für den Verwaltungs- und den Kontrollvorgang wichtigen Rechtsinstituten zeigen. Die Uberprüfung dieser Institute hat sich an der skizzierten Verantwortungstypologie auszurichten und zu versuchen, Uberschaubarkeit mit den Mitteln der Entflechtung alter und der Kontraktion neuer Zusammenhänge, sowie durch Reduktion und Einpassung zu erzielen.

\section{Dritter Abschnitt: Konkrete Zuordnungsprobleme}

A. Kontrollzugänglichkeit und Kontrollverfahren

I. Rechtsform und Rechtsschutzform

Entflechtungen und Ansätze zu neuer Bündelung sind zunächst bei den Rechtsschutzformen notwendig. Die überkom-

52) Darstellung bei Brunner, Kontrolle in Deutschland, 1972, 139 ff.; Schwarze, Zum Nutzen einer Systembildung für die Kontrolle der Staatsgewalt, DVBl. 1974, 893 ff.; weitergehend Loewenstein, Verfassungslehre, 1959, $127 \mathrm{ff}$. 
menen, nach wie vor primär gegen Einzelmaßnahmen mit AuBenwirkung gerichteten Klagetypen werden der Kontrolle komplexer Maßnahmen nicht gerecht, weil solche Entscheidungen häufig in einer historisch zufälligen Rechtsform ergehen ${ }^{53}$ ). Die Diskrepanz zwischen Rechtsform und Rechtsschutzform nimmt zu, je weiter die Vorgänge in den Verwaltungsinnenbereich verlagert sind. Vor allem paßt das Dogma ${ }^{54}$ ), den Gesamtzusammenhang über die Inzidentprüfung zu kontrollieren, hier nicht: Es verzögert für Bürger und Verwaltung die rechtzeitige Kontrolle und belastet dadurch die weitere Entwicklung mit Unsicherheiten. Es trägt in den Einzelprozeß zu viel Konfliktstoff hinein und läßt ihn oft zwischen Parteien spielen, die materiell nicht die Hauptbeteiligten sind ${ }^{55}$ ). Schließlich steigert es die Rechtswegezersplitterung ${ }^{56}$ ). Die letzteren Gesichtspunkte sprechen auch dagegen, Individualklagen wie die Feststellungsklage zum prinzipalen Normenkontrollinstrument ${ }^{57}$ ) umzumünzen.

\section{Prinzipale Normenkontrolle, $\$ 47$ VwGO}

Als eine erste Neuordnungsmaßnahme ist die prinzipale Kontrolle untergesetzlicher Rechtssätze bundesgesetzlich auszubau$e^{58}$ ). Die Prozeßordnungen müssen für Einzelmaßnahmen und für Entscheidungen mit normativ-programmhaftem Gehalt zwei im wesentlichen gleichwertige Rechtsschutzformen vorse-

53) Beispiele bei Ossenbühl, DJT-Gutachten (Fn 4), 45 ff.; $v$. Mutius, Rechtsnorm und Verwaltungsakt, Festschrift für Hans J. Wolff, 1972, $167 \mathrm{ff}$. Zum Formenproblem allgemein Pestalozza, Formenmißbrauch des Staates, $1973,2 \mathrm{ff}$.

54) BVerfGE 31, $364 \mathrm{ff}$.; $368 \mathrm{f.;}$ dazu krit. v. Mutius, VerwArch 1972, 207 ff. m. w. Nachw.

53) Das 1st überall dort der Fall, wo normvollziehende und normsetzende Behörde nicht identisch sind.

68) Z. B. bei Inzidentkontrollen eines Bebauungsplanes, dessen Vollzugsakte teilweise (Baugenehmigungen) von den Verwaltungsgerichten, teilweise (Enteignungs- und Umlegungsmaßnahmen) von den Baulandkammern ( $\$ \$ 157 \mathrm{ff}$. BBauG) kontrolliert werden.

57) Siemer, Normenkontrolle durch Feststellungsklage?, 1971; Maurer, Rechtsschutz gegen Rechtsnormen, Festschrift für Kern, 1968, $275 \mathrm{ff}$., $305 \mathrm{ff}$. („Feststellungsklage eigener Art"): ausführliche Darstellung und Kritik dieser Versuche jungst bei Schenke, Rechtsschutz bei normativem Unrecht (Habilitationsschrift Mainz 1973, maschinenschriftl.), 175 ff.

$\left.{ }^{58}\right) \mathrm{Zu}$ dieser vielfach erhobenen Forderung jüngst Stern, Zur verwaltungsgerichtlichen Normenkontrolle - Ein Plädoyer für ihre Ausweitung, Festschrift für $H$. Schäfer, 1973, 59 ff. m. w. Nachw. Als berechtigtes Postulat anerkannt auch im Regierungsentwurf eines Gesetzes zur Anderung des Bundesbaugesetzes, BundestagsDrucks. 7/2496, S. 34 sub 9 (Begründung). Ausführlich v. Engelhardt, Der Rechtsschutz gegen Rechtsnormen, 1971. 
hen. Nur eine solche Doppelgleisigkeit des Rechtsschutzes kann dem Gesetzgeber seine Befugnis, die dem Rechtsakt angemessene Form zu bestimmen, wenigstens teilweise zurückgeben. Das aber ist umso notwendiger, als vor allem polygonale Verwraltungsverhältnisse ohne die klarstellende Wirkung der Rechtsformen nicht verfaßt werden können ${ }^{50}$ ).

Inzwischen liegt ein Regierungsentwurf zur Novellierung des § 47 VwGO (Bundestags-Dr. 7/4324) vor, der für einige Hauptfälle komplexer Entscheidungen, für Bebauungspläne, Sanierungssatzungen und die Festlegung von Hochschulkapazitäten die oberverwaltungsgerichtliche Normenkontrolle von Bundes wegen einführen will. Im übrigen sollen die Länder wie bisher die Möglichkeit behalten, § 47 VwGO zu aktualisieren. Der Bund beschränkt sich insoweit darauf, einige Streitfragen zu klären, die bisher die Normenkontrolle belasten ${ }^{00}$ ).

50) Besonders belastend und unergiebig der Qualifikationsstreit bei Plänen; dazu zusammenfassend $v$. Mutius, Festschrift für Hans J. Wolff, S. 167 ff., $175 \mathrm{~m}$. w. Nachw. Die Auseinandersetzungen haben viel zu lange ausschlieBlich unter Rechtsschutzgesichtspunkten gestanden. Die differenzierte Aussageweise der Pläne und ihr programmhafter Charakter sind dabei oft genug nicht richtig gesehen worden. Weder gibt es "den Plan" als Rechtsform (Erichsen, in: Erichsen-Martens, Allgemeines Verwaltungsrecht 1975, $199 \mathrm{ff}$.), noch hat der einzelne Plan eine einheitliche Konsistenz seiner Festlegungen. Sehr häufig mischen sich bis in die einzelne Aussage hinein generell-abstrakte mit individuell-konkreten Elementen; vgl. OLG I.üneburg, DVBl. 1973, 151 ff., 153 (betr. Raumordnungsplan); BayVGH BayVBl. 1975, 168 ff. (betr. eine Rechtsverordnung zur Bestimmung zentraler Orte). In diesem "Zwischenbereich" kommt der gesetzlichen Einordnung in der Tat wesentliche Bedeutung zu. Diese Einordnung aber muß u. U. nach anderen Gesichtspunkten (Publizität, Erlaßverfahren, Beteiligung) vorgenommen werden als nach Rechtsschutzrücksichten; dazu Ossenbühl, DJT-Gutachten (Fn 4), 49; Schmidt-Aßmann, Grundfragen des Städtebaurechts, 1972, $149 \mathrm{ff}$. Selbst wenn man mit dem BVerwG, DOV 1974, 426 f. davon ausgeht, daß Verfassungsrecht enthalte kein Gebot, die Form hoheitlicher Maßnahmen so zu wählen, daß der einzelne dagegen einen möglichst umfassenden Rechtsschutz hat, bleibt ein Rechtsstaatsdefizit solange bestehen, wie nicht die Grundzüge des Rechtsschutzes formabhängig ausgestaltet sind. Vgl. Brohm, VVDStRL 30, 245 ff., 283 f., dessen These, der Ausschluß der abstrakten Normenkontrolle für untergesetzliche Normen in einigen Ländern verstoße gegen Art. 19 Abs. 4 GG (dazu die weitere Lit. Anm. 114), allerdings zu allgemein gehalten ist und allenfalls für einige besonders krasse Gruppen von Plänen aufrechterhalten werden kann.

o0) So vor allem das Problem des Prüfungsmaßstabes, das der Entwurf im Sinne umfassender, das Verfassungsrecht einbeziehender Prüfung löst; dazu Stern (Fn 58), 73 ff. - Gestrichen werden soll dagegen das bisherige Behördenantragsrecht. Der Entwurf begründet diese Maßnahme damit, § 47 VwGO solle in erster Linie dem Rechtsschutz des einzelnen dienen. 
Mit Allgemeinverbındlichkeit ausgestattet bleibt allein die normverwerfende Entscheidung. Rechtsmittel gibt es nicht.

Wir dürfen diesem Entwurf einige Ergänzungsvorschläge anfügen: So erscheint der Katalog der obligatorischen Kontrollgegenstände zu eng. Nach aller Erfahrung kann nicht damit gerechnet werden, da $\beta$ die bisher hartnäckig kontrollfeindlichen Länder ${ }^{61}$ ) den Minimalkatalog landesgesetzlich auffüllen werden. Die Zweispurıgkeit der Rechtsschutzform aber bleibt unvollständig, wenn nicht auch die Festlegung städtebaulicher Entwicklungsbereiche ${ }^{62}$ ) und Regionalpläne ${ }^{63}$ ) prinzipal kontrolliert werden können. Desgleichen müssen bestimmte Sätze des bisherigen Innenrechts als kontrollfähig anerkannt wer$\left.\operatorname{den}^{84}\right)$, weil gerade hoherstufige Pläne sich oft dieser Rechtsform bedienen. Einer Ausuferung des Instituts, wie sie nach der Statistik zur bisherigen Kontrollpraxis ${ }^{65}$ ) ohnehin nicht zu befürchten ist, läßt sich mit der an die Gefährdung rechtlicher Interessen ${ }^{86}$ ) gebundenen Antragsbefugnis gegensteuern.

61) $\mathrm{Zu}$ den jüngsten erfolglosen Bemuhungen um Einführung der Normenkontrolle nach $\$ 47$ VwGO in Bundesländern Redeker, Einführung des Normenkontrollverfahrens in Nordrhein-Westfalen, NJW 1974, $1648 \mathrm{f}$.

02) Festlegung durch RechtsVo der Landesregierung, § 53 StBauFG. Zum Rechtsschutz hiergegen Oldiges, Gerichtlicher Rechtsschutz gegen Gebiets- und Bereichsfestlegungen nach dem Städtebauförderungsgesetz, Wirtschaftsrecht 1974, 277 ff.

09) Gerade diese Pläne sind in Inhalt und Form länderweise so unterschiedlich geregelt (vgl. Aufstellung bei Ernst-Zinkahn-Bielenberg, BBauG, Stand 1975, \& 1 Rdnr. 20), daß nur eine Zweispurigkeit willkuirlich wirkende Differenzierungen vermeiden kann.

o4) Dazu b.-w. VGH ESVGH 23, 90 ff. (betr. Festsetzung des Regelstundensatzes); Ossenbühl, Ministerialerlasse als Gegenstand verwaltungsgerichtlicher Normenkontrolle, DVBl. 1969, 526 ff. mit zutreffender Einschränkung auf Verwaltungsvorschriften eigenständigen, rechtsergänzenden Inhalts. Lorenz, Rechtsschutz (Fn 34), 37 ff. Ablehnend OVG Lüneburg DVBl. 1973, $151 \mathrm{ff}$. und die h. M. (Nachw. bei Lorenz, S. 38 Anm. 1).

o5) Nach Angaben in der Begründung des Regierungsentwurfs (S. 6) waren zwischen 1970 und 1974 in Baden-Württemberg 259 Verfahren anhängig, in Bayern 147, in Bremen 4, in Hessen 123, in Schleswig-Holstein 31. Das Gros betraf Verfahren zur Uberprüfung von Bebauungsplänen (ca. $55 \%$ ). Weitere Angaben zur Statistik bei Schlez, Die Fehlerquelle beim Bebauungsplan und das Abwägungsgebot des $\S 1$ Abs. 4 S. 2 BBauG, BauR 1974, $289 \mathrm{ff}$; $K$. Meyer, Die verwaltungsgerichtliche Normenkontrolle, in: Zehn Jahre Verwaltungsgerichtsordnung (Fn 3), $161 \mathrm{ff}$.

o6) So die ganz h. M.; bayVGH BayVBl. 1975, 168 ff., 169; Redeker$v$. Oertzen, VwGO \& 47 Rdnr. 13;B.-F. Hoffmann, Antragsbefugnis im verwaltungsgerichtlichen Normenkontrollverfahren nach $\$ 47$ VwGO, Diss. Heidelberg 1974. 
Die präventive Entlastungs- und Stabilisierungswirkung des Normenkontrollverfahrens ließe sich wesentlich steigern, wenn auch der normbestätigenden Entscheidung Allgemeinverbindlichkeit zukäme ${ }^{67}$ ). Trotzdem kann eine entsprechende Erstrekkung der Urteilswirkungen nicht empfohlen werden, weil die revisionslose Kontrollentscheidung des Oberverwaltungsgerichts instantiell nicht hoch genug verortet ist, um abweichende Inzidententscheidungen anderer Gerichte auszuschließen ${ }^{68}$ ). Das Gericht wäre zudem überfordert, sollte es im Rahmen eines einzigen Verfahrens den formellen und den gesamten materiellen Regelungsgehalt von Planungsnormen in allen Auswirkungen überprüfen. Hier läßt auch die prinzipale Normenkontrolle Lücken, die sich nur in sukzessiver Prüfung schließen. Zu überlegen ist allerdings, ob nicht wenigstens die formelle Rechtmäßigkeit der Verwaltungsentscheidung ein für allemal umfassend geprüft und allgemeinverbindlich festgestellt werden sollte.

2. Rechtsschutzgegen Einzelakte

Im Rechtsschutz gegen Einzelakte läßt sich die notwendige Verfahrenskonzentration nur durch ein Maßnahmebündel erzielen, zu dem Anfechtungslast, Fristen und Ausschlußwirkung gehören und dessen Kern der Verwaltungsakt bildet. Dieses Institut hat zwar seine rechtsschutzeröffnende Schlüsselfunktion eingebüß $\left.t^{69}\right)$. Unverzichtbar aber sind die prozeßrechtlichen Ausstrahlungen seines materiellen Anliegens, verbindliche und bündelnde, der Bestandskraft fähige Regelung zu sein ${ }^{70}$ ). Ja, es erweist sich als eine adäquate Rechtsform gerade dort, wo es die zeitliche Abfolge mehrerer Entwicklungsphasen eines Planungsprozesses $\mathrm{zu}$ verfassen gilt, von denen die nachfolgende

67) K. Meyer, (Fn 65) 171; Bettermann, Zur Verfassungsbeschwerde gegen Gesetze und zum Rechtsschutz des Burgers gegen Rechtssetzungsakte der öffentlichen Gewalt, AóR 86 (1961), 129 ff., 161

6) Auf längere Sicht muß die Frage einer Revisibilität der oberverwaltungsgerichtlichen Entscherdung erneut überdacht werden, zumal dann, wenn es sich bei zunehmenden bundesrechtlichen Planungsmaßnahmen (z. B. Bundesraumordnungsprogramm Bundestags-Drucks. 7/3584, Rahmenpläne für Gemeinschaftsaufgaben, z. B. Bundestags-Drucks. $7 / 3563$ und 3601) als notwendig erweisen sollte, Bundesrecht als überprüfungsfähiges Recht in $\S 47$ VwGO einzubeziehen. Vgl. Stern (Fn 58), S. 69 ff.

69) Frotscher, Rechtsschutz nur gegen Verwaltungsakte?, DOV 1971, 259 ff.; zu neueren Fällen Rspr.-Ubersicht DOV 1975, 174 f. Nr. $31-36$.

70) Dazu Rüfner, Die Rechtsformen der sozialen Sicherung und das allgemeine Verwaltungsrecht, VVDStRL 28, $187 \mathrm{ff}$., 204-206; Vogel, dort 268 (Diskussionsbeitrag); Bachof, VVDStRL 30 (1971), $153 \mathrm{ff}$., 230-233; Wolff-Bachof, Verwaltungsrecht I, 9. Auflage, 1974, 46 I a. 
die früher getroffenen Rahmenentscheidungen nicht wieder zur Disposition stellt, sondern ausfüllend weiterführt $\left.{ }^{71}\right)$. Das alles gehört bereits heute zur Praxis der Vor- und Teilbescheide ${ }^{72}$ ). Nur ist diese Praxis zu sehr von historischen Zufälligkeiten geprägt, bei denen Verfahrenszergliederungen und nicht voll verarbeitetes Zusammenwachsen ursprünglich selbständiger Verwaltungsverfahren unvermittelt nebeneinander stehen ${ }^{73}$ ). Das bewirkt, wie die Flughafen-Urteile ${ }^{74}$ ) zeigen, Unsicherheiten des Rechtsschutzes, indem man zu einer zu spät ansetzenden, phasenverzerrenden Konzentration seine Zuflucht nimmt ${ }^{75}$ ). System läßt sich in dieses Dickicht nur mit Hilfe des Gesetzgebers bringen, der vor allem mehrstufige Planfeststellungsverfahren präziser gliedern mu$\left.{ }^{76}\right)$. Dabei sind drei Punkte beachtlich:

71) Wahl, DOV 1975, 373 ff., 375-377; auch Brohm. VVDStRL 30. 285 ff., der allerdings die Außenwirkung des regelnden Gehalts eines Verwaltungsaktes $\mathrm{zu}$ gering veranschlagt. Zum Begriff des "Entwickelns" eines Planes aus dem nächsthöherstufigen BVerwG Urt. vom 28. 2. $1975=$ BauR 1975, 257 ff.

72) Z. B. Vorbescheide im Baugenehmigungsverfahren, dazu Scheerbarth, Bauordnungsrecht, 2. Auflage, 1966, \& 125; speziell zur Bebauungsgenehmigung, BVerwG DOV 1969, 143; ferner $\$ \S 8,9$ BImSchG, \& 7 a AtomG; \& 21 BBauG (Zusammenwachsen von Bodenverkehrs- und Baugenehmigung); zu Teilgenehmigung und Vorbescheid instruktiv Sellner, Die Genehmigung nach dem BundesImmissionsschutzgesetz, NJW 1975, 801 ff., bes. 804; BVerwGE 24, 23 ff.; Anschauungsmaterial bietet auch das Verwaltungsvollstrekkungsrecht, das gleichsam das klassische Gebiet „gestufter Verwaltungsentscheidungen" ist, dazu G. Arndt, Der Verwaltungsakt als Grundlage der Verwaltungsvollstreckung, 1967; zu einem atypischen Vollstreckungsfall OVG Münster BauR 1973, $308 \mathrm{ff}$.

73) Vollends das neuere Fachplanungsrecht zeigt eine deutliche Tendenz, Entscheidungsstufen zu formulieren, z. B. \$16, \$\$ $17 \mathrm{ff}$. BFStrG, § 13, §§ 14 ff. WaStrG; § 6, §§ 7 ff. AbfallbeseitigungsG; §§ 28 ff. PBefG. Hoppe, Rechtsschutz bei der Planung von Straßen und anderen Verkehrsanlagen, 1971, Rdnr. 25 ff.; Badura in: ErichsenMartens, Allgemeines Verwaltungsrecht, 1975, 290 ff.; Wahl, DOV $1975,373 \mathrm{ff}$. und Blümel in zahlreichen Beiträgen, jüngst DVBl. 1975, 695 ff., 702 mit Nachw. Anm. 173.

${ }^{74}$ ) Aus der großen Zahl von Entscheidungen: BVerwG Urt. vom 22. 3. $1974=$ DVB1. $1974,562=$ DOV 1974, 418 ; Beschl. vom 21.3. $1973=$ DVBl. 1973, $448=$ DOV 1973, 344; Urt. v. 11. 10. $1968=$ DOV 1969, 283, bayVGH DVBl. 1972, 790; weitere Nachw. bei Blümel, a. a. $\mathrm{O}$.

75) Kritik bei Wahl, DOV 1975, 373 ff.; Blümel, DVBl. 1975, 703 ff.

76) Dazu die eingehende Ausarbeitung eines gestuften flurbereinigungsrechtlichen Planfeststellungsverfahrens von Blïmel-Ronellen$f_{2} t_{s c h}$, Die Planfeststellung in der Flurbereinigung, 1975, 62-85. Die Ausführungen zeigen, wie sehr eine bereichsspezifische gesetzl. Regelung notwendig und wie sehr sie von den Sachbezügen des jeweiligen Rechtsgebiets abhängig ist. Aussagen allgemeiner Dogmatik lassen sich zur Zeit nur wenig treffen. 
- Diejenigen Einschnitte, die den Eintritt der Verbindlichkeit markieren, sind mit Regelungsgehalt so auszustatten, $\mathrm{da} B$ in den dazwischenliegenden Phasen eine Beschränkung der Angreifbarkeit zumutbar ist, „dazwischenschieBenden" Klagen daher typischerweise das Rechtsschutzbedürfnis abgesprochen werden kann.

- Der Kreis der Anfechtungsberechtigten und -verpflichteten muß aus dem Gesetz bestimmbar sein.

- Mit Anfechtungslast, materieller Ausschlußwirkung und Bestandskraft muß Ernst gemacht werden ${ }^{77}$ ). Gesetzlich hinreichend verdeutlicht, sind diese Institute nicht rechtsstaatwidrig78), sondern notwendig, um große Verwaltungsverfahren administrativ steuerbar zu halten und die rechtzeitige Erfüllung der in ihnen angelegten Verteilungsaufgaben nicht $\mathrm{zu}$ gefährden ${ }^{79}$ ). Die divergierenden Interessen in polygonalen Verwaltungsverhältnissen zwingen hier dazu, allen Beteiligten Obliegenheiten zuzuweisen und ihnen fur den Schutz ihrer Rechte auch selbst Verantwortung $\mathrm{zu}$ übertragen. Iura vigilantibus!

\section{Individualrechtsschutz und andere Rechtsschutzverfahren}

1. Subjektives öffentliches Recht

Die Uberschaubarkeit des Rechtsschutzes hat gelitten durch Ausweitungen des subjektiven öffentlichen Rechts ${ }^{81}$ ), die nur zum Teil notwendige Reaktionen auf die zunehmende Breiten-

77) Dazu BVerwG DVBl. 1970, 65; Weyreuther, Probleme der Rechtsprechung zum Enteignungsverfahren, DVBl. 1972, 93 ff., $99 \mathrm{f}$.: „Jede zwischen- oder vorgeschaltete förmliche Entscheidung schafft also, weil sie die Anfechtungslast auslöst, für die nachfolgenden Verfahren gesicherten Boden." Blumel, Anm. DVB1. 1972, $796 \mathrm{ff}$., 798; Schwarze, Rechtsfragen bei der Errichtung von Kernkraftwerken, DŐV 1973, 700 ff., 703 f. m. w. Nachw.; Wahl, DVBl. 1975, 373 ff., 378. OVG Münster Urt. vom 20. 2. 1975 - VII A 911/69 - (unveröffentlicht), AU S. 23 f. Ausdrückliche Regelung in $87 \mathrm{~b}$ Abs. 2 AtomG; $\S 11$ BImSchG, dazu Ule, Umweltschutz im Verfassungsund Verwaltungsrecht, DVBl. 1972, 437 ff., 442. Zur Präklusion innerhalb eines Verwaltungsverfahrens \$ 10 Abs. 3 BImSchG; BVerwG DVBl. 1973, 645 mit abl. Anm. Zuck; Landmann-RohmerEyermann-Fröhler, Gewerbeordnung, Stand 1969, \$17 Rdnr. $12 \mathrm{~m}$. w. Nachw.

78) Unbegründet daher Bedenken und Einschränkungen in OVG Lüneburg DVB1. 1975, 190 ff., 193.

79) Dazu oben bei Fn. 45, 46.

80) Vgl. BVerwGE 10, 47 ff., 48; ferner BVerwGE 44, 294 ff.; dazu Menger, Die Grundsätze von Treu und Glauben im Gerichtsverfahrensrecht, VerwArch 1975, 85 ff.; ferner BVerwG BRS Bd. 27 Nr. 167 und BVerwG Urt. vom 15. 10. $1974=$ AgrarR 1975, 101 ff., 102.

81) Grundlegend Bachof, Reflexwirkungen und subjektive Rechte im öffentlichen Recht, Gedächtnisschrift für W. Jellinek 1955, 287 
wirkung des Verwaltungshandelns sind. Auf makroadministrative Vorgänge, auf die Tiefenwirkung übertragen, laufen die Ausdehnungen Gefahr, über den Einzelprozeß Aspekte in die Verwaltungsentscheidung hineinzuschleusen, die auf dieser Stufe noch keine Rolle spielen und so die Gesamtentscheidung verfälschen.

Eingrenzungen des subjektiven Rechts lassen sich nur über seine nach wie vor gültige normative Ableitung ${ }^{82}$ ) erzielen $^{83}$ ). Bei der danach notwendigen rechtssatzbezogenen Sinnermittlung können auch Sachbezüge des Betroffenenbereichs eine Rolle spielen $\left.{ }^{84}\right)$. Das ist aber nur die eine Seite. Beachtlich sein

ff.; Rupp, Grundfragen der heutigen Verwaltungsrechtslehre, 1965, $146 \mathrm{ff}$; Henke, Das subjektive öffentliche Recht, 1968; Meinungsstand zusammengefaßt bei Lorenz, Rechtsschutz (Fn 34), S. 50 ff. Henke, Zur Lehre vom subjektiven öffentlichen Recht, Festschrift für W. Weber, 1974, 495 ff. Zur Rechtsprechungspraxis in den wichtigsten Gebieten subjektiver Rechte bei mehrpoligen Verwaltungsverhältnissen vgl. Gelzer, Bauplanungsrecht, 1972, Rdnr. 650 ff., 945 f.; Schrödter, BBauG, 3. Aufl., 1973, § 31 Rdnr. 4 ff.; Bender-Dohle, Nachbarschutz im Zivil- und Verwaltungsrecht, 1972; Friauf, Der Rechtsschutz des sog. Dritten in der verwaltungsgerichtlichen Rechtsprechung, JurAnalysen 1969, 1 ff.; 1970, 652 ff.; Scholz, Wirtschaftsrecht 1972, 35 ff.; Schmidt-Aßmann, Grundfragen des Städtebaurechts, 99 ff.; Sendler, Industrieansiedlung, Umweltschutz, Planungs- und Nachbarrecht, WiR 1972, $453 \mathrm{ff}$.

82) Wolff-Bachof, Verwaltungsrecht I \& 43 I b; Bachof, VVDStRL 33, 312-315 (Diskussionsbeitrag). Der normativen Ableitung angenähert jetzt auch Henke, Festschrift für W. Weber (Fn 81), S. 510 ff.; nicht ganz klar Bartlsperger, VVDStRL 33, 327 (Schlußwort) zu seinen Ausführungen dort S. 252 f. und früheren Beiträgen (Nachw. dort Anm. 127).

83) Dabei kann eine differenzierende grundrechtliche Schrankensystematik rechtsverdeutlichend wirken; Scholz, Wirtschaftsaufsicht und subjektiver Konkurrentenschutz, 1971, $122 \mathrm{ff}$; ihm folgend Lorenz, Rechtsschutz (Fn 34), S. 62 ff. Doch sollte der gesetzesunabhängige Aussagegehalt gerade der im Bereich komplexer Verwaltungsentscheidungen einschlägigen Art. 2 Abs. 1, 12, 14 GG nicht uberschätzt werden. So Wolff-Bachof, § 43 I b 2, S. 323 gegen Lorenz; zu weit auch Scholz, a. a. O., S. 139 unten, 145 (,subjektivierende Grundtendenz" als „idealtypischer Zug der Vorhofsprägung"); gänzlich unbestımmt Rehbinder-Burgbacher-Knieper (Fn 8), 39. Zu Problemen des Art. 5 GG bei Pressesubventionierung VG Berlin DOV 1975, 134 ff. mit Anm. Scholz, dort S. 136 f.

84) Die bleibende Bedeutung der insbesondere von Henke zunächst vertretenen I,ehre, auf das faktische Betroffensein abzustellen, liegt darin, die Schutznotwendigkelt einer Position zu verdeutlichen und im Rahmen der teleologischen Bedeutungsermittlung Interpretationsgesichtspunkte beizutragen; vgl. BVerwG vom 13. 6. $1969=$ DVBl. 1970, 57, ferner Urt. vom 14. 12. 1973 = DVBl. 1974, 358 mit Anm. von Schrödter, dort S. 362, das ohne einfach-gesetzliche nachbarschützende Norm den Nachbarschutz (ausnahmsweise) direkt aus Art. 14 GG herleitet (schwer und betroffen). Die Zumutbarkeitslehre 
kann auch ein institutionelles Element aus dem Administrativbereich, die Frage nämlich, wie der verpflichtete Verwaltungsträger nach Aufgabe, Organisation und Verwaltungskraft eingerichtet ist. Dieses Element kann für das subjektive Recht entstehungsfördernd wirken, etwa dort, wo die Verwaltung auf eine neue und umfassende Art Aufsicht über Sozialbereiche praktizier $\left.{ }^{85}\right)$. Es kann aber auch entstehungshindernd wirken, indem es zeigt, daß die Aufgaben der Verwaltung in einem bestimmten Gebiet nicht die für die Begründung subjektiver Individualrechte notwendige Dichte besitzen. Auf diesen Aspekt hinzuweisen besteht Veranlassung, weil die den makroadministrativen Bereich dirigierenden gesetzlichen Abwägungs- und Koordinationsklauseln mit ihren weitläufigen Katalogen beachtlicher Interessen ${ }^{86}$ ) zum Teil eine überschießende subjektivrechtliche Tendenz vorspiegeln, die sie aus institutioneller Sicht weder durchhalten können noch wollen. Komplexe Entscheidungen haben großflächig skizzierte Interessen zum Gegenstand ${ }^{87}$ ). Nur auf sie ist die Verwaltung in der Sachaufklärung und Informationsverarbeitung eingerichtet. Höhere Dichte und subjektive Individualrechte ließen sich nur um den Preis des Verwaltungsstaates begründen. Das institutionelle Element der bereichsspezifischen Verwaltungsaufgabe hat hier die notwendige teleologische Reduktion zu weit gefaßter Rechtssätze zu leisten.

zu Art. 14 GG vollzieht hier die Vermittlung von Faktizität und Rechtssatz.

85) Dazu die an der Amtshaftungsrechtsprechung ablesbare Erweiterung bauaufsichtlicher Pflichten; BGHZ 59, 358 ff., 362; BGH NJW 1969, 234; BGHZ 60, 112 ff. Wichtig z. B. auch die gesetzliche Zuständigkeitszuweisung an technisch spezialisierte und entsprechend ausgestattete Gewerbeaufsichtsämter oder an die allgemeine Ordnungsverwaltung. Vgl. auch Scholz, Wirtschaftsaufsicht (Fn 83), $16 \mathrm{ff}$.

86) Z. B. § 2 BROG, § 1 StabG, § 2 AbfallbeseitigungsG; § 1 KohleanpassungsG v. 15. 5. 1968 (BGBl. I, S. 365), dazu Seidler, Rechtsschutz bei staatlicher Wirtschaftsplanung 1973, 62 mit Anm. 74 . BayVGH Beschluß vom 21. 11. $1974=$ DVBl. 1975, 550 f.; Urt. vom 11. 6. $1975=$ DVBl. 1975,665 ; aber auch die inzwischen überholte Ansicht im Urt. des 1. Senats vom 15. 2. $1974=$ DVB1. 1975, 545 mit abl. Anm. Bettermann, dort 548 ff.; alle zur Frage, ob Art. 141 Abs. 3 S. 1 BV dem einzelnen ein subjektives Recht auf Erhaltung von Naturschönheiten gibt; ferner VG Ansbach DVBl. 1975, $150 \mathrm{ff}$.

87) Wahl, DOV 1975, 373 ff., 378 f.: „aggregierte Interessen“; dazu auch Ossenbiihl, DJT-Gutachten (Fn 177): "Stufensystem der Betroffenheit"; Schmıdt-Aßmann, DOV 1974, 543 ff., 547; Hinweis auch bei Bettermann, DVB1. 1975, 549. Kritisch dagegen Blümel, DVB1. 1975,705 ff. 


\section{Massenverfahren}

Selbst wenn es gelänge, das subjektive öffentliche Recht vor weiteren Ausdehnungen zu bewahren, werden sich die Gerichte künftig Verfahren gegenübersehen, an denen Hunderte, vielleicht Tausende beteiligt sind ${ }^{88}$ ). Die Probleme dieser Verfahren sind materieller und prozessualer Natur. Materiell geht es darum, wie die Gerichte jene vertiefende und individualisierende Aufbereitung noch sollen bewältigen können, die sie bisher als eine Art der Kompensation gegenüber schon bekannten administrativen Massenvorgängen etwa im Steuerrecht geleistet haben $\left.^{89}\right)$. Die prozessualen Probleme betreffen die praktikable prozeBtechnische Verfassung der beteiligten Massen. Dabei wird man zu unterscheiden haben zwischen denjenigen Verfahren, die nach wie vor die Grundstruktur der klassischen Baunachbarklage haben, bei der nur eine „Ecke" von einer Vielzahl mit gleichen Interessen Beteiligter besetzt wird, und einem vielgliedrigen Massenverfahren, in dem praktisch jeder gegen jeden kämpft, wie das bei der Verteilung geschlossener Fonds ${ }^{\mathbf{0}}$ ) denkbar ist.

Die derzeitige Diskussion richtet sich auf die prozeßrechtliche Bewältigung der „einfachen“ d. h. dreieckigen Massenverfahren des Straßen- und Anlagenbaus, auf die Schwierigkeiten der richtigen Ladungen, Zustellungen, der Akteneinsicht und Durchführung der mündlichen Verhandlungen ${ }^{91}$ ). Sie bezieht die Möglichkeit ein, daß das Verfahren bewußt als Kampfmittel eingesetzt und Fehler und Verzögerungen provoziert werden, um bestimmte Projekte um jeden Preis zu verhindern.

Hier Lösungen gegen eine drohende Immobilität der Verwaltung anzubieten, fällt schwer; denn alle Mittel einer strafferen Zusammenfassung der mit gleichen Interessen Beteiligten müssen sich auf dem Grat zwischen der unzulässigen Kollektivierung individuellen Rechtsschutzwillens ${ }^{92}$ ) einerseits und der Unpraktikabilität andererseits bewegen, mit der jeder Ansatz

88) Laubinger, Gutachten über eine künftige gesetzliche Regelung für Massenverfahren im Verwaltungsverfahrensrecht und im Verfahrensrecht fur die Verwaltungsgerichte, 1975, $S$. 7 f. mit statistischem Material; Blïmel, Masseneinwendungen im Verwaltungsverfahren, Festschrift für W. Weber, 1974, 539 ff.; Redeker, Zum neuen Entwurf eines Verwaltungsverfahrensgesetzes DVBl. 1973, 744 ff., 747.

$\left.{ }^{89}\right)$ Dazu sehr instruktiv Isensee, Verwaltungsraison gegen Verwaltungsrecht, StuW 1973, 199 ff.; zur "typischen Betrachtungsweise" im Steuerrecht Kruse, Steuerrecht I, 3. Aufl. 1973, 110 ff.

90) Z. B. im Flurbereinigungsverfahren, $\$ \$ 10$ ff. FlurbG.

91) Dazu Laubinger (Fn 88) $11 \mathrm{f}$.

92) BayVerfGHE 20, 167 ff ; vgl. BVerfGE 14, 263 ff., 287. 
einer Zusammenfassung deshalb belegt ist, weil er selbst wiederum eine mit Rechtsmitteln angreifbare Entscheidung darstellt. Auf diesem schmalen Terrain zulässigas) sind etwa die gerichtliche Bestellung eines gemeinsamen Prozeß- oder eines Zustellungsbevollmächtigten, sofern das Recht zur individuellen Prozeßführung nicht ausgeschlossen wird $\left.{ }^{94}\right)$. Auch öffentliche Zustellungen und Ladungen sind rechtsstaatlich unbedenklich, wenn sie gesetzlich vorgesehen sind und auf sie in hinreichender Weise aufmerksam gemacht wird ${ }^{\text {95}}$ ).

Erleichtert werden sollte außerdem die Gerichtspraxis, ein Verfahren als Musterprozeß zu behandeln. Dazu bedarf es einer Lockerung der Beiladungsvorschriften ${ }^{96}$ ). So sollte dort, wo der

99) Im einzelnen wird auf die ausfuhrlichen Erörterungen Laubingers (Fn 88), 23 ff. verwiesen. Als denkbare Lösungsansätze untersucht L.: Genehmigungserteilung und Planfeststellung durch Rechtssatz, Beschränkung des Beteiligtenkreises, Bildung von Zwangsverbänden, Zulassung freiwillig gebildeter Verbände, Umweltschutzbeauftrager, Sonderregelung für standardisierte Einwendungen, Bestellung gemeinsamer Vertreter oder Bevollmächtigter, Bestellung gemeinsamer Empfangsbevollmáchtigter, öffentliche $\mathrm{Zu}$ stellung von Ladungen und Entscheidungen sowie Sonderregelungen für das Recht auf Teilnahme an der mündlichen Verhandlung, für die Verhandlungsniederschrift, für die Akteneinsicht, die Zuleitung von Gutachten und das Rubrum.

94) Laubinger (Fn 88), 41 ff.; BayVerfGHE 20, $167 \mathrm{ff}$.

95) Laubinger (Fn 88), 56 ff.; für das Verwaltungsverfahren vorgesehen z. B. in $\$ 22$ Abs. 1 S. 3 AbfallbeseitigungsG; § 10 Abs. 4 Nr. 2 BImSchG; $\S 17$ Abs. 6 S. 3 BWaStraG; $\S 18$ Abs. 5 S. 2 Nr. 3 BFernStrG. Die von Blümel, Festschrift für W. Weber, S. 559 ff. dagegen erhobenen rechtsstaatlichen Bedenken überzeugen nicht. Eine für die verfahrensrechtliche Behandlung wesentliche, $d . h$. also schon $\mathrm{zu}$ Beginn des Verfahrens $\mathrm{zu}$ treffende Unterscheidung zwischen den unmittelbar Betroffenen (und Klagebefugten) und den übrigen Beteiligten, wie sie Blümel, S. 560 vorschlägt, ist in großen Verfahren nicht praktıkabel. Keineswegs sind nur Grundstückseigentümer (vgl. Blümel, S. 558) betroffen. Der funktionelle Nachbarbegriff reicht weiter und schließt es nicht aus, daß auch Mieter und Paichter "unmittelbar betroffen sind“. Der Kreis ist zunàchst unüberschaubar; jedenfalls rechtfertigt sich eine Sonderbehandlung der Grundeigentümer nicht. Die Probleme des Massenrechtsschutzes zwingen dazu, daß auch die „evident" Betroffenen hier soweit zurucksstecken, wie es notwendig ist, um den ProzeB mobil zu halten und wie es möglich ist, ohne den Rechtsschutz wesentlich zu erschweren. Auch die hohe Publizitait derartiger Massenvorgange, z. B. in der örtlichen oder regionalen Presse, läßt öffentliche Ladungen und Zustellungen tragbar erscheinen.

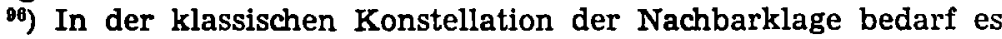
zwar nur der Beiladung des Bauherrn, nicht anderer Nachbarn (BVerwG DVBl. 1974, $767 \mathrm{ff} ., 768$, allerdings zu weitgehend mit der Anregung zur einfachen Beiladung). Schon die einfach verschränkte Konstellation einer Verpflichtungsklage des Bauwilligen auf Erteilung eines Dispenses und ebenso die Anfechtungsklage gegen nach- 
Kreis notwendig Beizuladender unüberschaubar wird, Beiladung nur auf Antrag erfolgen, dem eine befristete Aufforderung mit Ausschlußwirkung voranzugehen hätte.

\section{Verbandsklagen, Körperschaftsklagen}

Wenig Positives zur Problematik des Massenverfahrens tragen Verbandsklagemodelle bei, einerlei, ob man sie als eine Art überhöhter subjektıver Klage oder als verbandsinitiiertes objektives Beanstandungsverfahren konstruiert ${ }^{\mathrm{p7}}$ ). Ihre Vorteile, Einzelkläger $\mathrm{zu}$ entlasten und dadurch eine faktısche Verfahrensbündelung zu erreichen, werden aufgezehrt von der nachteiligen Beliebigkeit selbstbeigelegter Rechtswahrerschaft ${ }^{88}$ ). Sollte der Gesetzgeber in zeitgenössischer Verbandseuphorie sich trotzdem entschließen, Verbandsklagen in gewissen Bereichen einzuführen ${ }^{90}$ ), muß jedenfalls sichergestellt sein $^{100}$ ), daß Klagebefugnisse nur solche Verbände erhalten, die eine übersichtliche Verfassung der von ihnen vertretenen Interessen und dauerhaften Bestand gewährleisten. Klagen sog. ad-hoc-Gruppen ${ }^{101}$ ) dagegen würden den Prozeß mit vielen technischen Unsicherheiten der Vertretung, Zustellung und Ladung belasten und dann, wenn andere Individualberechtigte auf das Verfah-

barschützende Auflagen (dazu BVerwG DOV 1974, 318) aber verlangen die notwendige Beiladung aller betroffenen Nachbarn, denn die Entscheidung kann ihnen allen gegenüber nur einheitlich ergehen. Fehlt es an auch nur einer einzigen notwendigen Beiladung, so entfaltet das Urteil nach Ansicht der Rechtsprechung allen gegenüber keine materielle Rechtskraft; Redeker-v. Oertzen, VwGO \& $65 \mathrm{Rdnr}$. 22, 24 m. w. Nachw.; einschränkend Bettermann, Anm. MDR 1967, $951 \mathrm{f}$.

97) Systematisierung der Konstruktionen bei Bartlsperger, VVDStRL 33, 259 ff.; Rupp, Popularklage im Umweltrecht?, ZRP 1972, 32 ff.

88) Zur bisher durchgängig ablehnenden Rechtsprechung $v$. Mutius, Zulässigkeit der Verbandsklage?, VerwArch 1973, $311 \mathrm{ff}$; ferner VG Ansbach DVBl. 1975, 150 ff.; OVG Münster NJW 1975, 463; b.-w. StGH DOV 1975, 62 ff. In der Literatur positiv: Manfred Wolf (Fn 39); Faber, Die Verbandsklage im Verwaltungsprozeß, 1972; Rehbinder-Burgbacher-Knieper (Fn 8), Brohm, VVDStRL 30, $300 \mathrm{f}$. Weitere Nachw. bei Blumel, Festschrift fur W. Weber, 564 Fn. 143; ders., Flurbereinigung (Fn 78); Wälde, AöR Bd. 99 (1974), 585 ff., 622 f. Ablehnend Bettermann, Zur Verbandsklage, ZZP 1972, 133 ff.; ders., AöR Bd. 99 (1974) 501 ff.; Wolff-Bachof, Verwaltungsrecht I § 43 I b 2; s. auch Fn 97; W. Schmidt, VVDStRL 33, 210.

99) Gemeinsamer Entw. des BMI, BMJ und BML (Stand Juni 1975); Initiativentwurf der FDP-Fraktion im b.-w. Landtag, Landtags-Drucks. 6/2153.

100) Zum folgenden auch Stelkens, Einige verwaltungsprozessuale Fragen zur Verbandsklage, DVB1. 1975, $137 \mathrm{ff}$.

101) So aber Rehbinder-Burgbacher-Knieper (Fn 8), 151. 
ren angewiesen sind, sehr schnell an die Grenze eines rechtshindernden, verfahrenswidrigen Gerichtsschutzes führen.

Ohne Gesetzesänderung, allein durch eine präzisere Fassung der Selbstverwaltungsaufgaben, lassen sich dagegen Klagen von Gemeinden und Gemeindeverbänden in Fällen begründen, in denen höherstufige Planungen das Wohl der Einwohner berühren, private Klagen jedoch mangels faßbarer individueller Betroffenheit ausscheiden ${ }^{102}$ ). Die Gemeinden sind im Rahmen dessen, was sie durch öffentliche Einrichtungen betreuen dürfen, originäre Sachwalter zum Wohle ihrer Einwohner. Entsprechende kommunale Klagen scheinen weit eher als Verbandsklagen geeignet, eine Art prảventiven und faktisch bündelnden Rechtsschutzes zu gewähren ${ }^{103}$ ).

\section{B. Intensität verwaltungsgerichtlicher Kontrolltätigkeit}

Die Maßstäbe der gerıchtlichen Kontrolle hat das Erstreferat ausführlich behandelt. Ich beschränke mich auf Bemerkungen zum Kontrollumfang, denen ich folgende Feststellungen vorausschicke:

(1) Verwaltungsermessen und Planungsermessen dürfen nicht als qualitativ Verschiedenes verstanden werden, schon deshalb nicht, weil sie sich in den gesetzlichen Tatbeständen nicht trennen lassen ${ }^{104}$ ). Beide Typen finden zusammen in der Maxime, daß Verwaltungshandeln nur unter umfassender Ermittlung und Abwägung aller einschlägigen Gesichtspunkte er-

102) Schmidt-Aßmann, DÖV 1974, 541 ff., 547; Blümel, DVBl. 1975, 708 ff.; Wahl, DƠv 1975, 373 ff., 379 Anm. 36; zur Notwendigkeit eines "Systems gestufter Betroffenheit" Ossenbühl, DJT-Gutachten (Fn 4), 177. Die Rechtsprechung ist bisher auch hier zurückhaltend: Ansàtze in BVerwGE 40,323 = DVBl. 1973, 34 ("Krabbenkamp II"); ausführlich erörtert, aber nicht abschließend entschieden BayVGH DVBl. 1975, 199 ff., 202-204 („Grafenrheinfeld“); positiver VG Freiburg DVBl. 1975, 343 ff., 344 (,Wyhl").

109) De lege ferenda könnte uberlegt werden, auch andere Körperschaften öffentlichen Rechts in ganz bestimmten, eng mit ihren Aufgaben verbundenen Beziehungen mit Klagebefugnissen auszustatten, wie das in $\$ 8$ Abs. 4 HdwO geschehen ist; $z$. B. für Teilnehmergemeinschaft im Flurbereinigungsverfahren vgl. Blümel, Flurbereinigungsrecht (Fn 76), 82 ff.

104) Z.B. das baurechtliche Dispensationsermessen ( $\$ 31$ Abs. 2 BBauG), das zunehmend als "kleiner Planungsakt" erscheint; vgl. Schmidt-Aßmann, Grundfragen des Städtebaurechts (Fn 59), $175 \mathrm{ff}$. Altere gewerberechtliche Tatbestände werden mit planerischem Gehalt angefüllt, z. B. im Verkehrswirtschaftsrecht, dazu Lange, Verkehr und öffentliches Recht, 1974, 127 ff. Jüngst W. Schmidt, Abschied vom „unbestimmten Rechtsbegriff“, NJW 1975, 1753. 
folgen darf. Abwägen als rechtliche Chiffre rationalen Handelns schlechthin, als Essentiale gesetzesdirigierter Verwaltung $\left.{ }^{105}\right)$ ! Die quantitativen Unterschiede zwischen Planungsund Verwaltungsermessen liegen in der Genauigkeit der vorhandenen Gesetzesaussagen und in der Utberschaubarkeit möglicher Abwägungsfolgen ${ }^{108}$ ).

(2) Ähnlich sind Beurteilungsspielräume und Ermessen nicht kategorial getrennt ${ }^{107}$ ), sondern Differenzierungen, herausgearbeitet für Bereiche gesetzlich eng gebundener Verwaltung und hier zur rechtlichen Durchdringung nach wie vor geeignet, weil sie unterschiedliche Einstellungen zum Gesetz kennzeich-

105) BVerwG Urt. vom 11. 10. $1968=$ Buchholz 442, 60, § 6 LuftVG Nr. 1; BVerwG Urt. vom 30. 4. $1969=$ DVBI. 1969, 697 ff., 699; BVerwG Urt. vom 20. 10. 1972 = BRS $25 \mathrm{Nr}$. 25; BVerwG Urt. vom 14. 2. 1975 = NJW 1975, 1373 ff., 1375; s. auch Haberle, Offentliches Interesse (Fn 3), $691 \mathrm{ff}$.

100) Wolff-Bachof, Verwaltungsrecht I, § 31 II b 2 und III; Badura, Das Planungsermessen und die rechtsstaatliche Funktion des Allgemeinen Verwaltungsrechts, Festschrift zum 25jährıgen Bestehen des bayerischen Verfassungsgerichtshofs, 1972, 157 ff. mit dem zutreffenden Hinweis, daß „das Planungsermessen nicht einfach den Regeln des als Rechtsfolgeermessen definierten Verwaltungsermessens unterworfen werden “ kann (167); Häberle, Offentliches Interesse (Fn 3), 692; fur eine stärkere Trennung Ossenbihl, DJT-Gutachten (Fn 4), 183 ff. Hoppe, Zur Struktur von Normen des Planungsrechts, DVBl. 1974, 641 ff., 644 will den Begriff "Planungsermessen" ganz vermieden wissen, weil er eine deutliche Absetzung vom Verwaltungsermessen für notwendig hält; seine Ansicht beruht jedoch auf einer Uberbewertung der Trennung von final und konditional programmiertem Verhalten (vgl. dazu Fn 29). Das Planungsermessen ist in sich kein einheitliches Phänomen, sondern tatbestandsweise unterschiedlich ausgebildet mit konditional und final determinierten Bezügen. So wirken auf das Ermessen bei der Bauleitplanung ( $\$ 1$ BBauG) sowohl zielgerichtete Aussagen (Abs. 4 und 5) als auch landesplanerische Aussagen ein (Abs. 3), die sehr wohl auch konditional programmiert sein können; dazu auch Oberndorfer, Strukturprobleme des Raumordnungsrechts, Verwaltung 1972, 257 ff.

107) Ehmke, "Ermessen" und nunbestimmter Rechtsbegriff“ im Verwaltungsrecht, 1960; Häberle, Offentliches Interesse (Fn 3), 693; Schmidt-Eichstaedt, Ermessen, Beurteilungsspielraum und eigenverantwortliches Handeln der Verwaltung, AöR 99 (1974), 173 ff.; Soell, Das Ermessen der Eingriffsverwaltung 1973, 205 ff.; Obermayer, Die Beurteilungsfreiheit der Verwaltung, BayVBl. 1975, 257 ff.; GemSen. OVG Beschl. vom 19. 10. $1971=$ BVerwGE 39, $355 \mathrm{ff}$. = NJW 1972, 1411 = DVBl. 1972, $604 \mathrm{ff}$. W. Schmidt, NJW 1975, 1755. Anders die noch $h$. M. s. Wolff-Bachof, Verwaltungsrecht I \& 31 II a (vgl. auch III a. E.) m. w. Nachw.; Redeker, DVBl. 1972, $608 \mathrm{f}$. und $896 \mathrm{f}$. Klar stellt Bachof, JZ 1972, 641 ff., 642 heraus, daß er selbst die Grenze zwischen beiden Phänomenen nicht als "absolut" verstanden wissen will. 
nen ${ }^{108}$ ). In der gestaltenden Verwaltung dagegen läßt sich die Aufteilung nicht durchhalten ${ }^{100}$ ).

Diese Relativierung bisheriger Zasuren ist notwendig, um die gleitenden Utbergänge in den Dichtegraden gesetzlicher Aussagen in die gerichtlichen Kontrollmechanismen aufnehmen zu können. Die kontrollgerechte Neubundelung freilich hängt nicht allein von der Genauigkeit gesetzlicher Maßstäbe, sondern auch noch von zwei weiteren Aspekten ab:

- den bereichsspezifischen Rechtsschutznotwendigkeiten ${ }^{110}$ ),

- der administrativen Kompetenz zu eigenverantwortlicher Sachwalterschaft und ihrer speziellen Organisation ${ }^{111}$ ).

108) Grundlegend Bachof, Beurteilungsspielraum, Ermessen und unbestimmter Rechtsbegriff im Verwaltungsrecht, JZ 1955, $97 \mathrm{ff}$. Zur unterschiedlichen Einstellung des Rechtsanwenders auch $L a$ renz, Methodenlehre der Rechtswissenschaft, 3. Aufl., 1975, 281 f.; Bachof, JZ 1972, $641 \mathrm{ff}$., 644. In der Rspr. ist jedenfalls gegenüber überschaubaren Zusammenhängen die alte, zwischen unbestimmten Rechtsbegriffen auf der Tatbestands- und Ermessen auf der Rechtsfolgenseite unterscheidende Konstruktion der „Koppelungstatbestände" auch nach der Entscheidung des GemSenats (Fn 107) beibehalten worden; z. B. BVerwG Urt. vom 21. 5. $1974=$ DVBl. 1974, 849 ff. ("Gründe öffentl. Gesundheitsinteresses" i. S. § 3 Abs. 3 BAO); Hess. VGH Beschl. vom 10. 4. $1974=$ DVBl. 1974, $877 \mathrm{ff}$.

109) BVerwG Urt. vom 21. 1. 1972 = DVBl. 1972, 895 ("Importquo-

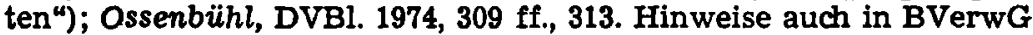
Urt. vom 5. 7. $1974=$ BVerwGE 45,309 ff., = DVBl. $1974,767 \mathrm{ff}$. = DOV 1975, 92 = NJW 1975, 70 (,Flachglas"), das die Planungsnorm des $\$ 1$ Abs. 4 und 5 BBauG zwar im alten Sinne eines zweiteiligen Koppelungstatbestandes interpretiert, aber gleitende Ubergänge zwischen „Bestimmung und Gewichtung des Abwägungsmaterials“ in der Praxis anerkennt (774). Früher schon Kellner, Einiges zum behördlichen Ermessen, DOV 1969, 309 ff., 312 mit Nachw. zur älteren Rspr.; ders., Neue Erkenntnisse zum sogenannten Beurteilungsspielraum?, DOV 1972, $801 \mathrm{ff}$., 807.

$\left.{ }^{110}\right)$ Diese Notwendigkeiten können sich aus differenziert ermittelten grundrechtlichen Schutzaussagen (dazu Seetzen, Der Prognosespielraum des Gesetzgebers, NJW 1975, $429 \mathrm{ff}$.), aber auch aus einer beanstandenswerten Verwaltungspraxis ergeben; so auch Bullinger, NJW 1974, 769 ff., 772 (,im Wege einer Art Schocktherapie"). Der letztere Gesichtspunkt muß dazu anleiten, die bisher häufig unterbliebene gebietsweise Realanalyse praktischen Verwaltens nachzuholen und in die Dogmatik einzubeziehen; $v$. Welck, Rechtstatsachenuntersuchungen zum Verwaltungsermessen, DOV 1973, 732 ff.

111) Der Gesichtspunkt der administrativen Verantwortung ist in diesem Zusammenhang vor allem von Redeker, Fragen der Kontrolldichte verwaltungsgerichtlicher Rechtsprechung, DOV 1971, 757 ff. und Ossenbühl, Zur Renaissance der administrativen Beurteilungsermächtigung, DOV 1972, 401 ff.; ders., DVBl. 1974, 309 ff. hervorgehoben worden. Das Indizierungs-Urteil (BVerwG Urt. vom 16. $12.1971=$ BVerwGE $39,197 \mathrm{ff} .=$ DVBl. $1972,388=$ DOV 1972, $419=\mathrm{NJW} 1972,596)$ beruht auf der gleichen Uberlegung. Die 
Erst diese Trias konstituiert die Problemlösung insgesamt ${ }^{\mathbf{1 2}}$ ). Zwischen ihren Bezuggspunkten ist das Kontrollproblem nach Zeit und gesetzlichem Standort dogmatisch nicht festgeschrieben $^{113}$ ), sondern bewegt sich in Abgrenzungszonen. Die folgenden Erörterungen stellen daher, sofern sie allgemein sind, auch nur „Rahmenüberlegungen" dar.

\section{Programmbegriffe als Abwägungsdirektiven}

Gesetzliche Tatbestände, auf denen komplexe Verwaltungsentscheidungen basieren, lassen sich regelmäßig aufgliedern in einen Teil, der die Abwägungsdirektiven, und einen zweiten Teil, der den Abwágungsvorgang umfaßt. Die Abwägungsgesichtspunkte erscheinen dabei in der Form unbestimmter Gesetzesbegriffe, weisen aber Merkmale auf, die im Problem der Beurteilungsermächtigung nur unzureichend erfaßt werden. Es geht um eine typische Bezogenheit solcher Gesetzesbegriffe auf vorgängige, begleitende oder künftige administrative Program-

Uberlegung bedarf jedoch der Präzisierung: ein uberzeugendes Argument zur Kontrollbeschränkung liefert sie nicht schon in jedem Fall administrativer Selbständigkeit, sondern nur dort, wo die Weitläufigkeit der von der Begriffshandhabung ausgelösten Folgen weit über den Einzelfall hinaus die administrative Vorbereitungs-, Stimmigkeits- und Folgenverantwortung trifft, d.h. wo ein Verwaltungsprogramm empfindlich gestört wird. In einfachen, singulären Fallkonstellationen dagegen bietet der Hinweis auf die administrative Eigenverantwortung für sich noch kein kompaktes Argument, weil hier die Filterwirkung des Einzelfalles ein nachhaltiges, in $\mathrm{Ab}$ wägung zu Rechtsschutzüberlegungen unzumutbares „Hineinregieren" der Gerichte regelmäßig verhindert. Als Beispiel einer flexibel auf alle drei Aspekte reagierenden Gerichtspraxis die Rspr. des französischen Conseil d' Etat, dazu Bullinger, Unbestimmte Gesetzesbegriffe in der neueren deutschen und französischen Verwaltungsrechtsprechung, Festschrift für Jahrreiß, 1974, 19 ff.

${ }_{112}$ ) Auf die Bedeutung aller drei Gesichtspunkte hinzuweisen, besteht Veranlassung, weil nach einer Seite, die das Problem zu stark erkenntnistheoretisch sah und dabei die hermeneutische Leistungsfähigkeit der Gesetzesbegriffe überschätzte, heute rechts- und verwaltungspolitische Aspekte $\mathrm{zu}$ sehr in den Vordergrund gestellt werden; zu beiden Gesichtspunkten Jarosch, Die Fiktion des unbestimmten Rechtsbegriffs, DOV 1974, 123 ff. Die Leistungsfähigkeit der Gesetzesbegriffe bildet, wie nicht übersehen werden darf, nach wie vor die Basis; sie kann mit zunehmender Erfahrung im Verwaltungsbereich, aber auch durch Präjudizien wachsen. Berühmtestes Beispiel einer solchen "Disziplinierung" ist die polizeiliche Generalklausel des \& 10 II 17 preuB. ALR, die von der Rechtsprechung nach und nach durchdrungen worden ist; dazu Soell, Ermessen (Fn 107), $122 \mathrm{ff}$. Hier scheint uns auch die eigentliche und künftige Bedeutung der vom derzeitigen Kenntnisstand zu $\$ 1$ Abs. 4 und 5 BBauG aus gesehen allerdings zu weit gehenden Entscheidung des BVerwG vom 5. 7. 1974 - „Flachglas“ - (Nachw. Fn. 109) zu liegen.

113) W. Weber, VVDStRL 14, 192 (Diskussionsbeitrag). 
me, die das Gesetz mit Blankettbegriffen wie dem der "Ziele der Raumordnung und Landesplanung "118") rezipiert"114). Diese Begriffe sind „mehrstöckig“: Sie kennzeichnen administrative Entfaltungsverantwortung und nehmen dabei regelmäßig auf instantielle Gliederungen des Organisationsgefüges Bezug'15).

1194) § 1 Abs. 3 BBauG; § 1 Abs. 3 StBauFG; \& 2 S. 2 AbfalliG; zu diesen Raumordnungsklauseln Forsthoff-Blümel, Raumordnungsrecht und Fachplanungsrecht, 1970; G. Klein, Zur Rechtsnatur und Bindungswirkung der Ziele der Landesplanung, 1972.

114) Treffend Kellner, DOV 1969, 309 ff., 312: „Allen Entscheidungen ist gemeinsam, daß jene Rechtsbegriffe weder als Ermessensermächtigung gedeutet werden können noch einen Beurteilungsspielraum einräumen." Auf diese von Kellner sog. Faktorenlehre nimmt auch Redeker, DVBl. 1972, 896 f. Bezug.

115) (1) Der administrative Programmbezug dieses Begriffs tritt schon in ihrer Formulierung ausdrücklich hervor: „Verdichtungsraum" ( $\$ 2$ Abs. 1 Nr. 6 BROG); „Entwicklungsbereich" ( 53 StBauFG); "Entwicklungsschwerpunkte und Entwicklungsachsen" ( $\$ 21$ n.-w. LandesentwicklungsG vom 19. 3. 1974, GVBl. S. 96); „Belastungsgebiete" ( $\$ 44$ BImSchG). - (2) Bald nimmt das Gesetz mit solchen Begriffen inzidenter auf Planvorstellung der Verwaltung Bezug: die "stadtebaulichen Mißstände" ( 11 Abs. 2, $\$ 3$ StBauFG; dazu VG Aachen, Städte- und Gemeindebund 1974, 116), die „Funktionsfähigkeit" und die „Versorgungsfunktion im Verflechtungsbereich“ (\$ 3 Abs. 3 Nr. 2 StBauFG), "die anzustrebende Entwicklung des Landesgebiets" ( $\$ 53 \mathrm{Nr}$. 1 StBauFG) beziehen sich auf administrative Zielvorgaben. Zum Begriff „sozialer Brennpunkt" (§ 14 Abs. 2 n.-w. KindergartenG vom 21. 12. 1971, GV S. 534), vgl. den begriffsausfüllenden Erlaß des Sozialministers vom 20. 9. 1972 (MBl. NW S. 1765) und die Anfrage zur Weiterentwicklung dieses Begriffs (Landtags-Drucks. 8/84). Zu den Begriffen des Kohleanpassungsgesetzes eingehend Seidler, Rechtsschutz bei staatlicher Wirtschaftsplanung (Fn 86), 46 ff. Hierher gehört auch der Begriff ,volkswirtschaftlich besonders förderungswürdig“ ( $\$ 1 \mathrm{Abs} .4$ InvestitionszulagenG 1969 BGBl. I, S. 1211); dazu VG Frankfurt Urteile vom 13. 3. 1974, 26. 6. 1974, 4. 12. 1974, VG Köln Urt. vom 22. 2. 1972 (alle unveröffentl.); OVG Munster Urt. vom 9. 4. 1973 = GewArch. 1974, 244 ff.; BVerwG Urt. v 7.5. $1975=$ DVBl. 1975, $723 \mathrm{ff}$. Die in sich variantenreiche Rspr. zu diesem Begriff kann hier nicht referiert werden: Im Sinne einer Begriffsausfullungsermächtigung VG Frankfurt im Urt. vom 4. 12. 1974 (AU S. 6 f.) mit Hinweis auf die Dynamik des Realvorganges. Das OVG Münster lehnt einen Vorrang der Verwaltung bei der Auslegung und Anwendung des Begriffs zwar ab, hat aber keine Bedenken, zur Definition auf Verwaltungsvorschriften zurückzugreifen, die „in Kenntnis und mit Billigung des Parlaments" praktiziert worden sind. Das BVerwG schließlich läßt es offen, ob ein Beurteilungsvorgang bei der Anwendung besteht; die Begriffsauslegung nimmt es selbst vor, allerdings in tbereinstimmung mit der Ansicht der Verwaltung. - (3) Teilweise unterscheiden sich solche Programmbegriffe äußerlich von voll kontrollierbaren Rechtsbegriffen nicht. Die Mehrschichtigkeit wächst hier erst später, mit zunehmender Planung in den Begriff hinein. Ein Beispiel bildet der ursprünglich aus dem baupolizeilichen Bereich stammende Begriff „erforderlich“ (\$ 2 Abs. 1 BBauG). BVerwG Urt. vom 7. 5. 1971 
Der Verwaltung wird hier nicht eigentlich, oder jedenfalls nicht ausschließlich, ein Beurteilungsvorrang im Subsumtionsbereich, sondern primär die Kompetenz zu sukzessiver Begriffsbildung und Definition, bei technischen Begriffen auch der Methodenwahl ${ }^{116}$ ) eingeräumt. In einem weiteren Sinne hat man diese Vorgänge dem Problem ermessenslenkender Verwaltungsvorschriften zuzurechnen. Genauer betrachtet sind sie gesetzliche Bestätigungen originärer administrativer Maßstabssetzung für den Innenbereich, die erst über eine Kette von Koordinationsklauseln ${ }^{117}$ ) auf das Staat-Bürger-Verhältnis einwirken.

Das erfordert ein zweistufiges gerichtliches Kontrollschema: Die normativen Begriffsausfüllungen der Verwaltung genießen ohne Rücksicht auf ihre Rechtsform den Vorrang der klassischen Außenrechtssätze, nur daraufhin untersucht zu werden, ob sie den gesetzlich gesteckten Rahmen wahren $\left.{ }^{118}\right)$. Gerechtfertigt ist diese Privilegierung der ersten Stufe, weil auf ihr durch die allgemeine Fassung der Normativaussagen Vorhersehbarkeit gewährleistet wird und weil die regelmäßige instantielle Trennung von Maßstabssetzung und -anwendung Sicherungen verwaltungsinterner Gewaltengliederung, sowie häufig besonderen Sachverstand bietet.

Innerhalb des administrativ verdichteten Begriffsgefüges kann die konkrete Anwendung dann schon die Genauigkeit bloßen Normenvollzugs haben, dessen gerichtliche Kontrolle auf der 2. Stufe keine Schwierigkeiten bereitet. Das muß allerdings nicht so sein. Häufig wird es sich auch bei der sog. Sub-

$=\mathrm{DOV} 1971,633 \mathrm{ff} ., 634$ bestımmt ihn jetzt als „nach der planerischen Konzeption (!) der Gemeinde erforderlich".

116) Die Bedeutung des Vorrangs der Methodenbestimmung läßt sich ablesen an der Methodenvielfalt fur die Bestimmung des $\mathrm{Be}$ griffs „zentralörtliche Gliederung" ( $\$ 20 \mathrm{n}$.-w. LandesentwicklungsG vom 19. 3. 1974 GVBl. S. 96); dazu Hellberg, Zentrale Orte als Entwicklungsschwerpunkte in ländlichen Gebieten, 1972. Erst die Methode entscheidet hier über das Programm.

117) Hierüber dringen Entwicklungen des Verwaltungsinnenbereichs in die Außensphären, die Uberlegungen zu einem selbständigen Verordnungsrecht der Exekutive notwendig machen; dazu jüngst $\boldsymbol{H}$. $\boldsymbol{H}$. Klein, Erwägungen der Enquête-Kommission Verfassungsreform des Deutschen Bundestages zu einer Neufassung des Art. 80 GG, DOV 1975, 523 ff. Kennzeichnend die Entwicklung im Bereich des Schulwesens (Bestimmung der Lehrinhalte), dazu BVerwG DVBI. 1975, $421 \mathrm{ff}$. und 423 ff.; bayVerfGH DVBl. 1975, 425 ff.; Dietze, Verfassungsfragen lernzielorientierter Curricula, DVBl. 1975, $389 \mathrm{ff}$.

118) In diese Richtung weist $\$ 70$ Abs. 4 S. 2 GWB; dazu Soell, Ermessen (Fn 107), 54 ff.; Seidler, Rechtsschutz (Fn 86) 62 f.; zu eng BGHZ 49, 367 ff. 
sumtion weniger um Anwendung als um Anpassung und Entwicklung handeln, die ihrerseits normativ nicht exakt vorgezeichnet sind. Für die gestaltende Verwaltung ist dieses Anpassen die typische Form der Anwendung eigengesetzten Rechts, weil sie allein den Flexibilitätenanforderungen zeitlich fortschreitender Entscheidungsbildung gerecht wird $\left.{ }^{119}\right)$. Sie involviert durchgängig und nicht nur ausnahmsweise Einschätzungsmargen im Bereich der Subsumtion ${ }^{120}$ ), die nach dem zum Beurteilungsspielraum entwickelten Kontrollschema ${ }^{121}$ ) überprüfbar sind.

\section{Kontrolle des Abwägungsvorgangs und des Abwägungser- gebnisses}

Die konkrete Gestaltung innerhalb der Zielvorgaben vollzieht sich im Abwägen. Auch ihm gegenüber ist die gerichtliche Kontrolle zweistufig ausgebildet ${ }^{122}$ ): (1) Voll überprüfbar sind

110) Anschauungsmaterial dazu in der Kommentarliteratur zu \$ 1 Abs. 3 BBauG („Die Bauleitpläne sind den Zielen der Raumordnung und Landesplanung anzupassen") und in der Rspr. zu $\$ 8$ Abs. 2 S. 1 BBauG („Bebauungspläne sind aus dem Flächennutzungsplan zu entwickeln“), b.-w. VGH BRS Bd. 27 Nr. 1, 2, hess. VGH BRS Bd. 27 Nr. 172, Schmidt-Aßmann, Grundfragen des Städtebaurechts, 120 ff. und jüngst BVerwG Urt. vom 28. 2. $1975=$ BauR 1975, 257 ff.

120) Anders BVerwG Urt. vom 5. 7. 1974 (Fn 109) „Flachglas“, das die in \$ 1 Abs. 4 und 5 BBauG verwandten Rechtsbegriffe für voll kontrollierbar hält. Dem Urteil ist darin zuzustimmen, daß sich aus der "Indizierungsentscheidung“ (Fn 111) nichts für die Behandlung des $\$ 1$ BBauG ableiten läßt. Nicht zwingend erscheint mir aber die Verabsolutierung des Rechtsschutzarguments, die das Flachglasurteil mit dem Hinweis auf die eigentumsgestaltende Funktion des Bebauungsplanes vornimmt. Der Uberhang an allgemeinen Aussagen wird allerdings durch den Hinweis des Gerichts auf die Verschrankung von voll kontrollierbaren Abwägungsdirektiven und beschränkt kontrollierbarem Abwägungsvorgang gemildert. Auf die Verhältnisse höherstufiger Planungen ist das Urteil nicht unbesehen ubertragbar. Zu einer positiven "Vorgreiflichkeit" der Entscheidung vgl. oben Fn 112. Gegen die volle Uberprüfung des Abwägungsmaterials Redeker, DOV 1971, 757 ff.; Hoppe, Zur Rechtskontrolle von Bebauungsplänen, Festschrift für Scupin, 1973, 121 ff., 129-133 (mit Anerkennung auch eines Auslegungsvorrangs der Verwaltung); Ossenbühl, DJT-Gutachten (Fn 4), 187; Schröder, Die richterliche Kontrolle des Planungsermessens, DOVV 1975, 308 ff.; Papier, Die rechtlichen Grenzen der Bauleitplanung, DVBl. 1975, $461 \mathrm{ff}$.

121) Dazu Erichsen, Unbestimmter Rechtsbegriff und Beurteilungsspielraum, VerwArch $1972,337 \mathrm{ff}$.

122) Dazu im einzelnen BVerwGE 34, $301 \mathrm{ff}$; ausführlich BVerwG Urt. vom 5. 7. 1974 (Fn 109); Gelzer, Bauplanungsrecht, 2. Aufl., 1972, Rdnr. 33 ff. Hoppe, Rechtskontrolle (Fn 120); ders., DVB1. 1974, 641 ff., 644 mit weiteren Differenzierungen, die jedoch Gefahr laufen, in der Vielzahl ihrer Kontrollansätze von der eigentlich freien Gestaltung der Verwaltung im Ergebnis nichts mehr ubrigzulassen. 
die prozeduralen Vorgange, d.h. der Ablauf des Verfahrens, Form und Begründung, die Informationsverarbeitung und die Abwägungsmotivation - letztere jedoch nicht als „anständige Gesinnung" der betreffenden Organwalter fehlgedeutet! (2) Die verbleibenden materiellen Entscheidungsbereiche dagegen kann das Gericht nur in einem àßßeren Rahmen kontrollieren, weil es hier um Bewertung und Gewichtung von Varianten geht, die ihrerseits mit anderen Sektoren des Finanz- und Organisationswesens rückgekoppelt sind und so über Folgen und Stimmigkeit auf die administrative Gesamtverantwortung ${ }^{123}$ ) verweisen, die die Dimensionen des einzelnen Prozesses übersteigt. Die Vielzahl moglicher Abwägungsvarianten macht das gerichtliche Kontrollinstrumentarium, die Fragen nach Geeignetheit, Erforderlichkeit und Verhältnismaßigkeit unscharf, so daß es nur noch auf grobe Verstoße reagiert ${ }^{124}$ ). Alternativen (z. B. der Standortwahl oder Trassenführung), wie sie bei einer Erforderlichkeitsprüfung sensu stricto zu behandeln wären, fallen aus dem Prozeß praktisch gänzlich heraus. Die Frage nach der zweckmäßigeren Entscheidung wird zum Kompetenzproblem, das im Blick auf die Verwaltungsverantwortung für den $\mathrm{Ge}-$ samtzusammenhang im Sinne eines administrativen Abwägungsvorrangs unter Evidenzvorbehalt ${ }^{125}$ ) zu lösen ist.

Auch hier konnen Verwaltungsvorgaben die Abwảgung allerdings eingrenzen und dem Gericht dadurch zusatzliche Kon-

123) Vgl. BVerwG vom 14. 2. 1975 = NJW 1975, 1373 ff., 1374 zur Planungsbefugnis und planerischen Gestaltungsfreiheit.

124) Brohm, VVDStRL 30, 257 f.; Badura, Planungsermessen (Fn 106), 181; Papier, DVBl. 1975, 461 ff., 465. Zur Angewiesenheit des Ubbermaßverbots aus uberschaubare Verhältnisse Lerche, Ubbermaß und Verfassungsrecht, 1961, 135.

${ }^{125)}$ Ossenbühl, DJT-Gutachten (Fn 4), 190 f.; Papier, DVBl. 1975, 461 ff., 464 f.; Stüer, Zum autonomen (kontrollfreien) Gestaltungsraum von Gesetzgeber und Verwaltung, DVBl. 1974, 314 ff., 320; W. Schmidt, NJW 1975, 1756; stark einschränkend Hoppe, DVBI. 1975, 692 f. Die Rspr. (Fn 109, 123) macht diesen Evidenzvorbehalt nicht hinreichend deutlich, obwohl er ihr zugrundeliegt. So muß "Abwägungsdisproportionalität" verstanden werden als klar erkennbare Unverhältnismäßigkeit. Nicht genugt, daß nach Ansicht des Gerichts Schaden und Nutzen der MaBnahme sich die Waage halten oder der erstere nur leicht überwiegt (Unzweckmäßigkeit); zutreffend Sendler, WiR 1972, 453 ff., 469; zur franzosischen Evidenzpraxis Bullinger, Festschrift für Jahrreiß, 26. Aber auch bei der Abwägungsfehleinschätzung kann es, worauf vor allem Papier (a.a. O.) hinweist, nur um einen evidenten Fehler gehen, weil eine objektive Rangordnung der Abwägungsbelange, auf die das Gericht zurückgreifen konnte, nicht besteht Der Evidenzvorbehalt sichert der richterlichen Entscheidung gegenüber komplexen Maßnahmen jene Einsichtigkeit ihrer Aussagen, die sie bei überschaubaren Sachverhalten und Wertungen auch in tiefergreifender Kontrolle durchhalten kann, dazu oben S. 13; Kruger, Allgemeine Staatslehre, S. 752. 
trollmaßstäbe an die Hand geben. Doch darf man auch bei solchen Vorgaben Gesichtspunkte der Gleichheit und Systemgerechtigkeit nicht als Vollzugsgleichheit mißverstehen ${ }^{126}$ ).

Als Hilfsmittel gerichtlicher Kontrolle werden schließlich wirtschaftswissenschaftliche Methoden wie Kosten-Nutzenoder Nutzwertanalysen in Betracht gezogen ${ }^{127}$ ). Zur Zeit ist von solchen Anleihen allerdings nicht viel zu erwarten. Ihre Anwendbarke1t auf hochkomplexe Verwaltungsentscheidungen ist bisher nicht hinreichend erprobt ${ }^{128}$ ). Als Kontrollmethoden des Gerichts eigneten sie sich nur dann, wenn die originäre Verwaltungsentscheidung entsprechend zustande gekommen oder das Gesamtgebiet über „operational formulierte“ Ziele verfügte. Nachträglich im gerıchtlichen Verfahren mobilisiert, stiften solche Methoden nach aller Erfahrung mehr Verwirrung als Nutzen. In die Zukunft hinein allerdings kann das Verrechtlichungsgebot als Gebot exakterer Bestimmbarkeit hier auf eine stärkere Verwissenschaftlichung drängen ${ }^{129}$ ), die jedoch im Verwaltungsbereich anzusetzen hat.

\section{Sicherung und Begrenzung der Urteilswirkungen}

\section{Die Sicherung rechtzeitigen Rechtsschutzes}

Rechtzeitiger Rechtsschutz ist vorrangig mit jenen Institu$\operatorname{ten}^{130}$ ) zu erstreben, die auch sonst dem uneffektiven Dogma der Inzidentprüfung entgegenwirken sollen, also der prinzipalen Normenkontrolle, den Verfahrenszäsurierungen und den darauf ausgerıchteten storungspräventiven Klagen ${ }^{131}$ ).

120) $\mathrm{Zu}$ den Mutationen des Gleichheitssatzes gegenuber der Planung Imboden, VVDStRL 18, $112 \mathrm{ff}$; Brohm, VVDStRL 30, $277 \mathrm{mit}$ Nachw. Anm. 91.

127) Schmidt-Aßmann, DOV 1974, 541 ff., 546; Blümel, DVB1. 1975, $695 \mathrm{ff}$. Zu solchen Techniken vgl. Zangemeister, Nutzwertanalyse in der Systemtechnik, 1970; Eekhoff, Nutzen-Kosten-Analyse und Nutzwertanalyse als vollständige Entscheidungsmodelle, Raumforschung und Raumordnung, 1973, $93 \mathrm{ff}$.

128) Dazu Sellnow, Kosten-Nutzen-Analyse und Stadtentwicklungsplanung, 1973; Bullinger, Festschrift für Jahrreiß, 24.

129) § 6 Abs. 2 HGrG: Kosten-Nutzen-Analyse für Maßnahmen von erheblicher finanzieller Bedeutung. Hoppe, DVBl. 1974, 641 ff., 646: "Postulat der operationalen Formulierung".

130) Zu ihrer Systematik Bettermann, Vorbeugender Rechtsschutz in der Verwaltungsgerichtsbarkeit, in: Zehn Jahre Verwaltungsgerichtsordnung (Fn 3), 185 ff.; Ule, Vorbeugender Rechtsschutz im Verwaltungsproze $ß$, VerwArch 1974, 291 ff ; 294-298.

131) Vgl. oben S. 240; ferner Bartlsperger; Subjektives öffentliches Recht und störungspräventive Baunachbarklage, DVBl. 1971, 723 ff.; Friauf, "Latente Störung“, Rechtswirkungen der Bauerlaubnis und vorbeugende Nachbarklage, DVBl. 1971, 713 ff.; BVerwG DVBl. 1971, 746 ff. 
Die vorbeugenden Unterlassungs- und Feststellungsklagen müssen demgegenüber auf eine Hilfsfunktion beschränkt bleiben ${ }^{132}$ ). Sie sind zwar grundsätzlich anerkannt ${ }^{139}$ ), in ihrer prozessualen Verwendung aber mit starken Unsicherheiten belastet, weil das bei ihnen positiv festzustellende Rechtsschutzbedürfnis mit den Elementen der konkreten Gefährdung und der Unzumutbarkeit des Zuwartens ${ }^{134}$ ) stark auf den Einzelfall ausgerichtet ist. Die Literatur versucht, die vorbeugenden Klagen durch Typenbildung zum Rechtsschutzinteresse einsatzfähiger zu machen ${ }^{185}$ ). Doch wird man gerade bei mehrpoligen Rechtsverhältnissen auf eine noch exaktere Fassung dieser Klagetypen zu sehen haben und ihre Ausweitung dort nicht befürworten können, wo sie ein angemessen strukturiertes Verwaltungsverfahren in Zwischenphasen ohne zwingenden Grund stören.

Die größten Belastungen für das Verhältnis der Verwaltung zur Justiz bringen die Instrumente des vorläufigen RechtsSchutzes - vor allem die Verfahren nach $\S 80$ Abs. 5 VwGO $\left.{ }^{186}\right)$. Das Gericht muß hier interimistisch Verantwortung für weitreichende Sachentscheidungen übernehmen, ohne durch eine eigene gründliche Prüfung der materiellen Rechtslage abgesichert zu sein. Auf der Suche nach festen Merkmalen der Verantwortungssicherung bemüht sich die Praxis, die Abwägung der Beharrungs- und der Vollziehungsinteressen durch eine eingehende Prüfung der Erfolgsaussichten des Hauptverfahrens

132) Bettermann (Fn 130), $201 \mathrm{ff}$.

183) Erichsen, Vorbeugende Unterlassungs- und Feststellungsklage, Verwaltungsarchiv 1971, 418 ff.; Ule, VerwArch 1974, 291 ff. mit Nachw. aus der Rspr. dort Anm. 14, 15; Maetzel, Bemerkungen zum vorbeugenden Rechtsschutz gegen künftige Verwaltungsakte, DVBl. $1974,335 \mathrm{ff}$.

134) Bettermann (Fn 130), 151 ff.; vgl. BVerwG Urt. vom 21. 2.1973 = BRS Bd. 27 Nr. 15.

135) Schenke, Vorbeugende Unterlassungs- und Feststellungsklage im VerwaltungsprozeB, AöR Bd. 95 (1970), 223 ff., 250 ff.; Ule, VerwArch 1974, 291 ff., 305 ff.

136) Zur Systematik und Tragweite dieser Institute allgemein Baur, Studien zum einstweiligen Rechtsschutz, 1967; Leipold, Grundlagen des einstweiligen Rechtsschutzes, 1971; Rohmeyer, Geschichte und Rechtsnatur der einstweiligen Anordnung im Verwaltungsprozeß, 1967; Wieseler, Der vorläufige Rechtsschutz gegen Verwaltungsakte, 1967; Finkelnburg, Vorläufiger Rechtsschutz im Verwaltungsstreitverfahren, 1973 . Speziell zum vorläufigen Rechtsschutz in polygonalen Verwaltungsverhältnissen BVerfGE 35, 263 ff.; Papier, Ungelöste Fragen beim vorläufigen Rechtsschutz im öffentlich-rechtlichen Nachbarrecht, VerwArch 1973, 283 ff. und 399 ff.; Ercchsen, Zur Anordnung der sofortigen Vollziehung durch das Verwaltungsgericht, VerwArch 1974, 99 ff. 
zu unterfangen ${ }^{137}$ ). Vorabbewertet werden nicht mehr nur offensichtliche, sondern zunehmend mehr auch hinreichende Erfolgsaussichten des Hauptverfahrens ${ }^{138}$ ). Diese Tendenz ist richtig, weil bei Großprojekten vollendete Tatsachen volkswirtschaftlich sinnvoll nicht $z u$ beseitigen sind $\left.{ }^{139}\right)$. Sie wird aber erkauft mit einer Ausweitung des summarischen Verfahrens und einer Verlängerung des Hauptprozesses, der während des Eilverfahrens regelmäßig nicht vorangetrieben wird. Als unergiebig erweist sie sich schließlich, wenn sich die Erfolgsaussichten nach summarischer Prüfung nicht beurteilen lassen und nun doch nach der Interessenlage entschieden werden muß. Jedenfalls bei Großvorhaben mit unüberschaubaren Umweltauswirkungen sollte die Behörde von Vollzugsanordnungen absehen, das summarische Verfahren nicht ausreizen, und die normale Dauer eines gerichtlichen Verfahrens erster Instanz von vornherein in die Zeitplanungen einstellen ${ }^{140}$ ). Diese Rückverlagerung der Verantwortung für den zeitlichen Ablauf in den Administrativbereich bewahrt zugleich vor psychologischen Entscheidungszwängen, denen sich ein Gericht, das sich im summarischen Verfahren festgelegt hat, im Hauptverfahren nur schwer wird entziehen können.

\section{Urteilswirkungen und administrative Folgenverantwortung}

Urteile zu verflochtenen Verwaltungsvorgängen lassen sich in den Gesamtzusammenhang regelmäßig nur mittels einer speziellen administrativen Folgenverantwortung eingliedern.

\section{Urteilsbegrenzende Folgenverantwortung}

Das gilt einmal für diejenigen Urteile, die in Vorgänge der Kapazitätsverteilung oder der Prioritätensetzung hinein entscheiden, bei denen die dem Kläger günstige Entscheidung ein „Einsparen“ an anderer Stelle erzwingt. Als nicht verallgemei-

197) D.h. es vollzieht sich ein tbergang vom Typ der "offenen" zur "materiell-akzessorischen" oder "vorausprüfenden Eilentscheidung", dazu Leipold (Fn 136), $52 \mathrm{ff}$. und $187 \mathrm{ff}$.; BayVGH VerwRspr. Bd. $25 \mathrm{~S} .27 \mathrm{ff}$., $29 \mathrm{f}$.

138) OVG Münster OVGE 29, 113 = BauR 1974, 265; OVG Hamburg, DVBl. 1975, 207 ff., 208 („Reynolds“); ältere Rspr. des OVG Lüneburg zit. bei Hoppe, Rechtsschutz (Fn 73), Rdnr. 229 ff.; im Ergebnis auch BayVGH DVBl. 1975, 199 ff., 202; BVerwG Urt. vom 29. 4. $1974=$ DVBl. 1974,566 führt die materiell-akzessorische Prüfung dagegen nur bis zu den "offensichtlichen“ Erfolgsaussichten der Hauptanträge.

139) Zustimmend auch Blümel, DVBl. 1975, $695 \mathrm{ff}$., $701 \mathrm{ff}$.

140) Gelzer, Die Industrieansiedlung unter Berücksichtigung des Planungsrechts und des Immissionsschutzes, BauR 1975, 145 ff., 156 f.; VG Freiburg DVBl. 1975, 343 ff., 346 ("Wyhl“). 
nerungsfähig erweist sich hierbeı die Lösung des Flurbereinigungsrechts, die schon auf eine Klage hin den Prozeß auf die Dimensionen eines Verwaltungsverfahrens erweitert und das Gericht ermächtigt, den Flurbereinigungsplan insgesamt nach eigenem Ermessen umzustellen ${ }^{141}$ ). Auf weitere Planungsfälle übertragen, entzöge eine solche Lòsung über die jeder Kapazitäts- oder Prioritätenfrage elgenen Zeit- und Finanzverflechtungen der Verwaltung de Verantwortung für den Bereich insgesamt und wäre daher unzulässig(42). Verwaltungsverantwortung wirkt hier urteilsbegrenzend ${ }^{143}$ ). Das Gerıcht darf die primäre Vergabe partiell aufheben und für die Neuverteilung rechtliche Richtlinien vorzeichnen. Weiter ist die Sache regelmàßig aber nicht entscheidungsreif $\mathrm{Bel}$ geschlossenen Fonds mit einer sich nicht erneuernden Masse muß das Gesetz der Verwaltung die Moglıchkeit vorbehalten, alle gewährten $\mathrm{Be}-$ günstigungen neu in de Utberprüfungen mit einzubeziehen, ohne durch Grundsatze des Vertrauensschutzes gebunden zu sein. Bei Verteilungsmassen mit großem Beteiligungskreis dagegen erweist sich die Revision der abgeschlossenen Vorgänge als undurchführbar. Dem obsiegenden Kläger erwächst dafür das Recht, be1 der nächsten routinemäßigen Neuverteilung vorrangig beruicksichtigt zu werden ${ }^{144}$ ). Auch hier hat die Verfahrensherrschaft grundsätzlich aber bei der Verwaltung zu liegen ${ }^{145}$ ).

141) Nach $\S 146 \mathrm{Nr} .2$ FlurbG pruft das Flurbereinigungsgericht auch, ob die Flurbereinigungsbehörden bei der Gestaltung des Flurbereinigungsplanes in zweckmaß1ger Weise von ihrem Ermessen Gebrauch gemacht haben. Das Gericht ist gem. Nr. 1 an Anträge der Beteiligten nicht gebunden. Steuer, Flurberennigungsgesetz, 2. Aufl., 1967, $\S 144$ Anm. 3 und $\S 146$ Anm. 4.

142) Nur als eine aus den Besonderheiten des Flurbereinigungswesens erklärbare Ausnahmeerscheinung läßt sich $\S 146 \mathrm{Nr}$. 2 FlurbG unter Gewaltentellungsgesichtspunkten uberhaupt rechtfertigen, vgl. BVerwGE 4, 191 ff., 194.

143) $\mathrm{Zu}$ weitgehend daher die eigenen Prıoritäts- und Kapazitaitsberechnungen des VG Hannover DVBl. 1974, 785 ff., betr. den Umfang der aus einem Raumordnungsplan ableitbaren gemeindlichen Eigenentwicklung, dazu meine Urtellsanmerkung DVBl. 1974, $787 \mathrm{f}$.

144) So z. B. im Hochschulzulassungsrecht $\$ 12$ Abs. 4 n.-w. VO zur Durchführung des Staatsvertrages über die Vergabe von Studienplàtzen 1. d. F. vom 21. 10. 1974 (GV NW S. 1442).

145) Das gilt vor allem für die gerichtlıche Kapazitätskontrolle. Sie darf nicht dazu führen, daß das Gericht die Rangfolge der kapazitätsbildenden Ressourcen anstelle der Verwaltung bestimmt (z. B. Änderungen in einem Universitathaushalt, Personalentscheidungen); vgl. Fn. 143. Zur Gefahr gerichtlichen "Hineinregierens" uber Leistungsgrundrechte Böckenförde, Grundrechtstheorie und Grundrechtsinterpretation, NJW 1974, 1529 ff., 1536; Martens, Grundrechte im Leistungsstaat, VVDStRL 30, $7 \mathrm{ff}, 35 \mathrm{f}$. - Aber auch auf einer zweiten Stufe, bei zulàssigerweise gerıchtlich ergánzter Kapazitáts- 
Die bei dieser Verantwortungsverteilung unvermeidbaren Lükken zwischen gerichtlichem und administrativem Handeln müssen durch eine Zentralisierung belder Verfahren ausgefüllt werden $^{146}$ ).

\section{Urteilsergänzende Folgenverantwortung}

Eine urteilsergänzende Folgenverantwortung der Verwaltung wird dort wirksam, wo das Gericht Genehmigungen aufhebt, auf Grund derer schon Investitionen vorgenommen worden sind. Mit dem Urteil steht nur die Rechtswidrigkeit der bisherigen Genehmigung, nicht aber die Notwendigkeit einer dauerhaften Stillegung oder Beseitigung der Anlage fest. Das Uber-

bestimmung durch Aufdeckung von Reserven, muß die Verteilung grundsätzlich administrativ vorgenommen werden, weil sie den einzelnen Prozeß jedenfalls dann sprengt, wenn mehrere Bewerber vorhanden sind, so BVerwG Urt. vom 22. 6. $1973=\mathrm{DVBl}$. 1973, 805 ff., 808 = DOV 1974, 62 ff.; OVG Münster DVBl. 1970, 930; OVG Berlin, OVGE 11, 210 ff. = JR 1972, 38 ff., 40 f.; vgl. auch Barbey, Rechtliche Aspekte der Zulassungsbeschränkung fur das Hochschulwesen (numerus clausus), $\mathrm{JZ} 1971,473 \mathrm{ff}$., $483 \mathrm{f}$. Unbefriedigend bleibt allerdings, daß freie Platze dabei haufig nicht besetzt werden, weil die Einbeziehung des nicht klagenden rangnachsten Bewerbers in das gerichtliche Verfahren nicht möglich ist. Die Gegenmeinung (VGH Mannheim, DVBl. 1969, 935 ff., 938; OVG Koblenz, DVBl. 1970, 324 ff., 328; fruher VGH Múnchen, BayVB1. 1970, 66 ff., 69; Czermak, Verfahrensfragen zur Studienzulassung bei Zugangsbeschräkungen, NJW 1973, 1783 ff.; Schmidt, Aktuelle Probleme der Zulassungsbeschränkungen an den Hochschulen, NJW 1974, 773 ff., 777; Haas, Zur Rangfrage in Numerus-Clausus-Prozessen, DVBl. 1974, 22 ff.; Naujoks Anm. DƠV 1974, 65 ff.) läßt mit Rücksicht auf die Eilbedürftigkeit die Rangfolge der Bewerber außer acht und teilt freie Plätze den klagenden Bewerbern zu. Ihr hat sich das BVerfG Beschl. vom 9. 4. $1975=\mathrm{NJW} 1975,1504$ angeschlossen. Das kann allenfalls als ,richterliche Nothilfe“ zur ubergangsweisen Effektuierung der Grundrechtsverwirklichung gerechtfertigt sein. Grundsätzlich dagegen bleibt die Ǔberspringung eines erneuten zusammenfassenden Verwaltungsverfahrens bedenklich.

146) Auch insoweit weist das Hochschulzulassungsrecht noch Mängel auf. Zur widerspruchlichen Judikatur der Oberverwaltungsgerichte über die Verwaltungszuständigkeit zur Vergabe frei gebliebener Studienplätze VGH Mannheim, NJW 1974, 1211 und NJW 1975, 1427; anders OVG Munster, DVBl. 1974, 946; OVG Koblenz, NJW 1975, 991; ingesamt BVerfG Beschl. vom 9. 4. $1975=$ NJW 1975, $1501=$ DƠV 1975, 564; krit. dazu Roellecke, Verfassungsrechtliche Verwirrung der Numerus-Clausus-Praxis, DOV 1975, 561 ff. Behoben durch AnderungsG zu $\$ 52$ Nr. 3 VwGO vom 26. 2. 1975 (BGB1. I, S. 617) sind immerhin die nach der Entscheidung des BVerfG vom 7. 5. $1974=$ BVerfGE 27, $191 \mathrm{ff}$. aufgetretenen Mängel einer zentralen ortlichen Zustándigkeit der Gerichte in Zulassungssachen, soweit die ZVS entschieden hat; dazu auch Menger, Ortliche Gerichtszuständigkeit bei Klagen gegen die Zentralstelle für die Vergabe von Studienplätzen, VerwArch 1974, $441 \mathrm{ff}$. 
maßverbot, das zugunsten des Genehmigungsempfängers im Prozeß bisher nicht berücksichtigt worden ist, erweist im erneuten Verwaltungsverfahren seine bei komplexen Vorgängen charakteristische mehrdimensionale Wirkung, bei der einschichtiges Werten durch umfassende Abwägung ersetzt wird. Es zwingt die Verwaltung dazu, einen von Grund auf neuen Ausgleich aller beteiligten Belange zu suchen, bei dem neben Auflagen auch kombiniert planungs-entschadigungsrechtliche Lösungen bedacht werden müssen: Die klägerischen Nachbarrechte werden in einen neuen Abwaigungsproze $B$ einbezogen, dessen Ergebnis auch einmal die entschädigungsrechtlich abgesicherte Aufopferung dieser Rechte, etwa die umwidmende Einbeziehung des Grundstücks in einen Schutzstreifen, bedeuten kann ${ }^{147}$ ). Der obsiegende Kläger muß unter Umständen also letztlich der von ihm bekämpften Nutzung weichen. Keine Renaissance des „Dulde und Liquidiere!“, sondern eine Konsequenz der Tatsache, daß die Verantwortung der gestaltenden Verwaltung über das einzelne Gerichtsverfahren hinausgeht und die punktuellen Ergebnisse des Individualrechtsschutzes mit einem angemessenen Ausgleich aller Interessen zu überwölben hat.

Vierter Abschnitt: Komplementäre Rechtsschutzeinrichtungen und Änderungen der Gerichtsorganisation

Es unterliegt keinem Zweifel, daß auch dann, wenn die Dogmatik und einige Gesetzesänderungen die Instrumente des verwaltungsgerichtlichen Rechtsschutzes den geänderten Kontrollobjekten anpassen, die Verwaltungsgerichte komplexen Vorgängen gegenüber den Rechtsschutz nicht werden in dem Maße leisten können, in dem das gegenüber einfachen Entscheidungen üblich ist. $\mathrm{Zu}$ unterschiedlich sind Verantwortungsverteilung und Entscheidungssituation, als daß die richterliche Beurteilung komplexe Entscheidungen in ihren Vor- und Folgewirkungen erreichen konnte. Das lenkt die Gedanken auf andere Rechtsschutzeinrichtungen und auf die Frage, ob Änderungen der Gerichtsorganisation hier helfen können.

147) BVerwG Urt. vom 1. 11. 1974 = DVBl. 1975, 492 ff., 497 („Stelling"). Als Entschädigungstatbestände kommen $\$ \S \quad 40-44$ BBauG in Betracht. Darüber hinausgehende enteignende Wirkungen darf sich der Plan nicht beilegen, weil es für andere als die dort genannten Umwidmungen am notwendigen formell-gesetzlichen Entschädigungsjunktim fehlt. Vgl. auch Gelzer, BauR 1975, 145 ff.; BGH BauR $1975,270 \mathrm{ff}$. 


\section{Die Komplementarfunktion des Verwaltungsverfahrens}

Unter den Einrichtungen, die komplementäre Funktionen zum gerichtlichen Rechtsschutz ausüben, nimmt das Verwaltungsverfahren in der Diskussion eine favorisierte Stellung ein $\left.{ }^{148}\right)$. Allerdings ist vieles von dem, was zum funktionellen Zusammenhang zwischen administrativem und gerichtlichem Verfahren heute gesagt wird, nicht so neu, wie es manchmal erscheint. Vieles ist in der Entstehungszeit der Verwaltungsgerichtsbarkeit ${ }^{149}$ ), in den Auseinandersetzungen, die sich mit den Namen Gneist und Bähr verbinden ${ }^{150}$ ), bereits gesehen worden und hat ähnlich die Erarbeitung der Verwaltungsgerichtsordnung begleitet ${ }^{151}$ ). Vieles geht auf Anregungen aus Nachbarländern zurück ${ }^{152}$ ) oder ist in Gesetzen und Dogmen längst verarbeitet.

Der Gedanke, Verwaltungsverfahren komplementär zum Verwaltungsproze $B$ einzusetzen, wird gespeist aus rechtsstaatlichen und demokratischen Quellen, die sich begegnen in Uberlegungen der Partizipation ${ }^{153}$ ), in den praktischen Beobachtungen zur Aufbereitungs-, Informations- und Filterfunktion vor-

148) Häberle, VVDStRL 30, 43 ff., 87 f., 112; Brohm, VVDStRL 30, 245 ff., 279 f.; eingehend Schwarze, Der funktionale Zusammenhang von Verwaltungsverfahren und verwaltungsgerichtlichem Rechtsschutz, 1974; ders., Zum Nutzen einer Systembildung für die Kontrolle der Staatsgewalt, DVBl. 1974, 893 ff.; Ule, Verwaltungsverfahren und Verwaltungsproze $B$, VerwArch 1971, 144 ff.; Lorenz, Rechtsschutz (Fn 34), 178 ff.; Badura, in: Erichsen-Martens, Allgemeines Verwaltungsrecht, 1975, 233 ff., 237.

149) Scheuner, Die neuere Entwicklung des Rechtsstaats (Fn 49), 461 ff.; Erichsen, Verfassungs- und verwaltungsgeschichtliche Grundlagen (Fn 39), 207 ff.

150) Vor allem Gneist, Uber die rechtliche Natur, die Zuständigkeit und die Verhandlungsformen der Verwaltungsjurisdiktion, Verhandlungen des 12. DJT, Bd. 3, 1875, $220 \mathrm{ff}$.

151) Bettermann, Das Verwaltungsverfahren, VVDStRL 17, $118 \mathrm{ff}$., bes. 164 ff.; Bachof, Wehrpflichtgesetz und Rechtsschutz, 1957; Ule, Verwaltungsverfahren und Verwaltungsgerichtsbarkeit, DVB1. 1957, 597 ff.; dazu die Erwiderung Bachofs, DVBl. 1958, 6 ff. und die Gegenäußerung Ules, dort $9 \mathrm{f}$.

152) Besonders Osterreich, dazu Melichar, Das Verwaltungsverfahren, VVDStRL 17, 183 ff.; Winkler, Der gerichtliche Rechtsschutz des einzelnen gegenüber der vollziehenden Gewalt in Osterreich, in: Gerichtsschutz gegen die Exekutive (hrsg. von Mosler), Bd. 2, 1967, 413 ff. Zum amerikanischen Recht, Scharpf, Die politischen Kosten des Rechtsstaats, 1970, 14 ff. Rehbinder-Burgbacher-Knieper (Fn 8), $74 \mathrm{ff}$. Mitchell, Verwaltungskontrolle in Großbritannien, VerwArch 1973, 162 ff.; Hahn, Die Reform der Verwaltungsgerichtsbarkeit in Schweden, VerwArch 1974, 335 ff.; Lammich, Die gerichtliche Kontrolle der Verwaltung in den sozialistischen Verfassungssystemen, VerwArch 1973, 246 ff.

${ }^{153}$ ) Schmitt Glaeser, VVDStRL 31, 179 ff., 240 ff. mit weit. Nachw. 
geschalteter Verwaltungsverfahren ${ }^{154}$ ) und in den Feststellungen, daß Uberzeugung das beste Mittel der Entscheidungsverwirklichung bildet Innerhalb der Komplementärfunktion des Verwaltungsverfahrens ist $\mathrm{zu}$ trennen nach sichernden, ergänzenden und verdrangenden Wrrkungen.

(1) Sichernd sind alle diejenigen Verfahrensausprägungen, ohne die der nachfolgende Gerichtsschutz wesentlich erschwert würde. Bei komplexen Entscheldungen zählen hierzu neben bekannten Punkten (Rechtsmittelbelehrung, Begrundung $\left.{ }^{155}\right)$ ) vor allem Einrichtungen, die die Ubersichtlichkeit und die Erkennbarkeit der Klageansatze und -aussichten verbessern sollen (Zentralisierungen und Zasurierung verschachtelter Regelungsgehalte). Sichernde Institute genießen den Schutz eines vorwirkenden Art. 19 Abs. 4 GG.

(2) Ergänzende Einrichtungen sind rechtspolitisch wünschenswert, um Verwaltungsbereiche einsichtig und kontrolliert zu machen. Hierher zählen die Absicherung von Bewertungs- und Prognosevorgängen durch Sachverständigengremien ${ }^{158}$ ), die disziplinierenden Wirkungen von Anhörungen ${ }^{157}$ ), die qualifizierten Verwaltungsverfahren und die verwaltungsinternen Aufsichtsverfahren. Steigende Bedeutung kommt dabei den Haushalts- und Finanzkontrollen $\mathrm{zu}^{158}$ ). Sie müssen jene Effektivitätsprüfungen leisten, die aus dem gerichtlichen Rechtsschutz so gut wie gänzlich herausfallen ${ }^{159}$ ), die aber in einer "Verwaltung des Mangels" auch aus Gründen individueller Rechtssicherung zunehmend wichtig werden. Es sind die er-

154) Dazu Ule, DVB1. 1957, 597 ff.; Kopp, Verfassungsrecht und Verwaltungsrecht, 1971, $200 \mathrm{ff}$.

155) Kopp, Verwaltungsverfahrensrecht, $67 \mathrm{ff}$. Schmitt Glaeser, VVDStRL 31, $244 \mathrm{f}$. jeweils mit weiteren Beispielen: Anhörung, Beratung, Akteneinsicht. Abwendungsrecht zu hinreichender Fristbestimmung BVerwG, DOV 1973, $785 \mathrm{f}$.

156) Gedanke des Indizierungsurteils BVerwGE 39, 197 ff. (Nachw. Fn 111); Ossenbühl, DVBl. 1974, 309 ff., 312. Allerdings sollte die rechtsschutzsichernde Kompensation gerade gruppenrepräsentierender Sachverstandigengremien mit Vorsicht beurteslt werden. Der Sachverhalt des auf den gleichen Gedanken zuruckgreifenden Urteils des VG Berlin, DVBl. 1974, 375 ff. bietet ein wenig ermutigendes Bild, wie das Verfahren in einem solchen Gremium ablaufen kann.

157) Dazu uberzeugend Lange, Zur Anhörung im verwaltungsrechtlichen Genehmigungsverfahren, DVBl. 1975, $130 \mathrm{ff}$.

158) Piduch, Bundeshaushaltsrecht, Stand: November 1971, zu $\$ \S 88$ ff. BHO; Neitzel, Die kommunale Rechnungsprufung Diss. Göttingen, 1969; A. Schmid, Möglichkeiten und Probleme der fiskalpolitischen Effizienzkontrolle, 1975; Brunner, Kontrolle (Fn 3), 184 ff.

${ }^{150}$ ) $\mathrm{Zu}$ diesem Mangel Kriger, Allgemeine Staatslehre, 753 f: "Atrophie“ der Prüfung der Sachfragen. Brunner, Kontrolle (Fn 3), 288 ff. 
gänzenden Kontrolleinrichtungen, die in ein gezieltes Verhältnis zum verwaltungsgerichtlichen Rechtsschutz gebracht werden müssen.

(3) Verdrängen dagegen kỏnnen Verwaltungsverfahren den Gerichtsschutz vor Verfassungs wegen nicht. „Verfahren und Beteiligung statt Individualrechtsschutz" umschreibt keine zulàssige Kompensation ${ }^{160}$ ). Aber auch gegenüber Lösungen einer stark beschränkten gerichtlichen Inhaltsüberprüfung bei ausgreifender Verfahrenskontrolle ${ }^{161}$ ) ist Distanz zu halten. Nach Verfassungsauftrag und Tradition hat unsere Verwaltungsgerichtsbarkeit stets auch materielle Kontrolle zu leisten. Uberhaupt scheint bei der derzeitigen Faszination des Verfahrensgedankens mittlerwelle ein Wort der Vorsicht geboten - Vorsicht vor Uberspannungen dieses Gedankens; denn extensive Verwaltungsverfahren können auch in Formalismus ${ }^{162}$ ), Einschnurungen der Verwaltung und in Verzögerung des Gerichtsschutzes ausarten.

\section{II. Änderungen der Gerıchtsorganisatıon (Sachverständigen- problem)}

Bei Uberlegungen zur Änderung der Gerichtsorganisation geht es um das Problem, wie der außerjuristische Sachverstand, den Gerichte gegenuber komplexen Verwaltungsentscheidungen aufwenden müssen, organisatorisch angemessen zu verfassen ist. Anders als die Gerichte verfugt die Verwaltung über einen weit ausgebauten Apparat technischen und ökonomischen Sachverstandes, der bei komplizierten Spezialfragen um Kommissionen und Beiràte ergànzt zu werden pflegt ${ }^{169}$ ). So unverkennbar gerade solche Gremien Sachangemessenheit der Entscheidung verbürgen und ergänzende Rechtsschutzfunktionen ausüben mögen, entbınden sie die Gerıchte nicht einer Tatsachenprüfung, die Art. 19 Abs. 4 GG nun einmal verlangt ${ }^{164}$ ). Es kann andererseits nicht ubersehen werden, daß der alte Satz,

180) Ossenbühl, DJT-Gutachten (Fn 4), 193 f.; auch Schmitt Glaeser, VVDStRL 31, 242 ff. Auch Bettermann, VVDStRL 17, $168 \mathrm{f}$. fügt seinen berühmten „Gleichungen“ den Satz an: „Aber die Justizförmigkeit der Verwaltung macht die Verwaltungsgerichtsbarkeit nicht entbehrlich."

101) So die Uberlegungen von Scharpf, Die Politischen Kosten des Rechtsstaats, pass.

102) Z.B. die überspannte Rechtsprechung zu den Auslegungsfri-

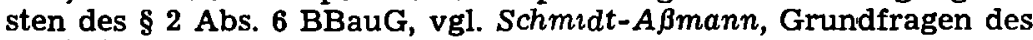
Städtebaurechts, 77 mit Anm. 61.

163) Dazu instruktiv die Antwort der BReg, betr. friedliche Nutzung der Kernenergie in der Bundesrepublik Deutschland, Bundestags-Drucks. 7/3871, bes. S. 27 ff.

104) BVerfGE 15, 275 ff., 282; Bettermann, AöR 96 (1971), 528 ff., 550. BVerwG Urt. v. 16. 3. $1972=$ DVBl. 1972, 681 ("Würgassen“) 
Sachverhaltsermittlung sei eine originär richterliche Aufgabe, gegenüber technisch und ökonomisch schwierigen Zusammenhängen zum neuralgischen Punkt der Verwaltungsgerichtsbarkeit wird ${ }^{165}$ ), weil es dem Richter schon schwer fällt, an Sachverständige und Gutachten mit der richtigen Fragestellung heranzutreten. Daher liegt das Modell einer sachkundigen Besetzung der Richterbank ${ }^{166}$ ) nicht ganz fern, das im Blick auf das Bundespatentgericht ${ }^{107}$ ) nicht vorbildlos dasteht. Gerade dieses Beispiel zeigt aber auch die Grenzen des Modells: Es ist anwendbar nur auf Gerichte mit eng umgrenztem Tätigkeitskreis $^{168}$ ), nicht aber für die Verwaltungsgerichtsbarkeit, die in allen ihren Zweigen so breit gestreute Aufgaben wahrzunehmen hat, daß die Einbeziehung hochspezialisierter Sachverständiger in den Spruchkörper nicht in Betracht kommt. Auch sachverständige Laienrichter helfen hier nicht weiter $\left.{ }^{168}\right)$. Uberlegt werden sollte allerdings, inwieweit die Bildung von Spezialkammern das Problem richterlichen Sachverstandes entschärfen kann.

\section{Schluß}

Tiefgreifende, abrupte Änderungen der Verwaltungsjustiz in Organisation oder Funktion sind auf jeden Fall zu vermeiden $\left.^{170}\right)$. Wir verstehen Verwaltungsgerichtsbarkeit vielmehr als dauerhafte Aufgabe, an deren Erfüllung sie selbst, aber ebenso auch die Verwaltung, der Gesetzgeber (vor allem im Bereich des materiellen Rechts) und die Wissenschaft fortlaufend zu arbeiten haben. Institutionen von GröBe und Bedeutung der Verwaltungsgerichtsbarkeit erhalten ihren Wert nur durch kontinuierlichen Ausbau ihrer Arbeitstechniken, ihrer Anerkennung und ihres Selbstverständnisses.

verlangt, daß das Tatsachengericht die administrativen Gutachten in einem Genehmigungsverfahren nicht nur entgegennimmt, sondern sich mit ihnen "näher auseinandersetzt"; dazu Schwarze, DOV 1973, 700 ff., $704 \mathrm{f}$. und das 2. Berufungsurteil des OVG Münster vom 20. 2. 1975 ("Würgassen") - unveröffentl. - AU S. 29 ff.

${ }^{165)}$ Redeker, DOV 1971, 757 ff., 759 f.; Bachof, VVDStRL 27, 96 ff., 98 (Diskussionsbeitrag).

186) Rudolph, Möglichkeiten und Grenzen einer sachkundigen Besetzung der Richterbank, JZ 1975, 316 ff.

167) $\$ 36$ b ff. PatG.

188) Für die Kartellgerichte gefordert von Th. Raiser, Okonomen im Bundeskartellamt und in den Kartellgerichten, BB 1972, $421 \mathrm{ff}$.

160) Zum Laienrichtertum in der Verwaltungsjustiz Schiffmann, Die Bedeutung der ehrenamtlichen Richter bei Gerichten der allgemeinen Verwaltungsgerichtsbarkeit, 1974.

170) Bettermann, VVDStRL 17, 118 ff., 167. 


\title{
Leitsätze des Mitberichterstatters über: \\ Verwaltungsverantwortung und Verwaltungsgerichtsbarkeit
}

\author{
I.
}

Bestandsaufnahme: Komplexe Verwaltungsentscheidungen als Brennpunkte der derzeitigen Verwaltungssituation und des Rechtsschutzauftrages

1. Verwaltungsgerichte und Verwaltung haben heute auf das Ganze gesehen eine Zuordnung gefunden, die dem Bürger Rechtsschutz gewährt, ohne die Administration zu lähmen.

2. Neue, strukturelle Schwierigkeiten sind dem gerichtlichen Rechtsschutzauftrag und dem Verhältnis der Dritten zur Zweiten Gewalt in den letzten Jahren jedoch aus dem Typ komplexer Verwaltungsentscheidungen erwachsen, wie sie die Gerichte $z u$ beschäftigen beginnen (Urteile $z u$ Industrieansiedlungen, Verkehrswegebauten, Raumordnungsverfahren, Hochschulkapazitäten, staatlichen Organisationsakten).

3. Diese in Sachverhalt, Bezügen, Beteiligten und Folgen verflochtenen Entscheidungen erweisen sich als die Brennpunkte der derzeitigen Verwaltungssituation überhaupt. Sie kennzeichnen die hinter den einzelnen Eingriffs- und Leistungsvorgängen stehende administrative Verteilungs- und Gestaltungsfunktion.

4. Schwierigkeiten eines angemessenen Rechtsschutzes ergeben sich gegenüber komplexen Entscheidungen

a) aus der ihnen eigenen Dynamik, die die normativen Grundlagen in Begriffsbildung und Systematik häufig undeutlich bleiben und Gerichtsschutz außerdem zu spät einsetzen läßt (Probleme der zeitlichen Dimension),

b) aus der Tatsache, daß die von solchen Entscheidungen betroffenen privaten Interessen unter sich schon so stark divergieren, daß sie mit den Mitteln überkommenen zweipoligen Prozeßrechts nicht richtig erfaßt werden (Probleme polygonalen Rechtsschutzes),

c) aus der Notwendigkeit, mit den Instrumenten eines bisher am "Außenrecht" orientierten Rechtsschutzes in den Verwaltungsinnenbereich, in die Zentren höherstufigen Entscheidens vorzudringen, ohne die unterschiedlichen Ausmaße administra- 
tiver und richterlicher Verantwortung in der Folgensteuerung $z u$ übersehen (Rechtsschutz im makroadministrativen Bereich).

II.

Verwaltungsverantwortung und verwaltungsrichterliche Verantwortung (verfassungsrechtlicher Standort, Typologie, Relationen)

5. Verantwortung wird konstituiert aus den Elementen der Aufgabe, der Eigenstandigkeit und der Einstandspflicht im Sinne einer Kontroll- und Steuerungsabhängigkeit. Das Grundgesetz versteht Verantwortung als heuristischen Begriff zur Kennzeichnung eines Ausgleichssystems von Rechtssätzen und Institutionen, das Befugnisse, Bindungen und Entlastungen verdeutlicht.

6. Verwaltungsverantwortung gründet sich verfassungsrechtlich in der Position der Verwaltung als eigenständiger Staatsgewalt (Art. 20 Abs. 2, 28 Abs. 2 GG): Verwaltung als System tagtäglicher Verwirklichung der sozial-rechtsstaatlichen Verfassung, als „Arbeit" und Leistung.

7. Verwaltung ist heute durchgángig eine vom Gesetz dirigierte Verwaltung. Gesetze lenken die Verwaltung als Organisations- und Verfahrensregelungen, als Rahmen, als Leitlinien und Richtpunkte und als Eingriffsermáchtigungen. Die gesetzlichen Direktiven differieren in den Graden exakter Vorzeichnung; in ihren Wirkungen sind sie partiell wechselseitig substituierbar.

8. Im Spiegel dieser Direktiven zeigt eine aufgabenbezogene Typologie Verwaltungsverantwortung als

- Vollzugsverantwortung

- Entfaltungsverantwortung

- Stimmigkeits-, Ausgleichs- und Kontinuitätsverantwortung

- Initiativ- und Vermittlungsverantwortung

- Gesamtverantwortung.

9. Verwaltungsrichterliche Verantwortung ist gegründet in der richterlichen Unabhängigkeit und in der Verpfluchtung zu positiver Wahrung des Rechts. Verwaltungsrichterliches Denken wird geprägt von dem Bemuhen, den Sachverhalt mit dem speziell rechtswissenschaftlichen Instrumenten in den Griff zu bekommen. Diese Rückbindung an das Recht ist das Korrelat richterlicher Unabhängigkeit.

10. Verwaltungsgerichtsbarkeit ist zum einen bestimmt durch ihren Auftrag, subjektive Rechte in einem reaktiv arbeitenden Verfahren zu schutzen (Art. 19 Abs. 4 GG). Die hierin wirk- 
same Distanz zum Verwaltungsgeschehen gehört zu ihrem verfassungsfesten Bilde.

11. In Anbetracht polygonaler Verwaltungsverhältnisse tendiert subjektiver Rechtsschutz, verstanden als effektiver Schutz materieller Rechtsverwirklichung, allerdings nicht notwendig $z u$ einem Höchstma $\beta$ an gerichtlichem Verfahren, sondern kann auch Beschränkungen des Gerichtsschutzanspruchs eines Beteiligten aus Rücksichten materiell-grundrechtlicher Rechtsverwirklichungsansprüche anderer verlangen.

12. Verwaltungsgerichtsbarkent ist zum anderen bestimmt durch ihre Bezogenheit auf die Zweite Gewalt. Verwaltung und Verwaltungsjustiz begegnen sich in ihrer Verantwortung für das Recht, die sie arbeitsteilig (antithetisch und komplementär) wahrnehmen. Antithetisch wirken dabei die Unterschiede der Entscheidungssituationen, die es dem Richter verwehren, in der Sachzugewandtheit mit der Exekutive zu konkurrieren. Komplementär dagegen wirken die Entlastungsfunktionen, die der Richter für die Verwaltung über das Recht ausübt.

13. Die weitaus meisten Urteile haben die richterlich-administrative Verantwortungsverteilung zutreffend erfaßt im Sinne einer Angleichung der Entschendungsstrukturen, wie sie bei überschaubaren Vorgängen möglich und geboten ist. An komplexen Vorgängen und der ihnen eigenen Unüberschaubarkeit dagegen brechen die Unterschiede zwischen der administrativen und der richterlichen Entscheidungssituation, vor allem in den Möglichkeiten der Information und Folgensteuerung auf. Die daraus resultierenden Belastungen des Rechtsschutzauftrages und der Verwaltungsverantwortung lassen sich nur dann abtragen, wenn es gelingt, für Kontrollgegenstände und -verfahren jene Uberschaubarkeit und Einsichtigkeit zurückzugewinnen, auf die richterliches Handeln angewiesen ist.

III.

Konkrete Zuordnungsprobleme

\section{A. Rechtsschutzform und Verfahren}

14. Komplexen Verwaltungsentscheidungen gegenüber müssen die Rechtsschutzformen in ihrer zeitlichen Abfolge übersichtlicher gegeneinander abgesetzt werden. Die bisher geübte Praxis der Inzidentkontrollen erweist sich einem abschnittsweise sich entwickelnden Entscheidungsproze $\beta$ gegenüber als unzulänglich.

15. Notwendig ist der bundesgesetzliche Aufbau der prinzipalen Normenkontrolle ( $\$ 47 \mathrm{VwGO}$ ), um eine Uberprüfung 
normativ-programmhafter Entscheidungen in einem frühen Stadium zu ermöglichen.

16. Notwendig ist ferner die Aufgliederung großer Entscheidungszusammenhänge in Abschnitte, deren Regelungsgehalt in einem Verwaltungsakt zusammengefaßt wird. Dem haben Anfechtungslast und materielle Ausschlußwirkungen zu korrespondieren, um eine sukzessive Stabilisierung der Verfahrensabschnitte zu ermöglichen.

17. Erforderliche Eingrenzungen des subjektiven öffentlichen Rechts lassen sich nur über seine normative Ableitung erreichen. Die Bedeutungsermittlung höherstufiger Planungsrechtsnormen mu $\beta$ dabei mit überschießenden subjektiv-rechtlichen Tendenzen des Wortlauts rechnen, die sich jedoch durch den Auslegungsgesichtspunkt der „bereichsspezifischen Verwaltungsaufgabe" auf ihren wirklichen Gehalt reduzieren lassen.

18. Als prozeßtechnische Erleichterungen gerichtlicher Massenverfahren sind zulässig öffentliche Zustellungen und Verkündungen, sowie die gerichtliche Bestellung gemeinsamer Prozeßbevollmächtigter für solche Beteiligten, die gleiche Interessen verfolgen. Außerdem sollte die Behandlung einzelner Verfahren als Musterproze $\beta$ durch eine Lockerung der Beiladungsvorschriften erleichtert werden.

19. Die gesetzliche Einführung von Verbandsklagebefugnissen kann nicht empfohlen werden. Wo sich der Gesetzgeber trotzdem zu einem solchen Schritt entschlie $\beta t, m u \beta$ eine dauerhafte Organisation des klagebefugten Verbandes gewährleistet sein. Ausbaufähıg dagegen sind Klagemöglichkeiten von Verbänden öffentlichen Rechts, insbesondere solche kommunaler Körperschaften.

\section{B. Kontrolldichte}

20. Die Frage nach der Intensität gerichtlicher Kontrolle läßt sich nicht mit festen Formeln beantworten. Entscheidend sind vielmehr die Genauigkeit des jeweiligen gesetzlichen Tatbestandes, sowie die spezifischen Rechtsschutznotwendigkeiten und die administrative Gesamtverantwortung in dem betreffenden Bereich. Zwischen diesen drei Bezugspunkten variiert die Kontrolldichte auch in der Zeit.

21. Beurteilungsspielraum und Rechtsfolgenermessen sind Differenzierungen, herausgearbeitet für die gesetzlich eng gebundene Verwaltung, und in diesem Bereich nach wie vor sinnvoll. In der planenden Verwaltung dagegen läßt sich die Trennung nicht aufrecht erhalten. 
22. Für die gesetzlichen Direktiven der planenden Verwaltung charakteristisch sind zum einen Programmbegriffe. Sie kennzeichnen eine administrative Kompetenz zu letztverantwortlicher sukzessiver Programmentfaltung (Definition, Begriffsbildung, Methodenwahl). Normativ-allgemeine Entfaltungsakte werden gerichtlich nur darauf überprüft, ob sie den Gesetzesrahmen wahren.

23. Die gesetzlichen Direktiven der planenden Verwaltung werden zum anderen gekennzeichnet durch Abwägungsklauseln. Sie ermächtigen die Verwaltung dazu, unter nicht harmonisierbaren Teilzielen den Vorrang zu bestimmen, Kapazitäten $z u$ verteilen und Prioritäten zu setzen. Dieses Abwägen kann vom Gericht voll nur in verfahrensmäßiger Hinsicht, im übrigen nur daraufhin überprüft werden, ob die Gewichtung der relevanten Belange und die Schaden-Nutzen-Relation offensichtlich verfehlt worden sind (Evidenzvorbehalt).

\section{Sicherungen und Begrenzungen der Urteilswirkungen}

24. Rechtzeitiger Rechtsschutz gegenüber komplexen Verwaltungsentscheidungen muß primär mit den Mitteln der prinzipalen Normenkontrolle und der auf Verfahrensabschnitte bezogenen Anfechtungsklage (LS 15, 16) nachgesucht werden. Vorbeugende Unterlassungs- und Feststellungsklagen sind auf Ausnahmefälle zu beschränken.

25. Die erheblichen Belastungen, die Entscheidungen nach $\S 80$ Abs. 5 VwGO für das Verhältnis der Justiz zur Verwaltung mit sich bringen, lassen sich mindern durch eine intensivere materiell-akzessorische Prüfung der Erfolgsaussichten des Hauptverfahrens, wie sie die Gerichte zunehmend üben. Bei Großprojekten mit unüberschaubaren Umweltauswirkungen sollte die Verwaltung ihrerseits von Vollzugsanordnungen absehen und die Dauer eines erstinstanzlichen Gerichtsverfahrens in ihre Zeitplanungen einstellen.

26. Urteile in Angelegenheiten administrativer Kapazitätsverteilung oder Prioritätensetzung können eine für notwendig befundene Neuverteilung regelmäßig nicht selbst vornehmen, sondern haben eine urteilsbegrenzende Folgenverantwortung der Verwaltung, der die Neuvergabe obliegt, zu respektieren.

27. Eine urteilsergänzende Folgenverantwortung trifft die Verwaltung dort, wo das Gericht, $z$. B. durch Aufhebung einer Anlagengenehmidung, einen von der Verwaltung versuchten Ausgleich widerstreitender Interessen annulliert. Die Verwaltung hat hier die Ergebnisse des Individualrechtsschutzes durch einen neuen Ausgleich aller beteiligten Belange zu überwöl-

Veroffentl. Dt. Staatsrechtslehrer, Heft 34 
ben, der auch planungs-entschádigungsrechtliche Lösungsmöglichkeiten einzubeziehen hat.

IV.

Komplementäre Rechtsschutzeinrichtungen und Problematik gerichtlichen Sachverstandes

28. Lücken des gerichtlichen Rechtsschutzes können und müssen durch komplementäre Einrichtungen ausgefüllt werden. Unter ihnen kann dem Verwaltungsverfahren besondere Bedeutung zukommen.

a) Gerichtsschutzsichernd wirken solche Verfahrensregelungen dort, wo sie die Ansatzpunkte des Gerichtsschutzes in komplexen Verwaltungsverfahren klarstellen. Sichernde Institute genießen den Schutz eines vorwirkenden Art. 19 Abs. 4 GG.

b) Als gerichtsschutzergänzende Verfahrenseinrichtungen haben vor allem die Haushalts- und Finanzkontrolle jene Effektivitätsprüfungen der Verwaltung zu leisten, die aus dem gerichtlichen Verfahren herausfallen.

c) Verdrängen können Verwaltungsverfahren möglichen Gerichtsschutz in keinem Falle. Insgesamt dürfen die Erwartungen, die man heute im Blick auf den Rechtsschutz an den Verfahrensgedanken stellt, nicht überspannt werden.

29. Besondere Schwierigkeiten erwachsen den Gerichten aus den vielfach hochkomplizierten technischen und ökonomischen Bezügen komplexer Verwaltungsentscheidungen (Sachverständigenproblem). Die Bewältigung des Tatsachenmaterials wird daher immer mehr zum neuralgischen Punkt gerichtlicher Kontrolltätigkeit. Trotzdem kann eine gerichts-organisatorische Verfassung des Sachverstandes nach dem Modell sachkundiger Besetzung der Richterbank nicht empfohlen werden. 


\section{Aussprache und Schlußworte \\ Verwaltungsverantwortung und Verwaltungsgerichtsbarkeit}

Vorsitzender (Ossenbühl): Ich brauche nicht auf den engen Zusammenhang zur Thematik von gestern besonders hinzuweisen. Heute werden wir die Diskussion von gestern eine Stufe tiefer und damit vielleicht auch um einige Grade konkreter und konfliktreicher fortsetzen müssen.

In dem gestellten Thema „Verwaltungsverantwortung und Verwaltungsgerichtsbarkeit" bündeln und konzentrieren sich, wie leicht erkennbar ist, zahlreiche Themata und Problembereiche, die wir schon in früheren Tagungen behandelt haben. Dies als Uberlastung der Thematik von heute zu werten, würde die Intention, die hinter der Themenfassung steht, verkennen. Denn mit der Gegenüberstellung von Verwaltung und Verwaltungsrechtsschutz sollte der Schlußpunkt in der Themenreihe gesetzt werden, dee der Vorstand in seinem Zweijahresprogramm als Zwischenbilanz grundgesetzlicher Ordnung ins Auge gefaßt hat.

Ich glaube, daß beide Referate den damit angesprochenen Problemkomplex in ausgezeichneter Weise aufgezeigt, analysiert und diagnostiziert haben. Uber die angebotenen Therapien kann man selbstverständlich streiten. Und dafür ist ja auch der heutige Nachmittag ausdrucklich vorgesehen. Beide Referate sind sehr exekutivfreundlich, und, um eine Bemerkung von Herrn Ipsen von heute früh fortzusetzen, ich glaube, Herr Peters hätte nicht nur Herrn Scholz, sondern auch Herrn Schmidt-Aßmann nach diesem Vortrag an seine Brust gedrückt.

Bachof: Die Referate des heutigen Tages haben uns eine so reiche Palette an Uberlegungen geboten, $\mathrm{da} \beta$ es schwer fällt, daraus einige Punkte herauszugreifen. Ich muß das deshalb ein wenig willkürlich und sehr subjektiv tun.

Beachtenswert scheint mir als erstes die weitgehende Ubereinstimmung in der Bejahung der „Elgenständigkeit der Verwaltung " zu sein. Herr Ossenbühl hat schon festgestellt, welche Freude Herr Peters an den Referenten gehabt hätte. Diese Ubereinstimmung mag überraschen, zumal mir scheint, daß sie nicht nur die beiden Referenten verbindet, sondern, wie ich 
Gesprächen in der Mittagspause entnehmen zu können glaube, von der großen Mehrheit der Mitglieder unserer Vereinigung geteilt wird; sicher gibt es Ausnahmen. Solche Ubereinstimmung hat mich nach der Bielefelder Tagung freilich nicht mehr überrascht; aber es muß eigentlich für denjenigen überraschend sein, der doch wohl noch vor drei oder vier Jahren sehr andere Meinungen als vorwiegend ansehen mußte.

Mir scheint, wir können eine Art von Wellenbewegung feststellen, wenn wir auf die Zeit seit 1945 sehen; man kann dabei auch auf noch frühere Jahre zurückgreifen. Eine Wellenbewegung: einmal eine Intensivierung des Verwaltungsrechtsschutzes, eine Zurückdrängung aller - ich sage das jetzt ganz allgemein und untechnisch - Ermessens- oder sonstigen Freiräume der Verwaltung; dann wieder eine stärkere Betonung der Eigenständigkeit der Verwaltung unter Anerkennung jener Freiräume: ein Auf und $\mathrm{Ab}$. Im Augenblick scheinen wir uns wieder einmal auf einer Woge der Eigenständigkeitsbetonung zu befinden. Wir sollten dabei freilich nicht übersehen, daß uns heute morgen in den Referaten nur ein Teil der Verwaltung - der sicher auch stärker interessierende Teil - vorgeführt wurde, nämlich die gestaltende, die sozialordnende Verwaltung; daß es aber daneben auch weite Bereiche der Verwaltung gibt, die nach wie vor strikt gesetzesgebunden sind: die Steuerverwaltung etwa. Man könnte noch eine Reihe anderer Verwaltungszweige anführen.

Ein zweites: Einigkeit besteht zwischen den Referenten - ich würde ihnen hierin voll beipflichten - darüber, daß die Verwaltungsgerichtsbarkeit ihrer Aufgabe als Mittler zwischen Verwaltung und Bürger, aufs Ganze gesehen, gerecht geworden ist. Das gilt m. E. jedenfalls für die Ergebnisse der Verwaltungsrechtsprechung; es gilt wohl nicht in gleichem Maße für die sehr unterschiedlichen und zum Teil gegensätzlıchen dogmatischen Begründungen dieser Ergebnisse.

Drittens: Wenn in den Referaten sichtbar wurde, daß die Verwaltungsgerichtsbarkeit ihrer Aufgabe bisher im wesentlichen gerecht geworden ist, so doch auch, daß sie sich jetzt in einer zunehmend schwieriger werdenden Lage befindet. Das deshalb, weil die quantitativ wie qualitativ gewandelten Aufgaben der Verwaltung (Schlagwort: Komplexität der Verwaltung), weil auch das veränderte Verhältnis der Verwaltung zur Gesetzgebung und insbesondere die immer stärkere Amalgamierung zwischen beiden Gewalttrágern - vor allem auf dem Gebiet der Planung - auch an die Verwaltungsgerichtsbarkeit ganz neue Aufgaben herantragen, die sie mit den bisherigen Mitteln und mit den bisherıgen Formen des Rechtsschutzes 
nicht mehr voll zu bewältigen vermag. Die Verwaltungsgerichte versuchen, u. a. mit Hilfe des Art. 19 Abs. 4 GG, durch eine in vieler Hinsicht schöpferische Rechtsgestaltung - Herr Roellecke wird vielleicht fragen, ob sie das dürfen - die an sie herantretenden neuen Aufgaben und Probleme so gut wie möglich zu bewältigen. Aber ich meine, daß hier auf lange Sicht nur der Gesetzgeber helfen kann und muB; und zwar mit mehr als mit bloBem Flickwerk an der Verwaltungsgerichtsordnung. Er muß die Formen des Rechtsschutzes, er muß auch das Verhältnis der Verwaltungsgerichtsbarkeit zum kompensatorischen Rechtsschutz innerhalb der Verwaltung neu überdenken und muß diese Fragen - wenn auch nicht durch eine Anderung von Grund auf, aber doch mit Mut zur Reform - energisch anpacken. Es scheint mir rückblickend so zu sein, daß die Verwaltungsgerichtsordnung, die letztlich auf die maßgeblich von Walter Jellinek beeinflußten süddeutschen Verwaltungsgerichtsgesetze von 1946 zurückgeht, ein - fast möchte ich sagen: genialer - Wurf für die damalige Zeit gewesen ist; daß sie aber den Anforderungen der Gegenwart nicht mehr voll gerecht wird und daß wir uns deshalb gerade in der verpflichtenden Nachfolge dessen, was damals geleistet wurde, um eine Reform bemühen müssen. Ich halte die konkreten Vorschläge, die beide Redner gemacht haben, für außerordentlich dankenswert. Ich würde vieles unbesehen unterschreiben, anderes mit gewissen Vorbehalten, so etwa bezüglich der inhaltlichen Ausweitung des $\S 47 \mathrm{VwGO}$. Ich habe übrigens von Herrn Zacher gehört -ich weiß nicht, ob er hier ist und es bestätigen kann-, der Entwurf zur bundeseinheitlichen Einführung der Normenkontrolle des $\$ 47 \mathrm{VwGO}$ sei schon wieder unter den Tisch gefallen; ich würde das sehr bedauern.

So sehr ich also jene Vorschläge für wertvoll und wichtig halte, so meine ich doch, da $B$ wir uns in der Diskussion nicht in deren Details verlieren sollten. Das bedeutet keine Abwertung. Aber es handelt sich um Fragen, die eine spezielle Kenntnis der Prozeßordnungen voraussetzen und mit denen nicht alle Anwesenden gleichermaßen vertraut sind wie die Redner des Vormittags.

Viertens: Ich war erfreut, daB sich die Redner nicht an Begriffen festgehakt haben. Begriffe wie Beurteilungsspielraum, gestaltendes Ermessen, Rechtsfolgeermessen, Auswahlermessen und dergleichen mögen nützlich sein, vielleicht nach Meinung mancher auch unnütz. Sie sind jedenfalls nicht entscheidend. Das Entscheidende ist in beiden Referaten herausgekommen: $\mathrm{da} B$ es hier um die Frage geht, welches $\mathrm{MaB}$ an Freiheit - oder, da dieses Wort von manchen in unserem Zusammenhang nicht 
geschätzt wird - welchen Raum (Konkretisierungsraum, oder wie immer man das nennen will) de Verwaltung hat und haben muß, um ihrer Aufgabe und ihrer Verantwortung gerecht zu werden; ihrer Verantwortung für die Folgen ihres Handelns.

Wenn ich hier aber doch ein paar Worte zum Beurteilungsspielraum sagen darf, so folgendes: Diese Lehre - ebenso die Vertretbarkeitslehre von Herrn Ule, beide Lehren decken sich ja weitgehend - ist stets von zwel genau entgegengesetzten Seiten her angegriffen worden. Das habe ich fast als Bestätigung ihrer Richtigkeit betrachtet. Die eine Seite wirft ihr vor, sie wolle das gerade erst - zum Glück, wie diese Seite meint - auf der Tatbestandsseite des Rechtssatzes ausgeräumte Ermessen durch eine Hintertür wieder hereinmogeln, es habe sich also gar nichts geändert. Die andere Seite - zu der nach seinem Referat auch Herr Scholz gehört, nur deshalb gehe ich auf die Frage ein - meint, das Anliegen der Lehre vom Beurteilungsspielraum gehe dahin, den Handlungsfreiraum der Verwaltung zu minimalisieren. Beides ist falsch. Es ging mir vielmehr von Anfang an darum, zwei extremen Ansichten entgegenzutreten. Die Situation Im Jahre 1955 war die, daß die sogenannten unbestimmten Begriffe - trotz Herrn Schmidt möchte ich an diesem Ausdruck festhalten, weil das Austauschen von Begriffen an der Sache nichts ändert; daß wir „offene" Tatbestände und "offene" Begriffe haben, läßt sich nicht bestreiten, und daran ändert eine Umbenennung oder eine Eliminierung des Begriffes „unbestimmt" nichts -, es war also so, daß die unbestimmten Begriffe vom Bundesverwaltungsgericht ziemlich willkürlich in "Ermessensbegriffe“ und "Rechtsbegriffe" eingeteilt wurden mit der Folge, daß die einen gerichtlich voll überprüfbar und die anderen praktisch überhaupt nicht überprüfbar sein sollten. Diesem Entweder-Oder, dieser der Verantwortung der Verwaltung nicht gerecht werdenden schematisierenden Zweitellung sollte entgegengetreten werden. Diese "Verantwortung" war schon in meinem Aufsatz von 1955 und auch in allen spàteren einschlägigen Ausführungen der entscheidende Ansatzpunkt für die ganze Lehre: die der Verwaltung nicht $z u$ nehmende Verantwortung für die Folgen ihres Verhaltens sei es, die es notwendig mache, ihr in der Beurteilung der Voraussetzungen ihres Verhaltens einen gewissen Spielraum einzuräumen - vor allem dort, wo dieses Verhalten von ungewissen Prognosen über künftige Ereignisse, insbesondere über die Auswirkungen der Verwaltungsentscheidung abhänge. Ich meine, daß mit den Worten "Prognosen“ und "Erwartungen", die auch in der Rechtsprechung des Bun- 
desverfassungsgerichtes und der Landesverfassungsgerichte heute eine zunehmende Rolle spielen, entscheidende Stichworte sowohl für die Verfassungs- wie für die Verwaltungsgerichtsbarkeit angesprochen sind. Prognosen zu stellen, Erwartungen zu hegen und diese hemmend oder fördernd zur Grundlage des zukunftsorientierten Verhaltens zu machen, das macht ja im Grunde das politische Handeln aus. Verwaltungshandeln ist aber in weitem Umfang politisches Handeln. Wir sprechen z. B. nicht umsonst von Kommunal-„Politik“. Bebauungsplanung, Landesplanung, Regionalplanung usw. - zum Teil dem Gesetzgeber, zum Teil der Verwaltung überantwortet - sind politisches Handeln. Politisches Handeln $m u \beta$ von Prognosen und Erwartungen ausgehen, gerade sie machen solches Handeln aus. Prognosen sind stets mit einer gewissen Unsicherheit behaftet. Weder der Politiker noch der Verwaltungsbeamte kann seine Erwartungen wie ein Naturwissenschaftler durch Experimente verifizieren oder falsifizieren, er muß es vielmehr auf den erhofften Erfolg ankommen lassen. Deshalb meine ich, hat die Unterscheidung zwischen Tatbestands- und Rechtsfolgeermessen - ob man ihr nun in vollem Umfange folgt oder nicht doch mindestens einen richtigen Kern. Der Verwaltungsbeamte, der vor die Frage polızeilichen Einschreitens gegen eine Gefahr gestellt ist, überlegt zunächst, ob wirklich eine Gefahr besteht; denn nur dann darf er (und muß er eventuell) einschreiten. Er stellt also eine Prognose, er fragt sich: Wie wird sich der Zustand - ohne oder mit meinem Zutun - entwikkeln? Danach muß er dann handeln. Diese Prognose ist oft nicht absolut sicher; aber weil den Beamten die Verantwortung für die Folgen von Tun oder Nichttun trifft, muß der Verwaltungsrichter ihm hier eine gewissen Vorrang in der Beurteilung überlassen. Soweit also zur ersten Úberlegung, die dahingeht, was der Beamte darf. Auch wenn dieses Dürfen nur durch einen sehr "offenen" gesetzlichen Tatbestand begrenzt ist, so hat es dennoch Grenzen; könnte man einem Gesetzesbegriff solche Grenzen nicht mehr entnehmen, dann wäre dieser Begriff kein "unbestimmter", sondern überhaupt kein "Rechts“Begriff mehr. Nur wenn der Beamte zur Erkenntnis gelangt ist, daß er - unter Berücksichtigung solchen Beurteilungsspielraums oder -ermessens oder wie Sie es nennen wollen (am Wort hängt nichts!) - handeln darf, ist die weitere Uberlegung sinnvoll, ob er das Gedurfte auch tun soll und will. Das hängt z. B. davon $a b$, ob er uberhaupt die zur Gefahrenbekämpfung notwendigen Mittel hat, ob diese Mittel vielleicht im Augenblick anderweitıg zur Bekämpfung einer noch schwereren Gefahr eingesetzt werden müssen, usw. Es handelt sich also um 
zwei verschiedene gedankliche Uberlegungen (die freilich Hand in Hand gehen). Die erste lautet: Darf ich handeln?, die zweite: Will ich handeln? An dieser Unterscheidung halte ich fest. Ich habe als Landrat, als Bürgermeister, als Ministerialrat hunderte Male ähnliche Uberlegungen angestellt, und alle Verwaltungsbeamten machen das so und werden das auch weiter so machen. Daran werden sie sich jedenfalls durch eine Auswechslung von Begriffen nicht hindern lassen!

Aber zurück zur Prognose! Die Prognose des politisch Handelnden, ob des Verwaltungsbeamten oder des Politikers, des Abgeordneten oder des Regierungsmitglieds, muß, soweit sie nicht (mit den Worten des Bundesverfassungsgerichts) „eindeutig widerlegbar" ist, um der unaufgebbaren politischen Verantwortung der Handelnden willen vom kontrollierenden Richter in den genannten Grenzen akzeptiert werden. Und ebenso müssen wertende Urteile der politisch Handelnden - etwa bei der Frage, was dem öffentlichen Wohl am besten dient - dann akzeptiert werden, wenn sie nicht (wieder mit der Formulierung des Bundesverfassungsgerichtes) "offensichtlich fehlsam" sind. -

Ein fünfter und letzter Punkt betrıfft die „Austauschbarkeit der Formen". Die weitgehende Austauschbarkeit von Handlungsformen - innerhalb der Verwaltung z. B. zwischen Verordnung und Verwaltungsakt mit daraus folgenden Unterschieden der Beteiligtenstellung, der Kontrolldichte, des Verfahrenszeitpunktes usw. - bereitet den Gerichten große Schwierigkeiten. Noch schwieriger wird es beim Formenaustausch zwischen Gesetz und Verwaltungsmaßnahme. Dazu nur ein Beispiel, die Gemeindegebietsreform in Baden-Württemberg: Der zwangsweise Zusammenschluß zu Verwaltungsgemeinschaften erfolgt durch Gesetz, aufgelöst werden können die so gebildeten Verwaltungsgemeinschaften durch Rechtsverordnung des Innenministeriums. Rechtsschutz gewährt im einen Fall das Verfassungsgericht, im anderen das Verwaltungsgericht - zwei hinsichtlich der Kontrolldichte, der Beteiligtenstellung, der Antragsbefugnis $u$. a. $m$. völlig verschiedene Verfahren! Man kann aber nicht sagen, daß solche Formenvariationen schlechthin willkürlich seien. Sie hängen damit zusammen, daß heute bei allen solchen Planungen von Anfang an Exekutive und Legislative eng zusammenwirken. Zunächst werden von der Regierung Kommissionen eingesetzt, mitunter auf Grund von Initiativen des Landtages, die die Situation analysieren und Programme entwickeln sollen. Dann entwickelt - so jedenfalls bei der erwähnten Gebietsreform - zunächst das Innenministerium eine "Zielplanung", die sich die Regierung zu eigen 
macht. Der Landtag übernimmt sie im wesentlichen, bei Änderungen im Detail, die z. T. auf Vorschläge des mittlerweile eingeschalteten Landtagsausschusses für Verwaltungsreform zurückgehen. Das Ergebnis alles dessen findet schließlich seinen Niederschlag im Gesetz. Was aber geschieht nun, wenn das Gesetz vor dem Verfassungsgericht angefochten wird? Man sollte doch annehmen, es sei der Gesetzgeber, der sein Gesetz auch vor dem Staatsgerichtshof verterdigen werde. Das ist aber nicht so. Gewiß, auch der Landtag beteiligt sich förmlich am Verfahren, aber er beschrankt sich in aller Regel auf sehr allgemein gehaltene Ausführungen über die Gestaltungsfreiheit des Gesetzgebers und über die Grenzen verfassungsrichterlicher Kontrolle. Die konkrete Begründung und die konkrete Verteidigung der angegriffenen Maßnahmen, ja auch schon der allgemeinen Zielvorstellungen, übernimmt die Regierung; genauer gesagt, der Vertreter des Innenministeriums. Hier zeigt sich mit aller Deutlichkeit, daß nicht nur bei der Entstehung der Planung, sondern auch in den weiteren Stadien die beiden Gewalten völlig ineinander verzahnt sind. Noch deutlicher zeigt sich das bei der etwaigen späteren Auflösung der Verwaltungsgemeinschaften: es ist, wie schon gesagt, das Innenministerium, das durch Verordnung eine durch Gesetz gebildete Verwaltungsgemeinschaft wieder auflösen kann. Mir ist heute morgen in einem Gespräch von einem Tellnehmer gesagt worden, das erinnere ja an die Nazizeit: daß nämlich der Gesetzgeber dazu ermächtige, ein Gesetz durch eine Verordnung zu ändern. So würde ich das nicht sehen. Denn es handelt sich ja nicht um die Ermächtigung zur Korrektur des Gesetzgebers ex tunc, sondern es handelt sich darum, daß die Verwaltung ermächtigt wird, einen einst vom Gesetzgeber geschaffenen Zustand im Falle einer späteren Entwicklung, die diesen Zustand als nicht mehr angemessen erscheinen lassen kann, ex nunc zu ändern. Das mag auch deshalb angehen, weil es sich dabei nur um Einzeländerungen handelt, während der Gesetzgeber einen Gesamtkomplex geregelt und seine Maßnahmen im Zusammenhang getroffen hat. Aber man sieht doch sehr deutlich, daß hier Dinge, die im Grunde eng zusammenhängen, verfahrensrechtlich auf ganz verschiedene Geleise geleitet werden. Denn die Kardinalfrage, ob die vom Landtag oder vom Ministerium getroffene Maßnahme, nämlich die Bildung der Verwaltungsgemeinschaft einerseits oder ihre Auflösung bzw. deren Ablehnung andererseits, das Selbstverwaltungsrecht der von der Maßnahme betroffenen Gemeinden verletzt oder nicht, ob insbesondere Gründe des öffentlichen Wohles die Entscheidung rechtfertigen, ist im einen wie im anderen Fall voll und ganz 
dieselbe! Hier sehen wir das ganze Problem der Komplexität von Gesetzgebung und Exekutive, von Parlament, Regierung und Verwaltung in Reinkultur vor uns, aufgezeigt an seinen Folgen.

Lassen Sie es mich bei diesen Bemerkungen bewenden. Sie waren notgedrungen kursorisch und gewissermaßen "quer durch". Ich habe Detailfragen bewußt ausgeklammert. Die Grundsatzfragen werden uns genug Stoff zur Diskussion bieten.

Vorsitzender: Vielen Dank, Herr Bachof! Sie haben mit Recht lobend hervorgehoben, daß die Referenten nicht in eingefahrenen Begriffen gedacht haben und nicht dem Kästchendenken verfallen sind. Ich darf bemerken, daß dies auch von uns beabsichtigt war. Anregend sollte insofern der ungebräuchliche Begriff der Verwaltungsverantwortung wirken. - Es ist ja doch, wie ich meine, recht merkwurdig! Wenn man einem gebildeten Laien sagen würde, daß im Verwaltungsrecht der Begriff der Verwaltungsverantwortung so gut wie unbekannt ist, daß er als Kategorie dort eigentlich nicht gebräuchlich ist, wie im Schrifttum gesagt wurde, dann würde das bei einem Unbefangenen sicherlich einige Verwunderung auslösen.

(Bachof: So unbekannt war der Begriff, mir jedenfalls, nicht!)

- Ja, Herr Bachof! Sie haben den Begriff seit 1955 mehrfach verwendet. Aber er hat sich gleichwohl nicht durchsetzen können. Und das ist doch zunächst ein merkwürdiges Phänomen. Es war die Absicht, vom Begriff der Verwaltungsverantwortung ausgehend, das herkömmliche Kategoriensystem und die herkömmlichen Begriffe zu übergehen, um auf das zentrale Kompetenzproblem vorzustoßen.

Ich würde doch sehr bitten, vielleicht das Augenmerk nochmals auf diesen ungebräuchlıchen Begriff zu richten und zu überlegen, ob man aus ihm nicht einen sehr gebrauchsfähigen machen kann.

Lerche: Ich darf vielleicht aufgreifen das Stichwort von Herrn Bachof über die Austauschbarkeit der Formen und es verbinden mit der Anregung, die gerade Sie, Herr Vorsitzender, ausgesprochen haben.

Im Grunde haben - wenn ich es recht sehe - beide Referenten eine Vorstellung mit in den Mittelpunkt gestellt: den "adäquaten" Rechtsschutz, eine begriffliche Vorstellung, die ja gewöhnlich nur begleitend der Vorstellung des „effektiven“ 
Rechtsschutzes folgt. Auch in den Formulierungen der einzelnen Referate wird mehr summierend von effektivem und adäquatem Rechtsschutz gesprochen, ebenso in der Judikatur. Was aber, wenn ich die Referenten richtig verstehe, sie in der Sache selbst wollen, ist, daß sie den Begriff des effektiven Rechtsschutzes im Grunde ersetzen wollen durch die Vorstellung der Adäquanz. Das kommt besonders heraus bei dem Leitsatz, ich glaube es ist die Nummer 11, von Herrn Schmidt-Aßmann, aus dem sich ergibt, daß gerade durch die Orientierung an der Adäquanz auch Abstriche von Effektivität legitimiert werden können. Im Gedanken der Effektivität liegt eine isolierende Blickrichtung auf den einzelnen Betroffenen, auf den einzelnen Rechtsschutzsuchenden. Das reicht nicht aus, wie die beiden Referenten uns veranschaulicht haben. Entscheidend muß sein die Ausgestaltung des Rechtsschutzes so, daß eine Angemessenheit herauskommt, die über die bloße individuelle Rechtsschutzposition hinausführen kann und daher auch mit gewissen Abstrichen von ihr verbunden sein kann.

Auf der anderen Seite aber haben die Referenten, wenn ich mich recht entsinne, diese Vorstellung des angemessenen, wie Herr Schmidt-Aßmann sagt, oder des adäquaten, wie Herr Scholz sagt, Rechtsschutzes doch nur gesehen im Sinne der Forderung, daß die Rechtsschutzformen, die Rechtsschutztypik sich anpassen soll den rechtlichen Strukturen des Verwaltungshandelns. Nun hat aber doch Herr Forsthoff mit Gewicht darauf hingewiesen, daß diese Formtypik, also gerade auch die Formtypik des Rechtsschutzes, nicht nur die des Verwaltungshandelns, nicht beliebig veranderbar ist, daß sie in ihren Grundelementen erhalten bleıben muß aus Gründen der Praktikabilität, aber auch der Erfahrung, der dogmatischen Sicherheit und dergleichen.

Ich könnte mir daher vorstellen, daß sich die Frage der Adäquanz auch in umgekehrter Richtung stellt, das heißt mit der Fragestellung: Wie ist das Verwaltungshandeln seinerseits rechtlich $\mathrm{zu}$ strukturieren, um mit der vorgegebenen (freilich flexibel gedachten) Rechtsschutztypik zurechtzukommen, also so, daß die Rechtsschutztypik dann auch wirklich greift, daß die Instrumente, die wir schließlich zur Verfügung haben und die nicht beliebig austauschbar und ersetzbar sind, dann auch passen?

Also, ich wuirde meinen, daß auch drese Seite des Verhältnisses oder des Begriffs des adäquaten Rechtsschutzes mitbedacht werden soll, gewissermaßen die spiegelbildliche Seite, diese andere Dimension, wenn man - und darauf zielt gerade 
das Stichwort vom „Austausch der Rechtsformen" — das Verhältnis von Verwaltungsverantwortung und Verwaltungsrechtsschutz im Auge behalten will.

Zacher: Ich möchte auf einen Gesichtspunkt aufmerksam machen, von dem ich glaube, daß er einer von den ganz wenigen ist, die mir einerseits einfallen und die andererseits in den Referaten nicht angesprochen sind: die Frage nach der personellen Substanz. Ich möchte es so formulieren: Wer soll wofür verantwortlich sein? Ich glaube, diese Frage muß auch gestellt werden. Ich möchte sie zunächst für die Verwaltung stellen an Hand der Rechtmäßigkeitsverantwortung. Herr Schmidt$A \beta$ mann hat in einem Leitsatz formuliert, daß die Verantwortung für das Recht die Verantwortung ist, in der beide Institutionen konkurrieren: die Verwaltung und die Verwaltungsgerichtsbarkeit. Forsthoff hat früher schon einmal die Prognose gestellt: Wenn man die Verwaltungsgerichtsbarkeit so entwickeln wird, wie das mit der Generalklausel verbunden ist, dann wird die Rechtsverantwortung an die Verwaltungsgerichtsbarkeit abwandern. Und da sehe ich auch ein personales Substanzproblem. Wenn wir heute die Verwaltung betrachten - wir kennen die Stichworte wie das "Juristenmonopol“ —, da haben wir eine sehr differenzierte Gesellschaft, um mit Herrn Haberle zu sprechen, eine offene, mitunter auch eine schlechte Gesellschaft der Verwaltungsrechtsausleger, die in der Verwaltung unter sehr verschiedenen Bedingungen arbeitet. Wir haben Verwaltungshandlungen, die von Juristen ausgehen, solche, die von reinen Politikern ausgehen, und solche, die von Laienpolitikern, von angelernten Leuten, von Angestellten usw. ausgehen; da haben wir eine sehr große Spannbreite. Wir können also die Verwaltung auch in dieser Hinsicht der personellen Substanz nicht als eine Einheit betrachten.

Und die Frage ist: Was kann geschehen, um eine personale Adäquanz von Handelndem und Kompetenz herzustellen? Was kann geschehen, um unter Umständen eine gewisse Homogenisierung zu erreichen? Ich möchte als Beispiel des Ungenügens und der Scheinlösung die Vorlagepflicht des Beamten heranziehen. Wenn der Beamte eine Maßnahme für rechtswidrig hält, muß er nach oben vorlegen. Das trifft heute von allen in Betracht kommenden Verwaltungsfunktionären, von den Gemeinderäten und anderen Selbstverwaltungsorganen bis zu den Angestellten usw., nur noch einen ganz kleinen Ausschnitt. Nur ein relativ kleiner Tell der potentiell Handelnden ist dadurch überhaupt unter irgendeine Rechtmäßigkeitskontrolle zu bringen. Diese Innenstruktur der Verwaltungsverantwortung 
scheint mir also ein Punkt zu sein, dem wir noch weiter nachgehen müßten, der jedenfalls hier noch ins Bild gehört.

Dazu gehört dann im weiteren Sinne aber auch die Frage der richtigen Ausbildung, natürlich die Frage der richtigen Juristenausbildung, aber auch der richtigen Verwaltungsausbildung. Dann gehört dazu auch die Frage der Außeneinflüsse, vom Problem des contempt of court, übertragen auf die Verwaltung, bis zu den parlamentarischen Einflüssen - genauer: Parlamentarıer-Einflüssen - usw. Ich will nicht sagen, daß man eine heile Welt schaffen kann. Ich will nur sagen, daß man diese Probleme einbeziehen muß.

Unter dem Aspekt „Wer ist wofür verantwortlich?" muß man auch in die Gegenrichtung sehen, daß es auch bei der Verwaltungsgerichtsbarkeit nicht nur eine Verwaltungsrechtsverantwortung gibt, sondern auch so etwas wie eine Verwaltungsverantwortung. Das Verwaltungsrecht hat den Zweck, daß die Verwaltung ihre Aufgabe verrichten kann. So muß auch die Verwaltungsgerichtsbarkeit diesem Zweck dienen. Und die Frage ist: Was kann nun auf Seiten der Verwaltungsgerichtsbarkeit geschehen? Und hier stellt sich wiederum die Personalfrage: Wer kann diesen Dienst wirklich verrichten? Kann es eine Gerichtsbarkeit mit Assessoren leisten, die ohne vielfältige juristische Rollenerfahrung sind oder nur eine Rollenerfahrung haben, die sie in den $\mathbf{2}^{1 / 2}$ Jahren Referendarzeit gesammelt haben, mit der sie in das Geschäft eintreten, in dieser Gerichtsbarkeit bleiben und dann eigentlich in eine Selbstbehauptung dieser Gerichtsbarkeit hineinwachsen? Oder müßte nicht eine gesteigerte, diversifizierte juristische Rollenerfahrung vorhanden sein, damit diese Verwaltungsverantwortung von der Verwaltungsgerichtsbarkeit getragen werden kann?

Zur Verwaltungsrechtsverantwortung innerhalb der Verwaltung noch eine andere Frage: ob nicht doch Verfahrensund Organisationskomplikationen dazu beitragen könnten, innerhalb der Verwaltung gerade die Verwaltungsrechtsverantwortung zu steigern. Das würde ich nicht so skeptisch sehen, wie Herr Schmidt-Aßmann das getan hat. Vor allem möchte ich auf den Begründungszwang, von dem gestern so sehr die Rede war, auch im Verwaltungsbereich aufmerksam machen. Er könnte wahrscheinlich die Verwaltungsrechtsverantwortung steigern.

Eine kleine Bemerkung schließlich noch zu der Frage der Klagen in polygonen Verhältnissen. Hierzu möchte ich nur das Stichwort geben: Man muß Klagen in polygonalen Verhältnissen auch als Eingriffe der Kläger gegen die anderen Beteiligten betrachten. Ich glaube, ohne diese Einsicht kommt man auf lan- 
ge Sicht nicht mehr aus. Man muß gerade bei der Verbandsklage sehen, daß hiermit jemand befugt würde einzugreifen, indem er Verwaltungshandlungen auf lange Sicht inhibiert, und diejenigen, die diese Verwaltungshandlungen erwarten, die davon begünstigt werden können, die darauf angewiesen sind, praktisch um ihr Recht bringen kann. Wo steckt die Kontrolle, wo steckt die Legitimation des Klägers? Es genügt nicht, daß man wie bei einem normalen Prozeß unter unmittelbar Betelligten davon ausgeht, daß einer ein Recht gegen den anderen hat. Wenn sich jemand zum Wächter für die Offentlichkeit aufwirft, dann wird diese Klage zum Eingriff. Und wir müssen nach einer Eingriffslegitimation in der Sache fragen.

Dürig: Ich möchte doch den Nerv, den Herr Lerche getroffen hat, noch einmal anbohren. Bisher war es doch so, daß die Verwaltungsformen keine logischen A-priori-Kategorien waren, sondern, wie etwa der „Verwaltungsakt"-Begriff, vom Rechtsschutz her konzipiert waren. Ist es tatsächlich so - das wäre ja eine "Sternstunde" unserer Wissenschaft —, wie die beiden Referenten heute doch wohl einhellig gesagt haben, daß in $\mathrm{Zu}-$ kunft die Rechtsschutzformen den Verwaltungsformen anzupassen seien? Das wäre ein Richtungswechsel unserer bisherigen Verwaltungsrechtsentwicklung.

Bettermann: Ich würde meinen, Herr Dürig, daß diese Sternstunde spätestens im Jahre 1960 stattgefunden hat, als die Verwaltungsgerichtsordnung in Kraft trat, die sich nämlich vom "Verwaltungsakt" gelöst hat. Der Verwaltungsrechtsschutz hängt eben nicht mehr am Verwaltungsakt, sondern nur noch eine ganz bestimmte Klageform, nämlich die Anfechtungsklage. Bei der Verpflichtungsklage ist es schon streitig. Wir müssen nur die Konsequenzen des Gesetzes ziehen und die anderen Rechtsschutzformen, die unsere Verwaltungsgerichtsordnung in breiter Palette bietet, adäquat anwenden.

Vorsitzender: Es hat sich aber in der Praxis noch nicht ganz herumgesprochen, daß wir über den Zustand vor 1960 hinausgekommen sind.

Rupp: Ich möchte zunächst zu der „Wellenbewegung“, die Herr Bachof angesprochen hat, etwas sagen: Wenn es tatsächlich wahr ist, daß eine solche Wellenbewegung von Verwaltungsfreundlichkeit, Verwaltungsfeindlichkeit, Verwaltungsfreundlichkeit stattgefunden haben sollte - was ich nachdrücklich bezweifle; man kann jedenfalls nicht aus dem Tenor der 
jeweiligen Referate unserer Tagungen auf eine solche allgemeine Wellenbewegung schließen -, dann sollte man nach meiner Ansicht auch den ideologiekritischen Aspekt nicht außer acht lassen und sich fragen, woher es wohl komme, daß diese Wellenbewegungen stattfinden. Denn es ist natürlich ganz klar, daß derjenige, der in einer bestimmten politischen Linie die Gewähr des Richtigen sieht, sorgsam darauf bedacht ist, von der Staats- und Verwaltungsgerichtsbarkeit kein Störfeuer zu erhalten, wenn jeweils diese politische Linie gerade an der Macht ist.

In der Sache mochte ich auf folgendes hinweisen: Herrn Bachof bin ich für die Anregung außerordentlich dankbar, man möge sich doch nicht um Begriffe streiten. Man sollte deshalb von folgenden inhaltlichen Einsichten ausgehen:

a) Die Unterscheidung nicht nur zwischen Verwaltungsermessen und unbestimmten Rechtsbegriffen ist hinfällig - insofern stimme ich Herrn Walter Schmidt und Herrn Scholz zu -, sondern auch hinsichtlich der sogenannten bestimmten Rechtsbegriffe ist der Unterschied kein qualitativer, sondern allenfalls ein quantitativer. Das hat allerdings schon die Wiener Rechtsschule gewußt, daraus aber entsprechende Konsequenzen gezogen. Damit bricht nicht nur das ganze Theorem der Ermessens- und Beurteilungsspielräume einerseits und der "einzig richtigen Entscheidung“ andererseits in sich zusammen, sondern das ganze Denkgebäude erweist sich als praxisund theoriefern. Um es zu wiederholen: Man kann, wie dies Herr Scholz getan hat - vergleichen Sie bitte seine Thesen Nummer 10, 11 und 12, wo expressis verbis von der rechtssetzenden Funktion der Verwaltungsentscheidung die Rede ist -, die Wiener Stufenlehre neuentdecken, man muß dann aber auch die rechtspositivistischen Konsequenzen ziehen, die die Wiener Schule gezogen hat. Aus diesem Aspekt gibt es praktisch keine Interpretationstheorie mehr, alle Rechtsanwendung - einschließlich derjenigen des Richters - ist zugleich Rechtssetzung, nämlich Setzung von durch das Gesetz nicht vorgegebenen autonomen Determinanten. Ich verwende hier nur die Terminologie der Wiener Rechtsschule. Gestern haben wir allerdings - wie ich meine zu Recht - das genaue Gegenteil von dieser Konzeption gehört.

b) Alle Rechtsanwendung ist, jedenfalls erkenntnistheoretisch, Rechtsverwirklichung innerhalb mehr oder weniger weiter subjektiver Divergenzspannen. Und dies ist - wie ich an anderer Stelle ausgeführt habe - zugleich eines der tragenden Elemente des gewaltengeteilten Rechtsstaates. Rechtlich 
gebunden ist der Rechtsanwender allemal, aber diese Gebundenheit erzeugt, weil sie ein hochindividuelles Medium durchlaufen muß, niemals objektive „Eindeutigkeit“ oder absolute „Richtigkeit".

c) Die Verwaltungsgesetze sind für die Verwaltung Handlungsprogramme, also Handlungsnormen. Für den die Verwaltung kontrollierenden Richter sind sie Kontrollparameter, also Kontrollnormen - um eine von Herrn Forsthoff verwendete Formulierung zu gebrauchen. Das heißt: Der Richter hat eine bereits getroffene Entscheidung vor sich liegen und darf sie nur danach überprüfen, ob sie im Rahmen der Divergenzspanne liegt, die allemal vorhanden ist, auch bei den "bestimmten“ Rechtsbegriffen. Entgegen der Auffassung Herrn Bachofs gilt dies selbstverständlich auch für den Zivilrichter, wenn er beispielsweise eine Ehe scheidet oder ein Konkursverfahren eröffnet. Auch hier kann der Richter natürlich demjenigen, der geschieden sein will, oder dem Firmeninhaber, der die Konkurseröffnung beantragt, niemals die Verantwortung für sein Handeln abnehmen. Es ist meines Erachtens völlig falsch zu meinen, hier werde der Richter, nur weil er erstmalig als staatliche Instanz tätig werde, nicht mit dem Problem der Verantwortung und der Grenzen richterlicher Kontrolle konfrontiert.

Ein zweiter Aspekt hängt damit zusammen: Was ist nun eigentlich "Verantwortung"? Mir scheint, daß heute „Verantwortung" häufig schlicht gleichgesetzt worden ist mit bloßer "Zuständigkeit". Ich bin Herrn Zacher sehr dankbar dafür, daß er dieses Zentralproblem des heutigen Vortragsthemas aufgegriffen und darauf hingewiesen hat: Verantwortung ist ein personenbezogener Begriff. Die personale Verantwortung des einzelnen Verwaltungsbeamten wird aber, wie ich meine, nicht so sehr beeinträchtigt durch die Verwaltungsgerichtsbarkeit, sondern weit mehr durch die Verwaltung selbst, beispielsweise durch generelle Richtlinien, die gerade die Spannweite fallgerechter Konkretisierung des Gesetzes verstopfen. Oder denken Sie an elektronische Programmierungen, die dem Einzelfall ihr Schema aufzwingen.

Erlauben Sie mir noch eine kritische Schlußbemerkung: Ich fürchte, daß auch die neuen Kategorien begrifflicher und inhaltlicher Art, die uns heute beispielsweise in Gestalt „metajuristischer" Verwaltungszwecke oder von „Evidenzvorbehalten" angeboten worden sind, genauso wenig wie die alten Kategorien des „bestimmten" oder des "unbestimmten" Rechtsbegriffs oder des „Ermessens" mitsamt ihren „Spielraum"Theorien und „Eindeutigkeits"-Kriterien einen Schritt weiter- 
führen und sich damit das rechtselementare Problem nicht erfassen läßt, daß Handlungskontrolle anders beschaffen ist als Handlungsentscheidung, da $\beta$ im Grunde die neue Etikettierung nur alten Wein in neue Schläuche füllt und daB - das befürchte ich jedenfalls - am Schluß nur wieder die Sentenz übrigbleibt, der Richter dürfe eben nur die angeblich „exakt“ bestimmbaren Rechtsbegriffe zum Kontrollmaßstab nehmen. Und dann haben wir wieder den Rechtspasitivismus wie etwa vor 70 Jahren.

Vogel: Erlauben Sie mir, Herr Rupp, zu fragen, ob Sie neben Theorie und Praxis, die Sie nannten, auch der Dogmatik einen Ort einräumen? Man kann gewiß begründen, daß verschiedene Formen rechtlichen Handelns einander strukturell gleich seien - Norm und Verwaltungsakt, Ermessensausübung und Rechtsanwendung -, es gibt dafür immer gute Gründe. Aber sind nicht doch einige "gleicher" als andere?

Mir ist gerade an dem Referat von Herrn Schmidt-Aßmann so sympathisch - neben vielem anderen - , daß er sich zwar die Möglichkeit eröffnet, über die Unterscheidung von Ermessen und Beurteilungsspielraum hinauszugehen, da $\beta$ er aber doch zugleich diese Unterscheidung für die traditionellen, regelmäßig also: für die einfacheren Formen des Verwaltungshandelns aufrechterhält.

Bachof: Zu zwei Punkten in den Ausführungen von Herrn Rupp:

Erstens: $\mathrm{Da}$ der Zivilrichter dem die Scheidung Begehrenden die Verantwortung nicht abnehmen kann, hat mit meiner gestrigen Bemerkung nichts zu tun. Es ging vielmehr darum, $\mathrm{da} ß$ der Zivilrichter die erste mit staatlicher Autorität begabte Instanz ist, die über die Rechtmäßigkeit entscheidet. Dagegen liegt für den Verwaltungsrichter bereits eine staatliche Entscheidung einer Verwaltungsbehörde vor, die nachvollzogen wird. - Das gleichzeitig auch zu Herrn Roellecke als Antwort auf seine gestrige Frage an mich. Herr Roellecke hätte mir übrigens mit mehr Grund die Verwaltungsverträge entgegenhalten können. Aber auch in deren Abschluß liegt m. E. seitens der Verwaltung eine „Entscheidung“; dafür kann ich auf Früheres Bezug nehmen.

Zweitens: $\mathrm{Da}$ es eine gleitende Skala von (fast) ganz unbestimmten bis hin zu (fast) ganz bestimmten Begriffen gibt, das wußte nicht nur die Wiener Schule, das haben wir alle seit langem gewußt. Aber das nimmt mir nicht die Möglichkeit, trotz- 
dem diese Begriffe zu verwenden. $\mathrm{Da} B$ es zwischen klein und groß jede denkbare Skala gibt, verbietet mir doch nicht, ein Ding klein oder groß zu nennen.

Rupp: Zuerst die Frage von Herrn Vogel: Ich habe Ihre Fragestellung nicht recht verstanden, weil bei ihr ganz offensichtlich die Dogmatik zwischen Theorie und Rechtspraxis fungiert. Das scheint mir ein vollig neues Verständnis von Dogmatik zu sein, zu dem ich nicht Stellung nehmen kann. Dogmatik - wie ich sie verstehe - ist der Fundus dessen, was als geltendes Rechtsgerüst mit Einschluß des gesamten Rechtsmaterials vorhanden ist. Insofern ist die Summe der Rechtsprechung Teil der Dogmatik und kann dieser nicht entgegengesetzt werden. Ich habe daher die Frage in dieser Alternative nicht verstanden und kann deshalb auch keine Antwort geben.

Nun zu Herrn Bachof: Es freut mich, Sie sagen zu hören, Sie hätten gestern etwas anderes gemeint Nur: Der Begriff der Verantwortung, der hier im Mittelpunkt steht, ist ja wohl nicht davon abhängig, daß es sich um staatliche Verantwortung handelt. "Verantwortung" hat ihren Platz im Bereich des Zivilrechts und der Privatautonomie noch viel stärker als im Bereich staatlicher Verwaltung. Man kann auch nicht sagen, der Zivilrichter sei, weil er sozusagen als erste mit staatlicher Autoritait begabte Instanz dem Problem fremder Verantwortung begegne, in einer gänzlich anderen Situation als der Verwaltungsrichter, der es mit der Verwaltungsverantwortung, also bereits mit einer sich in Hoheitsakten prasentierenden Verantwortung zu tun habe. Für das Problem der Verantwortung ist dieser Unterschied irrelevant.

Zum Schluß: Zwischen groß und klein kann natürlich unterschieden werden. Nur: Wenn man schon so weit geht, den qualitativen Unterschied zwischen Ermessen - als Rechtsfolgeermessen - und Beurteilungsspielraum - als Tatbestandsermessen - fallenzulassen, dann ist es meines Erachtens unumgänglich, daß Sie auch die These von der „Eindeutigkeit“ der sogenannten bestimmten Rechtsbegriffe und damit jene Theorie aufgeben, die gerade auf dem qualitativen Unterschied zwischen „Ermessen“, „Beurteilungsspielräumen“ und „einzig richtiger Kognition" aufbaut. Denn Sie sagen mit Recht, daß auch die sogenannten "bestimmten" Begriffe in Wahrheit unbestimmt sind. Dann müssen Sie aber nach anderen Kriterien Ausschau halten, weil die bisherigen Kriterien nicht mehr tragen und die Verwaltungsgerichte nur in die Irre führen. Sie messen ja auch groß und klein nach derselben Maßeinheit. 
Knöpfle: Anknüpfend an das, was Herr Rupp eben gesagt hat, möchte ich zurückkommen auf das Referat von Herrn Scholz: Er hat unter Berufung auf das Verfassungsprinzip der Gewaltenteilung im Verhältnis VerwaltungsgerichtsbarkeitVerwaltung von einem "kompetenzgerechten Rechtsschutz", der durch die Eigenverantwortlichkeit der Verwaltung begrenzt wird, gesprochen und unter Abschnitt I Ziffer 4 seiner Leitsätze die These vom kompetenziellen Vorrang der Verwaltungsentscheidung im Bereich metajuristischer Richtigkeitsgewähr formuliert. In der Sache stimme ich $\mathrm{hmm}$ zu; hinzuweisen ist aber auf das Problem einer strengen, kategorialen Unterscheidbarkeit juristischer und außerjuristischer Maßstäbe, von der die Systematisierung des Referenten ausgeht. Die Schwierigkeit einer begrifflich-dogmatischen Trennung beider Maßstäbe steigert sich in dem $\mathrm{Maße}$, in dem sich der Gesetzgeber des Mediums des unbestimmten Rechtsbegriffes bedient, um auf diese Weise nicht selten eln ganzes - wie man in der Verwaltungslehre heute sagt - implementationsbedürftiges Programm, eine Fülle mehr oder weniger konkretisierbarer Zielvorstellungen zu umgreifen, die außerrechtlicher Art sind; diese werden so in Elemente auslegungsbedürftiger Rechtsbegriffe umgemünzt. Ein solches Vorgehen führt dann bei der Rechtsanwendung zu einer Aporie, die sich besonders deutlich aufzeigen läßt an den in vielen Rechtssätzen verwendeten $\mathrm{Be}-$ griffen "Gemeinwohl" und "öffentliches Interesse"; so stellen viele Gesetze ab auf das „Wohl der Allgemeinheit", auf „dringende Gründe des öffentlichen Wohls“ oder auf „öffentliche Interessen", so besonders im Enteignungsrecht. Das Bemühen, diese Begriffe mit den Methoden der juristischen Hermeneutik mit konkretem Inhalt zu füllen, führt bald zu der Erkenntnis, $\mathrm{da} \beta$ sie sich einer Interpretation mit Hilfe der bis heute entwickelten Methoden der Auslegungslehre entziehen, daß in ihnen Komponenten enthalten sind, die in Wirklichkeit Verweisungen auf die jeweiligen außerrechtlichen Richtigkeitsvorstellungen und den jeweiligen Konsens der maßgeblichen politischen Kräfte darstellen. Auf der Speyerer Tagung des Jahres 1968 über „Wohl der Allgemeinheit und öffentliche Interessen" (Band 39 der Schriftenreihe der Hochschule Speyer) hat Herr Ule in seinem Referat über die Anwendung dieser Begriffe in der Rechtsprechung aufgezeigt, daß sich grundsätzliche Erörterungen darüber, was unter dem Begriff der öffentlichen Interessen oder Belange zu verstehen ist, in der Judikatur kaum finden und daß die Ausführungen der Gerichte zur Methodik der Bestimmung des Inhalts dieser Begriffe erst recht unergiebig sind. Hat man erkannt, daß die Aufnahme dieser Be- 
griffe in Rechtssätze den unzulänglichen Versuch darstellt, außerrechtliche Gehalte in die Sphäre des rechtlich Normierbaren umzusetzen, dann verwundert einen die Hilflosigkeit der Rechtsprechung im Umgang mit ihnen nicht mehr. Das Streben nach einer materiellen Bestimmung ihres Inhalts, die dem Richter in einer Vielzahl von Fällen als Entscheidungskriterium dienen könnte, führt begreiflicherweise nicht zum Erfolg; möglich ist nur, eine "Leerformel" durch eine andere, etwas ausführlichere zu ersetzen. Wie soll das Verwaltungsgericht in einem Verfahren über die Zulässigkeit einer Enteignung für Universitätsneubauten vorgehen, wenn der Betroffene einwendet, in der gegebenen Situation diene der Ausbau einer Universität nicht dem Gemeinwohl, oder wenn er vorbringt, der Bau von Gymnasien oder Grundschulen liege weit mehr im öffentlichen Interesse als der Hochschulbau? Ist es hier berechtigt und verpflichtet, das gesamte Bildungskonzept des Landes zu überprüfen und eine bestimmte Prioritätenordnung - als Akt der Rechtsanwendung - aufzustellen? Obwohl es sich formal um "Anwendung" von Gesetzesrecht handelt, stößt man hier an Grenzen des Judiziablen. Wo bei der Prüfung der Frage, ob ein Vorhaben dem Gemeinwohl dient, die Grenze der von der Verwaltungsgerıchtsbarkeit anzustellenden Erwägungen liegt, ist weithin ungeklärt. Die Praxis verfährt in solchen Fällen, wenn ich recht sehe, vielfach ähnlich wie bei einer Enteignung, der ein Planfeststellungsverfahren vorausgegangen ist: hier steht der festgestellte Plan im Enteignungsverfahren nicht mehr zur Diskussion. Würde sich in dem Beispielfall einer Enteignung für Universitätszwecke das Verwaltungsgericht im wesentlichen nicht darauf beschränken zu prüfen, ob die Maßnahme in einer für den Betroffenen weniger einschneidenden Weise verwirklicht werden kann, sondern die Frage der Gemeinwohlbezogenheit des Projekts in ihrer ganzen Breite aufzurollen gehalten sein, dann müßte es in der letzten Konsequenz das Regierungsprogramm mit all seinen Zielvorstellungen und Prioritätsentscheidungen seiner Jurisdiktion unterstellen. Einen fundierten Rechtsspruch zu erlassen, wird vollends unmöglich, wenn sich herausstellen sollte, daß es an einem vernünftigen Konzept überhaupt fehlt. Dann müßte die Verwaltungsgerichtsbarkeit ihrerseits unter dem Deckmantel der Rechtsauslegung Gemeinwohlvorstellungen entwickeln und für die Beurteilung des konkreten Projekts relevante Maßstäbe setzen.

Damit würde aber der Ansatz für einen „kompetenzgerechten Rechtsschutz" - mit diesem Begriff soll die verwaltungsgerichtliche Kontrolle eingeschränkt werden -, wie ihn Herr 
Scholz fordert, wohl entfallen. Es wäre nicht mehr möglich, der Verwaltungsentscheidung, soweit sie sich an außerrechtlichen Maßstäben orientiert, den Vorrang vor ebensolchen Erwägungen der Verwaltungsgerichtsbarkeit einzuräumen.

Erlauben Sie mir abschließend, noch kurz einen anderen Aspekt der Problematik anzureißen: Setzt das Gewaltenteilungsprinzip, das ja auch einen genuinen eigenständigen $\mathrm{Be}-$ reich der Exekutive verfassungskräftig normiert, einer zunehmenden apokryphen „Verrechtlichung" ursprünglich außerrechtlicher Maßstäbe und politischer Zielvorstellungen - mit der Folge einer entsprechenden Ausweitung der Kontrollmöglichkeiten der Judikative - durch das Rekurrieren auf das Gemeinwohl und auf öffentliche Interessen in Rechtsnormen eine Grenze?

Badura: Aus den beiden Vorträgen des heutigen Vormittags hat man wohl doch etwas mehr an Neuem lernen können, als Herr Rupp gehört hat. Ich meine damit nicht die Relativierung der Unterscheidung zwischen Ermessen und Beurteilungsspielraum. Beide Referenten haben in gewisser Anknüpfung an die Referate von Bachof und Brohm das Problem der gestaltenden, der planenden Verwaltung in den Vordergrund gestellt und haben versucht, für einige Problembereiche, vor allem für den Bereich der Ermessensfragen und der Kontrollmöglichkeiten, eine Art neuen Grundriß zu zeichnen, dessen Haltbarkeit meiner Ansicht nach in der Diskussion heute überprüft werden müßte. Hinter dem allgemeinen Wort „gestaltende“ oder ,planende Verwaltung" verbirgt sich allerdings eine große Menge zum Teil ganz unterschiedlicher Vorgänge: Gesamtplanungen, die mit einbezogen waren - ich erinnere an die Regionalprogramme, an die Bauleitpläne, die erwähnt worden sind -, aber auch Fachplanungsentscheidungen, die ja zum Teil ganz anderen Grundsätzen folgen.

Ich möchte hier als einen Punkt, der meiner Ansicht nach etwas zu kurz gekommen ist, erwähnen, daß es in diesem Bereiche Entscheidungen gibt, die zugleich Planungsentscheidungen und Unternehmergenehmigungen sind, wie z. B. die Genehmigung eines Atomkraftwerkes oder eines Flughafens, wo es vielleicht mit dem allgemeinen Gesichtspunkt polygonaler Rechtsverhältnisse nicht sein Bewenden haben darf, sondern die besondere Rolle des Antragstellers, der eine Erlaubnis oder eine Genehmigung begehrt, auch rechtlich einen Ausdruck finden müßte.

Ich finde es weiter richtig, daß beide Referenten in betonter Weise, vor allem Herr Scholz, von der Aufgabe der Verwal- 
tung und von den Verwaltungszwecken ausgegangen sind und damit den Versuch unternehmen, diesen Bereich des Verwaltungsrechtes mit einigen neuen Gedanken anzureichern, um damit sowohl der Verwaltung we der Verwaltungsgerichtsbarkeit wie auch denjenigen, die ihr Recht vor den Verwaltungsgerichten nehmen müssen, zu helfen. Weniger deutlich ist mir allerdings die Frage geworden, wer diese Entscheidungen im Bereich der Verwaltung trifft. Ich meine damit nicht nur den Punkt, den Herr Zacher bereits erwähnt hat, nämlich die personale Seite der Verantwortung, sondern auch die Träger. Denn es macht einen Unterschied, ob eine bürokratische Planungsentscheidung getroffen wird oder ob sie auf der Basis von so oder anders organisierten Selbstverwaltungskörpern erfolgt. Also müßten insofern vielleicht doch Unterschiede gemacht werden zwischen Planungsentscheidungen, die von einer Gemeinde stammen (1m Rahmen der Bauleitplanung), die von einem Regionalverband ausgehen oder die rein administrativ, im Planfeststellungsverfahren beispielsweise, getroffen werden.

Ein ganz zentraler Punkt ist schließlich die Frage der Maßstäbe und die Frage, inwieweit solche Maßstäbe für die Kontrolle von gestaltenden oder Planungsentscheidungen überhaupt zur Verfügung stehen. Ich glaube, es war notwendig und richtig, daß beide Referenten die Bedeutung des Gesetzes und der Notwendigkeit einer möglichst spezifischen gesetzlichen Ausprägung sowohl der zu realisierenden Gestaltungsaufgabe als auch der Maßstäbe oder der Richtlinien herausgehoben haben. Selbst dort, wo Herr Scholz von den autonomen Maßstabsbildungen der Verwaltung spricht, glaube ich ihn doch richtig verstanden $\mathrm{zu}$ haben, daß er so weit wie möglich eine rechtsstaatliche Bestimmtheit der gesetzlichen Ermächtigung vor Augen hat und insofern möglicherweise die Umarmung von Herrn Peters doch nicht so herzlich ausgefallen wäre. Das Gesetz also und die Möglıchkeit der gesetzlichen Normierung dieser Maßstäbe ist zunächst einmal eine staatsrechtliche und verfassungsrechtliche Prämisse für die dann darauf möglicherweise aufzubauende Lehre eines Planungs- oder Gestaltungsermessens.

Ich finde weiter auch richtig, wenn zwischen dem Verfahrensermessen und dem sachlichen Ermessen unterschieden wird. Gerade wenn man dem Verfahren eine so große Bedeutung bei der Formung der Verwaltungsentscheidungen, der Gestaltungsentscheidungen der Verwaltung zumißt, muß man bemerken, daß natürlich auch allein in der Gestaltung des Verfahrens selbst - Beispiel Teilgenehmigung im atomrechtlichen Ver- 
fahren - ein wesentliches Element des Ermessens steckt, das ebenfalls einer sachgemäßen Kontrolle unterworfen werden muß.

Zum Schluß ein Wort zu den Thesen selbst hinsichtlich der Maßstäbe, der Kontrolldichte, namlich was unter IV, Thesen 15 ff. von Herrn Scholz und in den Thesen 21 bis 23 von Herrn Schmidt-Aßmann steht: Ich glaube, es ist noch nicht voll verständlich geworden, was es bedeutet, wenn Herr Scholz von der „Konkretisierungsgerechtigkeit“ und dem Prinzip der "maximalen Konkretisierung“, von der „verwaltungseigenen Maßstabsbildung" und ähnlichem spricht, vor allem dann auch, was in den Thesen 18 und 19 von den Grenzen gesagt ist, die der verwaltungsgerichtlichen Kontrolle gesetzt sind. Es ist zwar im Prinzip akzeptabel, aber es ist, glaube ich, für den Hörer noch nicht ohne weiteres verständlich geworden, was das praktisch eigentlich heißt. Es ist zu fragen, nur um ein Beispiel zu nehmen, unter welchen Maßstäben die Standortentscheidung eines Flughafens - bei der Genehmigung nach $\S 6$ des Luftverkehrsgesetzes - oder einer Atomanlage verwaltungsgerichtlich überprüfbar ist oder welche Maßstäbe da von Gesetzes wegen nach Auffassung der Referenten bestehen oder bestehen sollten. Herr Schmidt-Aßmann hat diesen Punkt der Standortentscheidung in seiner These 23 berührt; ich habe ihn so verstanden, daß dieser Punkt auch unter seinen Evidenzvorbehalt fällt. Nach meiner Auffassung wird an dieser Stelle die Möglichkeit der verwaltungsgerichtlichen Kontrolle zu weit zurückgenommen. Auch die bisher vorliegende Praxis sowohl des Bundesverwaltungsgerichts wie der Oberverwaltungsgerichte hat sich auf eine derartig weit zurückliegende Verteidigungslinie des einzelnen nicht bezogen, daß also lediglich „evident unrichtige" Entscheidungen überpruft werden könnten.

Und die letzte Bitte, die ich daran anknüpfen würde, wäre die, daß doch die beiden Referenten sich erklären mögen, ob und inwieweit sie mit der dazu vorliegenden Rechtsprechung des Bundesverwaltungsgerichts (BVerwGE 34, 301 und später) übereinstimmen oder aber abweichen.

Thieme: Ich möchte meine Ausführungen mit dem Begriff der Verantwortung beginnen. Das ist das Thema, das uns gestellt ist. Es geht davon aus, daß die Verwaltung eine spezifische Verantwortung hat, die wir ausloten müssen. Das Thema verlangt eine Antwort darauf, wie diese Verantwortung aussieht und wie sie durch die Verwaltungsgerichtsbarkeit relativiert wird. Sie wird relativiert. Denn wer kontrolliert wird, 
antizipiert unwillkürlich die Kontrolle und verändert sein Verhalten, stellt es auf die Kontrolle ein. Die Verwaltungsgerichtsbarkeit übernimmt mit ihrer Kontrolle ein Stück Verwaltungsverantwortung. Insofern scheinen mir die beiden Arten der Verantwortung, um die es hier geht, nicht etwas prinzipiell Unterschiedliches zu sein. Ich möchte daher auch Herrn Scholz widersprechen, wenn er von einem Dualismus von Verwaltungszweck und Rechtszweck spricht. Es handelt sich in beiden Fällen um dasselbe, das zwar in einem anderen Stück unserer Staatsorganisation wahrgenommen wird, aber auf denselben Zweck bezogen ist. Denn schließlich ist die Rechtsnorm ein Mittel, mit dem die Staatszwecke verwirklicht werden, wer immer die Norm handhabt.

Nach den heutigen Referaten stellt man sich die Frage, wo wir stehen. Stehen wir dort, wie es Herr Bettermann angedeutet hat, an einem Punkt, an dem es nur darum geht, die Verwaltungsgerichtsordnung von 1960 noch besser zu verwirklichen? Oder stehen wir an einem Punkt, den man etwas pointiert als "Götterdämmerung" der Verwaltungsgerichtsordnung bezeichnen könnte, wozu man sich veranlaßt fühlt, wenn man die lange Liste von Reformvorschlägen von Herrn SchmidtAßmann betrachtet?

Ich will die Punkte, bei denen wir mit der heutigen Konzeption der Verwaltungsgerichtsordnung - bezogen auf die Problematik unseres Themas - nicht fertig geworden sind, nicht im einzelnen ausbreiten. Das werden wir wahrscheinlich auch nicht sehr schnell leisten können, sondern werden die Spannung zwischen Verwaltung und Verwaltungsgerichtsbarkeit dogmatisch so oder so formuliert weiterhin ertragen müssen. Aber - und das ist von beiden Rednern heute morgen übereinstimmend gesagt worden - das Bild des materiellen Verwaltungsrechts hat sich gewandelt. Es 1st weitgehend ein Planungsrecht geworden. Eines wurde aber heute nicht gesagt: Der Entwurf des Allgemeinen Verwaltungsverfahrensgesetzes enthält, als besonderes Verfahren, das Planungsverfahren. Auch hier ist der Wandel sichtbar. Daher stellt sich die Frage, ob nicht auch die Verwaltungsgerichtsordnung das, was im materiellen Recht und im Verwaltungsverfahrensrecht geschieht, nachvollziehen muß, indem hier der noch fehlende Planungsrechtsschutz neben den Vollzugsrechtsschutz und den Normenrechtsschutz gestellt wird. Ich möchte meinen, daß in unsere Verwaltungsgerichtsordnung ein ganz neues Kapitel hineingehört, ebenso wie auch bei der Verfassungsrevision versucht wird, die Planung in das Grundgesetz einzubeziehen, was ja schon in Ansätzen gelungen ist. Insofern stehen wir durchaus 
an einem Punkt, an dem viel Neues geschieht. Darauf sollten wir unsere Aufmerksamkeit richten.

Denninger: Einen Teil dessen, was ich bemerken möchte, hat Herr Knöpfle bereits vorweggenommen. Ich frage mich und möchte auch Herrn Scholz fragen im Hinblick auf seine These 4 im I. Teil und auf den Leitsatz 9, ob es wirklich eine solche genaue begriffliche Abscheidung der beiden Verantwortungsbereiche, der Verwaltungsgerichtsbarkeit und der Verwaltung, nach dem Kriterium der metajurıstıschen bzw. der juristischen Richtigkeitsgewähr gibt. Wenn das der Fall ist, dann müßte man daran eine ganze Reihe von konkreten Folgen knüpfen können. Es ist mir in Ihrem Referat, Herr Scholz, nicht deutlich geworden, welche konkreten dogmatischen Folgerungen Sie nun etwa an den Begriff des kompetenziellen Vorrangs knüpfen wollen. Ich habe auch Bedenken, ob man in dieser Weise die Verantwortungsbereiche voneinander abscheiden kann, und möchte das an einem Beispiel exemplifizieren:

Herr Knöpfle hat ja schon die unbestımmten Rechtsbegriffe des "Gemeinwohls" und des "öffentlichen Interesses" genannt. Ich möchte noch auf eine andere Erscheinung aufmerksam machen. Es gibt in einigen Bereichen ein doppelspuriges Aufsichtsverfahren, etwa der Art, daß eine Beanstandung aus Zweckmäßigkeitsgründen ebenso möglich ist wie eine Beanstandung aus Rechtmäßigkeitsgesichtspunkten. In der Praxis zeigt sich nun, daß derjenige, der die Beanstandungskompetenz hat, häufig wirklich würfeln kann, ob er den einen oder den anderen Weg wählen will. Er kann haufig mit beiden Möglichkeiten zum Ziele kommen. Und es wird dann von seiner Auffassung von der Verantwortung der Verwaltung oder der Verwaltungsgerichtsbarkeit abhängen, ob er qua Exekutivbehörde die Justiz in einem eingeschränkteren oder aber in einem weiteren Umfang zum Zuge kommen lassen will. Ich möchte Sie also fragen: Was heißt in diesem Zusammenhang bei Ihnen „metajuristisch"?

In diesem Zusammenhang ein weiteres: Ich glaube auch, da ich zwischen Verantwortung und Kompetenz, die letztere verstanden als bloße Zuständigkeit, einen Unterschied machen möchte, daß man sich durchaus überlegen sollte - Herr Zacher hat das in einer etwas anderen Richtung angedeutet - , ob nicht auch die Verwaltungsgerichtsbarkeit Verantwortung für die Respektierung und Durchsetzung der Verwaltungszwecke oder des Verwaltungszwecks, wie Sie sagen, trägt. Hier beginnt, meine ich, das Problem der Sachverständigen in der Justiz. 
Götz: Ich stimme gern ein in den Chor derer, die es für richtig und fruchtbringend empfinden, da $\beta$ beide Referenten den ihnen aufgetragenen Begriff der Verwaltungsverantwortung nicht nur aufgenommen, sondern mit Leben erfüllt haben. Ich gehe allerdings nicht davon aus, daß der eigentliche Gewinn aus der Aufbereitung des Begriffes der Verwaltungsverantwortung darin zu erblicken ist, daß wir nun wieder die Verwaltung als eine eigenständige Staatsgewalt ansehen. Ich bin auch nicht der Meinung, daß die Mehrheit in unserem Kreise vor drei Jahren die Verwaltung noch nicht als eine eigenständige Staatsgewalt angesehen hätte. Das war eigentlich nie streitig, bestimmt nucht bei einer Mehrheit in unserem Kreıse. Ich meine, daß den Ausführungen beider Referenten die Tatsache der Verwaltung als einer eigenständigen Staatsgewalt oder eines eigenständigen Teiles der Staatsgewalt vorgegeben war. Aber was vor wenigen Jahren feststand, war doch dies, daß wir im Gesetz sowohl Auftrag wie auch Schranke der Verwaltungstätigkeit sahen. Und daran ist meines Erachtens festzuhalten. Deshalb habe ich Zweifel, ob wir mit Ihnen, Herr Scholz, von metajuristischen und außerrechtlichen Zwecksetzungen oder, wie Sie es an anderer Stelle tun, von Zuständigkeiten mit metajuristischem Zweckgehalt sprechen konnen oder gar von der Grenze der metajuristischen Verwaltungsverantwortung, an die die Verwaltungsgerichtsbarkeit stoße. Ich gehe davon aus, daß dann, wenn unsere Gesetze der Verwaltung aufgeben, gleichzeitig für die Sicherstellung der Energieversorgung und für optimale Umweltbedingungen zu sorgen, oder die deutsche Seeschiffahrt oder die Landwirtschaft zu fördern usw., diese aufgetragenen $Z$ wecksetzungen gesetzliche und rechtliche sind. Auf einem ganz anderen Blatt steht es, daß die Ausfüllung dieser Aufgaben der Verwaltung in einer Weise übertragen sein kann, die von der Verwaltungsgerichtsbarkeit nicht in vollem Umfang nachzuvollziehen ist, daß hier also ein Raum eigenständiger oder, wenn Sie so wollen, ermessensmäßiger Ausfüllung bleibt.

Ein Kernstück des Begriffes der Verwaltungsverantwortung, wie ihn uns Herr Scholz heute dargelegt hat, bildet der Umbau des gesamten Systems von Ermessen, unbestimmten Rechtsbegriffen und Beurteilungsspielraum. Ich halte es durchaus für eine fruchtbare Methode, diese Begriffe einmal beiseite $\mathrm{zu}$ lassen oder sich nicht von ihnen als vorgegebenen Schubkästlein unbedingt führen zu lassen. Aber ich glaube, wir sollten uns nicht geradezu dafür belobigen, daß wir die Probleme auch außerhalb dieser begrifflichen Einteilung angehen. Daß sich hinter diesen Begriffen auch eine bestimmte 
Lösung der Kompetenzfrage zwischen Verwaltung und Verwaltungsgerichtsbarkeit verbirgt, ist allgemein bekannt. Wir müssen in diesen Begriffen je gerade den Versuch einer nuancierten und differenzierten Lösung auch der Kompetenzfrage zwischen Verwaltung und Verwaltungsgerichtsbarkeit sehen. Um diese Begriffe ist gerungen worden. Sie haben sich doch, wie ich meine, im wesentlichen bisher als ein geglückter $\mathrm{Ab}$ grenzungsversuch erwiesen. Sie haben jedenfalls mit dazu beigetragen, daß heute beide Referenten - und darin stimme ich thnen voll $\mathrm{zu}-\mathrm{zu}$ dem Urteil gekommen sind, daß die Verwaltungsgerichtsbarkeit den Anforderungen, denen sie sich stellen muß, im wesentlichen - im ganzen, wie es Herr Schmidt-Aßmann eingangs gesagt hat - gerecht geworden ist.

Gestatten Sie mir noch eine kurze weitere Bemerkung zum Komplex Ermessen - unbestimmter Rechtsbegriff - Beurteilungsspielraum: Auch wenn wir diese Unterscheidungen beiseite lassen, müssen wir uns doch den Fragen stellen, die sich hinter ihnen verbergen. Hierzu meine ich, daß wir vielleicht die Fragen des Ermessens und der planenden Verwaltung im Referat von Herrn Scholz, vielleicht auch in dem Referat von Herrn Schmidt-Aßmann, zu stark in den Vordergrund gestellt finden. Lassen Sie mich doch ein Beispiel nennen! Wir haben vom Februar dieses Jahres eine Entscheidung des Oberverwaltungsgerichtes Münster zum Kernkraftwerk in Würgassen. Es handelt sich um die Anfechtung der Genehmigung, oder genauer einer der Teilgenehmigungen für das Kernkraftwerk Würgassen. Die Rechtsnorm, die in diesem Verfahren anzuwenden war, der $\S 7$ des Atomgesetzes, lautet an der einschlägigen Stelle sinngemäß etwa so: ein Kernkraftwerk muß der Anforderung genügen, daß die Gefahrenvorsorge für die Bevölkerung sichergestellt ist. Das war alles, was dem Gericht an normativer Grundlage vorgegeben war. Das Urteil des Oberverwaltungsgerichts Münster, dessen Begründung etwa Dissertationsstärke hat, ist in der Tat den Weg gegangen, alle Sicherheitsfragen, die sich hier stellen, im Wege des Sachverständigenbeweises zu ermitteln und eine selbständige, eigene Antwort des Gerichts auf die Frage, ob die technische Sicherheit dieses Kernkraftwerks gewährleistet 1 st, zu geben.

Obwohl dieses Beispiel in den Zusammenhang der Planung gehört, sind es, wie offensichtlich wird, nicht im technischen Sinn die Fragen des Ermessens und der Plangestaltungsfreiheit, welche dem Oberverwaltungsgericht solche Schwierigkeiten gemacht haben, sondern es ist so, wie Herr Schmidt-A $\beta$ mann in seiner These 29 sagt, daß die Bewältigung des Tatsachenmaterials schlechthin zum neuralgischen Punkt gericht- 
licher Kontrolltätigkeit geworden ist. Wir könnten aus dem Bereich der unbestimmten Rechtsbegriffe andere Beispiele anführen. Jedenfalls mussen wir uns aber der Frage stellen, ob die Verwaltungsgerichte nach wie vor, wie sie das tun, selbst abschließend entscheiden, auch wenn prognostische Elemente vorliegen, was natürhch, Herr Bachof, der Fall ist. Aber wir müssen die Fragen beantworten: Ist es die Aufgabe des Verwaltungsgerichts, eine abschließende eigene Entscheidung zu treffen, oder hat es sich mit der Vertretbarkeitsaussage $\mathrm{zu}$ begnügen?

Scholz: Ich darf auf die mehrfach an mich gerichtete Frage nach meiner Unterscheidung zwischen juristischer und metajuristischer Verantwortung kurz zu präzisieren versuchen. Im Grundsätzlichen sind wir, Herr Knopple, Herr Denninger und Herr Götz, nicht wesentlich auseinander. Gerade Ihre Beispiele und die Art, wie Sie diese verwaltungsgerichtlich behandelt wissen wollen, entsprechen meinem Anliegen. Wesentlich scheint mir auf der anderen Seite eines zu sein: Beim Verständnis von Verwaltungsverantwortung hat die klassische juristische Methode bisher zu einseitig und in allzu verengender Weise dominiert. Sicherlich sind jeder gesetzliche Auftrag und jede gesetzliche Ermächtıgung der Verwaltung auch juristischer Auftrag und juristische Ermächtigung, sind als solche zu handhaben und als solche auch in die Dimension der juristischen Kontrollmaßstäbe der Verwaltungsgerichtsbarkeit zu übersetzen. Verwaltung ist jedoch nicht ausschließlich in diesem Sinne juristischer Normvollzug. Die Aufträge der Verwaltung liegen auch auf außerjuristischem Gebiet und außerhalb rein juristisch verstandenen Normvollzugs. Das Stichwort metajuristischer Sachverstand ist von Ihnen, Herr Denninger, völlig zu Recht hervorgehoben worden. In diesem Sinne unterscheide ich zwischen Juristischem und Metajuristischem, so weit dies kompetenziell oder verantwortungsmäßig so vorgegeben ist. Die Verwaltung ist naturlich immer rechtlich gebunden und bedarf stets der rechtlichen Ermächtigung. Funktionell verwirklicht sie aber nicht nur Recht; sle betreibt ebenso beispielsweise Wirtschaft, Soziales usw. Sie betreibt etwa Raumplanung aufgrund von Ermächtigungen, deren funktioneller Inhalt für eine rein juristische Methodik kaum oder doch nur teilweise faßbar ist. Auch metajurıstıscher Sachverstand bestımmt das Verwaltungshandeln; metajuristischer Sachverstand bildet damit eine legitime Verwaltungskompetenz. Konfrontiert man diese Kompetenz mit der juristischen Kontrollkompetenz der Verwaltungsgerichtsbarkeit, so sind die funktionel- 
len Grenzen der Verwaltungsgerıchtsbarkeit zu erkennen; es sei denn, man wolle den umgekehrten Weg gehen und sagen: Alles, was die Verwaltung macht, ist zwingend und immer voll juristische Tätigkeit, ist voll juristische Kompetenz. Dann muß die Verwaltung auch gerichtlich voll, $d . h$. auch in eigentlich außerrechtlichen Funktionsbereıchen, kontrollierbar sein. Für die Verwaltungsgerichtsbarkeit hat dies aber zur Konsequenz, da $B$ die, Gerichte aus Gründen des dann erforderlichen umfassenden Sachverstandes mit den entsprechenden Spezialisten besetzt werden müßten. Dann wäre eines Tages vielleicht nur noch der Vorsitzende Richter eines Verwaltungsgerichts Jurist, die anderen Richter wären Spezialisten auch außerrechtlicher Herkunft. Verwaltungsgerichtsbarkeit hieße dann aber nicht mehr wirklich juristische, gerichtliche Tätigkeit im bisher geltenden Sinne.

Wenger: Ich habe eine Zwischenfrage: Was macht der Richter, der eine Obduktion anordnet, weil wegen Mordverdachts ein Sachverständigengutachten von Ärzten und Chemikern eingeholt werden soll. Und wenn dieses Kollegium dann feststellt, das nachgewiesene Gift sei tödlich gewesen. Ist das Rechtsanwendung, ist das metajuristisch und wo liegt hier der Unterschied zwischen Gerichtsbarkeit und Verwaltung?

Scholz: Das ist einfach zu beantworten. Das ist nichts anderes als Sachverhaltsaufklärung unter Zuhilfenahme von Sachverständigen. Das ist kein Problem.

Walter Schmidt: Eine Zwischenfrage an Herrn Scholz zur Terminologie: Könnte man statt „metajuristisch" nicht einfach "politisch" sagen?

Scholz: Ich glaube, daß man das teilweise sagen kann. Auf der anderen Seite hätte ich große Bedenken, das Wort „politisch" hier allgemein einkehren zu lassen. Denn der Begriff des "Politischen" ist einerseits weiter und andererseits auch enger. Es gibt politisches Recht, es gibt politische Rechtsanwendung mit rein juristischem Funktionsgehalt; es gibt politische Verwaltungstätigkeit aber auch mit metajuristischem Funktionsgehalt. Es gibt weiterhin Verwaltungsbereiche und Verwaltungsfunktionen mit metajuristischem Funktionsgehalt ohne politischen Inhalt, z. B. im Prüfungsbereich. Eine Prüfung in gleich welchem Bereich ist sicherlich keine Tätigkeit der Verwaltung, die genuin politisch ist. Wir würden die Prüfungsverwaltung nicht als politische Verwaltung bezeichnen. Auf der 
anderen Seite ist die Prüfungstätigkeit der Verwaltung nicht nur juristischer Normvollzug, weil bei ihr auch metajuristische Wertungen im Spiel sind. Deshalb würde ich im Ergebnis sagen: Das Wort „politisch“ sollte man nicht an die Stelle des Begriffs „metajuristisch" setzen.

Hans Meyer: Herr Scholz! Wie würden Sie es mit $\S 1$ des Bundesbaugesetzes halten, wo diese ganzen Zwecke als Auftrag dem das Bundesbaugesetz ausführenden Verwaltungsbeamten aufgegeben sind? Metajuristische Zwecke nach Ihrer Definition. Würden Sie dem zustimmen?

\section{(Scholz stimmt zu.)}

- Wenn ja, frage ich mich, warum Sie dann praktisch über die Thesen $16 \mathrm{ff}$. die Rechtsprüfung doch wieder hineinnehmen, indem Sie die These von der maximalen - es muß wohl „optimalen" heißen - Konkretisierung aufstellen und daran die Kontrolle anknüpfen. Dies scheint mir ein Widerspruch zu sein.

Scholz: Zunächst zu $\S 1$ Abs. 4 des Bundesbaugesetzes. Ich bin völlig einig mit Ihnen; hier sind in der Tat Ermächtigungen und Spielräume gegeben, über deren materiell metajuristischen Inhalt man sich im klaren sein sollte.

Zweitens: Einen Widerspruch würde ich bestreiten, Herr Meyer. Zum Thema Konkretisierung, das auch Herr Badura angeschnitten hat, möchte ich gleichfalls noch kurz antworten, ohne jetzt in einen Dialog verfallen zu wollen. Der Begriff der Konkretisierung und das, was ich als Auftrag der Verwaltung zur maximalen Konkretisierung bezeichnet habe, bilden für mich ein wesentlich formales Verfahren, eine methodenmäßige Verfahrenstechnik, mit der ich das gesetzes- und maßstabsgerechte Verwaltungshandeln gerade in so offenen Ermächtigungs- und Begriffsbereichen wie denen des $\S 1$ Abs. 4 des Bundesbaugesetzes messen kann. Gerade hier vollziehen sich stufenförmige Prozesse von Maßstabsbildung und Maßstabsanwendung, deren wirksame Kontrolle mir allein über die Vorstellung eines entsprechend formalen Konkretisierungsverfahrens möglich zu sein scheint.

Herr Badura, ich würde diese Theorie durchaus auf der Linie des Bundesverwaltungsgerichts sehen. Die Vorstellung von Abwägungsdefizıten, vom Abwägen als Vorgang wie als $\mathrm{Zu}-$ stand - dies alles scheint mir am ehesten über das formale Kriterium der Konkretisierung bzw. einer - ich würde am 
Wort „maximalen“ festhalten, Herr Meyer - maximalen Konkretisierung aufzufangen sein.

Maurer: Es geht hier wohl mehr um einen Streit um Worte. Die gesamte Verwaltungstätigkeit dient Verwaltungszwecken. Es kann sich sonach nur noch um die Frage handeln, ob und inwieweit die Verwaltungstatigkeit - und damit die Verwirklichung von Verwaltungszwecken - durch gesetzliche Regelungen determiniert ist.

Bettermann: Ich meine auch, Herr Scholz, daß Sie durch Thre Begriffe von metajuristischer und juristischer Richtigkeitsfeststellung und -prüfung das Problem nicht in den Griff kriegen, sondern davon fortfuhren. Die Verwaltungsgerichtsbarkeit hat in ihren klassischen Bereichen der repressiven Verwaltungskontrolle die Funktion der Rechtmäßigkeitskontrolle. Und die richtige Abscheidung ist die: Was fallt unter die Rechtmäßigkeit und was ist Zweckmäßigkeit, Angemessenheit, Sachgerechtigkeit, Billigkeit? Die Schwierigkeit liegt darin, ob alle die Begriffe und Maßstäbe, die Handlungsmaßstäbe, die in juristischen Normen für die Verwaltung enthalten sind, auch alle Kontrollmaßstäbe für die Gerichte sind. - Herr Rupp, die Unterscheidung von Handlungsmaßstab und Kontroll- oder Beurteilungsmaßstab stammt nicht von Herrn Forsthoff, sondern von James Goldschmidt. Herr Knöpfle, ich würde meinen, daß das Gemeinwohl, das ja auch Herr Bachof als Maßstab für die Kommunalreform genannt hat, für die Verwaltung eine ganz wichtige Handlungsnorm bildet. Die Gemeinwohlverpflichtung ist aber für das Verwaltungsgericht oder das Verfassungsgericht, je nachdem, wer für die Kontrolle berufen ist, ein ungeeigneter Maßstab ist, um daran die Rechtmäßigkeit oder gar Richtigkeit, die Gemeinwohladäquanz der Eingemeindung oder Umgemeindung, zu prüfen - aus dem einfachen Grunde, weil weder ein Verfassungsgericht noch ein Verwaltungsgericht kompetenter, sachverständiger und legitimierter ist, darüber zu entscheiden, was dem Gemeinwohl entspricht, als das Parlament, die Regierung oder die Aufsichtsbehörde, die den Eingemeindungsvorgang angeordnet hat.

Bachof: Genau dazu, Herr Bettermann! Der Staatsgerichtshof von Baden-Württemberg hatte noch im Kreisreformurteil (DOV 1973, 163) gesagt, der Gesetzgeber habe das von der Verfassung nicht näher umschriebene öffentliche Wohl erst selbst zu finden und zu konkretisieren. Der Staatsgerichtshof hätte sich auch damals nicht gescheut, einen offenbaren Mißbrauch 
zu korrigieren; aber nur das. Er hat in den - zeitlich späteren - Gemeindereformurteilen versucht, den Gemeinwohlbegriff in eine ganze Zahl von spezielleren Begriffen aufzulösen; ich habe schon gestern meine Skepsis gegenüber diesem Unternehmen bekundet. Im Kreisreformurteil steht etwa folgendes: Anders als der Gesetzgeber sei die Verwaltung an ein inhaltlich schon ausgefülltes Gemeinwohlgebot gebunden; sie bekomme ja regelmäßig genauere gesetzliche Direktiven mit, welche speziellen Gemeinwohlinteressen sie zu berücksichtigen habe. (Ich meine übrigens, der Gesetzgeber müßte der Verwaltung solche Direktiven mitgeben, wenn er seine Aufgabe richtig erfüllt.) Demgemäß enthält z. B. $\S 1$ Abs. 4 Bundesbaugesetz die Aussage, daß diese und jene namentlich aufgeführten Interessen besonders zu berücksichtigen und abzuwägen sind. Andere Normen lassen sich dahin auslegen, daß mit dem "öffentlichen Interesse", auch wenn es nicht näher benannt ist, etwa speziell das Verkehrsinteresse oder das regionale oder das kommunale oder das örtliche Interesse gemeint ist. Das sind dann Konkretisierungen. Diese Begriffe - das meine ich entgegen Herrn Scholz - kann man nicht als "metajuristisch" bezeichnen; sie enthalten vielmehr, so weit und so offen sie auch sind, rechtliche Grenzen.

Das „Politische“ beginnt meines Erachtens dann, wenn diese Begriffe bzw. die sie enthaltenden Normen in die Praxis umgesetzt werden sollen und die Verwaltung sich fragt: Was dient nun wirklich am besten dem Umweltschutz, was dient am besten dem Verkehr, was dient am besten der sozialen Ordnung der Wohngebiete? Das ist nun eine Frage wertender Beurteilung und einer niemals ganz sicheren Prognose, deren Richtigkeit nur in engen Grenzen gerichtlich überprüft werden kann. An dieser Stelle also würde ich das Politische ansiedeln oder meinetwegen das "Metajuristische", aber nicht schon in den grenzziehenden Begriffen.

Ule: Ich wollte nur einen dogmengeschichtlichen Hinweis geben: Die österreichische Verwaltungsrechtslehre der 80er Jahre des vorigen Jahrhunderts hat diesem Problem zu begegnen versucht mit dem Begriff technisch-administrativer Begriffe, in dem die ganze Problematik enthalten ist. Und ich verstehe, daß Sie, Herr Scholz, sich dagegen gewehrt haben, daß Ihre metajuristischen Begriffe als politische Begriffe bezeichnet werden. Das wäre in gewisser Weise eine Verengung oder auch eine Erweiterung, jedenfalls träfe es, glaube ich, nicht den Kern dessen, was Sie gemeint haben. 
Aber da ich nun schon einmal am Mikrophon stehe, darf ich mir noch einen Hinweis erlauben. Ich darf das vielleicht später bei anderer Gelegenheit näher ausführen. Eine Wellenbewegung, von der in den Ausführungen von Herrn Bachof die Rede war, würde ich, wenn ich die Rechtsprechung betrachte, nicht erkennen. Aber das müßte ich ausführen, und das kann ich im Augenblick nicht tun.

Schnur: Ich möchte Herrn Scholz und Herrn Schmidt-Aßmann im meisten zustimmen, vor allen Dingen in dem erfolgreichen Bemühen, den Verwaltungsrechtsschutz adäquat zu machen zur planerischen Verwaltung.

Aber ich glaube, in einem Punkt haben beide Referenten das darin liegende Problem etwas verharmlost, nämlich als sie einen Begriff im Verwaltungsrechtsschutz gegenüber planerischer Verwaltung weiterführen wollen, der aus der traditionellen Verwaltung kommt, wenn ich das summarisch so sagen darf. Sie sagen: Natürlich muß es dabei bleiben, daß das rechtliche Korrektiv bei der "offensichtlichen Fehlsamkeit" des angegriffenen Aktes zieht. Ich glaube, daß dieses Korrektiv bei planerischen Entscheidungen, insbesondere wenn es um das vorhin von Herrn Bachof erwähnte Prognoseelement geht, ganz anders aussieht als im traditionellen Sinn. Hier nämlich ist der Kontext der "offensichtlichen Fehlsamkeit" - um jetzt Herrn Roellecke zu zitieren - so dicht und so eng, daß der Konsens darüber in der Regel sehr schnell hergestellt ist. Der Konsens ist leicht $\mathrm{zu}$ fällen, weil im traditionellen Verwaltungsakt das Prognoseelement meistens keine entscheidende Rolle spielt. In dem Augenblick aber, wo in der verwaltungsgerichtlichen Utberprüfung das Prognoseelement entscheidende Bedeutung erhält, frage ich mich, wo denn dieser Kontext ist, in dem die "offensichtliche Fehlsamkeit" noch festgestellt werden kann. Ich bleibe bei dem Beispiel von Herrn Bachof: Wenn man versucht, bei einem planerischen Gesetz, zum Beispiel einem Organisationsplanungsgesetz wie der umfassenden Gebietsreform, die „offensichtliche“ Fehlsamkeit der zugrundegelegten Prognosen in den Griff zu bekommen, so werden Sie verstehen, was ich damit meine. Wenn wir mehr Gesetze oder Rechtsverordnungen ähnlicher Struktur bekommen, werden wir, so fürchte ich, feststellen, daß bei echter Planung mit stark prognostischem Element diese letzte Bremse rechtlicher Kontrolle möglicherweise nicht mehr greift. Dann kann dieser Begriff, den die Referenten als Bremse eingebaut haben, auch im Verwaltungsrechtşschutz gegenüber planerischer Verwaltung nur noch eine Feigenblattfunktion haben. 
(Bachof: Es fragt sich, ob der Gesetzgeber nicht in solchen Fällen der Verwaltung mehr Instruktionen an die Hand geben muß.)

Der Gesetzgeber wird dann, wenn das durch Planung gesteuerte Handeln, Herr Bachof, so stark prognostisch in die Zukunft geht, nıchts machen konnen, eben well auch der Gesetzgeber eine so weitgehende Prognose nicht präziser fassen kann - das gerade ist ja die objektiv unveranderbare Eigenart von Planung. Das unterscheidet auch diesen Fall von dem, den eben Herr Götz zitiert hat, weil man dort das Unsicherheitselement der Zukunft durch Sachverstandige so reduzieren kann, daß man eine richterliche Entscheidung fällen kann. Wenn jedoch Prognosen zugrundeliegen wie z. B. ob in fünf Jahren die Finanzmittel auch dazu reichen werden, den Zweck des jetzigen Eingriffes in die kommunale Struktur zu sichern, so findet man gar keınen Sachverständıgen. Herr Bachof hätte mit Recht gesagt: Sollen wir hier etwa den Wissenschaftlichen Beirat beim Bundesministerium der Finanzen einschalten? Die werden wahrscheinlich auch nur sagen: Wenn die und die Voraussetzungen vorliegen, wird das und das eintreten.

Ich befürchte also, daß der Begriff „offensichtliche Fehlsamkeit" als angebliches Kontrollinstrument in diesen Fällen den Sachverhalt verdecken wird, daß be1 planerıscher Verwaltung letztlich der gesamte Verantwortungsbegriff ins Schwimmen kommt. Eben ist schon erwahnt worden, daß versucht wird, von der parlamentarıschen Seite her die politische Verantwortung zu greifen. Aber bel prognostischen Handlungen ist der Verantwortungsbegrıff gar nicht mehr realisierbar, weil nur im Nachhinein das „Richtig“" oder „Falsch“ festgestellt werden kann, während dann, wenn die richterliche Entscheidung so früh gefällt werden kann wie jetzt bei dem Planungsgesetz der Gebietsreform, diese Frage volllig offen 1st. Ich befürchte also - um es noch einmal zu sagen - trotz aller Bemühungen der Referenten, die ich bis zu diesem Punkt unterschreibe und die ich für einen großen Erfolg beim Ausbau des Rechtsschutzes halte, daß wir bei stark planerischen Elementen wahrscheinlich auf das letzte Mittel des Rechtsschutzes, die „offensichtliche Fehlsamkeit", verzichten müssen. Damit nehme ich nicht für oder gegen Planung Stellung. Doch wollte ich auf diese Kehrseite der Planung, die vom Art. 19 Abs. 4 GG faktisch nicht mehr erfaßt wird, nachdrücklich hinweisen. Deshalb nur noch diese Bemerkung: Ich halte es nicht für pure Ideologie, wenn politische Systeme mit vollendeter Planung auf Verwaltungsrechtsschutz in unserem Sinne verzichten; sie müssen 
von der Sache her, d. h. der Eigenart der Planung her, darauf verzichten. Das staatliche Handeln dieser Art gerät außer Kontrolle. Deshalb halte ich die Beantwortung der Frage für unausweichlich, ob Art. 19 Abs. 4 GG dem Staat ein Handeln verbietet, mit dem die Entscheidenden außerhalb sowohl der politischen als auch der rechtlichen Kontrolle geraten. Anders gesagt: Liegt hier eine verfassungsgesetzliche Grenze des Planens?

Häberle: Im Sinne des von Herrn Dürig rechtzeitig inaugurierten „konzertanten“ Diskussionsstils möchte ich auf eine Bemerkung von Herrn Zacher eingehen. Er hat gesagt, daß auch die Verwaltungsgerichtsbarkeit dafür sorgen müsse, daß die Verwaltung ihrer Verantwortung gerecht werden könne. Diesen Gedanken möchte ich projızıeren auf Ebene und Funktion der Gesetzgebung und fragen, ob nicht von einer Gesetzgebungslehre her, gesetzgebungspolitisch, durch entsprechende Verfahrensnormen, Abstufungen und entsprechende Verwendung gesetzlicher Begriffe dafür zu sorgen ist, daß die Verwaltung die gerade ihr vorbehaltene Verantwortung optimal erfüllen kann. Ich beziehe mich auf die Leitsätze 7, 22 und 23 Herrn Schmidt-Aßmanns, wo er eindrucksvoll von der sog. gesetzesfreien Verwaltung Abschied nimmt und von der komplexen Entfaltung der Abwägungsklauseln, der mehrstöckigen Programmbegriffe als gesetzlichen Direktiven der planenden Verwaltung spricht. Jetzt ist doch wohl zu sagen, daß der „dirigierende" Gesetzgeber von Verfassungs wegen gehalten ist, jeweils an der richtigen Stelle, gemäß dem unterschiedlich entwicklungsoffenen Sachgebiet und Problembereich, diese, nach richterlicher Kontrolldichte und Offenhelt unterschiedlichen Blankettformeln, Rahmen- und Abwägungsklauseln usw. einzusetzen: zur guten, verantwortlichen Erfüllung der gerade der eigenständigen Verwaltung anvertrauten Aufgabe.

Im übrigen bin ich beeindruckt von der methodischen, verwaltungsrechtlichen und verwaltungswissenschaftlichen Art, in der der auch mir weithin unbekannte Begriff „Verwaltungsverantwortung" von beiden Referenten herausgearbeitet wurde (Herr Scholz, Leitsätze 1 bis 4, Herr Schmidt-Aßmann, 5 f.), nämlich einerseits außerordentlich wirklichkeitsnah, differenziert, flexibel und sensibel für Interdependenzen und Entwicklungen mit den entsprechenden konkreten Folgerungen bis in die späteren einzelnen Leitsätze hinein, andererseits auf der Höhe der Verfassungs- und Verwaltungslehre. 
Partsch: Den ersten Diskussionsbeitrag zum heutigen Thema hat eigentlich der Gastgeber gestern abend geliefert, der Herr bayerische Staatsminıster, indem er sich stolz dazu bekannt hat, daß er auch für die Verwaltungsgerichtsbarkeit zuständig ist. Der skeptische Gast von außerhalb Bayerns kann sich natürlich fragen, ob das auf derselben Ebene liegt wie der Vorgang der Einführung des 9. Schuljahres in Bayern. Aber ich glaube, daß dieser Skeptizismus hier unangebracht ist.

Ich habe eine Frage an Herrn Schmidt-Aßmann: Müssen Sie aus den Forderungen, die Sie hier erhoben haben für eine gewisse Parallelität hinsichtlich der Ausgestaltung der Verwaltungsverantwortung und der Verwaltungskontrolle nicht zu der Folgerung kommen, daß in allen deutschen Ländern die Verwaltungsgerichtsbarkeit wieder in die Zuständigkeit der Verwaltungsminister, also der Innenministerien, übergeht?

Scholler: Ich darf gleich dort anschließen, wo Herr Partsch aufgehört hat, und zu den Leitsätzen II 5 und 9 von Herrn Scholz und 6 und 7 von Herrn Schmidt-Aßmann etwas sagen.

Verwaltungsverantwortung hat eine personale Seite, was Herr Zacher bereits festgestellt hat, aber auch eine personelle. Verantwortung ist in diesem Sinne ein Teil einer „verwaltungspolitischen Theologie“, die offenbar noch nicht ganz abgebaut ist und Rudimente hinterlassen hat, trotz der Entmythologisierung, die sich überall breit macht. Ein solches Rudiment ist die Vorstellung der Verantwortung des Gottes der Verwaltung vor den Halbgöttern der Verwaltungsgerichtsbarkeit oder, wenn wir die Schwankungsbreite einbeziehen, von der Herr Bachof gesprochen hat, die Verantwortung der Halbgötter der Verwaltung vor dem Gott der Verwaltungsgerichtsbarkeit. Ich will gleich zu den Niederungen dieser Theologie kommen. Die Verwaltungsrichter rekrutieren sich zum größten Teil aus Verwaltungsbeamten. Es ist ein Prozeß der Regeneration. Vor allem beziehe ich mich auf die Verhältnisse hier in Bayern, wo nicht nur die Verwaltungsgerichtsbarkeit noch beim Innenminister ressortiert, sondern wo auch die Rekrutierung des Stammes der Verwaltungsrichter aus den Verwaltungsbeamten erfolgt.

Zur personellen Seite gehört auch das Laienelement der Gerichtsbarkeit. Dabei haben wir vielleicht auch folgendes übersehen: nämlich die Bedeutung des Laienelements in der Verwaltungsgerichtsbarkeit. Ich frage mich, der ich selbst Verwaltungsrichter gewesen bin: Wie können wir das, was wir heute gesagt haben, in einem konkreten Verwaltungsgerichtsprozeß den Laienbeisitzern klarmachen? Bedeutet nicht gerade das 
Laienelement, das ich für sehr wertvoll und wichtig halte, doch, daß die Verantwortung nicht nur im rein juristischen Bereich liegt, sondern darüber hinaus auch ins gesellschaftlich-politische ausstrahlen muß?

Von hier aus, glaube ich, sollte man sich überlegen, ob man vielleicht drei hypothetische Modellvorstellungen durchdiskutieren müßte mit der Frage, welche Einwirkungen sie auf eine Reform haben würden:

1. Auswechselbarkeit der Verwaltungsrichter innerhalb der gesamten Gerichtsbarkeit.

2. Verstärkung des Laienelements, aber in dem Sinne, daß der qualifizierte Laie mit entscheidet. Ich darf darauf hinweisen, daß man in Bayern diskutiert, die Kammern auf das Niveau eines Einzelrichters abzustufen, die Senate auf 3 Richter zu beschränken. Möglicherweise wird man auch das Laienelement auf der Ebene des Senats einführen wollen.

3. Eine stärkere Heranführung - im Zusammenhang mit diesen personellen Aspekten - der Verwaltungsgerichtsbarkeit an die übrigen Gerichtsbarkeiten, um damit zu einer wirklichen dritten Gewalt zu kommen.

Ich darf die Herren Referenten fragen: In Ihren Referaten war nicht die Rede vom historischen Zweifel an der Verwaltungsgerichtsbarkeit, der ja Ausdruck fand in dem Entwurf der Paulskirchenverfassung, der die Verwaltungsrechtspflege für beendet erklärte, ein Zweifel, der fortlebt in der Zuständigkeit der ordentlichen Gerichte auf Gebieten der Verwaltungsrechtspflege und der, glaube ich, heute nicht zuende ist. Ich glaube, $\mathrm{da} B$ in der Stärkung der dritten Gewalt ein wesentliches Element für die Verwaltungsverantwortung liegen sollte.

Menger: Ich glaube, Herr Scholler unterliegt einem Irrtum. Die Verwaltungsrechtspflege, gegen die die Paulskirche sich wendet, ist die sogenannte Administrativjustiz, also Entscheidung von Prozessen durch Verwaltungsbehörden. Nur deswegen, weil keine andere Gerichtsbarkeit existierte, wurden alle Prozesse, auch öffentlich-rechtliche, den Justizgerichten überlassen. Die weitere Frage, ob dann innerhalb der Justiz differenziert werden sollte, ist von der Paulskirche gar nicht gestellt und auch nicht entschieden worden.

Scholler: Herr Menger, das ist mir natürlich bekannt. Aber wir haben ja doch im angelsächsischen Bereich das Fortleben dieser Vorstellung, daß nur ordentliche Gerichte berufen sein 
sollen, in den Fragen der Verwaltung zu entscheiden. Das Mißtrauen ist ja auch dann noch vorhanden, wenn wir erkennen, daß die Paulskirche natürlich ein ganz anderes Konzept vor sich gehabt hat. Das Mißtrauen dokumentiert sich doch in $\mathrm{Zu}$ weisungen von Zustandigkeiten an die ordentlichen Gerichte.

Ule: Ich habe vorhin angekündigt, daß ich zu dem Problem der Wellenbewegung zwischen 1950 und 1975 etwas sagen wollte. Ich würde Herrn Bachof zustimmen, wenn er damit lediglich die Lehre im Auge hat. Wenn man die Lehre betrachtet, so kann man in der Tat wohl von einer solchen Wellenbewegung sprechen. Aber die Erörterungen heute und hier nötigen, meine ich, auch zum Aufwerfen der Frage nach dem Verhältnis von Lehre und Rechtsprechung. Mir scheint es ein sehr dunkles Kapitel dieser Beziehungen zu sein, das ich aufschlage, wenn ich dazu einıge Ausfuhrungen mache.

Nach 1945, also mit der Errichtung der neuen Verwaltungsgerichtsbarkeit und der Einführung der Generalklausel, kam es zunächst zur Entdeckung der unbestımmten Begriffe als Rechtsbegriffe schlechthin. Damit war das gebundene Ermessen, das man früher im Unterschied zu dem freien Ermessen gekannt hatte, durch diese unbestimmten Rechtsbegriffe ersetzt. Und wenn ich recht sehe, taucht das heute wieder auf in dem Referat von Herrn Scholz, wenn er von einem begrenzten Tatbestandsermessen spricht. Das ist doch etwas Ahnliches wie jenes gebundene Ermessen, das durch Begriffe in den Gesetzen gebunden war. Die Konsequenz, die aus dieser Feststellung gezogen wurde, war die volle gerichtliche Nachprüfung. Sie führte in den Jahren zwischen 1950 und 1955 zu einer gewissen Spannung, wenn ich das einmal so sagen darf, zwischen Verwaltung und Verwaltungsgerichtsbarkeit. Die im Jahre 1955 entwickelten Theorien vom Beurtellungsspielraum und von der Vertretbarkeit haben versucht, diese Spannung in gewisser Weise zu mildern. Einfluß auf die Rechtsprechung, vor allem auf die höchstrichterliche Rechtsprechung, haben diese Theorien nur in einem sehr beschränkten Maße gehabt. Einige Obergerichte haben sich thnen angeschlossen. Das Bundesverwaltungsgericht hat diese Lehre jedoch prinzipiell abgelehnt und sie lediglich für den Bereich der Schul- und Hochschulentscheidungen, der Prüfungsentscheidungen und der Beamtenentscheidungen akzeptiert mit einer, wie 1ch meine, theoretisch unzulänglichen Beschränkung gerade auf diese Rechtsgebiete. Auf allen anderen Rechtsgebieten, und gerade auf denen, die uns heute besonders interessieren, also im Baurecht, im Planungsrecht, im Umweltschutzrecht, hat das Bundesverwal- 
tungsgericht bis heute die unbeschränkte Nachprüfungskompetenz in Anspruch genommen.

Es ist heute noch nicht erwähnt worden, ich darf es hier tun: Die Entscheidung des I. Senats des Bundesverwaltungsgerichts vom 16. Dezember 1971, die im verwaltungsrechtlichen Schrifttum ein breites Echo ausgelost hat, war ein Schritt von diesem Wege, allerdings, wie auch die Vertreter der Lehre vom Beurteilungsspielraum und von der Vertretbarkeit sagen müssen, ein hochst unzulanglicher Schritt. Ich würde sagen, daß das zwiespältige Echo, das diese Entscheidung gefunden hat, durchaus berechtigt gewesen ist. Das Urteil hat im Bundesverwaltungsgericht keinen Nachfolger gefunden. Die anderen Senate haben sich dieser Auffassung nicht angeschlossen, und der I. Senat hat so getan, als ob diese Entscheidung nie von ihm gefällt worden wäre, und ist stillschweigend zurückgekehrt $\mathrm{zu}$ der These der vollen gerıchtlichen Nachprüfung.

Und damit bin ich beim heutigen Zeitpunkt angelangt. Mir scheint die Bedeutung dieser beiden Referate und wohl auch der bisherige Gang der Diskussion darin zu bestehen, daß nun erneut ein Zeichen gesetzt wird für eine Einschränkung der gerichtlichen Uberprüfung bestimmter Verwaltungsentscheidungen, und zwar nicht beschränkt auf die Rechtsgebiete, die das Bundesverwaltungsgericht bisher akzeptiert hat. Ich darf auf die These von Herrn Scholz verweisen, Nr. 12, in der er von einem begrenzten Tatbestandsermessen gesprochen hat. Auch Herr Schmidt-Aßmann spricht in seiner These 21 von einem Beurtellungsspielraum.

Die Hoffnung, der man hier am Schluß dieser Bemerkung Ausdruck geben kann, sst die, daß in den nächsten 25 Jahren die Anstöße, die von dieser Tagung ausgehen können, fruchtbarer sein mögen, als das bisher der Fall gewesen ist.

Fritz Münch: Es trifft sich schlecht, daß ich gerade jetzt spreche, weil ich eigentlich eine präliminare Frage hatte behandeln wollen. Als Justizjurist, als der ich aufgewachsen bin, habe ich erst bei Peters lernen müssen, daß das Wort „Exekutive" falsch und daß die Verwaltung eigentlich eine vorverfassungsmäßige Institution ist, die die Infrastruktur und die Abwehr der Gefahren vom Kollektiv zu sichern hat, Dinge, die gar nicht in jeder Verfassung stehen, die sich aber von selbst verstehen.

Das Anliegen der Verwaltung selbst und die Forderung, die das Publikum an die Verwaltung stellt, ist Effizienz. Und das verstehe ich hinter dem Wort "Verwaltungsverantwortung“, das von einem Autor eines Aufsatzes und auch hier von einigen 
Rednern nicht ganz verstanden ist. Die Effizienz der Verwaltung ist jetzt in einer Krise. Ich hätte gemeint, daß wir den Ursachen der Krise nachgehen. Denn die Krise der Effizienz ist eingebettet in die Frage nach dem Verhältnis dieser Verwaltung zu dem Recht überhaupt; ein Problem, das auch beim Strafverfahren auftaucht, ein Problem, das jeder erlebt, der einmal als Jurist in der Wirtschaft gearbeitet hat, wo er dauernd mit den Technikern und mit den Kaufleuten in Konflikt kommt. Es ist dasselbe Problem, das im humanitären Kriegsrecht mit der "militärıschen Notwendigkeit" gestellt ist. Die militärische Notwendigkeit ist seit der Haager Landkriegsordnung erfolgreich eingebunden in ein Ganzes. Und so ist an und für sich auch die Effizienz der Verwaltung eingebunden in das Recht des Staates. Wir haben gestern aus dem Munde des Herrn Innenministers und heute - so fasse ich beide Referate auf - eine prästabilisierte Harmonie zwischen Verwaltung und Recht, speziell Verwaltungsgerichtsbarkeit, gezeichnet gefunden und daran geglaubt. Ich würde aber doch meinen, daß die Krise da ist und daß das Problem vertieft werden müßte.

Kirchhof: Die Problematik von Eigenverantwortung und Gesetzesbindung der Verwaltung ist schon von den klassischen Verwaltungsweisen her geläufig. Dort stellt sich die Schwierigkeit einer Grenzziehung zwar weniger komplex, könnte aber gerade deswegen in aller Deutlichkeit die Frage beantworten, ob es beim eigenverantwortlichen Verwalten um ein Problem der Bindungsintensitat geht, wie es Herr Schmidt-Aßmann angedeutet hat, oder um ein Problem der Bindungsferne, wie es Herr Scholz vorgetragen hat, oder gar um Bindungsfreiheit. Die klassische Prognoseentscheidung ist die polizeiliche Gefahrenabwehr. Der Polizeibeamte ist verpflichtet, auf Vermutung und Verdacht hin zu handeln. Polizeiliches Einschreiten nach Wahrscheinlichkeit sucht man hinreichend zu mäßigen, indem man das Verhalten einem strengen Rechtsmaßstab - insbesondere gesteigerten Sorgfaltspflichten - unterwirft und ein verbleibendes Erfolgsunrecht weitgehend auf die bloße Entschädigung verweist. Die klassische Planungsentscheidung ist die Haushaltsplanung. Die Ermächtıgung des Haushaltsgesetzgebers ermöglicht zwar ein planausfüllendes und planergänzendes Verwalten. Art. 114 GG verpflichtet dabei aber zu „wirtschaftlicher Haushalts- und Wirtschaftsführung“, macht damit die Wirtschaftlichkeit $\mathrm{zu}$ einem Rechtsbegriff und schafft so eine Rechtsbindung. Diese Verantwortlichkeit wird in der Regel nicht von den betroffenen Bürgern, sondern vom Bundesrechnungshof eingefordert; Herr Schmidt-Aßmann hat den 
Rechnungshof ja bereits als Parallele oder zumindest als Beispiel rechtsstaatlicher Kontrolle eines in die Breite wirkenden Verwaltens angeführt.

Schließlich gibt es auch beim kooperativen Verwalten, z. B. beim mitwirkungsbedürftigen Verwaltungsakt oder bei der verwaltungsrechtlichen Verständigung in vertragsähnlichen Formen, Entscheidungsfreiheit, die rechtliche Bindung jedoch nicht ausschließt. Ich erinnere nur an das Stichwort „Kopplungsverbot". Man hat insbesondere versucht, die einzelne Verwaltungsentscheidung dem Binnenraum des jeweiligen Besonderen Verwaltungsrechtes oder dem Anwendungsbereich eines bestimmten Grundrechts zuzuordnen und so materiell zu binden. Eine Ausnahme gilt dort für den Gleichheitsgrundsatz, der eben diese Binnenstrukturen übergreift.

Im Gegensatz dazu muß schließlich bezweifelt werden, ob es überhaupt je nur eine rein gesetzesvollziehende Verwaltung gegeben hat. Herr Bachof hat als Beispiel strikten Gesetzesvollzugs das Steuerrecht angesprochen. Aber gerade das Steuerrecht benötigt eine weitreichende Normenkonkretisierung durch die Verwaltung, etwa bei der Bewertung von Wirtschaftsgütern.

(Bachof: Richtig; es gibt vielleicht bessere Beispiele aus anderen Bereichen, aber das Steuerrecht ist jedenfalls relativ strikt normgebunden.)

- Aber selbst dann ist die Frage, ob die Rechtsbindung der Steuerverwaltung nicht gelegentlich weniger intensiv ist, wenn man sie auf das Gesetz und nicht auf die Verwaltungsvorschrift bezieht. Zu denken ist etwa an die Zurechnung eines Wirtschaftsvorgangs zur Privatsphäre oder zum Betriebsvermögen, an die Zuordnung zu bestimmten Zeiteinheiten - Kalenderjahr - oder an die Aufteilung eines grenzüberschreitenden Wirtschaftsvorgangs je nach Anwendungsbereich einer Steuerrechtsnorm.

Soell: Ich möchte zunächst Herrn Scholz sehr unterstützen in seiner Ansicht, daß es sich bei der Frage Ermessen und unbestimmter Rechtsbegriff, jedenfalls was die Eingriffsverwaltung anlangt, um ein einheitliches Problem, und zwar einheitlich nach Bindung, Denkvorgängen und nach Funktionen, handelt. Das habe ich an anderer Stelle näher ausgeführt; ich will das hier nicht wiederholen.

Zweitens: Die Eigenverantwortlichkeit der Verwaltung im Ermessensbereich. Ich habe immer betont, daß jedes Ermessen 
einen Restraum subjektiven Für-richtıg-Haltens voraussetzt. Aber ich frage doch, ob in der gesetzesvollziehenden Verwaltung, also in jener Verwaltung, deren Akte zur Grundrechtsbetroffenheit führen, diese Eigenverantwortlichkeit eine eigenstandıge in dem Sinne ist, daß die Verwaltung neben oder anstelle des Gesetzes eigene Maßstabe zu setzen hat. Ich verstehe die These von Herrn Scholz mit den metajuristischen Maßstäben in dieser Richtung, daß es eigene Maßstäbe der Verwaltung sein sollen. Denn hier, meine Herren - und ich spreche hiermit sowohl Herrn Schm $\imath d t-A \beta$ mann als auch Herrn Scholz an -, kann man sich nicht allein auf das Gewaltenteilungsprinzip als Rechtfertigung einer solchen These berufen. Denn daneben steht ja auch das Gesetzmäßigkeitsprinzip, insbesondere der Gesetzesvorbehalt. Artikel 80 Abs. 1 Satz 2 verlangt ja, daß der Gesetzgeber - Herr Badura hat das mit Recht schon herausgestellt - idie Verwaltung auch bei Einzelakten mit Eingriffscharakter nach Inhalt, Zweck und Ausmaß bindet. Der Gesetzgeber ist also verfassungsrechtlich verpflichtet, ein Zielprogramm aufzustellen, das in sich klar ist. Auf der Grundlage dieses Zielprogramms hat dann die Verwaltung zu handeln, wobei auch bei mehreren gleıchrangigen Zielen gewisse Grundsätze für die Zielharmonısierung bestehen; auch das habe ich an anderer Stelle des näheren zu begründen versucht.

Man muß zudem auf folgendes Rücksicht nehmen: Die Bedeutung einer inhaltlichen Bindung der Verwaltung im Ermessensbereich kann nicht hoch genug veranschlagt werden, auch zum Schutz der Verwaltung selbst. Ich denke hier an den Umweltschutz und an das Stichwort Vollzugsdefizit im Umweltschutz. Haufig hat ja das Opportunitätsprinzip bisher Im Umweltschutz dazu gedient, als Feigenblatt herhalten zu müssen, zur Rechtfertigung fur die Verfolgung von Zwecken, die das konkrete Umweltschutzgesetz an sich nicht gestattet. Ich denke an fiskalische Z1elsetzungen, etwa bei Gemeinden, die zugleich Ordnungsbehorden sind; ich denke an Kooperationsabkommen mit großen Unternehmungen, die etwa auf 10 Jahre die Nichtverfolgung von rechtswidrigen Abwassereinleitungen zum Gegenstand haben. Die Verwaltung, das dürfen wir nicht verkennen, ist ja viel stärker noch als der Gesetzgeber einem massierten Interessentendruck ausgesetzt; sie ist viel weniger fáhig, innerhalb des Verwaltungsverfahrens zu einem Ausgleich zu kommen, als das im Gesetzgebungsverfahren möglich ist, weil die Verwaltung in unserem pluralistisch-demokratischen Staat kein politisches Elgengewicht hat. Und gerade die Bindung auch im Ermessensbereich, nämlich der Rekurs auf die gesetzliche Programmierung, bietet einen gewissen Schutzwall 
für die Verwaltung, um solchem Interessentendruck wenigstens teilweise widerstehen zu können.

Ein letztes Wort zur Prognose:

Herr Schmidt-Aßmann! Muß man nicht bel dem Evidenzvorbehalt, den Sie gemacht haben, eigentlich schärfer nach der Rechtsschutznotwendigkelt differenzieren - darauf weisen Sie an anderer Stelle hin -, nämlich nach der Stärke des Eingriffs und den Folgen, die ein Verwaltungshandeln auslöst, beispielsweise irreparable Schaden? Das mußßte doch mit bedacht werden.

Und noch eine Bemerkung zu den Ausführungen von Herrn Bachof. Herr Bachof, das Bundesverfassungsgericht hat den Prognosegedanken nie so undifferenziert verwendet. Ein Spielraum für Versuch und Irrtum ist etwa der Wirtschaftsgesetzgebung zugebilligt worden. Es ist aber dafür auch ein Kompensat zur Verfügung gestellt worden, namlich die Restitutionspflicht, die Nachbesserungspflicht des Gesetzgebers, wenn die Prognose nicht gestimmt hat. Wie steht es aber bei irreversiblen Folgen, die nicht mehr beseitigt werden konnen? Ich meine, daß das doch wohl auch auf die Kontrollierbarkeit von Prognoseentscheidungen Rückwirkungen haben müßte, dergestalt, daß hier unter Aufbietung jeglichen Sachverstandes, auch des außergerichtlichen, nachgeprüft werden sollte, ob Diagnose und prognostische Erwartungen wirklich zutreffend sind. Sonst wird die Prognose, meine Herren, zum trojanischen Pferd des Rechtsstaates.

Wenger: Ich wollte eigentlich zur Frage "metajuristische und juristische Verwaltungszwecke" etwas sagen. Aber das ist ohnehin schon erörtert worden. Ich melne, beide Thesenpapiere stimmen darin überein, daß öffentliche Verwaltung - ich sage es jetzt vereinfacht - Konkretisierung von rechtlichen Vorschriften ist. Wenn das der Fall ist, dann, glaube ich, kann man letzten Endes auch nicht mehr sagen, die Verwaltungsverantwortung unterscheide sich von der Verantwortung des Richters dadurch, daß die Verwaltungsorgane mehr oder minder frei zu entscheiden hatten, wahrend der Richter an das Gesetz gebunden sei. Ich glaube, der Unterschied liegt lediglich darin, da $\beta$ der Bindungsgrad unterschiedlich ist. Wenn aber dieser Unterschied nur in der Unterschiedlichkeit des Bindungsgrades und des Konkretisierungsgrades gelegen 1st, dann muß man sich wohl fragen: Worin gipfelt letzten Endes der Unterschied zwischen der Staatsfunktion Verwaltung und der Staatsfunktion Gerichtsbarkeit bzw. Rechtsprechung? Letztlich doch nur 
darin, daß die Gerichtsbarkeit von Organen ausgeübt wird, die keinen Weisungen unterliegen und in eigener Verantwortung das Gesetz anwenden, während dies bei den Verwaltungsorganen nicht der Fall ist. Ich weiß, daß das nichts Neues ist; es steht in jedem Lehrbuch. Aber ich wiederhole es deshalb, weil die Frage nach der politischen Implikation der Verwaltung in der Diskussion zumindest angeklungen ist. Und ich meine, es war richtig, daß diese Frage angeklungen ist. Denn letzten Endes entscheiden im demokratischen Rechtsstaat über Verwaltungsfragen politisch und rechtlich verantwortliche oberste Organe. Es ist ja auch in der Diskussion schon mehrfach darauf hingewiesen worden, daß für diese Entscheidung eben ein Richter nicht das geeignete Organ ist. Aber das sollte man auch klar aussprechen.

Daher ist die Frage Verwaltungsverantwortung auf der einen und richterliche Verantwortung auf der anderen Seite, wenn man Verantwortung als eine personale Kategorie auffaßt, doch letzten Endes die: Wer wird für eıne falsche Entscheidung haftbar gemacht? Dazu braucht man ein Kriterium. Dieses Kriterium kann meiner Meınung nach nur ein rechtliches Kriterium sein. Die politische Verantwortung im Sinne des politischen Vertrauens ist eine ganz andere Sache. Wir haben im österreichischen B-VG in Artikel 142 die rechtliche Verantwortung der obersten Organe statuiert; diese haben sich zu verantworten. Und daher müßte man in die Frage nach der Verwaltungsverantwortung auch die Frage nach der Rechtsstellung der obersten Organe einbeziehen.

Dann zum Verwaltungsverfahren und zum Verwaltungsgerichtsverfahren: Ich darf nur darauf hinweisen, daß der österreichische Verwaltungsgerichtshof grundsätzlich nach dem Verwaltungsgerichtshofgesetz entscheidet. Wenn sich aber dort keine andere Regelung findet, nach den Verwaltungsverfahrensgesetzen ( $\$ 62$ VwGG), also genau nach den Vorschriften, nach denen die Verwaltung zu entscheiden hat. Daher kann man den Gegensatz zwischen Verwaltungsverfahren und Verwaltungsgerichtsverfahren weder verabsolutieren noch generalisieren.

von Unruh: Anknüpfend an das eben Gesagte, sollte die Ambivalenz der Verwaltungs-Verantwortung stärker im Hinblick auf den von administrativen Maßnahmen Betroffenen zum Ausdruck gebracht werden. Die Verwaltungsgerichtsordnung enthält sogar für gewisse Fälle eine Verpflichtung der Verwaltung hierfür, nämlich bei der Behandlung des Widerspruchsverfahrens. Das ist bisher in den Referaten und in den Dis- 
kussionen nicht hinreichend genug hervorgehoben worden. Hier liegt in der Praxis noch manches im argen. Manchmal gewinnt man den Eindruck, daß die Angehörigen der Verwaltung nicht hinreichend bereit sind, Irrtümer, auch wenn sie erkannt sind, zu korrigieren, sondern daruber lieber die Verwaltungsgerichtsbarkeit entscheiden lassen.

Zum Schluß möchte ich noch im Zusammenhang damit an den Gedanken anknüpfen, der ganz zu Beginn von Herrn Lerche und von Herrn Zacher angesprochen wurde, nun aber leider aus Gründen des Zeitablaufs nicht mehr vertieft werden kann: Um sowohl die Stellung der Verwaltung als auch ihr Ansehen beim Bürger - die, meine ich, von entscheidender Bedeutung im heutigen Staate sind - zu festigen, sollte in ihr der Jurist eine unabhängigere und bestimmende Stellung erhalten. Wie das geschehen kann, ist letzten Endes nur eine organisatorische Frage. Um hierfür noch konkrete Vorschläge zu machen, ist die Zeit zu fortgeschritten. Deshalb möchte ich nur zu bedenken geben, daß heute, wo - wie verschiedentlich gesagt wurde - manche Verwaltungsentscheidung nicht mehr so unabhängig erfolgt wie einst, um so mehr hier Stellung, Wert und Verantwortung des Juristen auf ihren angemessenen und notwendigen Rang hin überprüft und verbessert werden müssen.

Bartlsperger: Ich will die Erwartung von Herrn Bachof nicht enttäuschen, der Ausnahmen von der weitgehenden Zustimmung für die Referenten in der Frage eines Verwaltungsermessens angekündigt hat. Meine Kritik zu diesem Punkt ist etwas pointierter und stärker dogmatisierend als es bisherige Beiträge waren.

Zunächst möchte ich die von Herrn Badura eingeleitete Befragung zu den Leitsätzen von Herrn Scholz wieder aufnehmen. Es herrscht offenbar der Eindruck vor, daß Hans Peters nach dem heutigen Tag im verwaltungsstaatlichen Himmel bleiben konnte. Ich hätte jedoch gerne noch eine Aufklärung von Herrn Scholz gehabt zu seiner These 18 (Absatz 1). Dort heißt es, daß das Prinzip der maximalen Konkretisierung den gesamten Proze $\beta$ konkreter Verwaltungsentscheidungen umfaßt. Absatz 3 derselben These stellt ferner fest, daß eine wirksame Kontrolle metajuristischer, gestaltender, prognostischer und sonst ermessensmäßiger Verwaltungsentscheidungen stattfinden müsse. Wenn man das liest, muß sich der Eindruck einstellen, als sei Hans Peters doch ein Stück aus dem verwaltungsstaatlichen Himmel herabgestürzt. Diese Frage sehe ich noch als klärungsbedürftig an. 
Vielleicht bietet sich in These 15 von Herrn Scholz ein Ansatz für eine Antwort. Dort ist nämlıch dargelegt, daß das Strukturprinzip der Verwaltung in der Vorstellung von einer sowohl zweck- als auch rechtskonkretisierenden Verwaltung liege. Das verstehe ich so, daß jede Zweckverwirklichung innerhalb der Verwaltung zugleich Rechtsverwirklichung ist. Das würde eine vóllige Kongruenz beider Funktionsbereiche bedeuten und inhaltlich dem nahekommen, was die bekannte Staatsfunktionenlehre über die gleıchzeitige Verwirklichung des Verwaltungs- und des Rechtswertes sagt.

Daran móchte ich eine These anschließen, die Äußerungen von Herrn Kriele und Herrn Dürig bel der gestrigen Aussprache aufnimmt. Herr Kriele hat zutreffend ausgefihrt, daß es außerhalb des offentlichen Rechts anerkannt sel, auch die über den sogenannten deduktıven Rechtsvollzug hinausgehenden Entscheidungen als rationalisierbar und damit als gerichtlich kontrollierbar zu betrachten. Herr Durng hat es ferner als bedenklich bezeichnet, daß die Ture zu den Verwaltungsgerichten vielfach zu Unrecht bereits bei der Prüfung der Zulässigkeit von Klagen zugeschlagen wird. Diese Bedenken erscheinen berechtigt, allerdings mit der Maßgabe, daß bezüglich der Fragen des Verwaltungsermessens und des Beurteilungsspielraums die verwaltungsgerıchtliche Kontrolle erst bei der Prüfung der Begründetheit von Klagen versagt wird.

Angesichts dieses sozialpsychologischen Sachverhalts ist folgende Frage zu stellen: Ware es nicht sinnvoller, wenn sich die Wissenschaft vom öffentlichen Recht und die Verwaltungswissenschaft von der Problematik des Verwaltungsermessens und des Beurteilungsspielraums abwenden und stärker der Frage widmen wuirden, wo sich die Grenzen der Verwaltungsgerichtsbarkeit aus der Sache ergeben? Damit sind die Grenzen der Rationalısierbarkeit von Rechtsentscheidungen gemeint. Die Verwaltungsrechtslehre würde sich auf diese 'Weise besser in die allgemeine Entwicklung im Zivilrecht und im Strafrecht einfügen. So hat man im Strafrecht deutlich dem Beurtellungsspielraum den Abschied gegeben, etwa im Bereich der Strafzumessungslehre.

Hierzu will ich mit dem Zitat eines Rechtslehrers schließen, der dem öffentlichen Recht mit einer gesunden Distanz gegenübersteht. Engisch, der schon gestern zitiert wurde, hat einmal festgestellt: „Da das freie Ermessen die Seele der Verwaltung ist, ist nicht zu erwarten, daß der hier heimischen Unbestimmtheit ein Ende bereitet wird."

Zuletzt sei noch eine weitere Frage an Herrn Scholz erlaubt, die einen Bogen über sein Referat spannen kann: Wie weit 
kommt man mit seiner extensiven Ansicht zur Annahme subjektiver öffentlicher Rechte, wenn man gleichzeitig ein weitgehendes Verwaltungsermessen und damit eine Gerichtsfreiheit der Verwaltung annimmt?

Barbey: Die beiden heutigen Referate haben mich als vornehmlich praktisch arbeitenden Juristen sehr beeindruckt, weil sie das, was wir vor Ort versuchen - dabei auch versagen zu begrifflicher Prágnanz gebracht haben.

Aus meiner Sicht nur zwei Ergänzungen: Die erste zu These 7 des Referats von Herrn Scholz: Die Anpassung des gerichtlichen Rechtsschutzes an die Handlungsformen der Verwaltung hat die Verfassungsmảßigkeit dieser Handlungsformen zur unabdingbaren Voraussetzung. Dort, wo der gerichtliche Rechtsschutz auf nicht verfassungsmảiige Handlungsformen stößt - die er nıcht verándern kann -, wird er unvollstándig. Er mag vielleicht dem einzelnen Kläger innerhalb des Bezugsrahmens dieser Handlungsformen sein „Recht" geben, aber er verortet den Rechtsspruch nicht mehr hinlänglich in der Verfassungsordnung und verfehlt deshalb auf das Ganze der Verfassung gesehen seine Funktion.

Dazu zwei Beispiele: Das eine ist die gerichtliche Kontrolle der Leistungsvergabe ohne gesetzlıche Grundlage, nur notdürftig abgedeckt durch das Schamschürzchen der haushaltsrechtlichen Ermachtigung und durch die Bezugnahme auf den Gleichheitssatz. Sie hat zwar einerseits Willkür verhindert, andererseits aber dazu beigetragen, daß tiefgreifende gesellschaftspolitische Entscheidungen dem verfassungsmaßigen Gesetzgebungsverfahren auf die Dauer entzogen worden sind und selbst heute - in Notzeiten - als kaum noch auflösbar erscheinen.

Das andere Beispiel: In den Numerus-Clausus-Verfahren mußten die Gerichte anfangs zentrale Zulassungsentscheidungen infolge einer unsachgemaßen Verwaltungsorganisation als dezentralisierte Entscheidungen nachprüfen. Damit war weder ein effektiver noch ein adaquater Rechtsschutz möglich. Nach den Entscheidungen des Bundesverfassungsgerichts vom 9. April 1975 - die den funktionsspezifischen Problemen der nachträglichen gerichtlichen Kontrolle der im Verbund aller Bewerbungen zentral $\mathrm{zu}$ treffenden Zulassungsentscheidungen nicht gerecht werden - steht die Erörterung fast wieder an der Ausgangsposition.

Meine zweite Bemerkung gilt den Thesen 14 und 16 des Referats von Herrn Schmidt-Aßmann in Verbindung mit These 23 des Referats von Herrn Scholz. Der Versuch, komplexe Verfah- 
ren auch hinsichtlich des Rechtsschutzes abschnittsweise zu gliedern, ist zu begrüßen. Diese Gliederung muß allerdings so beschaffen sein, daß die gerichtliche Kontrolle des vorangegangenen Verfahrensabschnitts endgültig abgeschlossen sein kann, wenn der nächste Abschnitt einsetzt: Die Kapazitätsfestsetzung muß rechtskräftig überprüft sein, wenn das Verteilungsverfahren beginnt. Die isolierte Kontrolle von Verfahrensabschnitten, in denen über Individualinteressen weder unmittelbar noch abschließend entschieden wird, läßt nun die Frage entstehen: Wie kann die Klagebefugnis in diesem Vorfeld verortet werden, obwohl dort ein spezifisches materielles Individualinteresse und ein vom Individualrechtsschutz geprägtes Rechtsschutzbedürfnis möglicherweise noch gar nicht feststellbar sind?

Ferner: Selbst wenn der Jurist schon in diesem Vorfeld „das ein öffentliches Interesse inhaltstypisch repräsentierende Privatinteresse" im Sinne der These 23 von Herrn Scholz als legitimierenden Anknüpfungspunkt für Klagebefugnis und Rechtsschutzbedürfnis undeutlich auszumachen vermag, bleibt doch offen, ob der potentielle Kläger dieses legitimierende Interesse so intensiv als Eigeninteresse erkennt und erlebt, daß es ihn tatsächlich zur Einleitung eines Rechtsschutzverfahrens - z. B. einer Normenkontrolle gegen eine Kapazitätsfestsetzung bewegen könnte. Hier gibt es Schwellen und Hemmungen auch dann, wenn - was in der Konsequenz der erwähnten These 23 liegt - die Durchführung derartiger Rechtsschutzverfahren kostenrechtlich erleichtert würde.

Abschließend möchte ich zu Herrn Ule sagen, daß er, wie ich meine, das von ihm konstatierte Schweigen des I. Senats des Bundesverwaltungsgerichts vielleicht doch etwas überbewertet hat.

Adamovich: Ich kann mich um so kürzer fassen, als ich weitgehend mit dem übereinstimme, was mein Wiener Kollege Wenger schon gesagt hat. Ich möchte sagen, daß ich mich am Vormittag als Ósterreicher hier geradezu in eine andere Welt versetzt gefühlt habe. So unterschiedlich ist der Zugang, den man in Osterreich zu den Dingen hat, gegenüber dem, wie es hier gesehen wurde. Nur die Relativierung: Ermessen unbestimmter Gesetzesbegriff, das kam mir schon bekannter vor. Am Nachmittag hat sich die Distanz wiederum um ein sehr Beträchtliches verringert.

Der Unterschied liegt nicht nur darin, daß die österreichische Rechtslage in vielen wesentlichen Punkten anders ist, sondern er ist natürlich auch sehr weitgehend methodisch begründet. 
Es liegt aber auch an der Rechtslage. Die österreichische Bundesverfassung wird verstanden im Sinne einer Verpflichtung des Gesetzgebers, die Verwaltung zu binden; also nicht nur im Sinne einer Bindung der Verwaltung an das Gesetz, sondern umgekehrt auch im Sinne einer Verpflichtung des Gesetzgebers, die Verwaltung zu binden, und zwar ohne Rücksicht auf die Materie, ohne Rücksicht darauf, ob es sich um Eingriffe oder um die Gewährung von Leistungen handelt. Von da her ist auch begreiflich, daB man zwischen Verwaltung und Rechtsprechung nur einen quantitativen Unterschied zu sehen vermag.

Ich wollte auch ganz kurz noch etwas sagen zu der Frage "metajuristisch" - „juristisch". Ich glaube aber, daß mittlerweile in der Diskussion die Problematik geklärt ist. Es ist auch das ein methodisches Problem. Die ganze Unterscheidung ist offenbar nur verständlich auf dem Hintergrund des Kontrollmaßstabs. Der Sachverstand wird hier ins Spiel gebracht. Dazu aber möchte ich noch eine Bemerkung machen. Gibt es denn überhaupt ein Gebiet der staatlichen Tätigkeit, sei es nun Gesetzgebung, Rechtsprechung, Verwaltung, das heute ohne Sachverstand auszukommen vermag? Die Prognose ist ins Spiel gebracht worden; kann der Gesetzgeber auf eine solche verzichten? Man denke an Wirtschaftsgesetze und insbesondere an das Steuerrecht! Und dann ist die Planung ins Spiel gebracht worden; dazu ist $\mathrm{zu}$ sagen, daß ein planendes Element auch in Form eines formellen Gesetzes realisiert werden kann.

Außerdem möchte ich abschließend noch ganz kurz sagen, daß der sehr rigorose und ausgeprägte Standpunkt, den man in Osterreich hinsichtlich der Gesetzesgebundenheit der Verwaltung einnimmt, mir durch die beiden Referate jedenfalls nicht in dem Sinn widerlegt zu sein scheint, daß man notwendigerweise annehmen müßte, eine so weitgehende rechtliche Bindung mit anschließender verwaltungsgerichtlicher Kontrolle sei gar nicht möglich.

Krause: Ich meine, man sollte die Abgrenzung der Verwaltungsverantwortung von der Verwaltungsgerichts-Verantwortung auch unter dem Aspekt der Kompetenz im Sinne einer spezifischen Leistungsfähigkeit versuchen, weil die Fähigkeit zwar auch von den Entscheidungszuständigkeiten, aber eben nicht allein von thnen abhängt. Dieser Gesichtspunkt ist vielleicht heute etwas $\mathrm{zu}$ wenig beachtet worden. Es geht darum, da $B$ das Substrat der Entscheidung, der Entscheidungsträger, jeweils in bestimmter Weise strukturiert ist und daß offenbar die Vermutung besteht, ein Entscheidungsträger der einen 
Struktur sei besser geeignet, bestimmte Entscheidungen unter bestimmten Umständen zu treffen, als der der anderen Struktur. Demnach wären die organisatorischen, personellen, verfahrensmäßigen Strukturen festzustellen, die jeweils die Verwaltung oder die Rechtsprechung besser dazu befähigen, eine Entscheidungsaufgabe zu übernehmen. Ich kann dem hier nicht im einzelnen nachgehen, sondern es nur als Frage stellen.

Ein zweites Problem, das ich in die Diskussion werfen will, hängt damit zusammen, es ist gleichsam ein Anwendungsfall. Einen Hintergrund der Thematik der beiden Verhandlungstage bildet, glaube ich, daß der Gesetzgeber sich offenbar - ob zu Recht oder zu Unrecht - zunehmend der Aufgabe versagt, potentielle Konflikte der Interessen der Bürger untereinander und der Einzelinteressen mit dem Gemeinwohl abschließend zu regeln, indem er subjektive Rechte begründet. Soweit damit nicht irgendwelche außerstaatlichen 'Konfluktsbehebungsprozesse in Gang gesetzt werden, fällt die Aufgabe, mit einer geringen Anleitung durch das Gesetz diese Konflikte aufzulösen, auf den Richter oder auf die Verwaltung. Sie müssen jetzt die normativ nicht erfolgte Zuteilung vornehmen. Und damit kommt es zu einem neuen Konflikt, diesmal zwischen der Verwaltung und der Gerichtsbarkeit, wer von ihnen dazu berufen ist, wer die Kompetenz des Reservegesetzgebers besitzt. Dieser Streit kann mit der Formel des Artikels 19 Abs. 4 GG meines Erachtens nicht behoben werden; denn diese Formel setzt voraus, daß subjektive Rechte bestehen, sie mag auch fordern, daß der Gesetzgeber seiner Pflicht nachkommt, dort wo Interessenkonflikte drohen, die Entscheidung durch Zuteilung und Abgrenzung von subjektiven Rechten zu treffen. Wenn er das aber nicht tut, so muß der Streit um die Kompetenz entstehen, und es kann letztlich nur danach entschieden werden, ob Justiz oder Verwaltung besser in der Lage sind, den Konflikt unter diesen Umständen zu einer befriedigenden Lösung zu führen. Das schließt an das bereits Gesagte an.

Wenn aber das Gesetz kein subjektıves Recht gewährt und die Verwaltung deshalb gegebenenfalls selbst entscheidet, ohne an eine materielle Vorzeichnung von Ideallösungen gebunden zu sein, dann - und hier komme ich zu einem gewissen Widerspruch zu Herrn Schmidt-Aßmann - sind verfahrensrechtliche Bindungen erforderlich. Es handelt sich dabei nicht um komplementäre Rechtsschutzeinrichtungen, die der Absicherung subjektiver Rechte dienen, sondern um Substitute des fehlenden materiellen subjektiven Offentlichen Rechts durch subjektive öffentliche Verfahrensrechte, die eine Bindung der Ver- 
waltung ermöglichen und sie in den Stand setzen, die Entscheidungen abschließend zu treffen.

Kriele: Sie haben sich beide sehr reserviert gegenüber dem Problem der Verbandsklage geäußert. Das Problem ist wichtig und auch aktuell, weil es den Gesetzgeber in Bonn gegenwärtig beschäftigt.

Der Grund dafür ist folgender: Man will das Problem des sogenannten „Vollzugsdefizits" steuern, das uns Herr Soell eindringlich vor Augen geführt hat. Nehmen Sie als Beispiel die Wasserverschmutzung. Sie liegt nicht an unseren Wassergesetzen, sie liegt auch nicht an Gesetzesverletzungen durch einzelne Wassereinleiter, sondern man schätzt, daß mindestens $80 \%$ darauf zurückgehen, daß Genehmigungen zu Wassereinleitungen erteilt worden sind. In der Summe muß also $\S 6$ Wasserhaushaltsgesetz ständig verletzt worden sein. Und dem kann man bisher nicht beikommen. Das liegt $u$. a. an politischen Pressionen, denen auch die politische Aufsicht unterworfen ist. Ein Klagerecht für kommunale Körperschaften hilft auch nicht, da diese denselben politischen Pressionen unterliegen. Individualklagen, die gleichzeitig Allgemeininteressen wahrnehmen, können das Problem auch nicht lösen, weil ja Individualrechte meistens nicht betroffen sind. Man denkt daran, einzelnen Verbänden die Klagebefugnis besonders zu verleihen, wenn diese sachkundig, kompetent, bundeseinheitlich und dauerhaft sınd, um damit erstens den Verwaltungen Rückhalt gegen diese politischen Pressionen zu geben und zweitens das Argument, die Drohung zu entkräften: Wenn ihr uns die rechtswidrige Genehmigung nicht erteilt, gehen wir woanders hin. Denn diese Verbände mit ihrer Klagemöglichkeit sind überall im Bundesgebiet präsent.

Meine Frage wäre, ob es unter Berücksıchtigung dieser Erwägungen auch noch durchschlagende Einwände gegen die Verbandsklage gibt. Dazu hätte ich gerne noch eine kompetente Äußerung.

Püttner: Im Anschluß an Herrn Kriele eine ganz kurze Bemerkung: Die Referenten haben von der Verteilung der Verantwortung auf Verwaltung und Verwaltungsgerichtsbarkeit, zumindest inzidenter, gesprochen. Dazu nur eine Warnung: Meiner Ansicht nach muß die Verwaltung die volle Verantwortung für ihr Handeln tragen. Es darf nicht etwa der Eindruck entstehen, da $B$ ein Teil der Verantwortung von der Verwaltungsgerichtsbarkeit übernommen wird, was nämlich in der Praxis dazu führt, daß es zu einem Abschieben der Verant- 
wortung kommt, so wie es Herr Kriele gerade schilderte. Man behandelt nicht die Sache, die unangenehm ist, sondern sagt: Laßt doch einen klagen! Und wo dann kein Kläger ist, kommt es zu einem Verlust der notwendigen Verantwortung.

Steiger: Ich wollte auch zur Verbandsklage etwas sagen; das Wesentliche hat Herr Kriele schon ausgeführt. Ich möchte deswegen nur auf die Verbindung zur erweiterten Normenkontrolle, die Sie, Herr Schmidt-Aßmann, angesprochen haben, noch einmal hinweisen: Wer soll da eigentlich klagen, wer soll da eigentlich ein Interesse geltend machen? Kann man nicht gerade dafür die Verbände einsetzen? Es geht, wohlgemerkt, weder Herrn Kriele noch mir darum, allgemein Verbandsklagen einzuführen, sondern nur in den Fällen, wo Individualinteressen unter Umständen gar nicht in Frage kommen, wie etwa im Naturschutzrecht. Man kann ja dann sehen, ob das in anderen Fällen auch notwendig ist.

Suhr: Mich hat besonders beeindruckt, wie entschieden Herr Bachof im Streit um die unbestimmten Rechtsbegriffe und das Ermessen an den beiden Prüfungsetappen festhalten will: "Darf ich?" und: „Will ich?" Wenn man diese prozedurale Schrittfolge einmal so betrachtet, wie Herr Scholz es uns heute für die hier erörterten Probleme empfohlen hat, nämlich verfahrenstechnisch, stößt man auf Fundamentalstrukturen des Verwaltungshandelns und wird bis zu Einsichten zum Stichwort "Verantwortung" hingeführt:

In Herrn Bachofs Fragen: „Darf ich?" und: „Will ich?" zeigt sich nämlich der Unterschied zwischen Konditionalprogrammen und Finalprogrammen, den die Verwaltungswissenschaft herausgearbeitet hat und der auch in den heutigen Referaten berücksichtigt worden ist. Geht man von dieser Unterscheidung aus, so zeigt sich: Offene Begriffe tauchen sowohl bei der Konditionierung als auch bei der Finalisierung des Verwaltungshandelns auf, und beim typischen Handlungsermessen wird die finale Offenheit zum bewußten Prinzip. Nun gibt es aber in der Praxis die Idealtypen „Konditionalprogramm“ und „Finalprogramm" so gut wie nie in isolierter Form, sondern in der Form von Kombinationen der beiden mit ihren jeweils eigenen Unbestimmtheiten und Offenhe1ten: Das schafft die Unübersichtlichkeit, die der Dogmatik die Arbeit erschwert. Die Verwaltung verfährt zudem jetzt (ähnlich wie der Richter bei Engisch) so, daß sie ihren Blick hin- und herwandern läßt: „Was konditioniert mich?" und: „Was darf und will ich?" Führen die ersten Antworten in eine "Sackgasse", beginnt das 
Verfahren von vorn, und dabel werden die Unbestimmtheiten und Offenheiten der Programmierung prozedierend ausgenutzt.

Die Frage der Verantwortung stellt sich dann in mehrererlei Hinsicht: 1. Die typisch rechtliche Verantwortung zielt darauf, daß die konditionierenden Normen, aber auch darauf, daß die Normen, die im Blick nach vorn den Handlungsspielraum begrenzen, eingehalten werden. 2. Die typische Verwaltungsverantwortung betrifft die Zwecksetzungen, Entscheidungen und Aktionen, die in dem Bereich fallen oder getätigt werden, der rechtlich offen programmiert 1st. 3. Hinzu kommt die Verantwortung für Richtigkeit, Konsistenz und FairneB des Verfahrens, in dem die konditionalisierte und finalisierte Verwaltung entscheidet. Diesem Verfahren wiederum entspricht weniger der nachfolgende oder vorbeugende Rechtsschutz, der an den Entscheidungen ausgerichtet ist, sondern eher eine Art von begleitendem Rechtsschutz, durch den einzelne Fragen „unterwegs" geklärt werden können, ohne daß das Verfahren unnötig gehemmt oder blockiert wird.

von Mutius: Herr Scholz, Sie haben in Ihrer These 21 behauptet, die funktionsfahige Eingriffswehr erfordere die begriffliche Offnung des Verwaltungsakts. Das ist mir nicht ganz klar geworden. Einmal räumen Sie selbst nachfolgend ein, daß Eingriffe in die Rechtsposition des Bürgers nicht nur durch Verwaltungsakt erfolgen können. Zum anderen ist im Diskussionsbeitrag von Herrn Bettermann, dort allerdings unter Hinweis auf die verwaltungsgerichtliche Generalklausel, bereits deutlich geworden, daß es gem. Art. 19 Abs. 4 GG auf die Möglichkeit der Beeinträchtigung subjektiver Rechte, nicht aber auf die Handlungsform ankommt. Ihre These 21 nötigt daher insoweit zu der Frage, ob Sie die anderen Klagearten, die nicht an den Verwaltungsakt anknüpfen, möglicherweise für ungeeignet halten; eine funktionsfähige Eingriffswehr zu gewährleisten.

Das leitet über zu einem zweiten Problem. Angesichts dieser Regelung in Art. 19 Abs. 4 GG, $\$ 40$ VwGO stellt sich doch die Frage, ob nicht die dogmatischen Bemühungen noch verstärkter bei der Bestimmung subjektiver Rechte bzw. subjektiv öffentlicher Rechte einsetzen müssen. Hierzu haben Sie in These 23 die Schutznormtheorie als zu eng abgelehnt und statt dessen einen Rückgriff auf grundrechtliche Reaktionen befürwortet. Ich darf Sie fragen, wie Sie angesichts der Rechtsprechung zu den Schranken des Art. 2 Abs. 1 GG dann noch eine sinnvolle und rational überprüfbare Eingrenzung der Klagebefugten erreichen können. 
In diesem Zusammenhang ist auch eine Frage an Herrn $S c h m i d t-A \beta \operatorname{mann}$ zu richten. Sie haben vorgeschlagen, daß statt einer Verbandsklage eine Klagebefugnis öffentlich-rechtlicher Verbände und Körperschaften eingeführt bzw. ausgebaut werden soll (These 19). Halten Sie das elgentlich noch für systemkonform? Oder sind Sie der Meinung, daß derartige von den Körperschaften wahrgenommene Sachwalterfunktionen bereits aus dem derzeitigen subjektiv-rechtlich orientierten Rechtsschutzsystem herausfallen? Ist Sachwalterfunktion noch die Geltendmachung eigener subjektiver Rechte oder schon Prozeßstandschaft? Wie können Sie eine derartige Klagebefugnis auf bestımmte Verbande beschränken?

Und schließlich zu einem dritten Punkt: Beide Referenten haben m. E. mit begrüßenswerter Deutlichkeit die Notwendigkeit strikter Einhaltung von Normen des Verwaltungsverfahrens betont, weil angesichts der Unbestimmtheit der von der Verwaltung anzuwendenden Rechtsbegriffe die Inhaltskontrolle durch die Gerichte zunehmend schwierıg wird. Sie haben, Herr Schmidt-Aßmann, zwar gewısse Vorbehalte geäußert (These 28c), aber im Prinzip, glaube ich, das ebenfalls hervorgehoben. Ich frage Sie aber: Wie sehen nun die konkreten Konsequenzen dieses Gebots strikter Einhaltung verfahrensrechtlicher Normen aus? Dafür gibt es m.E. drei prozessuale Ansätze. Entweder sagt man, der Verfahrensakt selbst ist anfechtbar bzw. einklagbar. Dann aber fragt sich, ob ein derartiger Verwaltungsrechtsschutz noch effektiv sein kann. Beispiel: Kann ich ein Recht auf Anhörung einklagen? Wenn ja, nützt mir das uberhaupt etwas? Oder kommt es nicht vielmehr darauf an, wie solche Verfahrensbeteiligungen sich nachher auf den Inhalt der Entscheidung oder thre Begründung auswirken? Und wie ist angesichts einer derart ineffektiven Klagemöglichkeit hinsichtlich des Verfahrensaktes selbst der Zeitfaktor zu bewerten? Die 1solierte Klagé auf Aúfhebung bzw. auf Erlaß bestimmter Verfahrensakte der Verwaltung ist doch geeignet, die Verwaltungsentscheidung in der Hauptsache so zu verzögern, daß sie für alle Beteiligten uninteressant wird. Die zweite prozessuale Moglichkeit besteht darin - und die sollte man besonders hervorheben - , daß man auf eine strikte Einhaltung der Verfahrensnormen im Rahmen der gerichtlichen Kontrolle der Hauptentscheidung achtet, einen Verfahrensverstoß prinzipiell als Rechtswidrigkeitsgrund anerkennt und damit deutlich Position bezieht gegenüber Tendenzen in Gesetzgebung und Rechtsprechung, die Verfahrensnormen als Formalien abzutun oder sie für unbeachtlich $\mathrm{zu}$ halten, wenn in der Sache selbst nicht hätte anders entschieden werden können. 
Mit einem derartigen Grundsatz, meine ich, kann man letztlich jede Verfahrensnorm pervertieren. Und schließlich ein Drittes: Hat nicht die Einhaltung der Normen des Verwaltungsverfahrens und der Verwaltungsorganisation gerade Konsequenzen im Hinblick auf das, was Herr Zacher als erster Diskussionsredner heute angesprochen hat? Sollte man nicht die Möglichkeit in Betracht ziehen, über die Kontrolle der Einhaltung verfahrens- und organisationsrechtlicher Normen auf diejenigen Normen durchzugreifen, die wir herkömmlicherweise dem Innenbereich zurechnen, mit der Folge, daß z. B. auch Verletzungen interner Zuständigkeit oder der Regeln des internen Entscheidungsablaufs in der Verwaltung aus dem Gesichtspunkt der personellen Verwaltungsverantwortung Rechtsfolgen haben können, die u. U. auch eine Rechtswidrigkeit der Verwaltungsentscheidung nach sich ziehen?

Herrmann: Ich habe nur eine kurze Frage: Es besteht ja wohltuende Einigkeit darüber, daß jedem Betroffenen Verwaltungsrechtsschutz gewährt wird und daß dieser Verwaltungsrechtsschutz effektiv oder "adäquat" sein muß. Zutreffend ist auch die Beobachtung, daß Verwaltungsverfahren und Verwaltungsgerichtsverfahren in steigendem $\mathrm{Maße}$ nicht nacheinander, sondern oft gleichzeitig laufen, insbesondere beim vorläufigen Rechtsschutz. Die tatsächliche Handhabung manches Verwaltungsgerichtsverfahrens, das wegen Arbeitsüberlastung oder Planstellenmangels mehrere Jahre dauert und dadurch die Grenze der Rechtsverweigerung erreicht, steht aber im krassen Widerspruch zu diesen theoretischen Thesen.

Mich würde interessieren, welche Wege oder Auswege die Herren Referenten sehen, ob sie einen Anspruch auf effektiven, sprich: schnellen Rechtsschutz bejahen - ider ja sowohl im Interesse des Betroffenen als auch im Interesse einer effektiven Verwaltung liegt -, ggf. welchen Inhalt, welche Grundlage und welche Durchsetzbarkeit dieser Anspruch hat.

Thieme: Mein Beitrag schließt sich an das an, was Herr Herrmann gesagt hat. Ich möchte darauf aufmerksam machen, daß das Gericht gerade in den $\S 80$ Abs. 5-Verfahren keinerlei materielle Maßstäbe zur Verfügung hat. Natürlich läge das anders, wenn das Gericht materiell durchentscheiden würde. Aber es entscheidet ja gerade nicht materiell, sondern stellt nur eine Prognose über die spatere materiell-rechtliche Entscheidung auf. Wie bei Ungewißheit prognostiziert werden soll, sagt weder $\S 80$ Abs. 5 noch $\S 123$ der Verwaltungsgerichtsordnung. Mir scheint das, was Herr Suhr aufgegriffen hat, nütz- 
lich zu sein, wenngleich sein Modell wohl nicht realisierbar ist. Aber wir sollten doch - damit knüpfe ich an meine pointierte und mit einem Fragezeichen versehene Bemerkung von der "Götterdämmerung" der Verwaltungsgerıchtsordnung an ernsthaft darüber nachdenken, ob nicht der Zeitpunkt gekommen ist, dem vorgängigen Verwaltungsrechtsschutz wieder größeres Gewicht beizumessen und dem heute geltenden Modell des nachträglichen, des repressiven Verwaltungsrechtsschutzes - jedenfalls für Tellbereiche - Adieu zu sagen.

Dürig: Ich möchte vielleicht kurz ein kleines Informationsdefizit ausgleichen. Wir sind in einem Bundesland zu Gast Herr Partsch ist nicht da, um seine Bemerkungen zu machen -, in dem es in der Verfassungsgerichtsbarkeit die Popularklage gibt. Die prozessuale Welt geht davon auch nicht unter.

Ich würde meinen, daß Sie nicht zuviel Energie bei der Verbandsklage und bei dem Kreis der Bestimmung derer, die vielleicht potentiell individuell betroffen sein können, aufwenden sollten. Seien Sie großzügig in der Zulässigkeit und arbeiten Sie mit knallharten Ausschlußfristen! Nur so werden wir dieses Problem der Massenklagen mal wissenschaftlich vom Tisch kriegen.

Schmidt-ABmann (Schlußwort): Schon bei der Ausarbeitung des Referats zeigte sich, daß von einer Verantwortung "der" Verwaltung nur in stark differenzierender Weise gesprochen werden kann. Das gilt für die Verwaltungsorganisation und für die Gesetzesbindung der Verwaltung. Das gilt aber auch für die Frage der Wertschàtzung oder Einschätzung der Verwaltung. Die Diskussion heute nachmittag hat diese Annahme bestatigt und weitergeführt. Ich gestatte mir daher, jetzt nur auf wenige Differenzierungspunkte einzugehen, und nehme viele andere Anregungen, die wir in der Aussprache empfangen haben, eben als Anregungen zu weiterem Nachdenken.

Vorab: Nicht einverstanden bin ich damit, daß die Referate im Sinne besonderer Verwaltungsfreundlichkeit interpretiert werden. Mir jedenfalls - und ich meine, das auch für Herrn Scholz sagen zu können - ging es nicht darum, Verwaltung allgemein in einem besonders günstigen Lichte erscheinen zu lassen. Ich bin aber andererseits auch nicht bereit, Verwaltungsrechtsdogmatik und Verwaltungsgerichtsschutz nur von der Verwaltungspathologie her zu verstehen. Man muß hier doch wohl sehr deutlich unterscheiden zwischen der Vielzahl positiver Leistungen, die die Verwaltung erbringt, dann den Fällen, in denen an der Sachrichtigkeit der administrativen 
Entscheidung Zweifel bestehen und schließlich der Frage, was die Verwaltungsgerichte davon korrigieren können und sollen.

Differenziert müssen auch die Aussagen zur Frage des Verwaltungsgefüges getroffen werden. Hier bin ich dankbar für zwei Diskussionsbeiträge; zunächst eine Bemerkung von Herrn Badura, der sich nicht mit dem Begriff der planenden Verwaltung zufrieden gegeben, sondern weiter differenziert und auf die vielfältigen Planungsträgerschaften hingewiesen hat. Ich habe im Referat versucht, Ähnliches darzustellen, als ich davon sprach, in welchen instanziellen, föderalen und sonstigen Gliederungen die Verwaltungsverantwortung wirksam ist. In der Tat kann nur die konkrete Betrachtung des die Verwaltungsverantwortung ausubenden Organs weiterhelfen. Dies führt zu dem personellen und personalen Aspekt der Verwaltungsverantwortung. Im Referat sollte dieses Problem durch die Unterscheidung von externer und interner Verantwortung angedeutet werden. Herr Zacher hat es vorhin wesentlich plastischer herausgestellt; einige Diskussionsredner haben den Gedanken aufgenommen. Das Junktim zwischen Verwaltungsaufgabe und personalem Verantwortungsbereich ist ein wichtiger Punkt des Themas.

Die Aussprache hat sodann den Begriff des adäquaten Rechtsschutzes aufgenommen. Adäquater Rechtsschutz konstituiert sich aus drei Elementen:

1. dem „alten“, „effektiven“ Rechtsschutz im zweipoligen Verwaltungsverhältnis,

2. der Erweiterung dieses Rechtsschutzes in polygonale Verwaltungsverhältnisse hinein - eine Erweiterung, die ihrerseits auch schon zu gewissen Reduktionen alter Kontrollpraxen führen kann, und

3. dem kompetenzgerechten Rechtsschutz, der die Verwaltungsverantwortung für den Gesamtzusammenhang im Blick behält.

Gerade der Begriff des adäquaten Rechtsschutzes sollte zeigen, daß gegenüber komplexen Verwaltungsmaßnahmen weder die generelle Forderung nach einem $\mathrm{Mehr}$, noch die nach einem Weniger an Gerichtsschutz richtig ist, sondern ein Ausbalancieren zwischen den drei genannten Unterpunkten.

In der Frage der Rechtsform und der Rechtsschutzform kann es nicht einseitig darum gehen, Rechtsschutzformen den Rechtsformen anzunähern, sondern es muß ebenso, worauf in der Diskussion hingewiesen worden ist, in manchen Punkten auch das materielle Recht wieder auf das Prozeßrecht zugeschnitten werden, wie das am Beispiel des stufenweisen Entscheidens in 
Planfeststellungsverfahren gezeigt worden ist. Wesentlich erscheint mir vor allem, daß wir zu klaren Rechtsformen und klaren Rechtsschutzformen kommen. Wesentlich ist aber auch, da $\beta$ die alte Rechtsformabhängigkeit des Rechtsschutzes bei der Qualifikation eines Rechtsaktes nicht zu einseitiger Festlegung nur deshalb zwingen darf, weil der betroffene Rechtsvorgang sonst rechtsschutzlos gestellt würde. Die Auseinandersetzungen um die Rechtsnatur der Plane sind von solchen Qualifikationszwängen in der Vergangenheit oft in die falsche Richtung getrieben worden. Das war mein Ansatz, als ich sagte, die Doppelgleisigkeit der Rechtsschutzformen müsse dem Gesetzgeber wenigstens teilweise wieder die Moglichkeit eröffnen, die Rechtsform zu bestimmen, ohne sofort mit Art. 19 Abs. 4 GG in Konflikt zu geraten.

Was nun die gesetzesdirigierte Verwaltung betrifft, so muß auch hier sehr genau differenziert und der unterschiedliche Entwicklungsstand ihrer Rechtsgebiete im Auge behalten werden. Wir haben mittlerweile in Bereichen, die nicht dem klassischen Gesetzesvorbehalt unterfallen, gesetzgeberische Programme, die an Genauigkeit den Eingriffsermächtigungen nicht nachstehen. Wir haben andererseits Verwaltungsgebiete, deren Bedeutung für das Staat-Bürger-Verhältnis erst allmählich erkannt wird, die aus dem Innenbereich der Verwaltung über Koordinationsklauseln langsam ans Licht steigen und behutsamer gesetzlicher Diszıplinierung bedurfen. Hier gleich mit einer generellen gesetzgeberischen Bindungspflicht zu operieren, hieße Formulierbarkeit und Konstanz solcher Vorgänge überschätzen.

Ein letzter zentraler Punkt: Ermessen und Maßstabsfrage! Ich möchte mit Herrn Bachof und Herrn Götz an der Unterscheidung von Beurteilungsspielraum und Ermessen im Bereiche der gesetzlich eng gebundenen Verwaltung nach wie vor festhalten. Mich leitet dabei nicht zuletzt ein praktisches Argument, die Uberlegung namlich, daB unsere Verwaltungsgerichte auf dieses Begriffspaar eingespielt sind und man mit Ansätzen der Fortentwicklung, wenn sie auf die Praxis einwirken sollen, sinnvollerweise an bereits Bekanntes anknüpft.

$\mathrm{Zu}$ dem von mir vorgeschlagenen Evidenzvorbehalt als gerichtlicher Kontrollschranke hat Herr Schnur die Befürchtung geäußert, bei sehr großflächigen Planungen möchten damit nahezu alle materiellen Kontrollmaßstabe entfallen und sich alles in „Prognosen“ auflosen. Es mag solche Grenzfälle geben, in denen die gerichtliche Inhaltsprüfung faktisch auf eine bloße Willkürprüfung zusammenschrumpft. In den weitaus meisten Bereichen der Planung aber stehen heute gesetzliche oder min- 
destens administrative Maßstäbe zur Verfugung, die die Gerichte als Kontrollmaßstabe regelmäßig - allerdings in den markierten Punkten unter Evidenzbeachtung - heranziehen können. Herr Badura fragt, wie der Evidenzvorbehalt zur Flachglas-Entscheidung des Bundesverwaltungsgerichts passe. Nun, das Flachglas-Urteil beschäftigt sich mit einem Plan, der von allen Plänen noch den überschaubarsten und gesetzlich am exaktesten vorgezeichneten Typ darstellt, mit dem Bebauungsplan. Ich verstehe das Urteil als Versuch, in diesem überschaubaren Bereich vorsichtig zu einer weiteren rechtlichen Durchdringung anzusetzen, ähnlich wie es das preußische Oberverwaltungsgericht mit der polizellichen Generalklausel getan hat. Ein für alle komplexen Verwaltungsentscheidungen passendes Kontrollschema gibt das auf $\S 1$ Abs. 4 und 5 BBauG ausgerichtete Urteil dagegen nicht. Mindestens bei höherstufigen Planungen kónnen Evidenzvorbehalt und administrativer Beurteilungsvorrang nicht negiert werden, wenn anders nicht Prioritäten- und Standortentscheidungen künftig bis ins einzelne kontrolliert, d. h. praktisch eigentlich erst durch die Gerichte bindend getroffen und damit' Fragen in den Prozeß hineingezwängt werden sollen, die seine Dimensionen sprengen.

Kontrollintensität ist schließlich, auch bezogen auf einen konkreten Verwaltungsbereich, nıcht notwendig ein für allemal festgeschrieben, sondern hängt, darin gehe ich mit Herrn Soell einig, auch von den Rechtsschutznotwendigkeiten ab. Es können Verwaltungsübungen einreißen, die dazu zwingen, gerichtlich stärker durchzugreifen, und hier wäre es Aufgabe des Revisionsgerichts etwa, ein Signal zur Verschärfung der Kontrollpraxis zu setzen.

Zum Schluß die Stellungnahme zu einigen Einzelpunkten: Das Problem „Verbandsklage“ sollten wir, wie Herr Dürig zu Recht gesagt hat, nicht überbetonen. Ich habe meine rechtspolitischen Bedenken gegen eine Ausstaffierung der Klagemöglichkeiten in diesem Punkte genannt. Das schließt nicht aus, $\mathrm{da} ß$ man in dem Bereich, von dem Sie, Herr Kriele sprachen, die Verwaltungspraxis sehr genau weiter beobachtet und $u$. U. zu der Notwendigkeit gelangt, Verbandsklagebefugnisse gesetzlich einzuräumen. Eindeutig Stellung zu nehmen ist allerdings gegen Klagebefugnisse von ad-hoc-Gruppen. - Zur kompensatorischen Wirkung qualifizierter Verwaltungsverfahren bin ich mit Herrn von Mutius der Ansicht, daß Verfahrensnormen oft besser respektiert werden sollten. Ich bleibe aber bei meinem Vorbehalt, den Verfahrensgedanken nicht überzustrapazieren. - Mit einem tiefergreifenden Umbau der Verwaltungsgerichtsbarkeit insgesamt könnte ich mich nicht be- 
freunden. $\mathrm{Ob}$ die Verwaltungsjustız durch eine Stärkung des Laienrichtertums funktionsfähiger gemacht werden kann, erscheint mir zweifelhaft. Ein endgültiges Urteil hierzu möchte ich denen überlassen, die aus ihrer Gerichtspraxis Erfahrungen mit Laienrichtern haben. - Vor einer verwaltungsbegleitenden Verwaltungsgerichtsbarkeit ist zu warnen. Die Distanz des Richters zum Verwaltungsgeschehen hat wesentliche rechtsschutzsichernde Funktionen. Wer die Praxis aktiver gestaltender Verwaltung kennt, weiß, wie leicht man schon durch „begleitende" Mitarbeit der Faszination ihrer Sachgesetzlichkeiten erliegen kann. Ich fürchte, das bliebe auch einem „begleitenden" Gericht nicht erspart.

Von den Wechselbeziehungen zwischen Verantwortung und Kontrolle ist heute vielfach gesprochen worden. Für die $\mathrm{Zu}$ ordnung der Zweiten zur Dritten Gewalt haben beide Begriffe ihre zentrale Bedeutung gezeigt. Wir können sie transponieren auf die Wissenschaft: Wissenschaftliche Verantwortung ist angewiesen auf wissenschaftliche Kontrolle, wie sie heute nachmittag praktiziert worden ist, und dafür danke ich Ihnen.

Scholz (Schlußwort): Ich bitte um Nachsicht, wenn ich nicht auf jede der zahlreichen Fragen, die an mich gerichtet worden sind, antworte, wenn ich mir sozusagen das Privileg herausnehme, nur auf einige Fragen noch ganz kurz einzugehen.

Das erste ist - Herr Schmidt-Aßmann hat darauf eben auch schon Bezug genommen - das von Herrn Zacher hervorgehobene Stichwort der personalen Adäquanz und der gesteigerten juristischen Rollenverantwortung. Auch mir scheint dies ein ganz wesentlicher Punkt zu sein; ein Punkt, der sicher nicht ganz zu Recht der zeitlichen Beschränkung zum Opfer fiel.

Der zweite Punkt, der mir wichtig ist, liegt im Stichwort des adäquaten Rechtsschutzes. Adaqquater Rechtsschutz meint in der Tat etwas anderes als effektiver Rechtsschutz. Herr Lerche hat schon darauf hingewiesen, daß die Vorstellung des effektiven Rechtsschutzes allein von Artikel 19 Abs. 4 GG her verstanden worden ist. Die Vorstellung des adäquaten Rechtsschutzes ist dagegen auch von der kompetenziellen Abgrenzung zwischen Verwaltung und Verwaltungsgerichtsbarkeit her, verfassungsrechtlich also vom Prinzip der Gewaltenteilung her, und nicht allein von Artikel 19 Abs. 4, d. h. vom Prinzip des individualrechtlichen, effektiven Rechtsschutzes, her zu verstehen.

Herr Bettermann hat - Herr von Mutius, das richtet sich nicht gegen Sie - zu Recht darauf hingewiesen, daß die Verwaltungsgerichtsordnung schon seit 1960 mit der Generalklau- 
sel des $\S 40$ VwGO eigentlich alle prozessual erforderlichen Möglichkeiten eröffnet hat. Ich fürchte nur, daß diese Möglichkeiten noch nicht genügend ausgeschöpft worden sind; es geht also um keine Götterdämmerung unseres geltenden Verwaltungsprozeßsystems, Herr Kriele. Wesentlich erscheint mir vor allem aber der Ausbau der prinzipalen Normenkontrolle. Im übrigen glaube ich, daß die Verwaltungsgerichte ihre Rechtsprechung oft zu einseitig an den Möglichkeiten der Anfechtungsklage orientiert haben und die Möglichkeiten, die beispielsweise die Feststellungs-, Leistungs- und Unterlassungsklage geben, noch längst nicht so genutzt haben, wie dies im Sinne einer funktionsfähigen Eingriffswehr möglich, sinnvoll und geboten gewesen wäre.

Als letztes noch ein Wort zur verwaltungseigenen Maßstabsbildung. Herr Badura, Sie haben mich vollkommen richtig verstanden. Natürlich besteht keine rechtsfreie Maßstabsautonomie der Verwaltung. Ebenso zu Ihrer Frage, Herr Soell: Natürlich bedeutet verwaltungseigene Maßstabssetzung nur Maßstabssetzung im Rahmen der gesetzlichen Handlungsermächtigung. Das Problem ist nur, daß die Gesetze der Verwaltung oft derart offene Programme vorgeben, daß ein wirksamer verwaltungsrechtlicher Gesetzesvollzug kaum ohne eine gesetzeskonkretisierende Maßstabsbildung durch die Verwaltung selbst auskommt. Selbstverständlich ist jedoch, daß keine verwaltungseigene Maßstabsbildung dieser Art jenseits des Gesetzes oder gar contra legem erfolgen darf. Dies ist selbstverständlich ausgeschlossen; der Rechtsgedanke des Art. 80 GG wäre auch für mich in diesem Sinne zu verallgemeinern.

Damit darf ich es bewenden sein lassen und mit herzlichem Dank schließen. 